\title{
Demand for food products in Finland: A demand system approach
}

\author{
ILKKA P. LAURILA
}
The Research Council for Agriculture and Forestry, the Academy of Finland, and the Department of Economics and Management, the University of Helsinki criticism in Auditorium XII, the University, Aleksanterinkatu 5,

Helsinki, on October 14, 1994, at 12 noon. 



\section{ACKNOWLEDGEMENTS}

As this study goes to press, I wish to express my sincere gratitude to all those who helped me with this work. I am indebted to Dr. Paavo Mäkinen for first suggesting the topic of the study to me. During the initial phase of this study I had the opportunity to receive valuable guidance from my teacher, Rector, Professor Risto Ihamuotila, and Acting Professor Petri Ollila. Professor Viljo Ryynänen showed endless interest in my work and provided the necessary facilities at the Department of Economics and Management, University of Helsinki. To Professor Karl Johan Weckman I owe a particular debt of gratitude for encouraging me in my work during the whole research process. I wish to express my thanks to my colleagues at the Department for providing the pleasant atmosphere during these years.

The study was supervised by Acting Professor Jukka Kola, Dr. Juhani Rouhiainen, and Professor Karl Johan Weckman, and reviewed by Professor Lauri Kettunen and Professor Arie J. Oskam. I am greatly indebted to all of them for valuable guidance and suggestions.

The study was carried out parallel to the research project "Models and Projections of Demand for Food in the Nordic Countries," guarded by the Scandinavian Association of Agricultural Scientists. I want to express my sincere gratitude for the fruitful co-operation and stimulating discussions to my co-researchers Associate Professor Bengt Assarsson, Associate Professor David Edgerton, Anders Hummelmose, Associate Professor Kyrre Rickertsen, and Associate Professor Per Halvor Vale. Special thanks are due to David Edgerton for providing me with the software routines used in the computations, and Anders Hummelmose for collecting the data concerning retail prices in Denmark.

This work was completed during my stay as a visiting research fellow at the Department of Agricultural Economics and Policy of Wageningen Agricultural University, the Netherlands. I am grateful to Professor Piet C. van den Noort and Professor Arie J. Oskam for providing the congenial surroundings of the Department. I wish to thank Dr. Alison Burrell, Alfons Oude Lansink, Dr. Jack Peerlings, and Dr. Geert Thijssen for their constructive criticism during the final preparation of the thesis.

The research was financed by the Research Council for Agriculture and Forestry, the Academy of Finland, and, in part, by grants from Kyösti Haataja Foundation of Okobank Group, the Scandinavian Association of Agricultural Scientists, and August Johannes and Aino Tiura Foundation of Agricultural Research. I acknowledge my debt of gratitude to the institutions for the resources they have awarded me for this study. I thank the Central Statistical Office of Finland and the Research Institute of the Finnish Economy (ETLA) for providing me with the data for the study.

I thank Jaana Kola for checking the English text and Sari Torkko for editorial assistance. I would also like to thank the editorial board of Agricultural Science in Finland for accepting this study to be published in their Journal.

I am grateful to my dear wife Suvi for her support throughout this work. Little Pellervo was a major contributor of bringing joy to every-day life. I wish to thank my mother-in-law for taking care of our household during the last stage of this research. In addition, I would like to thank my parents and godmother for being inspiring examples of minds that are open for new innovations in life. 


\section{CONTENTS}

Abstract

1 Introduction

1.1 Background of food demand analysis in Finland ............................................................ 323

1.2 Objectives of the study .............................................................................................. 324

2 Food consumption in Finland in 1950-1991 ..................................................................... 325

2.1 Definition of commodity bundles and variables ............................................................. 326

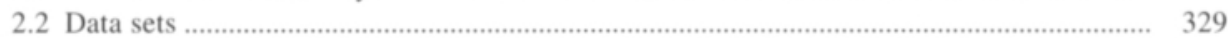

2.3 Budget shares ................................................................................................................ 329

2.4 Volumes and prices ............................................................................................................ 330

3 Demand theory and empirical analysis …................................................................................ 337

3.1 Determinants of consumer demand for food ...................................................................... 337

3.2 System of choice: preferences and utility maximisation ....................................................... 339

3.3 Duality in deriving a demand system ............................................................................ 340

3.4 Slutsky conditions for symmetry and negativity .......................................................... 342

4 Demand system specification and estimation ................................................................... 343

4.1 Complete demand systems approach: literature review ................................................... 343

4.2 Derivation of the Almost Ideal Demand System ............................................................ 346

4.3 Slutsky conditions on the AIDS …................................................................................... 348

4.4 Extensions of the AIDS ............................................................................................... 350

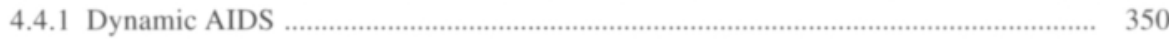

4.4.2 Switching static and dynamic AIDS ............................................................... 352

4.5 Aggregation over consumers ..................................................................................... 353

4.6 Aggregation over goods: separability and multi-stage budgeting ...................................... 356

4.7 Specification of the hierarchic demand system ................................................................. 358

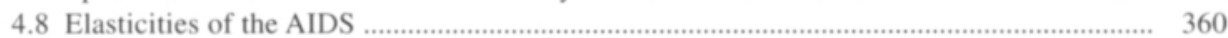

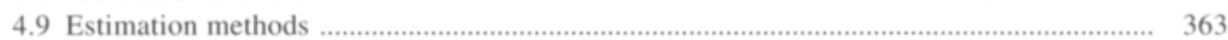

5 System of demand for food products: model selection and evaluation ..................................... 364

5.1 Selection of preferred specifications: testing parameter restrictions ................................ 364

5.2 Evaluation of the preferred model specifications …......................................................... 367

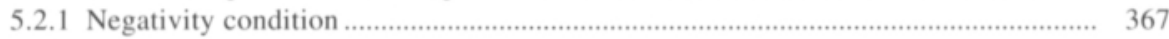

5.2.2 Parameter estimates ............................................................................................... 367

5.2 .3 Goodness of fit ................................................................................................... 368

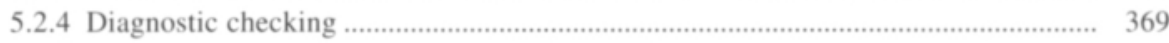

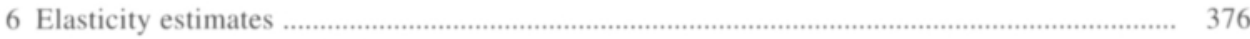

6.1 Within-group elasticities ............................................................................................. 376

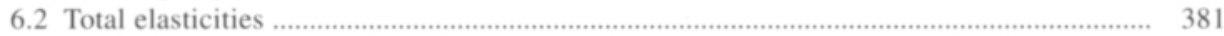

6.3 Elasticities compared with elasticities obtained in other studies ..................................... 384

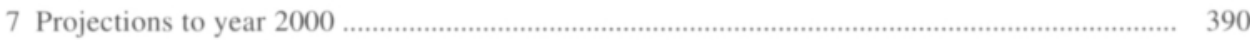

7.1 Introductory remarks ............................................................................................... 390

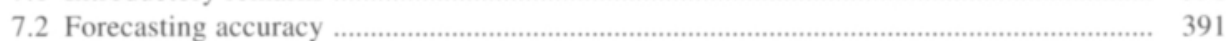

7.3 Projections of exogenous variables ..................................................................................... 393

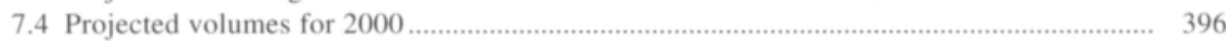

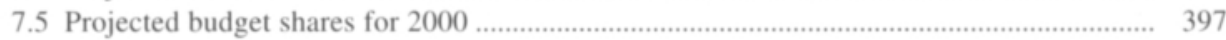




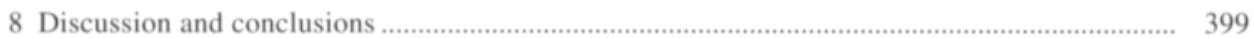

8.1 Food consumption in Finland .................................................................................. 399

8.2 Food demand system for Finland ……....................................................................... 400

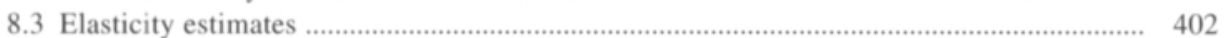

8.4 Projections to year 2000 ................................................................................................ 404

8.5 Conclusions and policy implications ........................................................................... 406

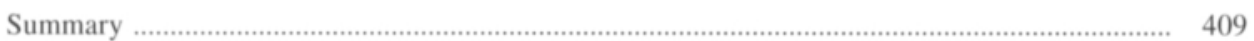

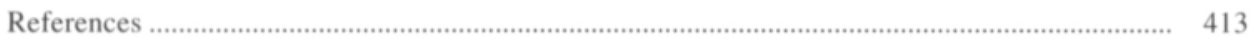

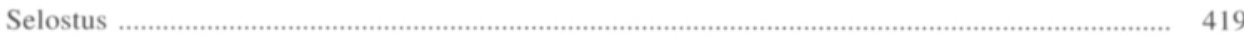

Appendix 1 Definition of commodity bundles

Appendix 2 Food demand system for Finland: parameter estimates

Appendix 3 Glossary 



\title{
Demand for food products in Finland: A demand system approach
}

\author{
ILKKA P. LAURILA
}

LAURILA, I.P. 1994. Demand for food products in Finland: A demand system approach. Agricultural Science in Finland 3: 315-420. (Department of Economics and Management, P.O. Box 27, FIN-00014 University of Helsinki, Finland.)

The study was concerned with the estimation of food-demand parameters in a system context. The patterns of food consumption in Finland were presented over the period 1950-1991, and a complete demand system of food expenditures was estimated. Price and expenditure elasticities of demand were derived, and the results were used to obtain projections on future consumption.

While the real expenditure on food has increased, the budget share of food has decreased. In the early 1950s, combined Food-at-Home and Food-away-from-Home corresponded to about $40 \%$ of consumers' total expenditure. In 1991 the share was $28 \%$. There was a shift to meals eaten outside the home. While the budget share of Food-away-from-Home increased from 3\% to $7 \%$ over the observation period, Food-at-Home fell from $37 \%$ to $21 \%$, and Food-at-Home excluding Alcoholic Drinks fell from $34 \%$ to $16 \%$.

Within Food-at-Home, the budget shares of the broad aggregate groups, Animalia (food from animal sources), Beverages, and Vegetablia (food from vegetable sources), remained about the same over the four decades, while structural change took place within the aggregates. Within Animalia, consumption shifted from Dairy Products (other than Fresh Milk) to Meat and Fish. Within Beverages, consumption shifted from Fresh Milk and Hot Drinks to Alcoholic Drinks and Soft Drinks. Within Vegetablia, consumption shifted from Flour to Fruits, while the shares of Bread and Cake and Vegetables remained about the same.

As the complete demand system, the Almost Ideal Demand System (AIDS) was employed. The conventional AIDS was extended by developing a dynamic generalisation of the model and allowing for systematic shifts in structural relationships over time. A four-stage budgeting system was specified, consisting of seven sub-systems (groups), and covering 18 food categories. Tests on parameter restrictions and misspecification tests were used to choose the most preferred model specification for each group.

Generally, the estimated models did not satisfy the Slutsky conditions. The goodness-of-fit measures were good, and, compared to static specifications, dynamics usually provided a better fit. The misspecification tests indicated that the dynamic specification was correct, but some form of misspecification was found. The structural change in parameters indicated that the modelling failed to track a stable preference structure - if there is one.

The estimated demand system was employed in projecting the future consumption of food products in Finland to the year 2000. The approach was to choose a certain change in the real total consumption expenditure and alternative sets of relative prices for the forecast period. Four different options of price variables were defined. Three of the options relied on the historical price trends recorded in Finland, whereas one option measured the expected consequences of Finland's possible membership in the European Union.

A predicted consequence of the membership in the European Union is that the share of food in consumers' budget would decrease. The expected decrease is somewhat faster than the decrease that would take place if future price developments were based on the historical trends. If Finland joins the Union, the budget share of Food-at-Home would decrease from $21 \%$ in 1991 to $18 \%$ in 2000, whereas the budget share of Food-at-Home excluding Alcoholic Drinks would decrease from $16 \%$ in 1991 to $14 \%$ in 2000 .

Key words: Almost Ideal Demand System, consumption, expenditure elasticity, food consumption, habit persistence, price elasticity, projections 


\section{Introduction}

Substantial changes have occurred in consumption patterns in Finland over the past four decades. There has been a marked increase in the proportion of food expenditures spent away from home: the real expenditure on food consumed in restaurants and cafes more than quadrupled, while the real expenditure on food consumed at home doubled. Real incomes have also risen - in the early 1950 s the average consumer spent $40 \%$ of his or her total budget on food and drink, while by the early 1990s the proportion had declined to $28 \%$.

Within food budget, processed meat products, cheese, fruits, soft drinks, and alcoholic drinks have become increasingly important, while flour, milk, butter, eggs, and coffee have lost importance. History shows large shifts in the consumption structure. For example, expenditures on carcase meat and soft drinks increased rapidly in the late 1960s and early 1970s. In both cases, the increase coincided with a decrease in respective real prices. Some of the trends that were visible in the past were cut off in the early 1990s. For example, the downturn in consumption of alcoholic drinks coincided with the downturn in the economy.
The objective of the present study is to explain the changes in food consumption patterns in Finland. In order to do that, the determinants of food demand will be identified and quantified. By knowing the past, future developments can be projected. After predicting exogenous variables, such as total expenditure, population, and prices, projections of food consumption patterns will be derived.

The study focuses on consumer demand, which refers to the demand given rise by individuals and households. Roughly speaking, it refers to all non-public demand in the economy. The concept demand structure or demand system or simply demand is a function that refers to the responses of a consumer to various economic and related factors, such as levels and changes in prices and income, that produce the observable consumption behaviour or consumption. The aggregate demand structure or market demand refers to the combined consumption responses of all consumers in the economy to the factors that determine the levels and changes in per capita consumption (HAIDACHER 1992, Johnson et al. 1986). When the distinction between the micro- and macrolevel phenomena is not essential, the behaviour 
of both an individual and all consumers will be called demand.

\subsection{Background of food demand analysis in Finland}

Economic analysis of food demand in Finland is well-founded. Three traditions can be named according to the data employed: studies using household budget data, studies using National Accounts data, and studies using disappearance data at the national level, often referred to as the Food Balance Sheets. KAARLEHTO (1961) pioneered in using the household budget data in order to estimate income elasticities for food commodities. A special interest was on how food expenditures depend on income levels. MARJOMAA (1969) started a series of studies employing the aggregate level National Accounts data, which became available from the year 1948 (later on, LAURILA (1985, 1987) derived the series backwards). In some studies the annual time-series were accompanied by household budget data, which have been collected at intervals of about five years since 1949 (e.g. MARJOMAa 1969, HämÄLÄINEN 1973). In addition to food items, the studies covered all patterns of households' expenditures. HÄMÄLÄINEN (1973) was the first to introduce forecasts for a wide range of food commodities. HAGGrÉn and KetTunen (1976) and KetTunen (1976) published the first forecasts for food commodities using the Food Balance Sheets, the annual series of which became available from the year 1950 . RouHIAINEN (1979) estimated demand elasticities and derived forecasts by using the Food Balance Sheets. In addition to the mentioned studies, which covered a wide range of food commodities, there were several studies that covered one commodity or a small number of commodities (KAARLEHTO 1959, SANDELIN 1959, KoIVISTO and KoPONEN 1961a, b, KoIVISTO and NAAPURI 1961, KoPONEN 1961, 1964, Nyberg 1967, KetTUNEN 1968).

Household budget data are cross-sectional data, whereas the National Accounts and the Food Balance Sheets are time-series data. Household budg- et data are micro-data, where observations consist of records of individual households, whereas the other two data sets record consumption at the aggregate level. Household budget data usually offer substantial variation in expenditure levels and limited variation in relative prices (unless there are several cross-sections). Thus, the data set has an advantage in estimating expenditure responses. Studies which use household budget data benefit from a large number of observations, but have several disadvantages, such as the problem of zero-purchases (i.e. all households do not consume all the analysed categories). Empirical demand analysis based on household budget data has traditionally focused on demographic effects and expenditure effects, and has ignored price effects (PollaK and Wales 1992, p. 66-67). Time-series data usually offer substantially more variation in relative prices and less variation in expenditure. Thus, they have an advantage in estimating cross-price effects.

By using micro-data, it is difficult to derive direct implications at the macro level. If interest is on macro-level market demand and, for instance, on (pre-)evaluation of policy instruments, micro-level responses do not offer the necessary information. In the present study, the interest is on macro-level market demand. Studies that employ macro-level disappearance data (the Food Balance Sheets) have the advantage that only by means of that data set one can study consumption in terms of physical quantities. However, the approach suffers from the fact that the price and volume series come from different sources. The price series can be derived by using representative goods. However, the derivation of consumption expenditures essential to a system-wide analysis with allocation models, which dominate the modern methodology, would be rather artificial. Moreover, by measuring the consumption in terms of kilograms rather than in monetary terms, for instance, the increase in the consumption of processed products is easily ignored.

The present study joins the tradition that employs the National Accounts data. Since the pioneering study by MARJOMAA (1969), a number of studies have been published. HÄMÄLÄINEN (1973) 
showed that Engel's law - that the budget share of food decreases as incomes increase - was evident in Finland.' VäISÄNEN (1980) updated the description and forecasts. VIRÉN (1983) was the first to use a system-wide approach. He estimated the price and income elasticities by using an extended Linear Expenditure System. The series of studies was continued by RAHIALA (1984) and MANKINEN (1988). In addition to the cited studies, a contribution was made concerning historical consumption: LAURILA $(1985,1987)$ presented a pioneer work on private consumption over the period 1880-1980. Mellin (1983, 1985) compared static and dynamic properties of the consumption expenditures in Finland.

The referred contributions have increased the understanding of the factors and relationships affecting food demand. However, recent developments in demand models provide new possibilities for empirical analysis. For example, models that are more consistent with the consumer theory have been developed (flexible functional forms). In addition to this, a great number of diagnostic tests and evaluation criteria are available for testing the model performance. A general feature with very few exceptions is that the former studies employed only the single equation methodology. There are several reasons why one should adopt a system-wide approach, which is nowadays a standard in demand analysis. An empirical demand system, in which interproduct dependencies are estimated in a simultaneous framework, gives information about the complete interdependent nature of food choice, which is not explored by single equation analysis.

\footnotetext{
${ }^{1}$ Ernst Engel observed in the mid-19th century that the poorer a family was, the greater proportion of total expenditures was allocated to food, which may be restated that, as consumer incomes increase, the proportion of income spent on food decreases, ceteris paribus. Engel's observation is one of the few patterns that has been observed with sufficient persistence to be called a law of economics (SENAUER et al. 1991, p. 134-136). In terms of elasticities, Engel's law states that food is income inelastic. The effect of income on the expenditure patterns, or the Engel function, has been one of the most extensively studied empirical relationships in economics.
}

\subsection{Objectives of the study}

Because of the budget constraint, increased consumption of one food item can occur only at the expense of another. As a result, food items compete with each other, and it is important to study intergroup and interproduct relations, substitutes and complements. Although the interest is in food demand, the interdependence in demand between food items and other commodities makes it reasonable to estimate a complete demand structure or system. The complete system approach allows the estimation of cross-commodity substitutions, which are essential in the demand theory.

Food demand is an interesting subject from various points of view. Applying a demand system on food is interesting as a methodological matter. The food system altogether - linking farmers and consumers by producing, transporting, storing, and processing agricultural commodities into food products and services - is dependent on consumption and, thus, information on demand structure and factors affecting it is essential. Manufacturers, retailers, and nutritionists are interested in consumption trends. Farmers are interested in consumer-oriented production and marketing.

The estimated models and elasticities will be used for structural analysis, which examines the causes for the changes in consumption patterns. Elasticities are important in the design and operation of policy and regulatory schemes. Together with some other elements (such as supply, foreign trade, environmental measures, and taxes), the demand for food is a central issue in making agricultural and food policy. For example, to some degree, farmers' income depends on the market demand for food products. Nutritional policy affects consumption by recommending to diminish or increase the consumption of certain products. Many policies that are not intended to affect the market may have indirect influence on food consumption patterns. To be able to evaluate the effects of various policy instruments, responses to income and price changes are of central importance. Government policy-makers and regulators are interested in changes in consumption in order 
to adjust production control. Demand analysis produces information which is needed when governments aim at intervening in the markets to achieve certain goals, for example, to increase or decrease the consumption of a certain item. The anticipated efficiency of the programme can be pre-evaluated.

In addition to the knowledge of the current structure of food consumption, strategic food sector planning often requires forecasts on future food demand. The estimated models will be used to forecast food expenditures to the year 2000 . The sensitivity of these forecasts to alternative options of price developments will be examined.

The objectives of the present study are:

1. To present the food consumption patterns in Finland over the period 1950-1991.

2. To estimate a demand system for a 18-category breakdown of food expenditures.

3. To verify how well the Finnish consumer behaviour corresponds to the consumer theory.

4. To estimate price and expenditure elasticities of food commodities.

5. To obtain projections on future food demand in Finland.

6. To examine the sensitivity of the projections to alternative price developments.

7. To derive policy implications.

The description of food consumption is probably interesting to anyone who likes to know about Finland's social and economic history. Demandsystem estimation as a methodological matter in- terests researchers, teachers, and students in economics. The derived elasticities and projections are useful for policy-makers as well as players in the food system.

The study is organised as follows. Chapter 2 defines the data sources, variables, and commodity bundles. It also explores the long-term developments of food consumption and food prices in Finland. Chapter 3 concerns the basic theoretical elements of the demand analysis. The discussion should facilitate the understanding of the nature and conditions the theory states for empirical analysis. Chapter 4 describes the methodology of the empirical analysis, and complete demand systems approach is presented. The formulation of the functional form starts from a static specification, then, dynamic behaviour is incorporated and, finally, variables allowing for structural change in consumer demand are introduced. The hierarchic demand system is specified. Chapter 5 describes the selection and evaluation of preferred model specifications. Chapter 6 provides the estimated price and expenditure elasticities. The elasticities are compared with elasticities obtained in other studies. Chapter 7 concerns consumption projections. The estimated models are used for simulations, both for evaluating the model performance over the sample period, and for projecting food expenditures to the year 2000. In Chapter 8, the results of the present study are discussed, and they are compared with the results obtained in other studies. The implications for future research and the suggestions for data revision are provided. Finally, concluding remarks are presented.

\section{Food consumption in Finland in 1950-1991}

Over the last four decades, the final consumption expenditure has corresponded to about three-quarters of the gross domestic product in Finland. Most of that has been the total private consumption. In the 1950s, the total private consumption expenditure was an average of $63 \%$ of the gross domestic product. The public sector and also private non-profit bodies have increased their expenditure over the years, so that in the 1980s the proportion of the total private consumption was $51 \%$. In 1990 the proportion was $49 \%$. Because in 1991 private consumption still increased, while 
Table 1. Consumption in Finnish economy in 1950-1991.a

\begin{tabular}{|c|c|c|c|c|c|c|}
\hline \multirow[t]{2}{*}{ Category } & \multicolumn{6}{|c|}{$\%$ (gross domestic product in current prices, FIM million) } \\
\hline & $\begin{array}{l}1950-59 \\
\text { average }\end{array}$ & $\begin{array}{l}1960-69 \\
\text { average }\end{array}$ & $\begin{array}{l}1970-79 \\
\text { average }\end{array}$ & $\begin{array}{l}1980-89 \\
\text { average }\end{array}$ & 1990 & 1991 \\
\hline $\begin{array}{l}\text { Gross domestic product } \\
\text { of which, \% }\end{array}$ & 10,139 & 26,373 & 98,108 & 326,740 & 525,900 & 503,645 \\
\hline $\begin{array}{l}\text { Gross fixed capital forma- } \\
\text { tion and net imports }\end{array}$ & 24 & 25 & 27 & 27 & 27 & 21 \\
\hline $\begin{array}{l}\text { Final consumption } \\
\text { of which, \% }\end{array}$ & 76 & 75 & 73 & 73 & 73 & 79 \\
\hline Public consumption & 15 & 19 & 23 & 27 & 29 & 30 \\
\hline $\begin{array}{l}\text { Private consumption } \\
\text { of which, } \%\end{array}$ & 85 & 81 & 77 & 73 & 71 & 70 \\
\hline Non-profit bodies ${ }^{c}$ & 2 & 4 & 4 & 4 & 6 & 6 \\
\hline $\begin{array}{l}\text { Total Private Consumption } \\
\text { of which, } \%\end{array}$ & 98 & 96 & 96 & 96 & 94 & 94 \\
\hline Durables & 6 & 8 & 10 & 12 & 11 & 9 \\
\hline Semi-Durables & 19 & 15 & 14 & 13 & 13 & 13 \\
\hline $\begin{array}{l}\text { Private Consumption } \\
\text { of which, \% }\end{array}$ & 75 & 77 & 76 & 75 & 76 & 78 \\
\hline Services & 29 & 36 & 38 & 40 & 44 & 45 \\
\hline Non-Durables & 19 & 19 & 20 & 20 & 19 & 19 \\
\hline $\begin{array}{l}\text { Food } \\
\text { of which, \% }\end{array}$ & 52 & 46 & 43 & 40 & 37 & 36 \\
\hline Food-away-from-Home & 8 & 10 & 17 & 21 & 26 & 26 \\
\hline Food-at-Home & 92 & 90 & 83 & 79 & 74 & 74 \\
\hline
\end{tabular}

Sources: HJERPPE (1989), Bulletin of Statistics (1986:1, 1989:1, 1993:1), National Accounts.

"A guide to compute, for example, the expenditure on Food-at-Home in the 1950s: FIM 10,139 million*.76*.85*.98*.75*.52*.92. The outcome corresponds with the FIM 2,312 million which is the actual value of the consumption. The figures have been rounded to the nearest final digit. Thus, there may de an apparent slight discrepancy between the actual values and the values derived as guided.

${ }^{b}$ Consumption of private and non-profit bodies. Non-profit bodies are housing corporations, etc.

${ }^{c}$ Consumption of non-profit bodies, and net value of direct purchases abroad.

${ }^{d}$ Final consumption expenditure of households in the domestic market.

the gross domestic product and investments dropped, total private consumption covered $52 \%$ of the gross domestic product.

About one-quarter of the total private expenditure has been classified as the consumption of durables and semi-durables, the rest is the bundle that is under consideration in the present study. This bundle, private consumption excluding durables and semi-durables, accounted for $47 \%$ of the gross domestic product in the 1950s. The share gradually declined to an average of $38 \%$ in the 1980 s, and was $37 \%$ in 1990 . In 1991 the share under consideration rose to $41 \%$, due to increased private consumption and decreased gross domestic product, investments, and purchases of durables (Table 1),

\subsection{Definition of commodity bundles and variables}

The demand system approach adopted in the present study allocates the total expenditure into smaller segments. In a few cases the "total" re- 
fers to the total private consumption (including durables and semi-durables) which covers the final consumption expenditure of households in the domestic market. However, in most cases the "total" refers to private consumption which covers the final consumption expenditure of households in the domestic market excluding durables and semi-durables. The approach follows ALESSIE and KAPTEYN's (1991) application of the AIDS. They removed durable components from the expenditure categories to avoid complications due to the investment nature of durables. By removing durables, it is implicitly assumed that the households' utility function is weakly separable in durables and non-durables (ALESSIE and KAPTEYN 1991, p. 412).

The consumption structure in Finland is studied by means of time-series on expenditure and prices. Altogether $\mathbf{2 8}$ groups of commodities are defined (Table 2, a detailed description of the categories is in Appendix 1). Hereafter, capital initials are used when referring to the defined categories.

The following variables are considered:

Quantity, or consumption volume, or real expenditure of good $i$ at period $t\left(q_{i i}\right)$ is measured as the per capita consumption in Finnish Markkaa (FIM) in prices of the year 1985. Since the data operate at the aggregate level, the implied consumption has to be interpreted with caution. The figures refer to the national averages, and there probably exists considerable variation in the behaviour between individuals. In order to obtain per capita figures, mean population of each respective year is used as the measure of the population size. To make the description consistent, mean population is used as the measure also in Alcoholic Drinks, despite the fact that alcohol is mainly consumed by adults.

Budget share, or expenditure share of good $i$ at period $t\left(w_{i t}\right)$ is defined as the value of purchases of a commodity group compared with the aggregate:

$$
w_{i t}=\frac{p_{i t} q_{i t}}{\sum_{i=1}^{n} p_{i t} q_{i t}}=\frac{p_{i t} q_{i t}}{x_{t}}
$$

where $p_{i}$ is the price of $\operatorname{good} i, x$ is the total expenditure, and $n$ is the number of goods in the system. Various definitions of $x$ are used. In this chapter, either Total Private Consumption or, alternatively, the expenditure on Food-at-Home is used as the aggregate. In later chapters, also subgroups of Food-at-Home are employed.

Relative price, or price ratio of good $i$ at period $t\left(p_{i t}{ }^{r}\right)$ is computed as follows. The data set contains two vectors for each good, $q_{i t}$ and $c_{i t}$, which is the per capita consumption of good $i$ in current values (FIM) at period $t$. The transformation from current to real values has been carried out by the Central Statistical Office by using a consumer price index [of Laspeyres type] for good $i$. A derived price index [of Paasche type], ${ }^{2}$ or the implicit price index of good $i\left(p_{i t}\right)$ is measured by dividing the value of purchases in current terms by the value of purchases in fixed 1985 terms $\left(c_{i t} / q_{i t}\right)$. To obtain $p_{i t}{ }^{r}$, the implicit price index is deflated by the implicit price index of the aggregate, or

$$
p_{i t}^{r}=\frac{p_{i t}}{P_{t}}=\frac{c_{i t} / q_{i t}}{\sum_{i=1}^{n} c_{i t} / \sum_{i=1}^{n} q_{i t}}=\frac{c_{i t} / q_{i t}}{x_{t} / \sum_{i=1}^{n} q_{i t}}
$$

In the present chapter, $n$ refers to all the categories that are included in Private Consumption. Thus, $P$, roughly indicates the general price level. In the econometric analysis, $n$ refers to the categories that are included in the group under examination. Consequently, $P$ indicates the price level of that particular group.

${ }^{2}$ The Laspeyres price index is a ratio of incomes needed in different years to purchase year 1 bundle. More exactly, it shows the ratio between the income needed to buy the year 1 bundle at year 2 prices and the actual year 1 income. By comparing the Laspeyres index (or, alternatively, the Paasche index) to the ratio of his or her actual income in the two years, a consumer can measure the change in his or her welfare over the two years. The Paasche price index is a ratio of incomes needed in different years to purchase year 2 bundle. More exactly, it shows the ratio between the income needed to buy the year 2 bundle at year 2 prices and the income needed to have purchased the same year 2 bundle at year 1 prices (e.g. CALL and Holahan 1983, p. 102-109). 
Table 2. Definition of the commodity bundles.

\begin{tabular}{|c|c|c|}
\hline Category & $\begin{array}{l}\text { Composition (budget shares, \%, in } 1991 \\
\text { in parentheses) }\end{array}$ & $\begin{array}{l}\text { Category number and } \\
\text { mutual dependency }\end{array}$ \\
\hline $\begin{array}{l}\text { Total Private } \\
\text { Consumption } \\
\text { (including Durables } \\
\text { and Semi-Durables) }\end{array}$ & $\begin{array}{l}\text { Private Consumption }(78 \%), \text { Semi- } \\
\text { Durables }(13 \%) \text {, Durables }(9 \%)\end{array}$ & \\
\hline Private Consumption & $\begin{array}{l}\text { Food-at-Home }(27 \%) \text {, Food-away-from- } \\
\text { Home }(9 \%), \text { Non-Durables }(19 \%) \text {, } \\
\text { Services }(45 \%)\end{array}$ & $\begin{array}{l}0 \\
=1+2+3+4\end{array}$ \\
\hline Food-at-Home & $\begin{array}{l}\text { Animalia }(34 \%) \text {, Beverages }(32 \%) \text {, } \\
\text { Vegetablia }(26 \%) \text {, Groceries }(9 \%) \text {. }\end{array}$ & $\begin{array}{l}1 \\
=1.1+1.2+1.3+1.4\end{array}$ \\
\hline $\begin{array}{l}\text { - Animalia (food from } \\
\text { animal sources) } \\
\text { - Meat and Fish }\end{array}$ & $\begin{array}{l}\text { Meat and Fish }(64 \%) \text {, Dairy Products }(33 \%) \text {, } \\
\text { Eggs }(4 \%) \text {. } \\
\text { Meat Products }(53 \%) \text {, Carcase Meat }(36 \%) \text {, } \\
\text { Fish }(10 \%)\end{array}$ & $\begin{array}{l}1.1 \\
=1.1 .1+1.1 .2+1.1 .3 \\
1.1 .1 \\
=1 \cdot 1 \cdot 1 \cdot 1+1.1 \cdot 1 \cdot 2+1 \cdot 1 \cdot 1.3\end{array}$ \\
\hline - Meat Products & Sausages $(56 \%)$, etc. & 1.1.1.1 \\
\hline - Carcase Meat & Beef and veal $(59 \%)$, pork $(22 \%)$, poultry $(12 \%)$, etc. & 1.1.1.2 \\
\hline - Fish & Unprocessed fish $(69 \%)$, etc. & 1.1.1.3 \\
\hline $\begin{array}{l}\text { - Dairy Products } \\
\text { (other than Fresh } \\
\text { Milk) }\end{array}$ & $\begin{array}{l}\text { Cheese }(40 \%) \text {, Sour Milk and Cream }(31 \%) \text {, } \\
\text { Butter }(17 \%) \text {, Margarine }(12 \%)\end{array}$ & $\begin{array}{l}1 \cdot 1 \cdot 2 \\
=1 \cdot 1 \cdot 2 \cdot 1+1 \cdot 1 \cdot 2 \cdot 2 \\
+1 \cdot 1 \cdot 2 \cdot 3+1 \cdot 1 \cdot 2 \cdot 4\end{array}$ \\
\hline - Cheese & Emmentaler and edam (51\%), etc. & 1.1.2.1 \\
\hline $\begin{array}{l}- \text { Sour Milk and } \\
\text { Cream }\end{array}$ & Sour milk products $(64 \%)$, cream $(36 \%)$ & 1.1.2.2 \\
\hline - Butter & Dairy butter, etc. & 1.1.2.3 \\
\hline - Margarine & Margarine $(90 \%)$, oils (10\%) & 1.1.2.4 \\
\hline - Eggs & Eggs & 1.1 .3 \\
\hline - Beverages & $\begin{array}{l}\text { Alcoholic Drinks (68\%), Fresh Milk (16\%), } \\
\text { Soft Drinks }(9 \%) \text {, Hot Drinks }(8 \%)\end{array}$ & $\begin{array}{l}1.2 \\
=1 \cdot 2 \cdot 1+1 \cdot 2 \cdot 2+1 \cdot 2 \cdot 3+1 \cdot 2 \cdot 4\end{array}$ \\
\hline - Alcoholic Drinks & Beverages which contain alcohol & 1.2 .1 \\
\hline - Fresh Milk & Standard milk, low fat milk, etc. & 1.2 .2 \\
\hline - Soft Drinks & Soft drinks and mineral waters & 1.2 .3 \\
\hline - Hot Drinks & Coffee $(89 \%)$, tea $(5 \%)$, cocoa $(4 \%)$, etc. & 1.2 .4 \\
\hline - Groceries & $\begin{array}{l}\text { Candies and chocolate }(36 \%) \text {, ice-cream }(17 \%) \text {, } \\
\text { sugar }(15 \%) \text {, etc. }\end{array}$ & 1.3 \\
\hline $\begin{array}{l}\text { - Vegetablia (food } \\
\text { from vegetable } \\
\text { sources) }\end{array}$ & $\begin{array}{l}\text { Bread and Cake }(41 \%) \text {, Fruits }(28 \%) \text {, } \\
\text { Vegetables }(19 \%) \text {, Flour }(13 \%)\end{array}$ & $\begin{array}{l}1.4 \\
=1.4 .1+1.4 .2+1.4 .3+1.4 .4\end{array}$ \\
\hline - Bread and Cake & Coffee cake $(52 \%)$, bread $(48 \%)$ & 1.4 .1 \\
\hline - Fruits & Cultivated fruits and berries $(58 \%)$, etc. & 1.4 .2 \\
\hline - Vegetables & Vegetables and potatoes & 1.4 .3 \\
\hline - Flour & Flour and hulled grain $(68 \%)$, etc. & 1.4 .4 \\
\hline Food-away-from-Home & $\begin{array}{l}\text { Food and drink in restaurants and cafes, } \\
\text { food catered at places of work }\end{array}$ & 2 \\
\hline Non-Durables & Non-durables excluding Food-at-Home & 3 \\
\hline Services & Services excluding Food-away-from-Home & 4 \\
\hline
\end{tabular}

In line with the interpretation of the relative price, if it is stated that a certain commodity has become cheaper, this must not imply that the nominal prices have gone down, but it is rather an outcome of the phenomenon where the price of the commodity increased less than the general price level. Thus, if a price changes by the rate of the general inflation, the relative price has not changed. 


\subsection{Data sets}

The annual data consist of expenditure series of goods and services for household consumption supplied in both current and constant monetary forms. The National Accounts time series for 1970-1991 were obtained from the Central Statistical Office. Because the volume series based on the year 1985 are available only from 1975 , to make the older values agree with the values after the year 1974, a level adjustment for the years 1970-1974 was made. The data that cover the years 1960-1969 were partly obtained from the Research Institute of the Finnish Economy, partly they were built up by the author by means of the data presented in LaURILA (1985). Data covering years 1950-1959 were built up by the author utilising the series presented in LAURILA (1985). To make these values agree with the post1960 values, a level adjustment was made. As a result, the base year for all the series was 1985 . The data covering 1950-1991 were used to describe the development of consumption patterns, whereas the econometric analysis employed the data covering 1960-1991. The reasons for not using the data from the $1950 \mathrm{~s}$ in the econometric analysis are as follows: (a) a number series are available only from 1960; (b) most of the post1960 values are derived from a uniform data source which is different from the data source utilised when deriving the pre-1960 values; and (c) consumer preferences tend to change over time, and, consequently, the observation period must not cover too long time period, because most of the econometric methods implicitly assume constant consumer preferences.

The National Accounts values refer to market values. The data are prepared according to the United Nations conventions. The data of the present study follow the 'new' Systems of National Accounts (United Nations 1968). For further discussion on the consumption in the National Accounts, see HÄMÄLÄINEN (1973), SÖDER (1984), LAurila (1985, Ch. A).

Implicit price series were derived by dividing current monetary expenditures by constant ones. The expenditure series were transformed to per capita expenditures. For diagnostic checking, data on disposable incomes were needed. The series of population and disposable income were taken from official statistics (Statistical Office 1992, Bulletin of Statistics).

It is noteworthy that the consumption in terms of expenditure is different from the consumption in terms of physical units. For example, the Food Balance Sheets by OECD and FAO measure the consumption as a raw-material disappearance, and in some commodities, as physical quantities of processed products. The Food Balance Sheets mostly ignore the changes in quality and the degree of preparation. In the case of food, changes in quality, rather than changes in quantity measured as raw materials, explain much of the changes in expenditures allocated to individual bundles. For example, per capita real expenditure on Foodat-Home excluding Alcoholic Drinks increased by $78 \%$ from 1950 to 1991 , while the average intake of energy, excluding Alcoholic Drinks, decreased from $2990 \mathrm{kcal}$ per day in 1950 to 2770 kcal per day in 1991, or 7\% (RouniaIneN 1979, MTTL 1992). The apparent contradictions between the volume trends in terms of monetary and physical units (LAURILA 1990) can be explained by the fact that food has become more prepared before it reaches the consumer. More has been spent per energy unit. Therefore, the consumption in terms of value may be increasing parallel to a decrease in the consumption in terms of weight. The added value originates mainly from services: the purchased good is further prepared than it used to be. Often there are several goods in one bundle. If those goods that are more processed increase their share in a bundle, the real expenditure of the bundle increases, although no quality changes have taken place in individual goods.

\subsection{Budget shares}

Although food expenditures have increased over decades, the share of food in the total expenditure has declined gradually. In the early $1950 \mathrm{~s}$, combined Food-at-Home and Food-away-from- 


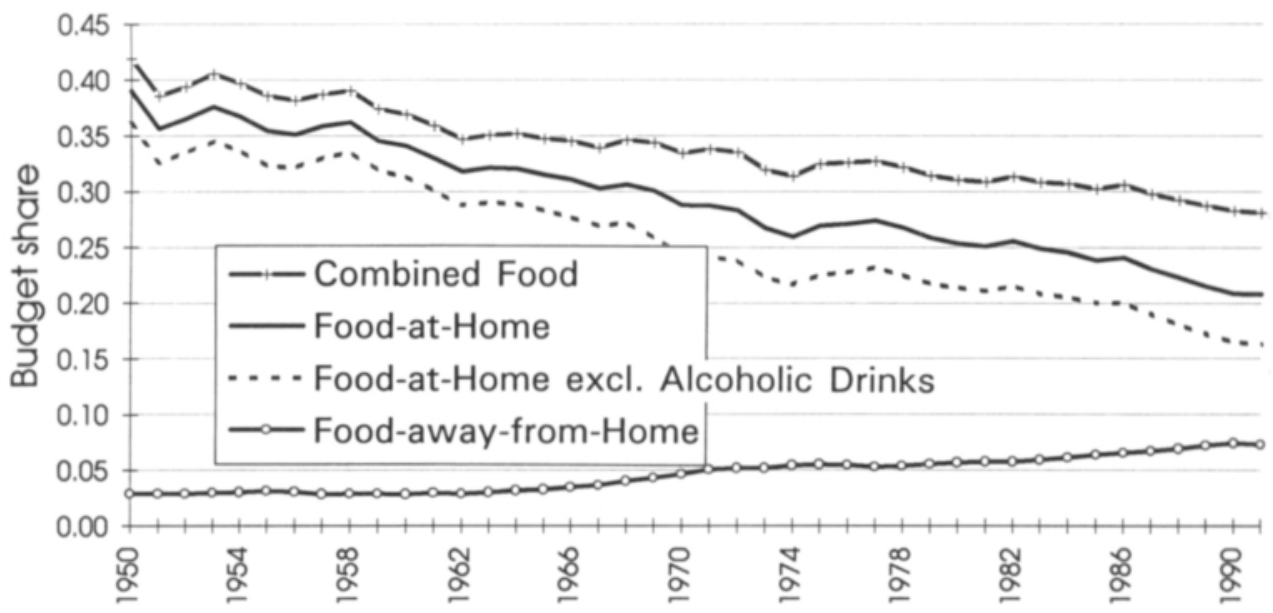

Fig. 1. Food expenditures related to Total Private Consumption (including Durables and Semi-Durables) in 1950-1991. Note: Combined food consists of Food-at-Home and Food-away-from-Home.

Home corresponded to some $40 \%$ of consumers' expenditure. In 1991 the share was 28\% (for a historical perspective over 100 years, see LAURILA 1987). There has been a shift to meals eaten outside the home. While the budget share of Foodaway-from-Home increased from $3 \%$ to $7 \%$ over the observation period, Food-at-Home fell from $37 \%$ to $21 \%$. Also Food-at-Home excluding Alcoholic Drinks was studied. That is because alcohol is specially treated in the Finnish tax-system, making it an artificially expensive commodity. Probably because good substitutes are lacking, alcohol is a big factor in households' budget. In 1991 the budget share of Food-at-Home excluding Alcoholic Drinks was $16 \%$ (Figure 1).

The data show that the budget shares of Cheese, Meat Products, Alcoholic Drinks, Soft Drinks, and Fruits have increased strongly over the observation period. The budget shares of Butter, Eggs, Fresh Milk, Hot Drinks, and Flour have decreased the most. A continuing shift from Carcase Meat to Meat Products has been recorded. The budget shares of the broad aggregate groups, Animalia, Beverages, and Vegetablia have remained quite steady over the observation period. Until the 1970s, the consumption of Vegetablia decreased in proportion to the consump- tion of Animalia. After that the trend disappeared (Table 3).

When studying the budget shares, it should be noted that a change in a share is a result of two components: change in the relative price and change in the relative volume. For example, the dramatic decrease in the budget share of Hot Drinks is, from one dimension, a consequence of a $300 \%$ increase in the consumption volume and, from another dimension, a consequence of an almost $90 \%$ decrease in the relative price.

\subsection{Volumes and prices}

Although the share of food in the total expenditure has decreased, food expenditures have increased over the observation period. On the per capita basis, Total Private Consumption (including Durables and Semi-Durables) became 3.4fold in four decades, while Food-at-Home doubled, and Food-at-Home excluding Alcoholic Drinks grew just $78 \%$. Over the observation period, Total Private Consumption increased, on an average, by $3.1 \%$ annually, while expenditure on Food-at-Home and Food-away-from-Home increased by $1.7 \%$ and $3.8 \%$, respectively. Food- 
Table 3. Budget shares of food items from 1950 to 1991.

\begin{tabular}{|c|c|c|c|c|c|c|}
\hline & \multicolumn{6}{|c|}{ Share of Food-at-Home, $\%$} \\
\hline & $\begin{array}{c}1950-59 \\
\text { average }\end{array}$ & $\begin{array}{c}1960-69 \\
\text { average }\end{array}$ & $\begin{array}{l}1970-79 \\
\text { average }\end{array}$ & $\begin{array}{c}1980-89 \\
\text { average }\end{array}$ & 1990 & 1991 \\
\hline Food-at-Home & 100 & 100 & 100 & 100 & 100 & 100 \\
\hline - Animalia & 33.7 & 36.9 & 36.6 & 35.2 & 34.1 & 33.5 \\
\hline - Meat and Fish & 18.1 & 20.4 & 22.6 & 21.6 & 21.7 & 21.3 \\
\hline - Meat Products & 5.6 & 9.5 & 11.0 & 11.1 & 11.5 & 11.4 \\
\hline - Carcase Meat & 9.8 & 8.5 & 9.0 & 8.1 & 8.1 & 7.8 \\
\hline - Fish & 2.7 & 2.4 & 2.6 & 2.4 & 2.1 & 2.2 \\
\hline - Dairy Products & 13.2 & 14.4 & 12.2 & 12.0 & 11.0 & 11.0 \\
\hline - Cheese & 1.5 & 1.9 & 2.4 & 3.4 & 4.1 & 4.4 \\
\hline - Sour Milk and Cream & n.a. ${ }^{a}$ & 3.0 & 3.7 & 3.4 & 3.4 & 3.4 \\
\hline - Butter & $11.8^{\mathrm{b}}$ & 7.5 & 4.2 & 3.7 & 2.1 & 1.9 \\
\hline - Margarine & n.a. ${ }^{b}$ & 2.1 & 1.9 & 1.5 & 1.4 & 1.3 \\
\hline - Eggs & 2.3 & 2.1 & 1.7 & 1.6 & 1.3 & 1.2 \\
\hline - Beverages & 32.0 & 30.6 & 32.6 & 29.9 & 31.4 & 31.9 \\
\hline - Alcoholic Drinks & 8.2 & 10.6 & 16.0 & 17.2 & 20.9 & 21.6 \\
\hline - Fresh Milk & $14.3^{a}$ & 11.5 & 8.4 & 6.1 & 5.2 & 5.1 \\
\hline - Soft Drinks & 1.0 & 1.3 & 2.0 & 2.3 & 2.7 & 2.7 \\
\hline - Hot Drinks & 8.5 & 7.1 & 6.2 & 4.2 & 2.7 & 2.5 \\
\hline - Groceries & 9.5 & 8.7 & 9.0 & 9.2 & 9.2 & 9.1 \\
\hline - Vegetablia & 24.8 & 23.8 & 21.9 & 25.7 & 25.4 & 25.5 \\
\hline - Bread and Cake & 8.1 & 10.2 & 9.3 & 10.1 & 10.4 & 10.4 \\
\hline - Fruits & 4.7 & 4.8 & 5.9 & 7.1 & 7.0 & 7.1 \\
\hline - Vegetables & 4.5 & 3.7 & 4.0 & 5.3 & 4.8 & 4.8 \\
\hline - Flour & 7.5 & 5.1 & 2.7 & 3.1 & 3.2 & 3.2 \\
\hline
\end{tabular}

Source: National Accounts; n.a.: not available

"Fresh Milk and Sour Milk and Cream cannot be separated. The combination is reported.

${ }^{\mathrm{b}}$ Fats cannot be separated. The combination is reported.

at-Home excluding Alcoholic Drinks has been even slower to grow: $1.5 \%$ annually over the observation period (Table 4).

The growth rates fluctuated a great deal over the observation period. In 1991 the consumption of Food-away-from-Home fell strongly for the third time over the observation period. The falls have been associated with falls in Total Private Consumption. A fall in Total Private Consumption has been realised as a stronger fall in Food-awayfrom-Home, indicating an expenditure-elastic demand. The demand has also been elastic during the economic booms of 1951, 1955, the late 1960s, and the 1980s. Expenditure on Food-at-Home has followed the changes in Total Private Consumption much more closely (Figure 2).
The consumption of Food-at-Home doubled in four decades. The highest volume was recorded in 1989. In both years 1990 and 1991, the consumption declined by $3 \%$. Related to the general price level, Food-at-Home became $24 \%$ cheaper over the observation period (Figure 3). In 1991, an average Finn consumed at home worth FIM 10,800 of food (in current values). This corresponded to FIM 900 per month.

The volume of Food-away-from-Home increased most of the time until 1990, with short drawbacks in the 1950s and late 1970s. The volume rose by $370 \%$ from 1950 to 1989 , and by $250 \%$ from 1960 to 1989 . The consumption stagnated in 1990 , and fell by $8 \%$ in 1991 . The consumption of Food-away-from-Home became more 
Table 4. Growth in the consumption volume from 1950 to 1991.

\begin{tabular}{|c|c|c|c|c|c|c|}
\hline & \multicolumn{5}{|c|}{ Per capita real expenditure, change from previous year, $\%$} & \multirow{2}{*}{$\begin{array}{c}\text { Change } \\
\text { from } 1950 \text { to } \\
1991, \%\end{array}$} \\
\hline & $\begin{array}{l}1951-59 \\
\text { average }\end{array}$ & $\begin{array}{l}\text { 1960-69 } \\
\text { average }\end{array}$ & $\begin{array}{l}1970-79 \\
\text { average }\end{array}$ & $\begin{array}{l}1980-89 \\
\text { average }\end{array}$ & $\begin{array}{l}1951-91 \\
\text { average }\end{array}$ & \\
\hline $\begin{array}{l}\text { Total Private Consumption } \\
\text { (including Durables and } \\
\text { Semi-Durables) }\end{array}$ & 3.0 & 4.3 & 3.2 & 2.9 & 3.1 & 237 \\
\hline $\begin{array}{l}\text { Private Consumption } \\
\text { (excluding Durables and } \\
\text { Semi-Durables) }\end{array}$ & 2.8 & 3.7 & 3.0 & 2.4 & 2.8 & 209 \\
\hline $\begin{array}{l}\text { Combined Food-at-Home and } \\
\text { Food-away-from-Home }\end{array}$ & 1.7 & 3.4 & 2.4 & 1.7 & 2.1 & 127 \\
\hline Food-at-Home & 1.5 & 3.1 & 2.1 & 1.1 & 1.7 & 100 \\
\hline $\begin{array}{l}\text { Food-at-Home excluding } \\
\text { Alcoholic Drinks }\end{array}$ & 1.6 & 2.4 & 1.9 & 0.8 & 1.5 & 78 \\
\hline Food-away-from-Home & 2.9 & 5.6 & 4.3 & 3.8 & 3.8 & 333 \\
\hline
\end{tabular}

Source: National Accounts

expensive over the decades. The price in 1991 was $85 \%$ higher than the all-time-low in 1952 (Figure 3). In 1991, an average Finn consumed away from home worth FIM 3,800 of food (in current values). This corresponded to FIM 320 per month.

\section{Meat and Fish}

Meat and Fish together corresponded to $18.1 \%$ of Food-at-Home in the 1950s. The share rose to $22.6 \%$ in the $1970 \mathrm{~s}$, then decreased to $21.6 \%$ in

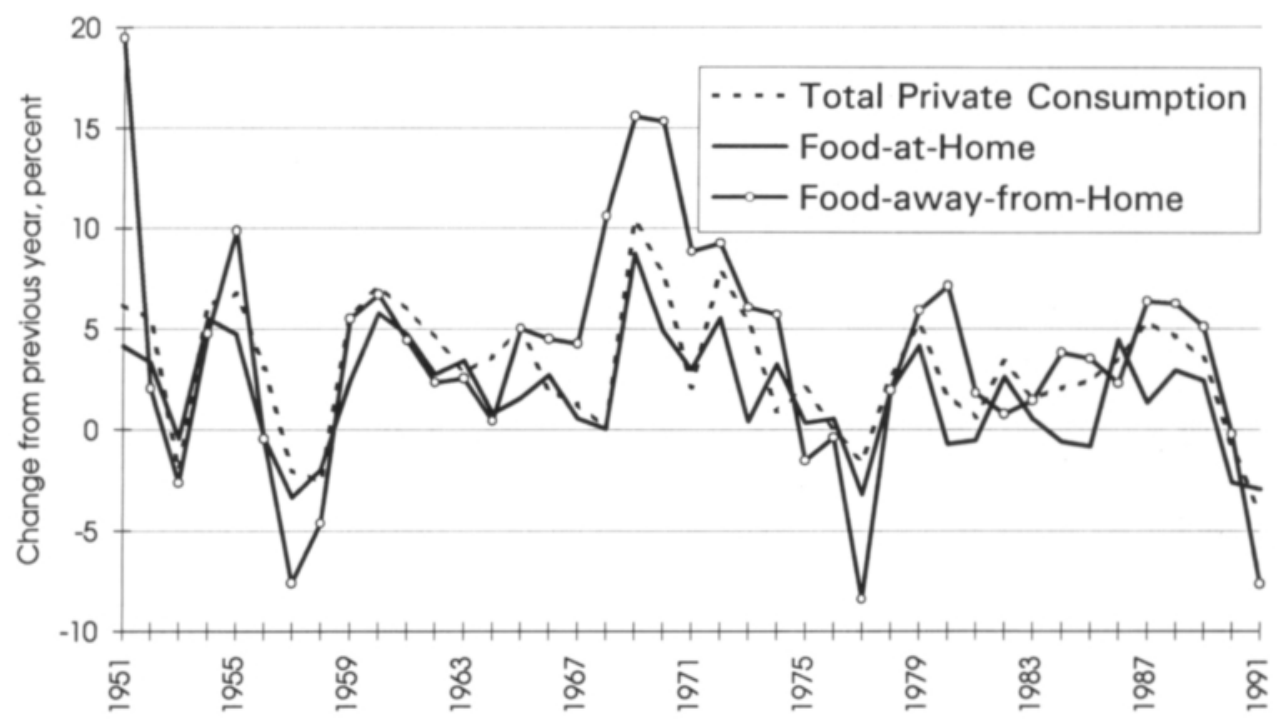

Fig. 2. Growth rates of Food-at-Home, Food-away-from-Home, and Total Private Consumption (including Durables and Semi-Durables) in 1951-1991: change in per capita real expenditure from previous year. 

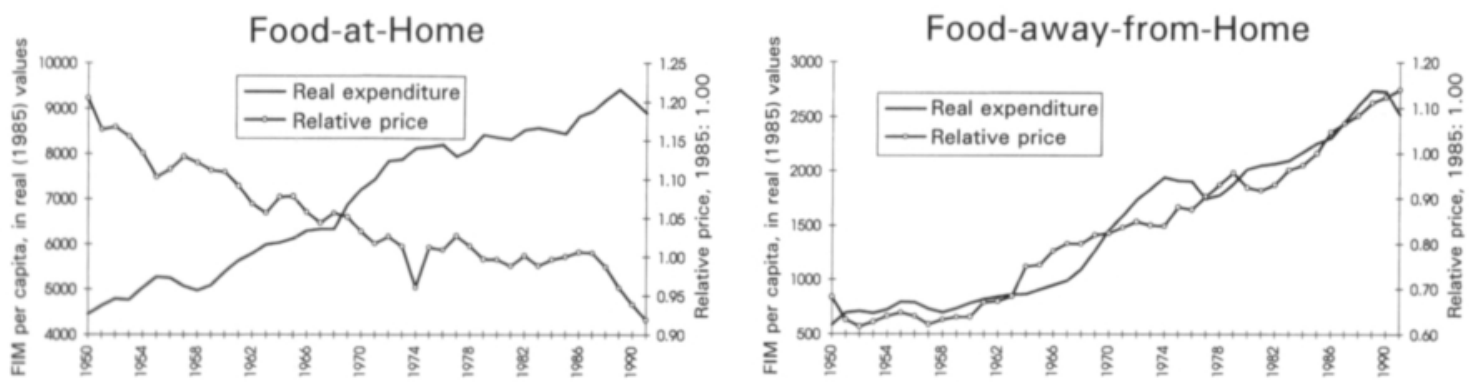

Fig. 3. Consumption and price of Food-at-Home and Food-away-from-Home in 1950-1991.

the 1980s. Of the sub-categories, Carcase Meat and Fish lost some of their importance in the consumer budget, while the budget share of Meat Products doubled over the observation period. The changing shares were due to the increased volumes of Meat Products, relatively slow increase in the volume of Carcase Meat, and the decreased price of Fish (Figure 4).

The consumption of Meat Products increased at an annual rate of $8 \%$ over the period 1950 to 1974. After 1974, the volume decreased for some years, then it started to increase again, and the 1974 consumption level was attained in 1987. The relative price of Meat Products has shown a decreasing trend: from 1950 to 1991, the price decreased by $35 \%$. The consumption of Carcase Meat decreased rapidly in the early 1950s. A clear turn upwards started in 1969, and the consumption increased by $50 \%$ in 11 years. After the alltime-high in 1979, the volume gradually declined by an average annual rate of $1.3 \%$. The price of Carcase Meat was at its highest in 1969. The price in 1991 was $16 \%$ below that level. The consumption of Fish rose gradually over the observation period, reached a peak in 1990, and declined in 1991. The Fish prices dropped by 57\% between 1956 (all-time-high) and 1991 (Figure 4).

\section{Dairy Products}

Dairy Products consisting of Cheese, Sour Milk and Cream, Butter, and Margarine took a share of $13.2 \%$ of Food-at-Home in 1950 s, $14.4 \%$ in the 1960 s, and about $12 \%$ in the 1970 s and 1980 s. Over time, fats, especially Butter, have had a decreasing budget share, the share of Sour Milk and Cream has remained about the same, while the budget share of Cheese has increased (Table 3 ).

Cheese consumption became eight-fold between 1950 and 1991, and five-fold between 1960 and 1991. The price series showed major shifts downwards in 1951, 1977, and 1985. As a result, Cheese was $40 \%$ cheaper in 1991 than it was in 1950. The consumption of Sour Milk and Cream doubled from 1960 to 1972 . The prices of Sour Milk and Cream rose gradually until 1972, and since then declined so that in 1991 the price level was $19 \%$ below the level of the year 1972 . Butter consumption reached a peak in 1962, and since then has declined at an average annual rate of $3.2 \%$. It is noteworthy that the consumption increased by $6 \%$ in 1991, while the price decreased by $22 \%$. Butter was most expensive in 1968 , i.e. $58 \%$ more expensive than in 1991. Margarine consumption was at its lowest in 1962, the very same year as the consumption of Butter was at its highest. During the following 12 years, the consumption of Margarine grew by $90 \%$. Over the years 1974-1984, the consumption fell at an annual rate of $3.6 \%$. Since then, the consumption has increased at the rate of $2.8 \%$ per year. The relative price declined gradually over the years 1960-1975, rose rapidly during the following two years, remained about the same until 1984, and since then has declined at an annual rate of $5 \%$ (Figure 4). 

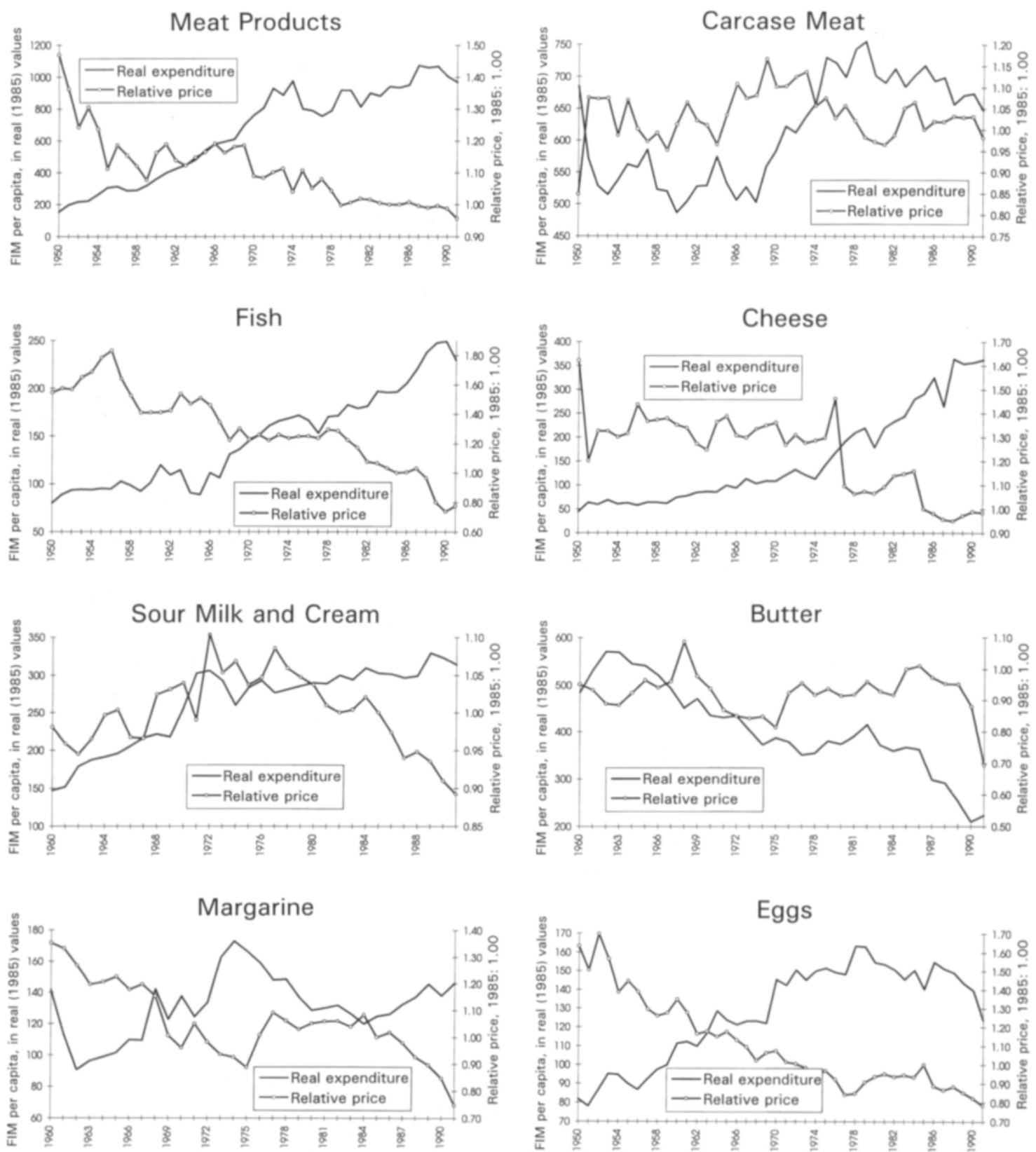

Fig. 4. Consumption and price of Animalia in 1950-1991.

There have been two major quality changes in Margarine. Soft margarine has been available since 1969 , thus widening margarine's use as a spread. Low-fat spreads were launched in 1987. In addition to quality shifts, an abnormality in fats mar- ket was recorded during the years 1961-1965: the market was affected by antagonistic publicity concerning production processes of margarine (RouHIAINEN 1979). 

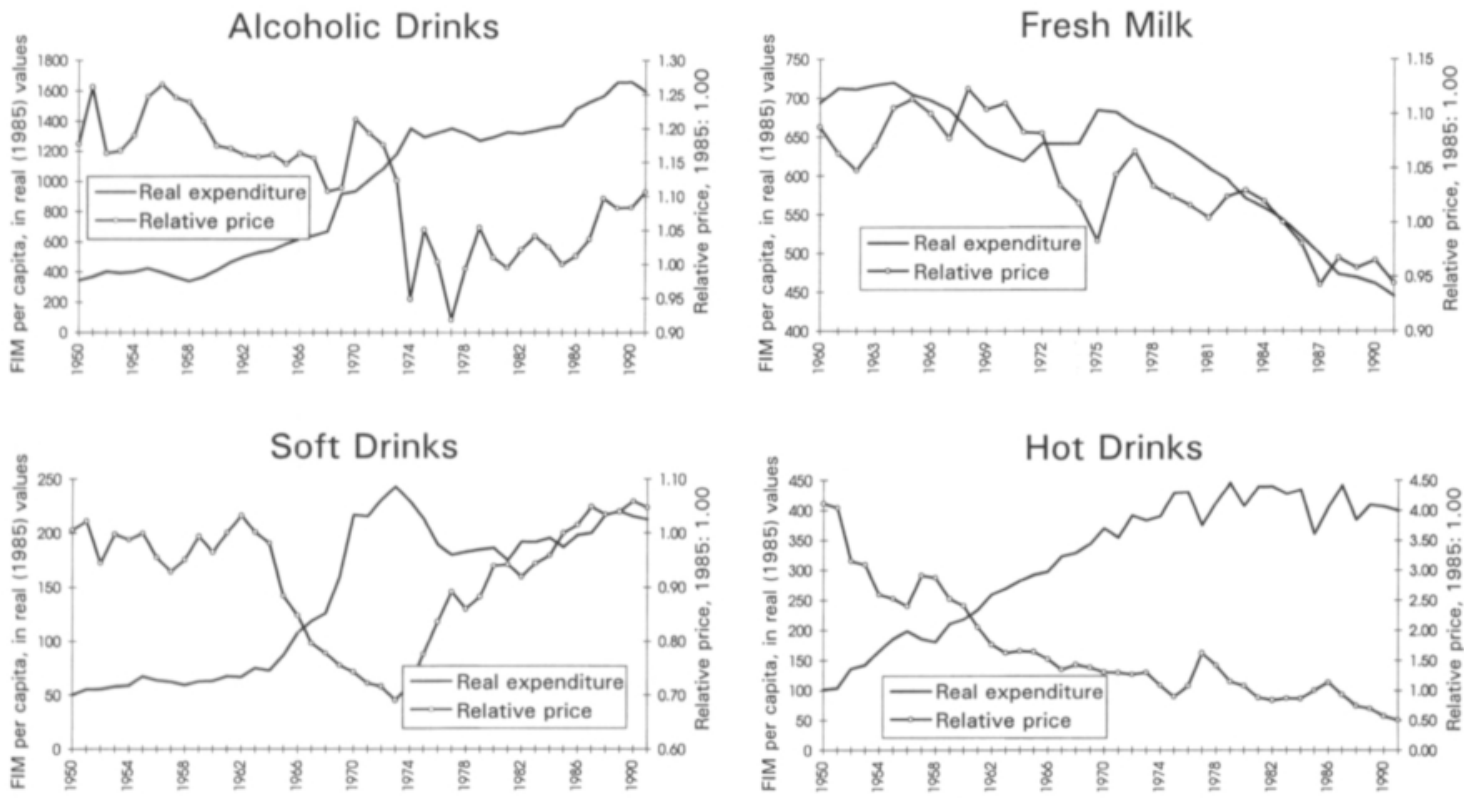

Fig. 5. Consumption and price of Beverages in 1950-1991.

\section{Eggs}

The consumption of Eggs doubled from the early 1950 s to the late 1970s. During the 1980s, the consumption of Eggs decreased, with a noticeable exception in 1986 , when a $10 \%$ price drop was reported. ${ }^{3}$ The fall in volumes speeded up in 1991. As a result, in 1991 Eggs were consumed in volumes which correspond to the volumes in the late 1960s (Figure 4). The consumption was probably affected by a growing concern on dietary cholesterol.

The budget share of Eggs fell from $2.3 \%$ in the 1950 s to $1.2 \%$ in 1991 (Table 3). The fall was not created only by the fall in volume, but the decrease was speeded up by a falling relative price.

\section{Beverages}

Over the observation period, Beverages corresponded to $30-33 \%$ of Food-at-Home. Behind the

${ }^{3}$ At the beginning of 1986, a dual price system for eggs came into effect, causing a decrease in retail prices. At the same time, strong marketing efforts were carried out. budget share there were mixed volume and price combinations. Over the observation period, the consumption of Alcoholic Drinks, Soft Drinks, and Hot Drinks increased by $360 \%, 320 \%$, and $290 \%$, respectively. From 1960 to 1991 , the consumption of Fresh Milk decreased by $36 \%$ (Figure 5),

Over the observation period, Alcoholic Drinks took an increasing share of the food budget of households. The rise was due to the consumption volume, which increased faster than the total consumption. The reasons for the increasing trend were supposed to be increasing incomes, better availability, and more positive attitudes towards Alcoholic Drinks (SIMPURA and ÖSTERBERG 1989). Over the observation period, the relative price of Alcoholic Drinks was at its highest in 1951 and in 1956. In the mid-1970s, the price shifted downwards, and tended upwards after that.

Fresh Milk consumption was at its highest in 1964. Over the years 1965-71, the consumption decreased annually by about $2 \%$. Then, the volumes increased until 1975. After that, the slope has been steadily downwards. From 1975 to 1991, Fresh Milk drinking diminished by $35 \%$, or at 

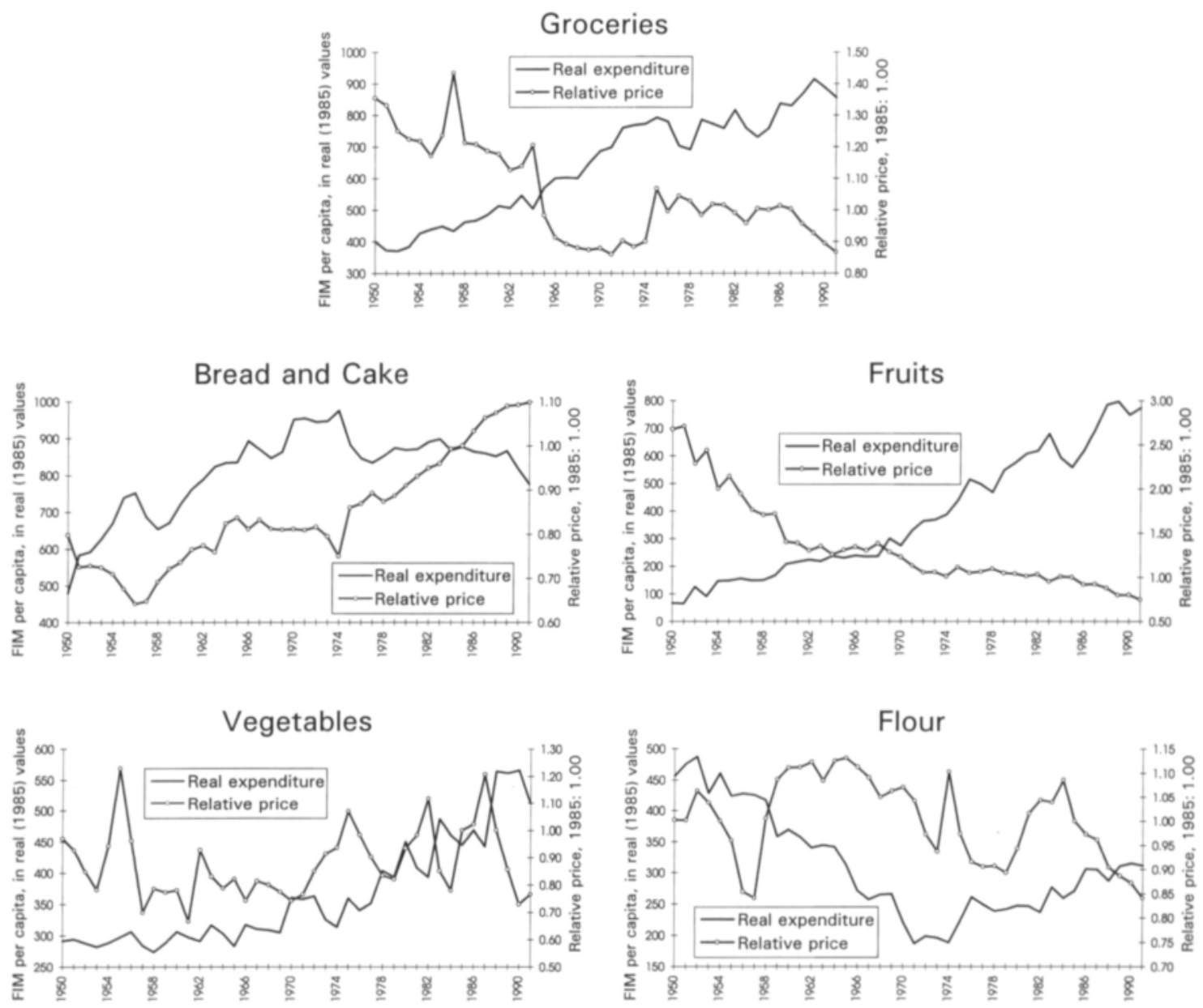

Fig. 6. Consumption and price of Groceries and Vegetablia in 1950-1991.

the annual rate of $2.7 \%$. The long-term price trend tended downwards, but there were several fluctuations that broke the trend. The price in 1991 was $13 \%$ below the level in 1960 .

The consumption of Soft Drinks was at its highest in 1973. Parallel to a strong increase in the consumption during the period 1963-1973, there was a strong price fall. Interestingly enough, simultaneously with the decrease in Soft Drinks consumption over the period 1974-1977, the prices of Soft Drinks increased rapidly. In the 1980s, both the prices and volumes increased.

A considerable change took place in the budget share of Hot Drinks. The average of $8.5 \%$ in the 1950 s decreased to $2.5 \%$ in 1991 , while the consumption quadrupled. The phenomenon is explained by falling prices: the relative price of Hot Drinks in 1991 was one-eighth of that in the early 1950 s.

\section{Groceries}

The budget share of Groceries remained about the same over the observation period: around 9\% of Food-at-Home (Table 3). While the consumption volume more than doubled, the increase was partially offset by the relative price that dropped by one-third (Figure 6). 


\section{Vegetablia}

The budget share of Vegetablia remained at 24$26 \%$ over the observation period, with an exception in the $1970 \mathrm{~s}$, when the share was $22 \%$. The consumption of Bread and Cake, Fruits, and Vegetables increased over time, while the consumption of Flour decreased. The price of Bread and Cake increased, that of Fruits decreased, while that of Vegetables and Flour fluctuated heavily (Figure 6).

Bread and Cake consumption reached the peak in 1974. In the 1980s the consumption was quite steady, but in 1990 and 1991 the volume decreased by $5 \%$ each year. In 1991, 20\% less was consumed than in 1974. The price of Bread and Cake was at its lowest in 1956. After that, the price changes have been mostly upwards, and in 1991 Bread and Cake were $71 \%$ more expensive than in 1956. Over the observation period, the consumption of Fruits became 12-fold, or increased at an average annual rate of $6.2 \%$, which was double compared with the growth of Private Consumption. From 1960 to 1991 , the growth was $270 \%$. The growth in the budget share of Fruits was more moderate, rising from an average of $4.7 \%$ in the 1950 s to $7.1 \%$ in the 1980 s. From 1950 to 1991, the prices of Fruits decreased by $72 \%$, or at an annual rate of $3.1 \%$. The consumption of Vegetables was at its highest in 19881990 , when the volume was nearly twice as much as the volume in the 1950s and 1960s. The price trend of Vegetables exhibited a great deal of inconsistency over time. Flour consumption decreased by $60 \%$ from the early 1950 s to the beginning of the 1970s. Between 1974 and 1991, the consumption of Flour increased by $60 \%$ (Figure 6).

\section{Demand theory and empirical analysis}

\subsection{Determinants of consumer demand for food}

The neoclassical theory of consumer behaviour names incomes and prices as the factors that determine demand. Extensions of the neoclassical model take into account socio-economic, demographic, socio-psychological, and nutritional factors, choices under risk and uncertainty, plus new commodities, multi-period consumption decisions, and time (CAPPS and HaVLiceK 1987, p. 17-23). In the present study, the static theoretical framework of consumer demand is extended to a dynamic theoretical framework in order to take into account multi-period consumption decisions.

HAIDACHER (1992) reviewed demand studies in order to evaluate the relative importance of price, income, and demographic factors in explaining year-to-year changes in consumption of dairy and related products in the United States. He stressed not to ignore cross-commodity inter- dependencies that have shown to be economically significant. He concluded that the changes were predominantly the result of changes in relative prices (own-price and other prices) and changes in income. Demographic variables were more important in explaining variations in expenditures between households than in explaining yearly fluctuations in market demand patterns. That was because demographic factors changed slowly over time (Haidacher 1992, p. 205-209). Heien and WESSELLS (1988) also studied the relative importance of demographic and economic variables in explaining the decrease in demand for milk and butter in the United States. They argued that the main cause was the own-price impact.

An economic analysis lays emphasis on possibilities and preferences. In this framework, given prices and income, the consumer is able to buy various combinations of quantities (possibilities), and consumers rank all relevant bundles of goods (preferences). Consumers are assumed to seek to 
maximise their own utility or satisfaction through a series of choices that are constrained by their limited income. The outcome is that a consumer picks a certain bundle of goods which ranks highest within the constrains. The observed outcomes, the demand relationships, reflect the optimum amount of each good to purchase, depending on the consumer's income, the set of prices (that is outside his control), and the consumer's preferences. This theoretical model suggests that economic factors, such as income ${ }^{4}$ and prices, should have a major impact on the choices which generate certain observable consumption patterns (c.f., Tangermann 1986, Senauer et al. 1991, Ch. 5). However, in economic analysis, some aspects in human food selection remain unexplained. The models are able to track the reality only as far as history repeats itself. The error term in econometric models has to absorb a number of factors which are difficult to identify.

Many non-income demographic variables cannot be separated from simple time trends. LEwBEL (1989, p. 353) concluded that there is insufficient variation in time-series data to identify a reasonable range of demographic effects on tastes. Although non-economic factors are not explicit in the statistical analysis, they may be absorbed by economic factors. A perfect capturer is the expenditure variable, ${ }^{5}$ which shows an almost monotonically increasing trend over the observation period. There is some evidence that price effects have also been attributed to demographic variables that are correlated with prices (BUSE

\footnotetext{
${ }^{4}$ In the present study, the consumption decisions are assumed to be based on current income. This current income hypothesis could be replaced by e.g. the permanent income hypothesis or by the relative income hypothesis. In the case of cross-sectional data, the relative income hypothesis could be interpreted as "keeping up with the Joneses" effect, in the case of time-series data consumers are assumed to keep up with their own established standard of living, and thus consumers' income is related to the prior level. Since the present study focuses on analysing merely non-durable goods which are consumed within the same period they are purchased, the current income hypothesis is a relevant approach.

${ }^{5}$ Because of the requirements of the econometric methodology applied, in the present study households' total expenditure is used as an indicator of income.
}

1986). Potential variables-to-be-absorbed are the demographic variables that show linear population dynamics, such as age structure and changes in the size of household, diminishing rural population, ethnic food consumption, shift from food producers to food consumers, and increase of catered food (see Roos and AHOLA 1989 on demographic and life-style factors in Finland).

Contrary to certain demographic variables, many socio-cultural variables are probably much less linear. For example, PrättäLÄ (1989, p. 5354) found a duality in cultural attitudes towards food that divides food into "real" foods and "junk" foods, or foods filling nutritional needs and foods for fun, such as energy-rich, high-fat desserts and snacks. Consumers have an interest in healthier eating and drinking. Growing interest in nutrition means that less fat, especially animal fat, less cholesterol, and more fibre are used. Some of the shift from butter to margarine must be attributed to health concerns related to butter. Consumers worry about chemicals, additives, and hard technology. The concern ranges from the way the raw-materials are grown to the nutritional value of the product, from well-being of domestic animals to environmental friendliness of packaging. Consumption patterns have become more fragmented. Some favour convenience in food purchasing and consumption, others favour less processing. Some life styles increase the interest in gourmet food. Travelling and internationalisation of all sorts probably brings more variation in eating. Advertising, accompanied with convenience-oriented supply of value-added items, fancy packaging, and myriad brandname aim to influence consumers' preferences and increase the overall consumption. Some foods are for breakfast, some for Christmas dinner, some for snacks, some for "real" meals. A whole new research scheme would be required to study the changes in the rule of etiquette, the nature of the occasions on which food items are consumed, and the symbolic meaning of food (e.g. GoFTON 1986).

It is obvious that the changes in the consumption of food items depend on a great number of determinants. However, to make the analysis feasible, the number of factors under consideration 
must be limited. While the importance of demographic and socio-cultural variables must not be forgotten, they probably play a minor role at the aggregation level adopted in this study. For example, the demand for fresh milk will be studied as a combined bundle, rather than the demand for various types of fresh milk. The adopted methodology allows the demand system to take into account certain amount of socio-cultural effects via the structural change parameters. For example, possible changes that have taken place in consumer attitudes towards milk products, butter, margarine, and alcoholic drinks can be taken into account to some degree.

The paradigm of the present study follows the main-stream of economics, which implies that the demand theory is employed in order to focus on essential factors. Consequently, the models will be a group of abstractions that represent simplifications of a very complex reality.

\subsection{System of choice: preferences and utility maximisation}

In the present study a complete demand system approach is adopted. The approach gives substantial importance to the properties of consumer behaviour implied by the demand theory. Thus, it is reasonable to discuss the theory which gives a framework to derive demand functions from a model of utility-maximising consumer and a representation of the consumer's budget constraint. In the theory, preference ordering gives rise to a utility function that, in turn, gives rise to demand functions.

Let $\boldsymbol{q}=\left(q_{1}, \ldots, q_{n}\right)$ be a commodity vector, where $n$ is the number of goods and $q_{i}$ is the quantity of the $i$ th commodity (for $i=1, \ldots, n$ ). Let the symbols $>, \geq, \sim$ denote "strictly preferred to," "weakly preferred to," and "indifferent to," respectively. The following axioms of choice describe the consumer's preferences (DEATON and MUELLBAUER 1980b, Ch. 2.1, VARIAN 1992, Ch. 7.1):

(a) Completeness, or comparability. For any two bundles $\boldsymbol{q}_{1}$ and $\boldsymbol{q}_{2}, \boldsymbol{q}_{1} \geq \boldsymbol{q}_{2}$ or $\boldsymbol{q}_{2} \geq \mathbf{q}_{1}$ or $\boldsymbol{q}_{1} \sim \boldsymbol{q}_{2}$, which is to say that consumers can judge between any two bundles. The consumer can decide whether one bundle of goods is preferred to another, or whether he is indifferent between the two bundles.

(b) Transitivity, or consistency. For any bundles $\boldsymbol{q}_{1}, \boldsymbol{q}_{2}$, and $\boldsymbol{q}_{3}$, if $\boldsymbol{q}_{1} \geq \boldsymbol{q}_{2}$ and $\boldsymbol{q}_{2} \geq \boldsymbol{q}_{3}$ then $\boldsymbol{q}_{1} \geq$ $\boldsymbol{q}_{3}$, which is to say, for example, that if the consumer prefers an apple to an orange and an orange to a banana, he is expected to prefer an apple to a banana.

(c) Continuity means that all the vectors of goods in the choice set are closed, i.e. the sets contain their own boundaries.

(d) Non-satiation, or strong monotonicity, states that for any two bundles $\boldsymbol{q}_{1}$ and $\boldsymbol{q}_{2}$, if $\boldsymbol{q}_{1} \geq \boldsymbol{q}_{2}$ then $\boldsymbol{q}_{1} \geq \boldsymbol{q}_{2}$, or, the consumer prefers more to less. This axiom restricts the preferences so that the best choice lies on the budget constraint, not inside it.

(e) Strict convexity states that, if $\boldsymbol{q}_{1} \sim \boldsymbol{q}_{2}$ and $\boldsymbol{q}_{1} \neq$ $\boldsymbol{q}_{2}$, then $\lambda \boldsymbol{q}_{1}+(1-\lambda) \boldsymbol{q}_{2}>\boldsymbol{q}_{1}$ for $0<\lambda<1$, or the consumer prefers averages to extremes. If two bundles are on the same indifference curve, any combination of these bundles is preferred to the extreme solutions. This also means that indifference curves are convex to the origin.

The axioms (a) to (d) imply that there is a continuous utility function, or preference representation function ( $c$. $f$. DEATON and Muellbauer 1980b, p. 28)

$u=v\left(q_{1}, \ldots, q_{n}\right)=v(q)$

such that, for any two bundles $\boldsymbol{q}_{1}$ and $\boldsymbol{q}_{2}, \boldsymbol{q}_{1} \geq \boldsymbol{q}_{2}$ $\Leftrightarrow v\left(\boldsymbol{q}_{1}\right) \geq v\left(\boldsymbol{q}_{2}\right)$. The term $u$ stands for a certain level of utility. The direct utility function (3) is an ordinal measure showing in which order the bundles are situated, ranging from the least preferred bundle to the most preferred bundle. Given also the axiom (e), the utility function is strictly quasi concave (CHIANG 1984, p. 403).

The axioms on the consumer's preference ordering define a rational consumer who chooses the most preferred bundle from the set of bundles that the consumer can afford. Given the conven- 
tional linear budget constraint, utility maximisation states that the consumer allocates his total expenditure, $x$, so that

$$
\text { Maximise } u=v(\boldsymbol{q}) \text { subject to } \sum_{i=1}^{n} p_{i} q_{i}=x
$$

where $p_{i}$ is the price of good $i$. To attain from utility to demand functions, one solves the first order conditions of (4), or the primal (or original) problem. The result is the system of Marshallian [income-uncompensated] demand functions, for $i=1, \ldots, \mathrm{n}$,

$$
q_{i}=g_{i}\left(x, p_{1}, \ldots, p_{n}\right)=g_{i}(x, \boldsymbol{p})
$$

Substituting (5) into (3) yields the indirect utility function

$$
u=v\left[g_{i}(x, \boldsymbol{p})\right]=\psi(x, \boldsymbol{p})
$$

The weakness of the primal problem is that the first order conditions are rarely solvable. Duality provides an alternative way to construct a demand function which is solvable in terms of the preferences and utility maximisation principle presented above.

\subsection{Duality in deriving a demand system}

Duality provides four equivalent ways of representing consumer preferences: (a) direct utility function, (b) indirect utility function, (c) expenditure function, and (d) transformation or distance function. By using duality relationships, theoretically plausible demand systems can be obtained by relatively simple differentiation rather than by direct optimisation techniques (BLANCIFORTI et al. 1986).

The primal problem, or utility maximisation, states that a consumer maximises utility for a given expenditure. The solution is a set of Marshallian demand functions, defined on prices and expenditure. Now the problem is reformulated. The dual problem, or cost minimisation, states that the consumer selects goods to minimise the expenditure necessary to reach a certain level of utility $u$ :

$$
\text { Minimise } x=\sum_{i=1}^{n} p_{i} q_{i} \text { subject to } v(\boldsymbol{q})=u
$$

Solution of this cost-minimising problem is the system of Hicksian [income-compensated] demand functions, ${ }^{6}$ defined on prices and utility, for $i=1, \ldots, \mathrm{n}$,

$q_{i}=h_{i}(u, \boldsymbol{p})$

Substitution of (8) into the budget constraint yields the cost or expenditure function

$x=\sum_{i=1}^{n} p_{i} h_{i}(u, \boldsymbol{p})=c(u, \boldsymbol{p})$

The expenditure function shows the minimum expenditure of attaining a given level of utility with alternative prices.

The Marshallian demand functions indicate how $q$ is affected by prices with $x$ held constant, while Hicksian demand functions tell how $q$ is affected by prices with $u$ held constant. In both problems, optimal bundles are sought. The solutions of the primal and dual problems are identical, or $q_{i} \equiv$ $g_{i}(x, \boldsymbol{p}) \equiv h_{i}\left[v\left(g_{i}\{x, \boldsymbol{p}\}\right), \boldsymbol{p}\right]$. Thus, the vector of goods chosen is the same in both cases, and the expenditure in the primal problem is the cost minimum in the dual problem. The choice of functions depends on the accessibility of the required variables. Utility cannot be measured directly. The empirical work concentrates on the resulting demand functions, and uses the underlying utility theory as a benchmark to understand the dependencies. Thus, the demand equations which are applied for empirical analysis should be the Marshallian type.

${ }^{6}$ For example, the income-compensated effect of a change in the price of commodity $i$ requires that the income effect is eliminated by compensating the fall in real expenditure, and what remains is the substitution effect. Thus, compensated demand function assumes constant expenditure in real prices, while uncompensated demand function assumes constant expenditure in nominal prices. 
Expenditure function $x=c\left(u, p_{1}, \ldots, p_{n}\right)$

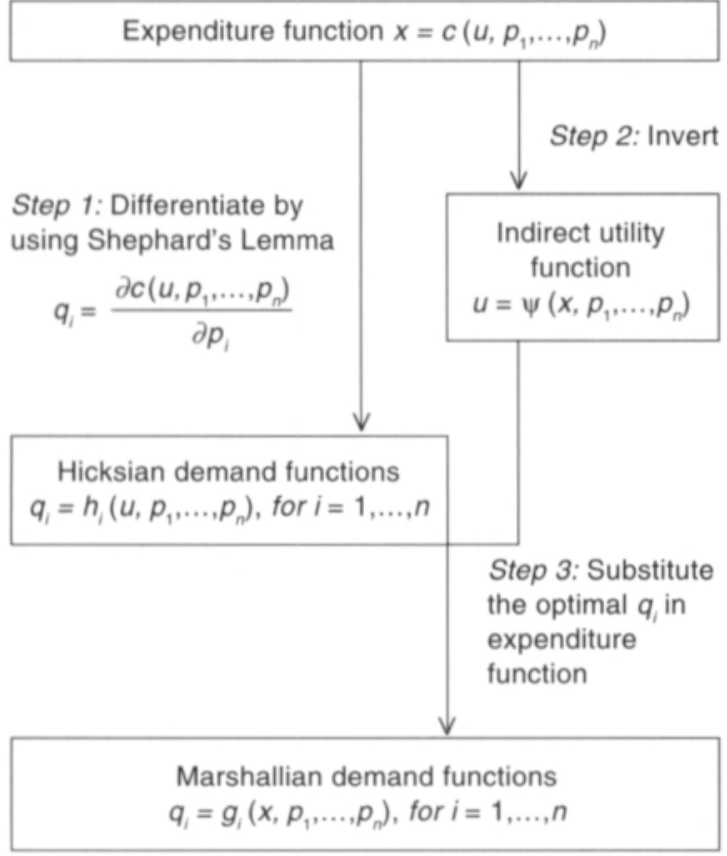

Fig. 7. Duality in deriving the Marshallian demand functions.

A stepwise procedure is used to derive Marshallian demand functions from the expenditure function that is available. First, Shephard's Lemma is employed to move from the known expenditure function to the cost-minimising demand functions that underlie it. In the procedure, the expenditure function is partially differentiated to obtain Hicksian demand functions, which consequently are the partial derivatives of the expenditure function with respect to prices (Step 1 in Figure 7). Then, since the expenditure and indirect utility functions are inverses, the expenditure function is inverted to obtain the corresponding indirect utility function (Step 2). The indirect utility function indicates the highest level of utility that can be obtained for the given prices and income. Finally, the indirect utility function is substituted into the Hicksian demand functions. The result is the desired system of Marshallian demand functions (Step 3). The functions attached to the Almost Ideal Demand System (AIDS), the demand system used in the present study, are spec- ified in more detail in Chapter 4. The duality approach to the consumer theory is presented completely in Deaton and Muellbauer (1980b, Section 2.3).

There are five properties that the expenditure function must satisfy before it can be used in the procedure:

(a) Homogeneity. The expenditure function is homogeneous of degree one in prices, or for $\theta>$ $0, c\left(u, \theta p_{1}, \ldots, \theta p_{n}\right)=\theta c\left(u, p_{1}, \ldots, p_{n}\right)$. The property follows from the linear budget constraint. For example, if prices double, twice as much total expenditure is required to stay on the same indifference curve. Note the difference between overall price level and relative prices. If all prices go up by $5 \%$, there will be no relative price effect, but only an impact on the real purchasing power of incomes, which would decline by $5 \%$ in real terms.

(b) "No-free-lunch." The expenditure function is increasing in $u$, non-decreasing in $p_{i}$, and increasing in at least one price. Thus, for example, at given prices the consumer has to spend more to be better off, or if $u \geq u^{\prime}$ then $c\left(u, p_{1}, \ldots, p_{n}\right) \geq c\left(u^{\prime}, p_{1}, \ldots, p_{n}\right)$. And, if the prices increase, at least as much expenditure is needed to stay on the same utility level, or if $p_{i} \geq p_{i}{ }^{\prime}$ then $c\left(u, p_{1}, \ldots, p_{n}\right) \geq c\left(u, p_{1}{ }^{\prime}, \ldots, p_{n}{ }^{\prime}\right)$. The properties follow from the non-satiation axiom.

(c) Concavity. The expenditure function is concave in prices, or for $0 \leq \theta \leq 1, c\left[u, \theta p_{1}+(1-\right.$ $\left.\theta) p_{1}{ }^{\prime}, \ldots, \theta p_{n}+(1-\theta) p_{n}{ }^{\prime}\right] \geq \theta c\left(u, p_{1}, \ldots, p_{n}\right)+(1-$ $\theta) c\left(u, p_{1}{ }^{\prime}, \ldots, p_{n}{ }^{\prime}\right)$. The concavity implies, for example, that, when prices increase, expenditure will increase no more than linearly because the consumer minimises expenditures by rearranging purchases in order to take advantage of the changes in the price structure. A necessary condition for concavity is that all the diagonal elements of the matrix of the compensated price elasticities are non-positive. Thus, violation of concavity may be the reason if one obtains positive compensated own-price elasticities.

(d) Continuity. Following from the concavity, the 
expenditure function is continuous in prices $p_{i}$, for $p_{i}>0$ for all $i$.

(e) Applicability. Following from the continuity, where they exist, the partial derivatives of the expenditure function with respect to prices $p_{i}$ are the Hicksian demand functions. Shephard's Lemma - employed in deriving the demand system (Figure 7) - is derived from this property.

It is relatively easy to specify an expenditure function which satisfies the five properties stated above. Duality provides a procedure to derive the required Marshallian demand functions. The strength of the method is that the attained functions automatically satisfy certain restrictions, namely adding-up, homogeneity, symmetry, and negativity. On the contrary to the described method, Marshallian demand functions could also be specified directly. Whatever was the method derivation or direct specification - the fulfillment of the four requirements may be checked ex post, and the results show whether the demand functions correspond to the consistent preference ordering.

\subsection{Slutsky conditions for symmetry and negativity}

To be able to test symmetry and negativity of a set of demand functions, one has to calculate the substitution or Slutsky matrix, $\boldsymbol{S}$, of compensated price responses, which is symmetric and negative semidefinite by the symmetry and negativity properties. $^{7}$ To make it empirically attainable, $\boldsymbol{S}$ must be defined in terms of the Marshallian demand functions. This is done through the Slutsky equation

$s_{i j}=\frac{\partial h_{i}}{\partial p_{j}}=\frac{\partial g_{i}}{\partial x} q_{j}+\frac{\partial g_{i}}{\partial p_{j}}$

${ }^{7}$ The adding-up, homogeneity, symmetry, and negativity properties, and the decomposition of a price change into a substitution effect and income effect were first stated explicitly in SLUTSKY (1915). where $s_{i j}$ is the unobservable substitution effect of a price change, or compensated price response, where $i$ denotes the commodity affected, and $j$ the commodity the price of which has changed. $g_{i}$ is the Marshallian demand function (5), $h_{i}$ is the Hicksian demand function (8), $\frac{\partial g_{i}}{\partial x} q_{j}$ is the observable income effect of price change, and $\frac{\partial g_{i}}{\partial p_{j}}$ is the observable uncompensated price response. Thus, the Slutsky equation links the price derivatives of compensated and uncompensated demand functions.

By rearranging, the Slutsky equation

$\frac{\partial g_{i}}{\partial p_{j}}=s_{i j}-\frac{\partial g_{i}}{\partial x} q_{j}$

divides the total effect of price change, $\frac{\partial g_{i}}{\partial p_{j}}$, into a substitution effect, $s_{i j}$, and an income effect, $\frac{\partial g_{i}}{\partial x} q_{j}$. If $s_{i j}>0$, goods $i$ and $j$ are substitutes, or Hicksian substitutes, and if $s_{i j}<0$, the goods are complements, or Hicksian complements (the definitions originate from Hicks 1936). If $\frac{\partial g_{i}}{\partial p_{j}}>0$ or $\frac{\partial g_{i}}{\partial p_{j}}<0$, goods $i$ and $j$ are classified into gross substitutes or gross complements, respectively.

The conditions also state a negative own-price and symmetric cross-price effects. However, the "law of demand" (Section 4.3) does not necessarily apply to the Marshallian demand functions. It becomes clear when rearranging (11) such as

$\frac{\partial g_{i}}{\partial p_{i}}=s_{i i}-\frac{\partial g_{i}}{\partial x} q_{i}$

As the price changes, the quantity demanded depends on the combination of income and sub- 
stitution effects. Although the compensated ownprice response, $s_{i i}$, is negative, it is possible that it is outweighed by a positive income effect. A positive price response is possible if the good is highly inferior and it is purchased in large quantities. This kind of good is called a Giffen good.

\section{Demand system specification and estimation}

\subsection{Complete demand systems approach: literature review}

In the previous chapter, the framework for the further work was provided. The presented demand theory is not informative about appropriate choices for functional form and other aspects of the model specification. Various specifications have been suggested.

The short history of empirical demand analysis presented here starts with a single equation methodology known as Stone's analysis (STONE 1954a). Stone's methodology models commodity demands individually, equation by equation. The elasticities can be measured directly as the parameters of a regression equation linear in the logarithms of total expenditure and prices. The advantage of the methodology is flexibility, i.e. if necessary, the functional form can be varied and extra explanatory variables can be attached from commodity to commodity. However, the methodology is not consistent with the demand theory, which implies that, for example, most of the restrictions derived from the theory have no consequence for the analysis.

Since Stone's analysis is not very well consistent with the theory, researchers started to work with the applications to complete systems of equations where theory becomes more relevant. Complete demand systems approach gives substantial importance to the preference ordering, which gives rise to the utility function, which, in turn, generates the demand functions. The common feature for the systems is that they allow - at least after the estimation - for checking if the model is consistent with the Slutsky conditions (adding-up, homogeneity, symmetry, and negativity). The systems describe the allocation of expenditures among commodities in a way that the expenditures on sub-groups sum up to the total expenditure. Also, the systems account for interdependency among commodities, and they try to specify a sound correspondence between the theory on an individual consumer and the market data. In specifying a complete Marshallian demand system, two approaches have commonly been used: (1) an approach based on a specific functional form for (a) direct utility function (e.g. the Linear Expenditure System), (b) indirect utility function (the Translog model), or (c) expenditure function (e.g. the Almost Ideal Demand System); and (2) an approach approximating the demand system directly (the Rotterdam model) (HUANG and HAIDACHER 1983).

STONE (1954b) started the era of complete systems approach in demand analysis with his Linear Expenditure System (LES). The revolutionary point in the new approach was the attempt to incorporate the elements of microeconomic theory of consumer demand in the analysis. The aim was to formulate a model which allows an empirical application of the theory at a very general level. The big advantage of the LES, in addition to the consistency with the theory, is that only $(2 n-1)$ parameters have to be estimated, and thus the method can be applied to a relatively large number of commodity groups ( $n$ is the number of commodities in the system). On the other hand, the LES suffers from inflexibility: the system has too few parameters to allow to test the consumer theory. There was a need for more general approaches.

Various types of empirical demand systems have been proposed since the LES. The Rotterdam model was introduced as more testable (THEIL 1965, 1975, 1976, BARTEN 1969). The Rotter- 
dam model is still widely used. Model development was directed towards flexible functional forms. ${ }^{8}$ The most commonly cited flexible functional forms are the Indirect Translog System by CHRISTENSEN et al. (1975) and the Almost Ideal Demand System (AIDS) by Deaton and Muellbauer (1980a, b), but there are many other forms (for a review, EDGERTON 1990).

Flexibility in the context of demand systems analysis means that the model has so many estimated parameters that the direct or indirect utility or expenditure function - which presumably generates the demand - can be estimated. The demand system allows explicit testing of the restrictions implied by the demand theory. Flexibility implies that the demand equations are derived by approximating a generating function (i.e. the expenditure function in case of the AIDS) in such a way that the Slutsky conditions and local flexibility are satisfied. A function is locally flexible if it can provide arbitrary (i.e. inconsistent) values of the elasticities at a particular set of prices and expenditure (EDGERTON 1990). On the other hand, an inflexible function has elasticities that are constant, while prices and expenditure vary.

Regarding to scientific journals, the AIDS (or its linear approximation, the LAIDS) now appears to be the most popular of all demand systems. However, all the introduced functional forms are widely used. Large is also the literature in which various functional forms are compared with each others. MANSER (1976) presented a comparison between various specifications of the Trans$\log$ model. She concluded that elasticity estimates for four food aggregates in the United States were very sensitive to the choice of the functional form. KLEVMARKEN (1979) compared various specifications of the LES, the Rotterdam model, and the Translog model by using Swedish expenditure data. In terms of goodness of fit, prediction error, and negativity of own-price elasticities, $e_{i i}$, the

\footnotetext{
${ }^{8}$ Recently the Rotterdam model has been found to be as flexible as any other locally flexible functional form (Alston and Chalfant 1993).
}

LES with habit formation was named as the preferred specification. GoDDARD (1983) compared the LES and the AIDS using Canadian time-series on food aggregates. The results suggested that, because of the greater sensitivity of the AIDS to the data (the LES is too restrictive a form), its use in research designed to estimate demand elasticities is preferable.

BLANCIFORTI et al. (1986) compared static and dynamic versions of the AIDS, the LAIDS, and the LES by employing expenditure data on four food aggregates in the United States. They concluded that (a) dynamic models were preferred over their static counterparts, (b) the AIDS was superior on a within-sample error criterion, whereas the LES was superior for the particular years outside the sample, and (c) in general, the AIDS and LAIDS gave higher price elasticities, $e_{i j}$, and lower expenditure elasticities, $E_{i}$, than the LES. HANSEN and SIENKNECHT (1989) compared different flexible functional forms, for example, a generalisation of the LES, various versions of the Translog model, and the AIDS. They concluded that the compared flexible demand systems gave similar results with respect to goodness-of-fit measures and income elasticities, while there was rather great variation with respect to own-price elasticities. Mergos and Donatos (1989) compared elasticities obtained from the Rotterdam model, the AIDS, and the LES using time-series on food expenditures in Greece. The elasticities obtained using the AIDS were rather similar to those of the Rotterdam model, but quite different from those of the LES. The LES gave smaller expenditure elasticities than the AIDS and the Rotterdam model, whereas the LES gave consistently the lowest and the Rotterdam model the highest price elasticities among the three models. The authors concluded that the elasticities obtained using the AIDS were superior when judged on the basis of a priori expectations.

Alston and Chalfant (1993) developed a test of the LAIDS against the Rotterdam model, and vice versa. In an application to the meat demand in the United States, the LAIDS was rejected, while the Rotterdam model was not. However, the authors stressed that the result should not be 
interpreted as evidence that the Rotterdam model is superior in any general way.

The AIDS has several advantages over the other forms. First, the AIDS is derived from a utility function which assumes weak separability (Section 4.6). Thus, the AIDS is indirectly non-additive, allowing the consumption of one good to affect the marginal utility on another good. Weak separability is a less restrictive assumption than the assumption behind the LES, i.e. strong separability (additivity of preferences). Derived from additive utility functions, the LES assumes that the preference ordering is additive. This means that the marginal utility provided by the consumption of a good is independent of the consumption of other goods. An implication is that the LES shows an approximate proportional relationship between estimated expenditure and own-price elasticities (so-called Pigou's law or relationship). This non-flexibility is not true with the AIDS (Deaton and Muellbauer 1980b, p. 137-142, Craven and Haidacher 1987). There are more non-flexibilities in elasticities of the LES. In the LES, marginal budget shares are restricted to be positive. An implication is that the expenditure elasticity becomes more elastic for a non-inferior necessity $\left(0<E_{i}<1\right)$ as its budget share, $w_{i}$, decreases. This is quite a restrictive assumption. In the AIDS, marginal budget shares are not restricted to be positive and, thus, expenditure elasticity can become less elastic as its budget share decreases. In the LES, as the $i$ th budget share decreases, the own-price elasticity becomes more inelastic (assuming the marginal budget share to be between 0 and 1). Actually, this is the phenomenon that one would expect, but still it is a restrictive assumption. The AIDS does not prejudge the sign to the change in $e_{i i}$ with respect to a change in $w_{i}$ (BLANCIFORTI and GREen 1983b, BLANCIFORTI et al. 1986).

Second, the AIDS expenditure function has the property of a flexible functional form: it contains sufficient parameters to be regarded as a close approximation to any expenditure function and hence any underlying preference ordering. Consequently, the AIDS demand functions contain sufficient parameters to be regarded as a first- order approximation to any observed demand system - i.e. the unknown relation between $w_{i i}, \ln x_{t}$, and $\ln p_{t}$ - derived from utility maximisation. This generality holds whether the system is consistent with the demand theory or not. Despite the flexibility, the AIDS is easier to estimate than e.g. the Translog models. Moreover, the Translog models require more sample information since the number of parameters to be estimated is larger (Thomas 1985, p. 153, TeKLU et al. 1992, p. 53-54).

Third, systems whose derivation starts from preferences represented by a price-independent, generalised logarithmic (PIGLOG) (or price-independent, generalised linear, PIGL) expenditure function will in general have better aggregation properties than other systems (EDGERTON 1990, p. 32). Contrary to, for example, the LES, the Rotterdam model, and the Translog model, the AIDS is based on PIGLOG. The AIDS is as flexible as other locally flexible functional forms (such as the Translog), but has the additional advantage of being compatible with aggregation over consumers (Alston and Chalfant 1993). Although the AIDS is principally valid only at the micro level, it can be generalised to the aggregate level by redefining $w$ as the aggregate budget share, and $x$ as the mean expenditure. The aggregate expenditure should be divided by an appropriate measure of the population size, which should take into account demographic changes. In time-series data the rate of demographic change is, however, probably so slow that a reasonable approximation can be obtained by dividing the aggregate expenditure by the mean population (EDGERTON 1992b).

Fourth, both the LES and the AIDS are derived from the microeconomic theory. When the AIDS suits well for testing the Slutsky conditions of homogeneity and symmetry, in the LES the restrictions are imposed a priori, and thus it is impossible to test them.

The AIDS suffers from the same disadvantages as most of the methods employed to analyse demand. First, the AIDS suffers from lack of degrees of freedom, and if this is overcome by imposing restrictions, there may exist a contradic- 
tion between these restrictions and the data (DEATON and MUELlbaUer 1980b, p. 79). Second, there is a separability problem that arises from the fact that econometric analysis deals, not with individual commodities, but with bundles. Third, there is an aggregation problem that arises from the fact that the demand theory describes the behaviour of one consumer, while the data set which is used in the present analysis refers to markets in which all the consumers operate. Aggregation theory is intended to provide the necessary conditions under which it is possible to treat aggregate consumer behaviour as if it were the outcome of the decisions of a single maximising consumer. Deaton and Muellbauer (1980b, p. 79) mention two other disadvantages, i.e. the existence of dynamic misspecification and important explanatory variables other than prices and total expenditure. These problems are alleviated in the present study by introducing dynamics and allowing structural change in parameters.

\subsection{Derivation of the Almost Ideal Demand System}

Engel curves show the relationships between various income (expenditure) levels and purchased volumes, per unit of time, given constant prices and constant consumer preferences or indifference map. A number of functional forms for Engel curves has been experimented (DEATON and Muellbauer 1980b, p. 19-20). A form which is consistent with adding up originates from WorkING (1943) and LESER (1963). The AIDS is an extension of their Engel curve formulation - extended by DeAton and Muellbauer $(1980 \mathrm{a}, \mathrm{b})$ - where value shares at time $t, w_{i t}$, are related to the logarithm of the total expenditure, $x_{t}$

$w_{i t}=\alpha_{i}+\beta_{i} \ln x_{t}$

However, the parameters have to be made functions of prices to extend the model to include price effects. The ground for that is laid using duality (Section 3.3). Instead of choosing quantities to maximise utility subject to budget constraint, the quantities are chosen to minimise expenditure needed to obtain a given utility. The AIDS Marshallian demand function is derived by minimising the expenditure function (rather than maximising the utility function). Thus, the expenditure function has to be specified first. The AIDS is derived from the consumer expenditure function, $\ln c\left(u_{t} \boldsymbol{p}\right)$, for the price-independent, generalised logarithmic (PIGLOG) class of consumer preferences

$$
\ln x_{t}=\ln c\left(u_{t}, \boldsymbol{p}_{t}\right)=a\left(\boldsymbol{p}_{t}\right)+u_{t} b\left(\boldsymbol{p}_{t}\right)
$$

that is linear in utility and nonlinear in prices, and where $x_{t}$ is the minimum level of expenditure that is necessary to achieve a given utility level $u_{t}\left(0 \leq u_{t} \leq 1\right)$ (or, minimum cost of reaching indifference curve $u_{f}$ ) at given vector of prices $\boldsymbol{p}_{t}\left(=p_{t t}, \ldots, p_{n t}\right)$, and $a\left(\boldsymbol{p}_{t}\right)$ and $b\left(\boldsymbol{p}_{t}\right)$ are functions of prices alone that are to be chosen. Two selection criteria have been used. For $\ln a(\boldsymbol{p})$, a sufficient number of parameters was desired in order to obtain a locally flexible functional form; for $\ln$ $b\left(\boldsymbol{p}_{t}\right)$, a convenient choice led to the Engel curves (13) (ChalFant 1987). The price aggregator function $a\left(\boldsymbol{p}_{t}\right)$ shows the fixed cost, or the cost of subsistence consumption $\left(u_{t}=0\right)$, of the following form

$$
\begin{aligned}
a\left(\boldsymbol{p}_{t}\right) & =\alpha_{0}+\sum_{k=1}^{n} \alpha_{k} \ln p_{k t} \\
& +1 / 2 \sum_{k=1}^{n} \sum_{j=1}^{n} \gamma_{k j}^{*} \ln p_{k t} \ln p_{j t}
\end{aligned}
$$

and $b\left(\boldsymbol{p}_{t}\right)$ shows the cost of joy consumption $\left(u_{t}=1\right)$ such as

$$
b\left(p_{t}\right)=\beta_{0} \prod_{k=1}^{n} p_{k t}^{\beta k}
$$

where $p_{k}$ and $p_{j}$ are prices. The equations (14) to (16) generate the AIDS expenditure function of 
the following form (Deaton and Muellbauer 1980a)

$$
\begin{aligned}
& \ln x_{t}=\ln c\left(u_{t}, p_{t}\right)=\alpha_{0}+\sum_{k=1}^{n} \alpha_{k} \ln p_{k t} \\
& +\frac{1}{2} \sum_{k=1}^{n} \sum_{j=1}^{n} \gamma_{k j}^{*} \ln p_{k t} \ln p_{j t}+u_{t} \beta_{0} \prod_{k=1}^{n} p_{k t}^{\beta k}
\end{aligned}
$$

where $\alpha_{0}, \alpha_{k}, \beta_{0}, \beta_{k}$, and $\gamma_{k j}$ are parameters. For $c\left(u_{t}, \boldsymbol{p}_{t}\right)$ to be homogeneous of degree one in prices $\boldsymbol{p}_{t}$, the parameters should satisfy

$$
\sum_{k=1}^{n} \alpha_{k}=1 ; \sum_{k=1}^{n} \gamma_{k j}^{*}=\sum_{j=1}^{n} \gamma_{k j}^{*}=\sum_{k=1}^{n} \beta_{k}=0
$$

By using the duality, (17) will be minimised to yield the AIDS Marshallian demand functions. Referring to Figure 7, a three-step procedure to derive the AIDS is as follows.

Step 1: From expenditure function to the Hicksian demand functions

Shephard's Lemma is applied to achieve the Hicksian or compensated demand functions. The Lemma means that (17) is differentiated with respect to prices. Simultaneously, the equation is switched to budget shares $w_{i t}$. The result is a Hicksian demand function for commodity $i$,

$$
\begin{aligned}
\frac{\partial \ln c\left(u_{t}, p_{t}\right)}{\partial \ln p_{i t}} & =\frac{\partial \ln x_{t}}{\partial \ln p_{i t}}=\frac{p_{i t} q_{i t}}{x_{t}}=w_{i t} \\
& =\alpha_{i}+\sum_{k=1}^{n} \gamma_{i k} \ln p_{k t}+\beta_{i} u_{t} \beta_{0} \prod_{k=1}^{n} p_{k t}^{\beta k}
\end{aligned}
$$

where $q$ is quantity, $x$ total expenditure, and $\gamma_{i k}=$ $1 / 2\left(\gamma_{i k}^{*}+\gamma_{k i}^{*}\right)$ (Deaton and Muellbauer 1980a).

Step 2: From expenditure function to the indirect utility function

Since $u$ is unobservable, the expenditure function (17) and the resulting share equations (19) cannot be estimated. That is why (14) is inverted to gather an expression for utility, or the corresponding indirect utility function

$$
\begin{gathered}
u_{t}=\psi\left(x_{t}, \boldsymbol{p}_{t}\right)=\frac{\ln x_{t}-a\left(\boldsymbol{p}_{t}\right)}{b\left(\boldsymbol{p}_{t}\right)}= \\
\frac{\ln x_{t}-\alpha_{0}-\sum_{k=1}^{n} \alpha_{k} \ln p_{k t}-1 / 2 \sum_{k=1}^{n} \sum_{j=1}^{n} \gamma_{k j}^{*} \ln p_{k t} \ln p_{j t}}{\beta_{0} \prod_{k=1}^{n} p_{k t}^{\beta k}}
\end{gathered}
$$

which is the real value of expenditure in excess of that required for subsistence (DEATON and MUELLBAUER 1980b, p. 144).

Step 3: From indirect utility function to the Marshallian demand functions

Finally, (20) is substituted into each share equation (19), which gives a Marshallian demand function, or the AIDS, for commodity $i=1, \ldots, n$,

$w_{i t}=\alpha_{i}+\sum_{j=1}^{n} \gamma_{i j} \ln p_{j t}+\beta_{i} \ln \left(\frac{x_{t}}{P_{t}}\right)$

where $p_{j t}$ is the price of the $j$ th commodity within the group, $x$ is the representative total expenditure of the group, which is approximated by the per capita total expenditure of the group (Section 4.5). The term $\left(x / P_{t}\right)$ is the nominal expenditure deflated by the group price index $P$, defined by

$$
\begin{aligned}
\ln P_{t} & =\alpha_{0}+\sum_{k=1}^{n} \alpha_{k} \ln p_{k t} \\
& +1 / 2 \sum_{k=1}^{n} \sum_{j=1}^{n} \gamma_{k j} \ln p_{k t} \ln p_{j t}
\end{aligned}
$$

It is noteworthy that (21) is nonlinear in the parameters because of the definition of (22); it is only the term $\beta \ln P$, in (21) that causes non-linearity in the parameters. A linear form of the AIDS, the LAIDS, is obtained by replacing the price index (22) by STONE's (1954a) geometric shareweighted price index, such as

$$
\ln P_{t}^{*}=\alpha_{0}+\sum_{k=1}^{n} w_{k t} \ln p_{k t}
$$


The LAIDS has shown to be a good approximation to the AIDS (e.g. BLANCIFORTI and GREEN 1983b), and it has been used more often than the AIDS.

The interpretation of the parameters in (21) and (22) is as follows. The intercept $\alpha_{i}$ represents the $i$ th budget share when expenditure is at the subsistence level, or all logarithmic prices and logarithmic real expenditure $\ln (x / P)$ equal zero (then $w_{i}=\alpha_{i}$ ). The parameters $\gamma_{i j}\left(=\partial w_{i} / \partial \ln p_{j}\right)$ measure the change in the $i$ th budget share following a unit proportional (one percent) change in $p_{i t}$ with $(x / P)$ held constant. The parameter $B_{i}\left[=\partial w_{i}\right.$ $\partial \ln (x / P)]$ measures the change in the $i$ th budget share with respect to a one percent change in the real expenditure with prices held constant. With $\beta_{i}>0, w_{i}$ increases with $x$ so that $\operatorname{good} i$ is a luxury; with $\beta_{i}<0$, the good is a necessity. The intercept $\alpha_{0}$ can be interpreted as the expenditure required for a minimum standard of living when prices equal one, as in the base year [then $a\left(p_{t}\right)=$ $\alpha_{0}$ in (15)].

\subsection{Slutsky conditions on the AIDS}

To be consistent with the consumer preferences (utility maximisation), a set of Marshallian demand functions, like the AIDS functions (21) and (22), ought to add up, be homogeneous of degree zero in prices and the total expenditure, and their compensated price responses ought to be symmetric and form a negative semidefinite matrix. The properties, called the Slutsky conditions (BARTEN 1967), are presented in terms of the AIDS parameters and elasticities, and budget shares. Negativity can be imposed on the AIDS only locally at a point, whereas adding-up, homogeneity, and symmetry can be globally imposed by means of parametric restrictions.

\section{Adding-up}

The adding-up restriction is an implication of the linear budget constraint and the non-satiation property of consumer preferences. The property means that demand functions satisfy the budget con- straint, or the sum of the purchases equals the total expenditure, or

$x=\sum_{i=1}^{n} p_{i} g_{i}(x, \boldsymbol{p}) ; \sum_{i=1}^{n} w_{i}=1$

where $g_{i}$ is the Marshallian demand function $\left[q_{i}=g_{i}(x, \boldsymbol{p})\right]$. The property has two implications for elasticities. The Engel aggregation states that

$$
\sum_{i=1}^{n} w_{i} E_{i}=1
$$

where $E_{i}(=\partial \ln g / \partial \ln x)$ is the expenditure elasticity. The Cournot aggregation states that, for $j=$ $1, \ldots, n$,

$$
\sum_{i=1}^{n} w_{i} e_{i j}+w_{j}=0
$$

where $e_{i j}\left(=\partial \ln g_{i} / \partial \ln p_{j}\right)$ is uncompensated price elasticity. For the parameters in (21), the restriction requires that (DeAton and Muellbauer 1980b, p. 76)

$$
\sum_{i=1}^{n} \alpha_{i}=1, \sum_{i=1}^{n} \beta_{i}=0 ; \sum_{i=1}^{n} \gamma_{i j}=0 \text { for all } j
$$

\section{Homogeneity}

Homogeneity [of degree zero] is another consequence of the specification of a linear budget constraint to demand functions. The condition reflects the fact that the budget constraint is homogeneous of degree one in expenditure and prices, and the assumption that the utility function is an expression in terms of constant (real) values rather than in current money terms. Homogeneity implies that the Hicksian demand functions are homogeneous of degree zero in prices, and the Marshallian demand functions in the total expenditure and prices. The latter type is applied in the present study, and it means that, if all prices and the total expenditure are multiplied by a positive constant, neither the budget constraint nor the utility function should change. Consequently, the 
quantity demanded remains unchanged. Restated, the condition states that there exists no money illusion. For elasticities, the implication is that the sum of the price and expenditure elasticities is zero, or, for $i=1, \ldots, n$, (EDGERTON 1990)

$$
\sum_{j=1}^{n} e_{i j}+E_{i}=0
$$

In (21) homogeneity is satisfied, if for all $i$ (Deaton and Muellbauer 1980b, p. 76)

$$
\sum_{j=1}^{n} \gamma_{i j}=0
$$

\section{Symmetry}

The Slutsky symmetry condition is a consequence of a rational choice, or four axioms describing the consumer's preferences, namely completeness, transitivity, continuity, and non-satiation (Section 3.2). The condition can be used to test whether consumers make consistent or inconsistent choices. Symmetry implies that the consumer's matrix of substitution terms (or cross-price derivatives of Hicksian demand functions) is symmetric. The condition can be expressed in terms of the Slutsky equation (10 in Section 3.4), for $i, j=1, \ldots, n$

$$
\begin{aligned}
s_{i j} & =s_{j i} \Leftrightarrow \frac{\partial h_{i}}{\partial p_{j}}=\frac{\partial h_{j}}{\partial p_{i}} \Leftrightarrow \frac{q_{i}\left(e_{i j}+w_{j} E_{i}\right)}{p_{j}} \\
& =\frac{q_{j}\left(e_{j i}+w_{i} E_{j}\right)}{p_{i}}
\end{aligned}
$$

where an element in the Slutsky matrix $\left(s_{i j}\right)$ is expressed in terms of quantities, budget shares, and elasticities (EDGERTON 1990). An implication of the condition is that, for $i, j=1, \ldots, n, i \neq j$

$$
\begin{aligned}
k_{i j} & =k_{j i} \Leftrightarrow w_{i}\left(e_{i j}+w_{j} E_{i}\right)=w_{j}\left(e_{j i}+w_{i} E_{j}\right) \\
& \Leftrightarrow w_{i} \tilde{e}_{i j}=w_{j} \tilde{e}_{j i}
\end{aligned}
$$

where $k_{i j}$ is an element in a substitution matrix $\boldsymbol{K}$ $\left(k_{i j}=p p_{j} s_{i j} / x\right)$, and $\tilde{e}_{i j}$ is the compensated price elasticity (EDGERTON 1990). For (21) the Slutsky symmetry condition implies that, for $i, j=1, \ldots, n$ (Deaton and Muellbauer 1980b, p. 76)

$\gamma_{i j}=\gamma_{j i} \Leftrightarrow \frac{\partial w_{i}}{\partial \ln p_{j}}=\frac{\partial w_{j}}{\partial \ln p_{i}}$

\section{Negativity of compensated own-price elasticities}

Negativity or concavity is another consequence of the existence of consistent preferences and the Slutsky equation. Negativity implies $e . g$. that the compensated price responses of demand functions form a negative semi-definite Slutsky matrix $S$. The diagonal elements of the Slutsky matrix must be non-positive for all commodities. Thus, an increase in $p_{i}$ with utility held constant cannot increase the compensated demand for $i$, or, for all $i$,

$s_{i i} \leq 0$

which is the "law of demand" that compensated demand functions can never slope upwards (DEATON and Muellbauer 1980b, p. 44). This means that an increase in the price with utility held constant must cause the demand for that good to fall or remain unchanged. Within the AIDS, it is easier to use, not matrix $S$, but matrix $\boldsymbol{K}$, the elements of which are, for all $i$ and $j$

$k_{i j}=\gamma_{i j}+\beta_{i} \beta_{j} \ln \left(\frac{x}{P}\right)-w_{i} \delta_{i j}+w_{i} w_{j}$

where $\delta_{i j}$ is the Kronecker's delta $\left(\delta_{i j}=1\right.$ when $i$ $=j$ and $\delta_{i j}=0$ when $i \neq j$ ) (DEATON and MuellBAUER 1980a). Since the diagonal elements of matrix $\boldsymbol{K}$ have the same signs as those of matrix $S\left(k_{i i}=p p_{i} s_{i i} x\right)$, negativity is obtained when the matrices $\boldsymbol{K}$ are negative semidefinite. Accompanied with the implication for elasticities, the property is written as

$e_{i i}+w_{i} E_{i} \leq 0 \Leftrightarrow \tilde{e}_{i i} \leq 0$ and $w_{i} \tilde{e}_{i i} \leq 0 \Leftrightarrow k_{i i} \leq 0$ 
where $e_{i i}$ is uncompensated own-price elasticity, and $\tilde{e}_{i i}$ is compensated own-price elasticity (EDGERTON 1990).

\section{Non-negativity of quantities}

Non-negativity of quantities or monotonicity simply means that Marshallian demand functions must imply non-negative quantities consumed. Consequently, for the restriction, budget shares must all be between 0 and 1 . The restriction is trivial if the data set is properly defined.

Estimation of the AIDS automatically satisfies adding-up (provided the data do). In restricted estimation homogeneity and symmetry are enforced by imposing (29) and (32) on (21) and (22). In unrestricted estimation, (29) and (32) are not imposed. The conditions can be used to test the consistency of the demand system with the theory. The negativity condition can be checked after the model is estimated. ${ }^{9}$ Providing the condition is satisfied, $\tilde{e}_{i i} \mathrm{~s}$ are non-positive.

Imposition of the restrictions is reasonable because it decreases the number of parameters to be estimated. In absence of restrictions, given the demand functions (5), there will be $n^{2}+n$ parameters to be estimated ( $n^{2}$ price and $n$ expenditure parameters), where $n$ is the number of equations in the system and also the number of commodities. Imposing adding-up, which implies one restriction, the number of estimated parameters is reduced to $n^{2}+n-1$. Imposing also symmetry, which implies $1 / 2\left(n^{2}-n\right)$ restrictions, the number of independent parameters is reduced to $1 / 2 n^{2}+n$ $+1 / 2 n-1$. Adding-up and symmetry together imply homogeneity, which implies $n$ restrictions and, thus, the number of estimated parameters is reduced to $1 / 2\left(n^{2}+n\right)-1$. Negativity has to be ignored because it is difficult to impose. Given intercepts are incorporated, the number of independent parameters increases to $1 / 2\left(n^{2}+n\right)-1+(n-1)$.

\footnotetext{
${ }^{9}$ The negativity can only be checked for a particular range of prices and expenditure. It is obvious that the AIDS can merely be locally regular (EDGERTON 1990, p. 13, 20). To be globally regular, the AIDS should satisfy the Slutsky conditions for all prices and expenditures.
}

In the present study, there are 18 food bundles to be estimated. The system estimation is required, since the imposition of adding-up and symmetry requires simultaneous estimation of all demand equations in the system. Thus, at least 170 parameters should be estimated simultaneously (given only price and expenditure parameters are estimated). If the homogeneity and symmetry restrictions were not imposed, the number of independent parameters would increase. The increase in the number of parameters caused by the nonimposition of homogeneity and symmetry is somewhat compensated by the fact that the adding-up restriction will replace $n$ of the symmetry restrictions. However, related to the available data and computing power, the number of parameters to be estimated is too high. Thus, further restrictions on demand equations has to be imposed. This is done by making assumptions about the consumer's preferences. Separability of preferences is of great importance in demand systems analysis (Section 4.6).

\subsection{Extensions of the AIDS}

In order to achieve a better fit of the data, several variations of the standard static AIDS have been suggested. In the empirical application of the present study, a dynamic AIDS and a dynamic AIDS incorporating systematic demand shifters are employed.

\subsubsection{Dynamic AIDS}

The consumer choice problem in a neoclassical model depends on decisions for a single period of time. However, due to factors such as consumer adjustments to changes in prices and income the choice problem may not be complete during the single period of time, thus making past consumption patterns an important determinant of present consumption patterns (POLLAK 1970, GoDDARD 1983, JOHNSON et al. 1986, BLANCIFORTI et al. 1986, CAPPS and HavliceK 1987). Hence, the static theoretical framework is extended to a dynamic theoretical framework. There are alterna- 
tive approaches to consumer dynamics in the context of the AIDS. One alternative, referred to as translating, is to allow some of the parameters of the demand equations to depend upon previous consumption levels (PoLLAK and WaLes 1981, BLANCIFORTI and GREEN 1983a, BLANCIFORTI et al. 1986, Chen and VeEman 1991). In translating, the dynamic feature in the adjustment of demand is incorporated by introducing $m$-period lagged consumption levels, $q_{i(t-m)}$, to the PIGLOG consumer expenditure function. Another alternative, adopted in the presented study, is to specify a dynamic expenditure function through the introduction of $m$-period lagged budget shares, $w_{i(t-m)}$, to the PIGLOG consumer expenditure function. Consequently, the demand equations will include lagged dependent variables.

From the econometric point of view, the dynamics is introduced because static models often suffer from serious serial correlation in the estimated residuals, thus indicating that the underlying models are misspecified. The Slutsky conditions may be rejected in empirical studies, because too little attention is paid to the dynamic aspects of consumer behaviour. The existence of cost adjustment and the costs involved in obtaining the information necessary for an immediate equilibrium decision imply that dynamic specifications should be considered when modelling demand functions (DEATON and MUELlbauer 1980a, ANDERSON and BLUNDELL 1982).

It is unlikely that consumers adjust to equilibrium within a time period (ANDERSON and BLUNDELL 1983). Habit persistence, adjustment costs, incorrect expectations, and misinterpreted real price changes are examples of the many possible reasons for such short-term behaviour. Due to habit formation and adjustment costs, a consumer faces a utility loss because it takes a certain time before he fully adjusts his consumption in response to changes in prices and income. Restated, consumers are supposed to carry stocks of habits which cause adjustments costs when consumers change habits. For example, if a consumer is used to eating meat, it takes time before he will take full advantage of a sharply decreased price of fish. The consumer is allowed to adjust his budget gradually to the change in relative prices.

A dynamic AIDS with a vector of lagged budget shares was proposed by ALESSIE and KAPTEYN $(1991)^{10}$ and ASSARSSON (1991) (see also EDGERTON 1992a, RICKERTSEN 1992). The model was modified from the interrelated partial-adjustment model suggested by ANDERSON and BLUNDELL (1982, 1983, 1984). Habits are introduced as adjustment costs in the AIDS expenditure function (17) such as (RICKERTSEN 1992):

$$
\begin{aligned}
\ln x_{t} & =\ln c\left(u_{t}, \boldsymbol{p}_{t}, w_{t-m}\right)=\alpha_{0}+\sum_{k=1}^{n} \alpha_{k} \ln p_{k t} \\
& +\sum_{k=1}^{n} \sum_{m=1}^{M} \sum_{j=1}^{n} \theta_{k j m} w_{j(t-m)} \ln p_{k t} \\
& +1 / 2 \sum_{k=1}^{n} \sum_{j=1}^{n} \gamma_{k j}^{*} \ln p_{k t} \ln p_{j t} \\
& +u_{t} \beta_{0} \prod_{k=1}^{n} p_{k t}^{\beta k}
\end{aligned}
$$

where $m$ is the length of a lag. In order to save degrees of freedom, only a one-period lag is used $(M=1)$. The term $\sum_{k=1}^{n} \sum_{m=1}^{M} \sum_{j=1}^{n} \theta_{k j m} w_{j(t-m)} \ln p_{k t}$ describes an adjustment cost resulting from habit persistence. Derived from (36), the Marshallian demand functions, or the dynamic AIDS with a one period lag is defined by

$$
\begin{aligned}
w_{i t} & =\alpha_{i}+\sum_{j=1}^{n} \theta_{i j} w_{j(t-1)} \\
& +\sum_{j=1}^{n} \gamma_{i j} \ln p_{j t}+\beta_{i} \ln \left(\frac{x_{t}}{P_{t}}\right)
\end{aligned}
$$

${ }^{10}$ According to AlessiE and KAPTEYN (1991), the micro-model should include at least three taste shifters, viz. demographic effects, habit formation, and preference interdependence. They built these effects into the AIDS. 
where $\boldsymbol{w}_{i t}$ is the $i$ th budget share, $\boldsymbol{w}_{j(t-1)}$ is the $j$ th budget share in the previous period, and $\theta_{i j}$ parameters measure a phenomenon which may be interpreted as habit persistence. Since the consumer's adjustment is assumed to be consistent with a stable long-run equilibrium, it is expected that $0<\theta_{i i}<1$. The term $P_{t}$ is a price index defined by

$$
\begin{aligned}
\ln P_{t} & =\alpha_{0}+\sum_{k=1}^{n} \alpha_{k} \ln p_{k t} \\
& +\sum_{k=1}^{n} \sum_{j=1}^{n} \theta_{k j} w_{j(t-1)} \ln p_{k t} \\
& +1 / 2 \sum_{k=1}^{n} \sum_{j=1}^{n} \gamma_{k j} \ln p_{k t} \ln p_{j t}
\end{aligned}
$$

In addition to the restrictions (27), (29), (32), and (35), to avoid a violation of budget constraint an extra adding-up restriction requires, for $j=1, \ldots, n$,

$$
\sum_{i=1}^{n} \theta_{i j}=0
$$

and to enable identification of (37) and (38), the condition

$$
\sum_{j=1}^{n} \theta_{i j}=0
$$

is imposed. In restricted estimation, homogeneity and symmetry are enforced by imposing (29) and (32) on (37) and (38). In unrestricted estimation, (29) and (32) are not imposed.

\subsubsection{Switching static and dynamic AIDS}

There are many hypotheses on what might cause changes in tastes concerning food choice. Health and nutrition concerns probably explain part of the change from butter to margarine and from high-fat to reduced-fat fluid dairy products, and the increasing consumption of fruits and vegetables. Changes in life-style (for example, increased opportunity cost of leisure) have increased the demand for convenience food and food-awayfrom-home. In addition, changes in the demographic composition of the population, development of household equipment (e.g. deep-freeze, micro-wave oven), advertising and product promotion are probably sources of changes in demand. The adopted model features a habit-forming mechanism as well as allows structural change in parameters.

Parametric analyses of structural change in demand systems can be carried out by (a) splitting the data set into sub-groups and testing for structural stability of the parameters, (b) allowing for systematic and stochastic variation in the parameter values over time, using techniques such as the Kalman filter, or (c) explicitly allowing for systematic structural change in parameters by incorporating time trends (BURTON and YouNG 1992). The method (c) is adopted in the present study. A switching regression technique is used to allow for a period of structural stability followed by an interval of change, followed by further stability. The change from one regime to the other is assumed to be gradual, rather than abrupt.

A gradually-switching dynamic form of the AIDS was modified by EDGERTON (1992a, b) from the model suggested by MoschinI and MeILKE (1989). The model is like the dynamic AIDS, but it incorporates a group-wise demand shifter $h_{t}$ :

$$
\begin{aligned}
w_{i t} & =\alpha_{i}+\sum_{j=1}^{n} \theta_{i j} w_{j(t-1)} \\
& +\sum_{j=1}^{n} \gamma_{i j} \ln p_{j t}+\left(\beta_{i}+\beta_{i}^{*} h_{t}\right) \ln \left(\frac{x_{t}}{P_{t}}\right)
\end{aligned}
$$

where

$$
\begin{aligned}
& h_{t}=0, \quad \text { for } t=1, \ldots, \tau_{1} \\
& h_{t}=\frac{t-\tau_{1}}{\tau_{2}-\tau_{1}}, \text { for } t=\tau_{1}+1, \ldots, \tau_{2} \\
& h_{t}=1, \quad \text { for } t=\tau_{2}+1, \ldots, T
\end{aligned}
$$


and $B_{i}^{*}$ is a shifting expenditure parameter, and $\ln P_{t}$ is as given in (38). The definition (42) implies that (41) becomes a gradually-switching regression model, where $\tau_{1}$ and $\tau_{2}$ are points in time associated with the beginning and ending of the transition period between regimes. Joint point $\tau_{1}$ represents the end point of the first regime, whereas joint point $\tau_{2}$ is the starting point of the second regime, where the transition path between the two regimes is linear. To save degrees of freedom, no other parameters than the expenditure parameter $B_{i}$ are allowed to vary. The dynamic model becomes a static one by imposing $\theta_{i j} \mathrm{~s}$ to be zero in (41). An alternative to $B_{i}{ }^{*}$ would have been to use shifting intercept $\alpha_{i}$ as the demand shifter (as done, for example, by BURTON and YounG 1992). Although $\alpha_{i}$ is interpreted as the $i$ th budget share when expenditure is at the subsistence level, in empirical work its interpretation is hindered by the fact that values vary considerably from one model specification to the other and, for example, negative values are frequent. That is why an interpretation in which a structural change of demand influences the demand function through an expenditure effect was preferred.

In addition to the restrictions (27), (29), (32), (35), (39), and (40), adding-up implies that (EDGERTON 1992a)

$$
\sum_{i=1}^{n} \beta_{i}^{*}=0
$$

In restricted estimation, homogeneity and symmetry are enforced by imposing (29) and (32) on (41) and (38), whereas in unrestricted estimation, (29) and (32) are not imposed.

\subsection{Aggregation over consumers}

Aggregation problem arises when making an empirical estimation of demand systems using aggregate time-series data. There are two separate aggregation problems. The first problem refers to the transition from the demand theory to the analysis of market demand. In this case the aggregation is made over consumers, and this will be discussed in this section. The following section deals with the second aggregation problem that refers to the structuring of food items into bundles and sub-bundles and the desirable level of commodity disaggregation. In this case the aggregation is made over goods. The discussion follows Deaton and Muellbauer (1980b, Ch. 5 and 6) and Edgerton (1990, Ch. 3).

The problem of aggregation over consumers arises from the fact that the microeconomics of consumer behaviour describes the behaviour of one consumer (household), while the data set used in the analysis describes the markets in which all the consumers (households) operate (for a review of discussion, TeKLU et al. 1992). The restrictions on demand functions, or the Slutsky conditions (Section 4.3), refer to the micro (household) level. A successful macro demand function must be able to aggregate over households to the macro level in such a way that the Slutsky conditions still hold at the macro level. DEATON and Muellbauer $(1980 \mathrm{a}, \mathrm{b})$ pioneered in deriving the macro demand functions from the consumer theory. The most critical condition is the generalised linearity of the aggregate expenditure function, which has given the PIGLOG type of expenditure function that was the starting point in deriving the AIDS (Section 4.2).

The concept of exact aggregation provided by the aggregation theory defines the necessary conditions under which aggregate consumer behaviour can be treated as if it were an outcome of decisions of a single consumer. Given these assumptions hold, the aggregate per capita values used in the present study relate to a representative consumer, or, the average behaviour of the population. Exact aggregation can be divided into exact linear aggregation and exact nonlinear aggregation.

\section{Quasi-homothetic preferences}

Quasi-homotheticity of preferences is a necessary and sufficient condition for the linearity of Engel curves. Preferences are homothetic if utility can be produced under constant returns to scale. This implies that, for some normalisation of the 
utility function, doubling quantities doubles utility. Consequently, budget shares are independent of utility or of the total expenditure. Homothetic preferences imply that Engel curves are straight lines through the origin and, consequently, all expenditure elasticities are unity, and the expenditure patterns are independent of the total expenditure or of utility. Homotheticity is too restrictive an assumption.

Quasi-homothetic behaviour (preferences) is assumed in the present study. Quasi-homothetic preferences imply that Engel curves of each individual are parallel straight lines, but not necessarily through the origin (i.e. the curves have the same slope but intercepts are allowed to vary). Consequently, expenditure elasticities only tend to unity as the total expenditure increases. Quasihomothetic preferences allow (a) subsistence expenditure and (b) expenditure in excess of that required for subsistence (i.e. the expenditure of joy consumption). The aggregate expenditure patterns are a weighted average of the budget shares appropriate to very rich and very poor consumers.

\section{Exact linear aggregation}

The micro level Marshallian demand function for a household $h$ is

$$
q_{h i}=g_{h i}\left(x_{h}, \boldsymbol{p}\right)
$$

where $q_{h i}$ is the household's demand for $\operatorname{good} i, \boldsymbol{p}$ is a price vector, and $x_{h}$ is the household's total expenditure. Exact aggregation is possible if average market response is a function of the average total expenditure and prices, or, for all $i$,

$$
\bar{q}_{i}=g_{i}(\bar{x}, \boldsymbol{p})
$$

where $\bar{q}_{i}\left(=\Sigma q_{i h} / H\right.$, for $\left.h=1, \ldots, H\right)$ is the average demand and $\bar{x}\left(=\Sigma x_{h} / H\right.$, for $\left.h=1, \ldots, H\right)$ is the average total expenditure $(H$ is the number of households in the population). Average demand functions will automatically satisfy the Slutsky conditions if households maximise utility and households' preferences satisfy the aggregation condition. The aggregation problem would be solved if one could find a function $g_{i}(\bar{x}, \boldsymbol{p})$ in (45) that is consistent with the utility function, which requires that the Slutsky conditions are satisfied (Deaton and Muellbauer 1980b, p. 150). If expenditure distribution varies over time, average expenditure can be used as a variable in (45) only if Engel curves are linear, and all households have income high enough to create non-negative demand of $i$. The aggregation condition of quasi-homothetic preferences may be unrealistic, especially if one wants to cover disaggregated commodity groups which are not necessarily consumed by all households. Under these circumstances, part of the measured macro level expenditure response is due to an entry of new consumers into the market, not just because "old" consumers increase their purchases. To allow for this, probably nonlinear, market response, a less restrictive assumption would be reasonable.

\section{Exact nonlinear aggregation}

Exact nonlinear aggregation requires that the market response should hold for some representative level of expenditure, which is not necessarily the same as the average level of expenditure. The exact aggregation is defined so that one aggregates over the different expenditure patterns of different consumers. Exact aggregation is possible if the aggregate budget share, $w_{i}$, is a function of prices and representative expenditure, $x_{0}$, or, for all $i$,

$$
w_{i}=f_{i}\left(x_{0}, \boldsymbol{p}\right)
$$

Note that $x_{0}$ can be a function of, for example, the distribution of expenditures and prices. A special case would be to allow $x_{0}$ to be the average expenditure. This would lead to the conditions for the exact linear aggregation (45). The condition for (46) to exist is that, for household $h$, the expenditure function takes the form

$$
c_{h}\left(u_{h}, \boldsymbol{p}\right)=\theta_{h}\left[u_{h}, a(\boldsymbol{p}), b(\boldsymbol{p})\right]+\phi_{h}(\boldsymbol{p})
$$


where $u_{h}$ is the utility level of household $h, a(\boldsymbol{p})$, $b(\boldsymbol{p})$, and $\phi_{h}(\boldsymbol{p})$ are linearly homogeneous functions of $\boldsymbol{p}, \theta_{h}$ is linearly homogeneous in $a(\boldsymbol{p})$ and $b(\boldsymbol{p})$, and, over all consumers, $\Sigma \phi_{h}(\boldsymbol{p})=0$ (DEATON and Muellbauer 1980b, p. 154-155). The aggregate expenditure function is given by, for the same functions $a(\boldsymbol{p})$ and $b(\boldsymbol{p})$,

$$
c\left(u_{0}, \boldsymbol{p}\right)=\theta\left[u_{0}, a(\boldsymbol{p}), b(\boldsymbol{p})\right]
$$

where $u_{0}$ is the representative utility level given the prices and the representative level of the total expenditure, or $u_{0}=\psi\left(x_{0}, \boldsymbol{p}\right)$. If the representative expenditure level is independent of prices and depends only on the distribution of expenditures, then the household expenditure functions are

$$
c_{h}\left(u_{h}, \boldsymbol{p}\right)=k_{h}\left[a(\boldsymbol{p})^{\alpha}\left(1-u_{h}\right)+b(\boldsymbol{p})^{\alpha} u_{h}\right]^{1 / \alpha}
$$

where $k_{h}$ stands for household tastes or preferences which, however, is a scalar at this stage indicating identical preferences over time. The scalar $k_{h}$ depends on household characteristics, for example, demographic factors, and it is defined in such a way that representative preferences, $k_{0}$, equal one. The representative, or the aggregate, expenditure function is given by, for the functions of the price vector $\boldsymbol{p}, a(\boldsymbol{p})$ and $b(\boldsymbol{p})$,

$$
c\left(u_{0}, \boldsymbol{p}\right)=\left[a(\boldsymbol{p})^{\alpha}\left(1-u_{0}\right)+b(\boldsymbol{p})^{\alpha} u_{0}\right]^{1 / \alpha}
$$

The functions (49) and (50) are known as the price independent generalised linear (PIGL) form. When the parameter $\alpha$ equals one, one has a special case of linear aggregation (the expenditure function is linear) and linear Engel curves and, consequently, the representative and average expenditures are the same. When $\alpha$ approaches zero, (50) can be written in a logarithmic form, known as PIGLOG,

$$
\log c\left(u_{0}, \boldsymbol{p}\right)=\left(1-u_{0}\right) \log a(\boldsymbol{p})+u_{0} \log b(\boldsymbol{p})
$$

where $a(\boldsymbol{p})$ and $b(\boldsymbol{p})$ are linear homogeneous concave functions. The form (51) is an approximation to the logarithm of the expenditure function that is linear in utility and nonlinear in prices. The PIGLOG expenditure function is a converter between micro and macro models. Given the PIGLOG expenditure function is appropriate, the parameters of both models are identical. For particular forms for $a(\boldsymbol{p})$ and $b(\boldsymbol{p})$, the AIDS can be derived from (51) (Section 4.2). Consequently, the aggregate AIDS budget share equations are written as (EDGERTON 1990)

$$
w_{i t}=\alpha_{i}+\sum_{j=1}^{n} \gamma_{i j} \ln p_{j t}+\beta_{i}\left(\ln X_{t}-\ln Z_{t}-\ln P_{t}\right)
$$

where $X\left(=\Sigma x_{h}\right.$, for $\left.h=1, \ldots, H\right)$ denotes the aggregate expenditure, the price index $P$, is defined by (22) and $\ln Z$, Theil's entropy measure of dispersion, is defined as

$$
\ln Z=\sum_{h=1}^{H}\left(x_{h} / X\right) \ln k_{h}-\sum_{h=1}^{H}\left(x_{h} / X\right) \ln \left(x_{h} / X\right)
$$

Contrary to linear aggregation, nonlinear aggregation allows nonlinear Engel curves. For the nonlinear aggregation, representative rather than average expenditure must be available. Given the expenditure distribution and, given differences in $k_{h} \mathrm{~s}$, the demographic composition vary over time, the representative expenditure is not proportional to the average expenditure (c.f. DEATON and MUELLBAUER 1980b, p. 157-158). Thus, to estimate the model, one needs to know the variable $Z$ and, thus, the taste variables $k_{h}$, the distribution of the total expenditure, and the correlation between taste and expenditure (EDGERTON 1990). However, because this information is not available, one sets $Z$ $=N$, where $N$ is the number of individuals in the population. "Thus, the representative level of the total expenditure, $x_{0}$, is set equal $x(=X / N)$, or the average per capita expenditure. Consequently, the usual approximation of the set of aggregate AIDS

\footnotetext{
"One could also use $H$ instead of $N$. An alternative approach would be to measure $k_{k}$ by specifying household or adult equivalence scales, a special case of which is that $k_{h}$ is set equal the number of household members (for adult equivalence scales in the context of demand for food, see Price 1986, Gould et al. 1990).
} 
budget share equations (21) is obtained. Almost all empirical applications of the AIDS model deflate the total expenditures by population. Household budget data would probably supply a sufficient basis to estimate $k_{h} \mathrm{~s}$ and the distribution of the total expenditure. However, for example in Finland, household budget survey is carried out only in every five years. Only after annual information is available, $x$ could be replaced by $x_{0}$ in (21).

Since the aggregate budget share is a function of prices and the average - instead of representative - expenditure, one is back in the conditions for linear aggregation. This, however, probably does not jeopardize the analysis. For example, RAY's (1985) results indicate that the idea of linear Engel curves or quasi-homotheticity of preferences may not be unacceptable for time-series data on broad groups of commodities. DEATON and Muellbauer (1980b, p. 151-153) concluded that, if linear aggregation is to work at all, it can only do so for broad aggregate goods which are probably consumed by all households. In the present analysis, one covers relatively aggregated commodity groups. Under these circumstances, a major part of the measured macro level expenditure response is due to the fact that "old" consumers increase (decrease) their purchases, not so much due to the entry of new consumers into the market (the exit of "old" consumers from the market), causing nonlinearity to the market response.

\subsection{Aggregation over goods: separability and multi-stage budgeting}

Aggregation over goods is the second type of aggregation problem. Multi-stage budgeting, or the structuring of bundles and defining the desirable aggregation level, extensively applies the terms (a) aggregation, which implies that fragmented categories are considered a single unit, and (b) separation of decision-making, which states that the allocation problem is handled in more manageable units (DEATON and MUELlBaUER 1980b, p. 119-120). For example, one is ag- gregating when the expenditure on Food-at-Home rather than its components, such as Beverages and Groceries, is made a function of the total expenditure and broad group price indices (for example, Food-at-Home and Services). Separable decision-making implies that research problems are constructed into sub-problems. For example, after determining the budget of Food-atHome, the allocation within Food-at-Home is made separately from allocation between Foodat-Home and Services. The problem of aggregation over goods is faced by using separability concepts. The implications of assuming separability are that (a) one can analyse aggregate groups and thus reduce the number of unknown parameters, and (b) one can specify a multi-stage budgeting process.

\section{Separability of preferences}

Certain restrictions on the preferences or behaviour are needed if one wants to include more than four or five commodities in a demand system. Separability states the conditions for aggregating the commodities into additive utility functions. Additivity means that the direct utility function can be written in an additive form if and only if the cross-price derivatives are proportional to the income derivatives. The restriction means, for example, that a change in the demand for Food-atHome caused by a change in the price of Services is proportional to the change in the demand for Food-at-Home caused by a change in the total expenditure. Under additivity, a change in the price of any other good will affect the demand for the good in consideration.

It is well-known that many flexible functional forms may have bad separability properties (e.g. BaCCOUCHE and LaISNEY 1991). The question is how to approximate the structure of consumers' preferences, and whether the separability can be modelled.

Various separability concepts have been suggested, such as (a) direct separability (separability of the utility function; quantities in the direct utility function are broken up into separable groups); (b) indirect separability (separability of 
the indirect utility function); (c) quasi or implicit separability (separability of the expenditure or distance function; prices in the expenditure function are broken up into separable groups); (d) direct pseudo separability (separability of an implicit representation of the direct utility function); and (e) indirect pseudo separability (separability of an implicit representation of the indirect utility function). PUDNEY (1981), who provided formal definitions of the separability concepts, showed that the various definitions make little difference to the empirical results. In addition, there is the concept of (f) strong separability (additivity of preferences), which implies, for example, that there is an approximate linear relationship between expenditure and price elasticities (Pigou's law).

In the present study, a priori structure of weak separability in consumers' preferences is assumed. The separability is presented in terms of direct separability, but the more general term of weak separability is used. Under the assumption of weak separability of the utility function, independence between sub-sets is not required. When aggregating commodities for the additive utility functions, the aim is to sort the consumption set into subsets which include commodities that are closer substitutes or complements to each other than to members of other sub-sets. A utility function is weakly separable if [and only if] the marginal rate of substitution between any two goods belonging to the same group is independent of the level of consumption of a third good in any other group (PHLIPS 1983, p. 66-69; the theorem originates from LEONTIEF 1947). Under weak separability, the utility function is written as, for commodity groups (sub-systems) $r=1, \ldots, n$ and goods $i=1, \ldots, m$ within each $r$,

$$
\begin{aligned}
u= & F\left[v_{1}\left(q_{11}, \ldots, q_{1 m}\right), v_{2}\left(q_{21}, \ldots, q_{2 m}\right), \ldots,\right. \\
& \left.v_{n}\left(q_{n 1}, \ldots, q_{n m}\right)\right]
\end{aligned}
$$

where $v$ is a sub-utility function and $q$ is consumed quantity (PHLIPS 1983, p. 68, BACCOUCHE and LAISNEY 1991). Separability means that goods can be allocated into groups, and within each group the preferences can be described independently from goods in other groups. Under weak separability, goods can be divided into a number of separate groups where a change of a price in one group affects the demand for all goods in other groups in the same manner. The main effort is required by the within-group allocation problem. The assumption of separability permits specifying a separate maximisation problem in which, for example, expenditure on Food-at-Home performs as a constraint. The advantage gained by imposing the weak separability can be shown by the following notation. If the utility in (54) is maximised subject to a budget constraint, the Marshallian demand functions are obtained, for groups $r=1, \ldots, n$ and goods $i=1, \ldots, m$ within each $r$,

$$
\begin{aligned}
q_{r i}^{*}= & g_{r i}^{*}\left(x, p_{11}, \ldots, p_{1 m}, p_{21}, \ldots, p_{2 m}, \ldots,\right. \\
& \left.p_{n 1}, \ldots, p_{n m}\right)
\end{aligned}
$$

where $p$ is price and $x\left(=\Sigma \Sigma q_{r i} p_{r i}\right.$, for $r=1, \ldots, n$ and $i=1, \ldots, m)$ is the total expenditure. Weak separability allows to limit the number of parameters to be estimated so that the demand function for good $i$ within group $r$ is

$$
q_{r i}=g_{r i}\left(x_{r}, p_{r 1}, \ldots, p_{r m}\right)
$$

where $x_{r}\left(=\Sigma q_{r} p_{r i}\right.$, for $\left.i=1, \ldots, m\right)$ is the group expenditure. Thus, in Marshallian terms, weak separability implies that the quantities demanded are a function of within-group prices and group expenditure, while in Hicksian terms, weak separability implies that the quantities are a function of within-group prices and group utility. In the context of the AIDS, the Marshallian demand function for the $r$ th group is approximated by

$$
q_{r}=g_{r}\left(x, P_{1}, \ldots, P_{n}\right)
$$

where $q_{r}$ is the $r$ th group's real expenditure, $P$ is the true cost of living index (for specification, EdgerTON 1992a, p. 4), $x(=\Sigma x$, for $r=1, \ldots, n)$ is the real total expenditure (where $x_{r}=q_{r} P_{r}$ and $q_{r}=\Sigma q_{r i}$, for $i=1, \ldots, m$, where $q_{r i}$ is the $i$ th good's real expenditure). 
The assumption of weak separability enabled solving the allocation problem within separate groups, which allowed to increase the number of commodities under consideration. Since the purpose of the present study is to analyse disaggregated food categories, a multi-stage budgeting process is adopted.

\section{Multi-stage budgeting}

Weak separability of preferences permits budgeting in stages. The separability is a necessary condition for the consistency of the multi-stage maximisation procedure which appears as a utility tree. In the multi-stage budgeting, consumers allocate the budget into successively disaggregated commodity groups. There is a sub-utility function for each group. The sub-utilities sum up to the utility of the group, and the values of all subutilities sum up to the total utility.

The first step is to allocate the total expenditure into broad aggregate commodity groups like Food-at-Home and Services. The subsequent steps allocate group expenditures into sub-sets. At each stage, only the group expenditure and the set of group prices are needed. It is important that commodities related to each other, either as substitutes or complements, are in the same group. If the separability of preferences is maintained, the results of multi-stage budgeting are identical to the results which are attained if the allocation is made in one stage.

\subsection{Specification of the hierarchic demand system}

There is no objective method for judging the relevance of a certain separability structure. However, afterwards it is possible to evaluate whether the separability assumptions hold. The aggregation problem is solved in terms of the research problem and data availability. First, since interest in the present study is in the demand for various food items, as detailed commodity partitioning as possible is desired. Consistent series starting from 1960 cover at most 18 sub-groups of food.
If one wanted to make a more detailed analysis, the data would be available only from 1970, which allows too short series regarding the employed estimation methods.

Second, public dietary recommendations handle food consumption as aggregate categories that should be in balance with each other. Within those bundles, food items can be chosen more freely. Agricultural policy measures may affect the price and supply conditions of only one item, e.g. Butter, but often the effect covers an aggregate bundle as a whole, e.g. Dairy Products. Since the results of the present study will be used for policy analysis, the functional interdependence between food items was maintained. For dietary reasons, analysing cross-effects within Animalia, Beverages, and Vegetablia, and also cross-effects between those aggregates was of interest. A priori theoretical expectations and conventional wisdom suggested that various types of beverages, Butter and Margarine, Meat Products and Carcase Meat, and Bread and Cake and Flour are closer substitutes to each others than to the commodities in other aggregates.

Third, the requirement for computational power increases rapidly with the size of the system. The criteria suggests the estimation of four simultaneous equations at the most. Also the length of available data series (32 observations) discourages the estimation of large systems (the number of degrees of freedom in the unrestricted switching dynamic AIDS, which is the most general model specification in the present analysis, is 23 in a 3-equation system, 21 in a 4-equation system, and 19 in a 5-equation system).

Given the predetermined conditions mentioned above, the estimated demand system forms a hierarchic process that is presented in Figure 8. The demand system is composed of stages and groups. Stage refers to an allocation round. Subsystem, or group, refers to one set of equations which are estimated simultaneously. At Stages 1 and 2, there is only one allocation process, and thus stage and group can be used interchangeably. All stages together form a system.

A consumer starts by determining the amount to spend on four commodity groups, one of which 


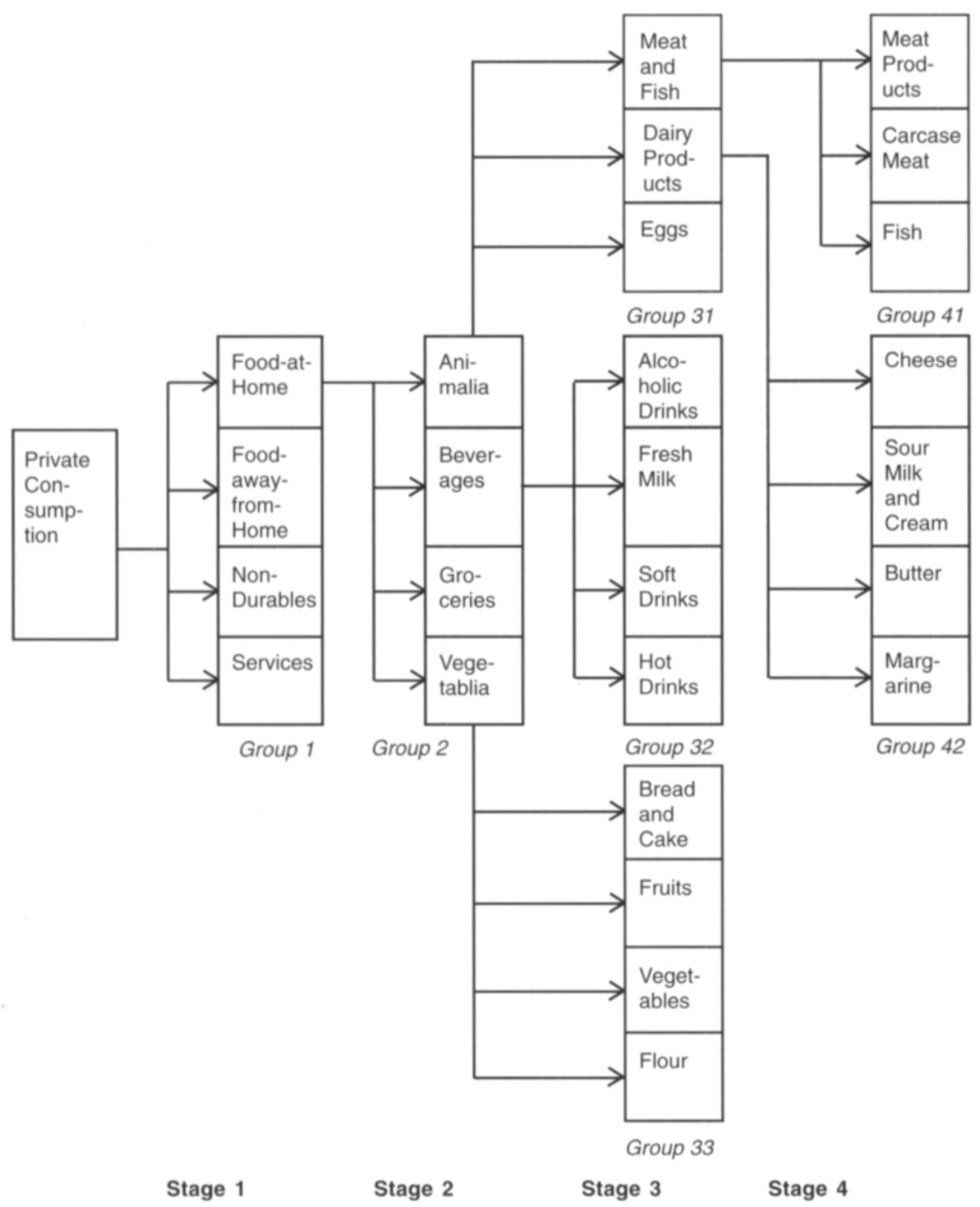

Fig. 8. The four-stage budgeting system employed in the present study.

is Food-at-Home. Food-at-Home is allocated into Animalia, Beverages, Groceries, and Vegetablia. Then, the broad groups are divided into 11 subgroups. Finally, two sub-groups are disaggregated further. The demand for Butter, for example, is assumed to be a result of a four-stage budgeting process, expressed as a function of the prices within Dairy Products and the total expenditure allocated on Dairy Products. The fact that just the within-group variables are used does not mean, however, that goods in different groups are independent of each others. Weak separability allows, for example, a change in the price of Butter to affect the demand for Services. The effect is chan- 
neled through stages so that, first, the change affects the demand for Dairy Products, then Animalia, then Food-at-Home, and finally the crossdependency between Food-at-Home and Services, which belong to the same group, determines the effect. Thus, the response of the price of Butter on the demand for Services depends on the mutual relationship between Food-at-Home and Services. However, the response does not tell anything about the substitution effects between Butter and Services, since a change in any price within Food-at-Home affects the demand for Services in the same way as a change in the price of Butter.

The multi-stage budgeting process has to be taken into account when deriving elasticities. A change in a relative price causes (a) direct effects on the allocation of expenditures within the group and, by affecting the group price index, (b) indirect effects on the allocation of expenditures between the groups at the preceding stages. This indirect effect influences all goods in the system, also the goods within the group where the initial price change took place. There the indirect effect is a "second wave."

\subsection{Elasticities of the AIDS}

Elasticities are used to interpret the estimation results. The derivation of the AIDS elasticities follows EDGERTON (1992a,b). The elasticities are point rather than arc elasticities. The expenditure elasticity, ${ }^{12}$ reflecting the responsiveness of consumption to expenditure changes, is derived for commodity $i$, and for $t=1, \ldots, T$,

$$
E_{i t}=1+\frac{\beta_{i}+\beta_{i}^{*} h_{t}}{w_{i t}}
$$

${ }^{12}$ Although it is common to talk about 'income' elasticity, in the present study, the term 'expenditure' elasticity is used because expenditure, rather than income, is used as an independent variable in models. Sometimes the two concepts are used as synonyms (as INTRILIGATOR 1978, p. 222), sometimes a clear distinction between them is made (as MANSER 1976). When referring to the total expenditure elasticities, to be presented later in this section, it would be almost appropriate to talk about income elasticities. where $w_{i t}$ is the $i$ th bundle's budget share. The expenditure elasticity of demand measures the percentage change in purchases of $i$ due to a percentage increase in the total expenditure [of the group], ceteris paribus. The price elasticities, reflecting the responsiveness of consumption to price changes, are for all $i$ and $j$, and for $t=$ $1, \ldots, T$,

$$
e_{i j t}=
$$

$\frac{\gamma_{i j}+\left(\beta_{i}+\beta_{i}^{*} h_{t}\right)\left[\left(\beta_{j}+\beta_{j}^{*} h_{t}\right) \ln \left(x_{t} / P_{t}\right)-w_{j}-1 / 2 \sum_{k}\left(\gamma_{k j}-\gamma_{j k}\right) \ln p_{k t}\right]}{w_{i t}}$ $-\delta_{i j}$

where $i$ denotes the commodity affected and $j$ the commodity the price of which has changed. $\delta_{i j}$ is the Kronecker delta $\left(\delta_{i j}=1\right.$ for own-price elasticity, or $i=j$, and $\delta_{i j}=0$ for cross-price elasticity, or $i \neq j$ ). If one imposes symmetry, then $\gamma_{k j}=\gamma_{j k}$. The equations, appropriate in the context of the switching dynamic AIDS, apply in the context of the static AIDS and dynamic AIDS when $\left(\beta_{i}+\right.$ $\beta_{i}^{*} h_{t}$ ) is replaced by $\beta_{i}$. (The equations are not appropriate in the context of the LAIDS. For correct formulas for the LAIDS elasticities, see GREen and ALSTON 1990.) The compensated price elasticity ${ }^{13}$ is defined as, for all $i$ and $j$, and for $t=1, \ldots, T$,

$$
\tilde{e}_{i j t}=e_{i j t}+w_{j t} E_{i t}
$$

Since annual data are used, the static AIDS implicitly assumes that consumers respond fully within one year. In the dynamic AIDS with annual data, the short-run elasticities refer to the equilibrium which is achieved within a year, while

${ }^{13}$ The Hicksian [income] compensated price elasticity measures only the substitution effect of a price change, while the Marshallian [income] uncompensated price elasticity also measures the income effect and, thus, shows the total effect of a price change. The compensated elasticity holds utility (or the total real expenditure) constant, while the uncompensated elasticity holds the total expenditure constant. If demand for a commodity is income neutral, the two elasticities are equal. 
the long-run elasticities refer to a longer - unknown - interval from one equilibrium to another. The vectors of long-run expenditure and price elasticities $\left(\boldsymbol{E}_{L R}\right.$ and $\boldsymbol{e}_{j L R}$, respectively) are derived as

$\boldsymbol{E}_{L R}=(\boldsymbol{I}-\boldsymbol{\theta})^{-1} \boldsymbol{E}$

$\boldsymbol{e}_{j L R}=(\boldsymbol{I}-\boldsymbol{\theta})^{-1} \boldsymbol{e}_{j}$

where $\boldsymbol{I}$ is an identity matrix, $\boldsymbol{\theta}$ is a matrix of $\theta_{i j}$ parameters, $\boldsymbol{E}$ is a vector of $E_{i} \mathrm{~s}$ and $\boldsymbol{e}_{j}$ is a vector of $e_{i j}$. If the dynamic effects are great, the AIDS easily leads to unstable long-run elasticities which have high numerical values (EDGERTON 1992b, RICKERTSEN 1992). That is why main attention is given to the short-run elasticities.

The presented elasticities refer to the responses to changes in expenditure and price in onestage budgeting. A multi-stage budgeting procedure adds requirements in the interpretation of the elasticities (the problem is often ignored, see a survey by EDGERTON 1992a). In a multi-stage system, a price change of a bundle will affect a group price index and thus the allocation of expenditures between groups. Consequently, one also has to take into account the effects which are channeled through group expenditures. The relation between expenditure elasticities in the different levels of multi-stage budgeting is widely known (e.g. MANSER 1976, BLANCIFORTI and GREEN 1983a), while the relation between price elasticities was established by EDGERTON (1992a).

The assumption of weak separability in consumer preferences implies that a change in the price of a commodity affects the demand for the commodities in the same group individually, whereas the demand for all the commodities in another group are affected in the same manner. The elasticities at different levels of the budgeting process have to be kept separate until they are combined to derive the total effects. With respect to a two-stage budgeting process, withingroup expenditure elasticities refer to the response which does not take into account between-group effects. The total expenditure elasticity measures the response in the demand for a certain commodity caused by a change in Private Consumption. Within-group price elasticity measures the direct effect on purchased quantities caused by a change in a price. Total price elasticities also take into account the change in the allocation of expenditures between groups caused by a change in a group price index which resulted from the price change of the commodity under investigation. Thus, the effects of price changes are channeled through group expenditures. The within-group price elasticity assumes an unchanged group expenditure, whereas the total price elasticity assumes changes in the group expenditures. The procedure to derive elasticities in a two-stage budgeting process can be applied to a multi-stage budgeting process by first considering stages 3 and 4 as a two-stage process, then considering stages 2 and 3 as a two-stage process and, finally considering stages 1 and 2 as a two-stage process (Table 5).

The value for the total expenditure elasticity $E_{i}$ in a two-stage system, for $r=1, \ldots, n$ and $i=$ $1, \ldots, m$ within each $r$, is derived as

$$
E_{i}=E_{(r) i} E_{(r)}
$$

The total uncompensated (Marshallian) price elasticity $e_{i j}$ is obtained, for goods $i$ and $j$ within groups $r$ and $s$, respectively

$e_{i j}=E_{(r) i} w_{(s) j} e_{(r)(s)}+\delta_{(r)(s)} \tilde{e}_{(r) i j}$

where the Kronecker delta $\delta_{(r)(s)}$ equals one when the commodities belong to the same group $(r=s)$ and zero elsewhere $(r \neq s)$. The share $w_{(s) j}$ is the within-group budget share defined as $w_{(s) j}=$ $\left(p_{(s) j} q_{(s) j}\right) / x_{s}$. Given $r=s$, the total price elasticity is a combination of a direct effect, or the withingroup price elasticity, and an indirect effect channeled through the group expenditures. The compensated analogy to price elasticity is obtained by, for $i$ within $r$ and $j$ within $s$

$\tilde{e}_{i j}=E_{(r) i} w_{(s) j} \tilde{e}_{(r)(s)}+\delta_{(r)(s)} \tilde{e}_{(r) i j}$ 
Table 5. Expenditure and price elasticities in a two-stage budgeting process.

\begin{tabular}{lccc}
\hline Class of elasticity & $\begin{array}{c}\text { Expenditure elasticity, } \\
\text { for groups } r=1, \ldots, n \\
\text { and goods } i=1, \ldots, m \\
\text { within each } r\end{array}$ & $\begin{array}{c}\text { Uncompensated price } \\
\text { elasticities, for goods } \\
i \text { and } j \text { and groups } r \\
\text { and } s\end{array}$ & $\begin{array}{c}\text { Compensated price } \\
\text { elasticities, for goods } i \text { and } j \\
\text { and groups } r \text { and } s\end{array}$ \\
\hline Within-group & $E_{(r) i}=\frac{\partial \ln g_{(r) i}}{\partial \ln x_{r}}$ & $e_{(r) i j}=\frac{\partial \ln g_{(r) i}}{\partial \ln p(r) j}$ & $\tilde{e}_{(r) i j}=e_{(r) i j}+w_{(r) j} E_{(r) i}$ \\
Group & $E_{(r)}=\frac{\partial \ln g_{r}}{\partial \ln x}$ & $e_{(r)(s)}=\frac{\partial \ln g_{(r)}}{\partial \ln P_{(s)}}$ & $\tilde{e}_{(r)(s)}=e_{(r)(s)}+w_{(s)} E_{(r)}$ \\
Total & $E_{i}=\frac{\partial \ln g_{(r) i}^{*}}{\partial \ln x}$ & $e_{i j}=\frac{\partial \ln g_{(r) i}^{*}}{\partial \ln p_{(s) j}}$ & $\tilde{e}_{i j}=e_{i j}+w_{j} E_{i}$ \\
\hline
\end{tabular}

Notes: $x_{r}\left(=\Sigma q_{r} p_{r i}\right.$, for $\left.i=1, \ldots, m\right)$ is the group expenditure, $x\left(=\Sigma x_{r}\right.$, for $\left.r=1, \ldots, n\right)$ is the total expenditure, $g_{(r) i}$ refers to the Marshallian demand function $q_{r}\left[=g_{r i}\left(x_{r}, p_{r r}, \ldots, p_{r m}\right)\right], g_{r}$ refers to $q_{r}=g_{r}\left(x, P_{l}, \ldots, P_{n}\right)$, and $g^{*}(r) i$ $\left.g^{*}(x) i, p_{(1)}, \ldots, p_{(1) m}, p_{(2) l}, \ldots, p_{(2) m}, \ldots, p_{(n) l}, \ldots, p_{(n) m}\right), w_{(r) j}\left[=\left(p_{(r) j} q_{(r) j)}\right) / x\right]$ is the $j$ th good's budget share within the $r$ th group, $w_{(s)}\left[=\left(P_{s} q_{s}\right) / x\right]$ is the $s$ th group's budget share, and $w_{j}\left[=\left(p_{(r) j} q_{(r) j)}\right) / x\right]$ is the $j$ th good's budget share.

EDGERTON (1991) has shown the cross-elasticities between goods and groups. Given the $i$ th commodity belongs to the $r$ th group, then

$$
\begin{aligned}
& e_{(s) i}=w_{(r) i} e_{(s)(r)} \\
& e_{i(s)}=E_{(r) i} e_{(r)(s)}
\end{aligned}
$$

The total expenditure elasticities are used to classify goods into three types. A good is said to be expenditure elastic or luxury if $E_{i}>1$, or the budget share of a good tends to increase with expenditure. This implies that luxuries are the goods that take up a larger share of the budget of better-off households. A good is said to be $e x$ penditure inelastic or necessity if $E_{i}<1$, or the budget share of a good tends to decrease with the total expenditure. Necessities are the goods that take up a larger share of the budget of lowerincome households. Usually the expenditure elasticity is positive, $E_{i}>0$. Given this, the Engel curve is positively sloped, and the good is said to be superior. Otherwise it is an inferior good with $E_{i}<0$, or the purchases decline absolutely, not just proportionately, as expenditure increases. For inferior goods, the Engel curve is negatively sloped. It is noteworthy that inferiority can only apply to a part of the expenditure range, because otherwise the good would never have started to be consumed.

Considering total own-price elasticities, the $\operatorname{good} i$ is said to be price elastic if $\left|e_{i i}\right|>1$ and price inelastic if $\left|e_{i i}\right|<1$. A price increase of a price-elastic good $i$ decreases the expenditure on $i$, whereas a price increase of a price-inelastic good $i$ increases the expenditure on $i$. A price change of the good $i$ that shows unit-elastic demand, $\left|e_{i i}\right|=1$, implies an unchanged expenditure on $i$. Usually the own-price elasticity is negative; given this, the good is said to be normal. Otherwise, it is a Giffen good with a positive ownprice elasticity. If the demand for good $i$ goes up as a result of price increase of $\operatorname{good} j$, or $e_{i j}>0$, then $\operatorname{good} i$ is a substitute for good $j$. In the context of food, substitutes are items that play approximately the same role in the diet, and, thus, one can easily replace one by another (e.g. beef and pork). On the other hand, good $i$ is a complement to $\operatorname{good} j$ if $e_{i j}<0$. Complements are eaten 
together and, thus, a decline in the consumption of one also decreases the consumption of another (bread and spread). If $\tilde{e}_{i j}>0$, then $\operatorname{good} i$ is a Hicksian substitute (a change in the price with utility held constant) for good $j$ and if $\tilde{e}_{i j}<0$, good $i$ is a Hicksian complement to good $j$. If $\tilde{e}_{i j}=0$, the goods are independent.

\subsection{Estimation methods}

A stochastic specification for each model is obtained by adding a vector of disturbance terms to the systems of equations (21), (37), and (41). For example, the stochastic specification of the switching dynamic AIDS is written as, for $i=1, \ldots, n$ and $t=1, \ldots, T$,

$$
\begin{aligned}
w_{i t} & =\alpha_{i}+\sum_{j=1}^{n} \theta_{i j} w_{j(t-1)}+\sum_{j=1}^{n} \gamma_{i j} \ln p_{j t} \\
& +\left(\beta_{i}+\beta_{i}^{*} h_{t}\right) \ln \left(\frac{x_{t}}{P_{t}}\right)+\varepsilon_{i t}
\end{aligned}
$$

where $\varepsilon_{i t}$ is the vector of disturbances corresponding to each observation, and $P$ is given by (38).

Assuming separability, the whole system is estimated stage by stage and group by group. First, the allocation is made between four major groups, then a further allocation is made between goods within each group. In most cases, the process is repeated so that goods which were already allocated turn into sub-groups which are further allocated into smaller bundles. The $n$ equations are estimated together. Thus, one can utilise the estimated correlation structure between the error terms within the group. By doing that one is performing a sub-system estimation which utilises more information than a single equation estimation (where no information on the error correlation structure is utilised) and less information than a full system estimation (where all the information on the error correlation structure in the system is utilised) (EDGERTON 1992b).

In order to estimate (68) and (38), certain assumptions have to be made concerning $\varepsilon_{t}$, which is a $(n * 1)$ vector of disturbance or error terms in the equations. The errors (a) have zero mean (average or expected value will be zero), $E\left(\varepsilon_{t}\right)=0$, (b) have zero covariance (serial non-correlation), $E\left(\varepsilon_{t} \varepsilon_{s}^{\prime}\right)=0$ for $(\mathrm{t} \neq \mathrm{s})$, (c) have scalar diagonal variance-covariance matrix of errors (homoskedasticity), $E\left(\varepsilon_{t} \varepsilon_{t}^{\prime}\right)=\sigma^{2} I$, where the scalar $\sigma^{2}$ is unknown, and (d) are normally distributed, $\varepsilon_{t} \sim$ $N\left(0, \sigma^{2} I\right)$ (EDGERTON 1992b). As a consequence of violating the assumptions, the estimation methods would be less efficient.

The AIDS is a nonlinear multivariate regression model (MRM), which can be seen as a set of nonlinear, seemingly unrelated regression (SUR) equations. These equations were estimated using the iterated feasible generalised least squares method (denoted IFGLS or ISUR [for iterated SUR]), which leads to maximum likelihood estimates if the errors are normally distributed (JUDGE et al. 1988, p. 551-555, AmEMiYa 1983, MaGNuS 1978). This estimation method allows cross-equation restrictions to be imposed. To avoid singularity of the residual variance-covariance matrix due to the adding-up condition, one equation was dropped, and the estimation was performed using only $(n-1)$ equations. The procedure gives joint estimates of all $n$ equations, and the parameter estimates obtained are invariant to which equation is dropped (BARTEN 1969, BERNDT and SAVIN 1975, Amemiya 1983, MCLaren 1990). The computations were performed using the nonlinear least squares routine (LSQ) of the TSP computer software package, version 4.2.

To make the estimated standard errors unbiased in the presence of unknown heteroskedasticity, White's heteroskedasticity-consistent estimates of the standard errors are calculated (WHITE 1980, the Robust option in TSP). ${ }^{14}$ The Wald tests

${ }^{14}$ White (1980) presented general conditions under which a consistent estimator of the ordinary-least-squares parameter covariance matrix can be obtained, regardless of the presence of heteroskedasticity in the disturbances of a properly specified linear model. The heteroskedasticity-consistent covariance matrix should allow correct inferences and confidence intervals to be obtained. Otherwise, one ought to model heteroskedasticity correctly or accept consequences. 
are heteroskedasticity robust, all other tests performed assume homoskedasticity.

The parameter $\alpha_{0}$ in (38) is interpreted as the real subsistence expenditure of the group. Because the likelihood is usually very flat around the maximum for $\alpha_{0}$, the empirical identification of $\alpha_{0}$ is difficult (Deaton and Muellbauer 1980a). Thus, for identification, the value of $\alpha_{0}$ has to be supplied. As a proxy for the expenditure needed for a minimum standard of living, $\alpha_{0}$ was a priori set equal one-third of the lowest per capita real total group expenditure over the observation period (Appendix 2). The expenditure parameter in (68) is assumed to vary over time. Two joint points, $\tau_{1}$ and $\tau_{2}$, define the beginning and end of the switch. The estimation strategy searches over all pairs of $\tau_{1}$ and $\tau_{2}$ (for $\tau_{1}<\tau_{2}$ ) for the pair that maximises the log-likelihood function.

The elasticities are estimated by replacing budget shares $w$ and the parameters $\beta, \beta^{*}$, and $\gamma$ by their estimated values $\hat{w}, \hat{\beta}, \hat{\beta}$, and $\hat{\gamma}$. The standard errors of elasticities are calculated by using the linearisation techniques of TSP (EDGERTON 1992b, p. 31).

The estimation of the models is based on the nonlinear AIDS. However, the AIDS is linearised by replacing $\ln P$ by $\ln \hat{P}_{t}$ in misspecification tests. The resulting approximation is similar to that used in the LAIDS (Section 4.2). The LAIDS is also employed when making projections. By the linearisation, one avoids the need to re-estimate the system for the tests and the iterative calculation of the equations in each future time period. The linearisation probably has only a minor effect on the test and projection results. This is because the AIDS is, in fact, not very nonlinear (EDGERTON 1992b), which means that the solution space does not include regions where there are sharp curves in the relationships between variables (STEWART 1991, p. 287).

\section{System of demand for food products: model selection and evaluation}

The system of demand is composed of seven subsystems (groups). For each group an appropriate or a preferred model specification will be chosen. The choice between different specifications will be based on hypothesis testing. Most of the hypotheses are either theoretical or statistical requirements. Test statistics will judge which specification achieves the best representation of the data. The hypothesis testing will be repeated for the preferred model specifications to evaluate how adequate representation of the data was achieved.

\subsection{Selection of preferred specifications: testing parameter restrictions}

Four versions of the AIDS were specified in Chapter 4: static AIDS, dynamic AIDS, switching static AIDS, and switching dynamic AIDS. Each version can be estimated either as an unconstrained form (homogeneity and symmetry not imposed), a homogeneity-constrained form, and a homogeneity-and-symmetry-constrained form. The strategy is to estimate all 12 specifications for each group in order to verify which version provides the best explanation of observed changes in consumption. In addition to the economic interest, the results can justify the reduction of the number of parameters to be estimated.

The model selection is a critical stage since results vary from one specification to another. The unrestricted switching dynamic AIDS is the most general model specification, the other 11 specifications are nested within it. Technically, four restrictions (static, non-switching, homogeneity, and symmetry including homogeneity ${ }^{15}$

${ }^{15}$ Adding-up and symmetry together imply homogeneity. The estimation method applied in the present study automatically satisfies adding-up. Consequently, testing for symmetry also tests for homogeneity. 
were nested on the parameters within the switching dynamic AIDS. In order to choose between alternative specifications, tests of parameter restrictions and misspecification tests were used to judge whether the restrictions can be imposed. Two extra hypotheses, also of interest, were adding-up and negativity. Adding-up holds automatically, and thus guarantees that the budget constraint is not violated.

Three general principles are available for generating test statistics for testing the hypotheses on linear constraints on the coefficients: the likelihood ratio (LR), Wald, and Lagrange multiplier criteria. The Lagrange multiplier and LR statistics are functions of the Wald statistics, and all the three test statistics are a function of the $F$ statistic (Evans and SAVIN 1982, BERNDT and SAVIN 1977). The LR and Wald tests were employed. Although they are asymptotically equivalent, in finite samples the results differ (JUDGE et al. 1985, p. 184-187). For the LR test of the restrictions, the maximum likelihood estimates are needed from both the restricted and unrestricted models. The test compares the restricted and unrestricted estimates; in the context of testing dynamics, the test compares the dynamic models to the static ones. Let $\Lambda=\lambda^{2 / T}$ be the LR test statistic, where $\lambda=L_{R} / L_{U}$ is the likelihood ratio between the values of the likelihood function for the restricted model likelihood $L_{R}$ (under $\left.\mathrm{H}_{1}\right)$ and unrestricted model likelihood $L_{v}$ (under $\mathrm{H}_{0}$ ).

For the Wald test, the maximum likelihood estimates are needed merely from the unrestricted models. The Wald test statistic is derived from the computed differences of the homogeneity and symmetry parameters, respectively. For example, concerning homogeneity, the null hypothesis is that a given set of linear combinations of parameters is jointly zero, i.e. that $\Sigma \gamma_{i j}=0$ for $i, j=$ $1, \ldots, n$ (Equation 29). The tested hypothesis for symmetry is $\gamma_{i j}-\gamma_{i i}=0$ for $i, j=1, \ldots, n$ (Equation 32) (Zellner 1962, Engle 1984, BeWLey 1986, EdGerTON 1991, MAdDALA 1992).

Since the Wald and LR tests have a bias towards rejection in small samples if the number of equations is large, small sample corrections are often made. The corrected Wald sta- tistic, $C W$, is derived from the Wald statistic, $W$, as follows

$C W=W \frac{T-k}{T}$

where $T$ is the number of observations and $k$ is the average number of estimated parameters per equation in the unrestricted system. The $\chi_{q}{ }^{2}$-distributed $P$-values are reported where $q$ is the number of restrictions being tested. The corrected LR statistic, Rao's exact LR statistic, $\Lambda^{*}$, is derived as follows (EDGERTON 1992b)

$\Lambda^{*}=\left(\frac{h s-r}{m_{1} m_{2}}\right)\left(\frac{1-U^{1 / s}}{U^{1 / s}}\right)$

where $m_{1}$ is the number of tested restrictions per equation ( $m_{1}=n / 2$ for symmetry hypothesis, otherwise $\left.m_{1}=1\right), m_{2}$ is the number of estimated equations in the group $\left(m_{2}=n-1, n\right.$ is the number of equations in the group). The other definitions are (EDGERTON 1992b)

$$
\begin{gathered}
h=T-k-\frac{m_{2}-m_{1}+1}{2} ; s=\sqrt{\frac{\left(m_{1} m_{2}\right)^{2}-4}{m_{1}^{2}+m_{2}^{2}-5}} ; \\
r=\frac{m_{1} m_{2}}{2}-1 ; U=e^{-\Lambda / T}
\end{gathered}
$$

$\Lambda^{*}$ is approximately distributed as $F_{m / m 2, h s-r}$ under the null hypothesis. Given identical restrictions in the equations, an exact Wald statistic, $W^{*}$, is also available (EDGERTON 1992b):

$W^{*}=W\left(\frac{T-k-n}{(n-1) T}\right)=C W\left(\frac{T-k-n}{(n-1)(T-k)}\right)$

The statistic is distributed as $F_{n-l, T-k-n}$ under the null hypothesis.

The exact LR test (70) is applied for homogeneity, symmetry, and dynamics. The exact Wald test (72) is applied for the homogeneity and switching hypotheses, whereas the corrected Wald test (69) checks symmetry and dynamics. The test statistics are calculated by the ANALYZ pro- 
Table 6. Tests of parameter restrictions for the switching dynamic AIDS and the preferred model specifications: $P$-values of corrected Wald test $(C W)$, exact Wald test $\left(W^{*}\right)$, and exact likelihood ratio test $\left(\Lambda^{*}\right)$.

\begin{tabular}{|c|c|c|c|c|c|c|c|c|c|c|}
\hline \multirow[t]{2}{*}{ Group } & \multirow[t]{2}{*}{ Model $^{\mathrm{b}}$} & \multicolumn{2}{|c|}{ Homogeneity } & \multicolumn{2}{|c|}{ Symmetry } & \multicolumn{2}{|c|}{$\begin{array}{c}\text { Symmetry } \\
\text { (conditional on } \\
\text { homogeneity) }\end{array}$} & \multicolumn{2}{|c|}{ No dynamics } & \multirow{2}{*}{$\begin{array}{c}\begin{array}{c}\text { No } \\
\text { switch }\end{array} \\
W^{*}\end{array}$} \\
\hline & & $W^{*}$ & $\Lambda^{*}$ & $C W$ & $\Lambda^{*}$ & $C W$ & $\Lambda^{*}$ & $C W$ & $\Lambda^{*}$ & \\
\hline 1 & SwDUnr & 0.0091 & 0.0259 & 0.0000 & 0.0005 & & & 0.0000 & 0.0100 & 0.0000 \\
\hline 2 & SwDUnr & 0.0000 & 0.0017 & 0.0000 & 0.0009 & & & 0.0000 & 0.0058 & 0.0000 \\
\hline 31 & SwDUnr & 0.0000 & 0.0001 & 0.0000 & 0.0001 & & & 0.9151 & 0.9052 & 0.0020 \\
\hline 31 & TUnr & 0.0001 & 0.0003 & 0.0000 & 0.0003 & & & & & \\
\hline 32 & SwDUnr & 0.0000 & 0.0003 & 0.0000 & 0.0000 & & & 0.0000 & 0.0125 & 0.0000 \\
\hline 32 & DUnr & 0.0001 & 0.0010 & 0.0000 & 0.0066 & & & 0.0000 & 0.1024 & \\
\hline 33 & SwDUnr & 0.0010 & 0.0019 & 0.0000 & 0.0057 & & & 0.0000 & 0.0000 & 0.0003 \\
\hline 41 & SwDUnr & 0.6029 & 0.5654 & 0.5595 & 0.4217 & 0.2555 & 0.1929 & 0.0179 & 0.0807 & 0.0000 \\
\hline 41 & SwDHS & 0.6029 & 0.5654 & 0.5595 & 0.4217 & 0.2555 & 0.1929 & $0.0187^{\circ}$ & 0.0807 & 0.0000 \\
\hline 42 & SwDUnr & 0.0001 & 0.0001 & 0.0000 & 0.0007 & & & 0.0000 & 0.0000 & 0.0000 \\
\hline
\end{tabular}

a The groups are as follows. Group 1: Private Consumption; Group 2: Food-at-Home; Group 31: Animalia; Group 32: Beverages; Group 33: Vegetablia; Group 41: Meat and Fish; and Group 42: Dairy Products.

${ }^{\mathrm{b}}$ The abbreviated notations are SwDUnr (switching dynamic AIDS, unrestricted), TUnr (static AIDS, unrestricted), DUnr (dynamic AIDS, unrestricted), and SwDHS (switching dynamic AIDS, homogeneity and symmetry restricted).

c Conditional on homogeneity and symmetry.

cedure of TSP. In the Wald test, White's robust standard errors are used to avoid the trouble caused by the presence of unknown heteroskedasticity. The LR test assumes homoskedasticity. The indicator of each test is the $P$-value of the test statistic. If the $P$-value is less than 0.05 , the given hypothesis is rejected at the $5 \%$ significance level. Given this, the tested restriction should not be imposed on the system. The results are presented for the unrestricted switching dynamic AIDS, which is the most general model specification and, in addition, for the model which was chosen as the preferred specification for each particular group (Table 6).

Keeping unrestricted switching dynamic AIDS as the starting point, switching was accepted everywhere. In Animalia (Group 31), the switching static AIDS produced some peculiarities in ownprice elasticities and, moreover, the Cusumsq test ${ }^{16}$ indicated parameter instability. By rejecting the switching parameter, the problem was alleviated.

Dynamics was rejected in Animalia (Group 31)

\footnotetext{
${ }^{16}$ Misspecification tests will be presented in Section 5.2 .4 .
}

by the Wald and LR tests, and in Meat and Fish (Group 41) by the LR test. The RESET, Hausman-Wu, and Cusumsq tests indicated a serious misspecification in Beverages (Group 32). The misspecification was alleviated by rejecting the switching parameter. After this, the LR test suggested to reject dynamics, while the Wald test did not. When the dynamic AIDS was replaced by the static AIDS and the results of diagnostic tests were compared, the Hausman-Wu tests indicated a serious misspecification in the static AIDS, while other tests remained about the same. Consequently, the dynamic specification was chosen for Beverages.

In all cases except Meat and Fish (Group 41), both homogeneity and symmetry were rejected. In Meat and Fish, the homogeneity and symmetry restricted specification of the switching static AIDS suffered from functional misspecification (the RESET test), group expenditure endogeneity (the Hausman-Wu tests), and parameter instability (the Cusumsq test). The problems were alleviated by accepting dynamics which was, in fact, suggested by the Wald test but rejected by the LR test. 
Table 7. Preferred specifications of the AIDS with estimated joint points $\left(\tau_{1}\right.$ and $\left.\tau_{2}\right){ }^{a}$

\begin{tabular}{llcr}
\hline Group & Preferred specification & \multicolumn{2}{c}{ Joint points } \\
\cline { 2 - 4 } & & $\tau_{1}$ & $\tau_{2}$ \\
\hline Private Consumption (Group 1) & Switching dynamic AIDS, unrestricted & 1975 & 1984 \\
Food-at-Home (Group 2) & Switching dynamic AIDS, unrestricted & 1961 & 1984 \\
Animalia (Group 31) & Static AIDS, unrestricted & & \\
Beverages (Group 32) & Dynamic AIDS, unrestricted & 1961 & 1989 \\
Vegetablia (Group 33) & Switching dynamic AIDS, unrestricted & 1967 & 1975 \\
Meat and Fish (Group 41) & Switching dynamic AIDS, homogeneity & & \\
Dairy Products (Group 42) & and symmetry restricted & 1965 & 1974 \\
\hline
\end{tabular}

a Joint point $\tau_{1}$ represents the end point of the first regime, whereas joint point $\tau_{2}$ is the starting point of the second regime.

The unrestricted switching dynamic AIDS was chosen as the preferred model specification for four groups. Static specification was chosen for one group (Table 7). The joint points, to present the beginning and end of the gradually switching period, were estimated by the maximum-likelihood procedure. The joint points vary from group to group. In Food-at-Home and Vegetablia (Groups 2 and 33), the first joint point is 1961, whereas in Meat and Fish and Dairy Products (Groups 41 and 42) it is 1967 and 1965, respectively. In Private Consumption and Food-at-Home (Groups 1 and 2), the second joint point is 1984, whereas in Meat and Fish and Dairy Products (Groups 41 and 42) it is 1975 and 1974, respectively (Table 7). The models for Animalia and Beverages (Groups 31 and 32) did not include a switching parameter.

\subsection{Evaluation of the preferred model specifications}

\subsubsection{Negativity condition}

The negativity condition was tested by checking if all compensated (Hicksian) own-price elasticities were negative. The restriction cannot be accepted because the non-positivity did not hold for the whole range of prices and expenditures in all commodities. In the preferred specifications of the AIDS, 16 of the 26 categories satisfied the negativity condition. Food-at-Home, Beverages, Vegetablia, and Dairy Products (Groups 2, 32, 33, and 42) showed only a few violations, whereas Private Consumption, Animalia, and Meat and Fish (Groups 1, 31, and 41) included categories where all the estimated compensated ownprice elasticities were positive (Table 8 ). It remains unexplained why all the estimated models did not satisfy the negativity condition. The discussion on potential causes for the outcome is postponed to Chapter 8 .

\subsubsection{Parameter estimates}

Altogether 133 of the 258 estimated parameters, or $52 \%$, were at least twice the size of the corresponding standard error, which is roughly the condition for the significance at 5\% level. Using the share of significant parameters from all estimated parameters as the criteria, the expenditure parameters for the switch $\left(\beta_{i}^{*}\right)$ had the best performance. Noteworthy is that the shifting variable was included only in those models where its relevance was accepted by a diagnostic test. The performance of the expenditure variable was not good in Beverages (Group 32), where all the coefficients $(\beta)$ were insignificant. The performance of the price parameters (coefficients $\gamma_{i j}$ ) was not good in Meat and Fish and Dairy Products (Groups 41 and 42). The habit persistence pa- 
Table 8 . Number of violations of the negativity condition.

\begin{tabular}{|c|c|c|c|c|c|}
\hline \multirow[t]{3}{*}{$\begin{array}{l}\text { Group (group number } \\
\text { in brackets) }\end{array}$} & \multirow[t]{3}{*}{ Model $^{a}$} & \multicolumn{4}{|c|}{$\begin{array}{c}\text { Number of positive compensated } \\
\text { own-price elasticities }\end{array}$} \\
\hline & & \multicolumn{4}{|c|}{ Category $^{b}$} \\
\hline & & 1 & 2 & 3 & 4 \\
\hline Private Consumption (1) & SwDUnr & $31^{\mathrm{c}}$ & 0 & 15 & 31 \\
\hline Food-at-Home (2) & SwDUnr & 0 & 0 & 0 & 0 \\
\hline Animalia (31) & TUnr & 31 & 18 & 4 & \\
\hline Beverages (32) & DUnr & 0 & 0 & 0 & 4 \\
\hline Vegetablia (33) & SwDUnr & 0 & 7 & 0 & 0 \\
\hline Meat and Fish (41) & SwDHS & 31 & 0 & 0 & \\
\hline Dairy Products (42) & SwDUnr & 11 & 0 & 0 & 0 \\
\hline
\end{tabular}

a The abbreviated notations are SwDUnr (switching dynamic AIDS, unrestricted), TUnr (static AIDS, unrestricted), DUnr (dynamic AIDS, unrestricted), and SwDHS (switching dynamic AIDS, homogeneity and symmetry restricted).

${ }^{\mathrm{b}}$ The categories refer to the commodity bundles presented in Table 2.

${ }^{c}$ The maximum number of violations of negativity is 31 , or the total number of estimated elasticities.

rameters $\left(\theta_{i j}\right)$ were estimated for all groups except Animalia (Group 31). Especially Foodat-Home and Meat and Fish (Groups 2 and 41) suffered from insignificant $\theta_{i j}$ estimates (Table 9). Parameter estimates are presented in Appendix 2 .

\subsubsection{Goodness of fit}

Goodness of fit was measured by the usual coefficient of determination $\mathrm{R}^{2}$, which is the ratio of explained variation to the total variation, written for each equation in an allocation model as

Table 9. Significance of the estimated parameters in the preferred model specifications. ${ }^{a}$

\begin{tabular}{|c|c|c|c|c|c|c|c|c|c|c|c|c|c|}
\hline \multirow[t]{2}{*}{ Group $^{b}$} & \multicolumn{2}{|c|}{$\alpha_{i}$} & \multicolumn{2}{|c|}{$\theta_{i j}$} & \multicolumn{2}{|c|}{$\gamma_{i j}$} & \multicolumn{2}{|c|}{$\beta_{i}$} & \multicolumn{2}{|c|}{$\beta_{i}^{*}$} & \multicolumn{3}{|c|}{ Sum } \\
\hline & $t>2$ & Total & $t>2$ & Total & $t>2$ & Total & $t>2$ & Total & $t>2$ & Total & $t>2$ & Total & $t>2, \%$ \\
\hline 1 & 1 & 4 & 10 & 16 & 10 & 16 & 3 & 4 & 3 & 4 & 27 & 44 & 61 \\
\hline 2 & 3 & 4 & 3 & 16 & 10 & 16 & 3 & 4 & 3 & 4 & 22 & 44 & 50 \\
\hline 31 & 3 & 3 & - & - & 8 & 9 & 2 & 3 & - & - & 13 & 15 & 87 \\
\hline 32 & 2 & 4 & 7 & 16 & 9 & 16 & 0 & 4 & - & - & 18 & 40 & 45 \\
\hline 33 & 2 & 4 & 8 & 16 & 7 & 16 & 3 & 4 & 4 & 4 & 24 & 44 & 55 \\
\hline 41 & 3 & 3 & 2 & 9 & 0 & 9 & 3 & 3 & 3 & 3 & 11 & 27 & 41 \\
\hline 42 & 3 & 4 & 9 & 16 & 2 & 16 & 2 & 4 & 2 & 4 & 18 & 44 & 41 \\
\hline Sum & 17 & 26 & 39 & 89 & 46 & 98 & 16 & 26 & 15 & 19 & 133 & 258 & 52 \\
\hline Sum, \% & 65 & 100 & 44 & 100 & 47 & 100 & 62 & 100 & 79 & 100 & 52 & 100 & \\
\hline
\end{tabular}

a Groups 1, 2, 33, and 42: switching dynamic AIDS, unrestricted; Group 41: switching dynamic AIDS, homogeneity and symmetry restricted: Group 32: dynamic AIDS, unrestricted; Group 31: static AIDS, unrestricted: The $t$-values were obtained by dividing the value of the estimated parameter by the corresponding standard error. A $t$-value greater than two roughly indicates the condition for significance at $5 \%$ level.

b The groups are as follows. Group 1: Private Consumption; Group 2: Food-at-Home; Group 31: Animalia; Group 32: Beverages; Group 33: Vegetablia; Group 41: Meat and Fish; and Group 42: Dairy Products. 


$$
R^{2}=1-\frac{\sum_{t=1}^{T}\left(w_{t}-\hat{w}_{t}\right)^{2}}{\sum_{t=1}^{T}\left(w_{t}-\bar{w}\right)^{2}}
$$

where $T$ is the number of observations and $\bar{w}$ is the average of the dependent variable. $R^{2}$ can be adjusted for the loss in degrees of freedom due to the addition of more explanatory variables. The statistics, $\operatorname{adj} R^{2}$, was derived as

$\operatorname{adj} R^{2}=R^{2}-\frac{k-1}{T-k}\left(1-R^{2}\right)$

As a system-wise counterpart, the following measure was used (EDGERTON 1992b):

$$
\tilde{R}^{2}=1-\sqrt[m]{\frac{\operatorname{det} \Sigma_{\hat{e}}}{\operatorname{det} \Sigma_{\hat{w}}}}
$$

where $m=n-1$, or the number of estimated equations in the group, $\Sigma$ is the covariance matrix of the estimated residual, $\operatorname{cov}\left(\hat{e}_{\hat{p}} \hat{e}_{s}\right)$, and $\Sigma_{\hat{w}}$ is the estimated covariance matrix of the dependent variables, $\operatorname{cov}\left(\hat{w}_{i} \hat{w}_{j}\right) \cdot \tilde{R}^{2}$ is a form of the weighted geometric mean of the equation-wise $R^{2} \mathrm{~s}$, and it was adjusted for degrees of freedom (EDGERTON 1992b, p. 30).

To measure the relative improvement of a dynamic model over a nested static model (static model was nested within the dynamic model), one can write

$$
R_{D: \mathrm{S}}^{2}=\frac{R_{D}^{2}-R_{S}^{2}}{1-R_{S}^{2}}
$$

where $R^{2}$ is the goodness of fit from a dynamic model, and $R^{2}{ }_{s}$ is the goodness of fit from a static model. $R_{D: S}^{2}$ was adjusted for degrees of freedom to obtain $\operatorname{adj} R_{D: S}^{2}$ as

$$
\operatorname{adj}_{D: \mathrm{S}}^{2}=R_{D: \mathrm{S}}^{2}-\frac{k-1}{T-k}\left(1-R_{D: \mathrm{S}}^{2}\right)
$$

Restated, adj $R_{D: S}^{2}$ is the coefficient of determination for the dynamic model adjusted for the static model and degrees of freedom. $R_{D: S}^{2}$ and $\operatorname{adj} R_{D: S}^{2}$ can be applied for single equations and systems (EDGERTON 1992b).

The goodness of fit was low in Beverages, Groceries, Carcase Meat, Fish, and Margarine; in other cases it was rather high. A comparison between dynamic and static models showed that dynamics generated an improvement in the goodness of fit in most cases. Measured by $\operatorname{adj} R_{D: S}^{2}$, in 5 of the 23 dynamic equations more than $50 \%$ of the variation remaining in the static model was explained. More than $20 \%$ was explained in 16 cases. In addition to Animalia (Group 31), which was estimated as a static specification (because of the poor performance of dynamics), only Groceries and Fish did not benefit from dynamics (Table 10).

\subsubsection{Diagnostic checking}

The diagnostic tests are used in applied work to check whether something is wrong with the model under consideration, and thus to reduce the risk of accepting misspecified models. The tests are described in the context of a single-equation linear regression model, for $t=1, \ldots, T$,

$y_{t}=x_{t}^{\prime} \beta+\varepsilon_{t}$

where $y_{t}$ is an observation of the dependent variable, $x_{t}$ is a $k \times 1$ vector of independent variables, $\beta$ is a $k \times 1$ vector of estimated parameters, and $\varepsilon_{t}$ is an error term. Where possible, system-wise diagnostic tests were calculated by generalising the equation-wise tests for the whole system. The methodology employs GODFREY's (1988) theory of local equivalent alternatives. The description follows EDGERTON (1992b), RICKERTSEN (1992), PAgAn and Wickens (1989), STEWART (1991), and MAdDALA (1992).

There are alternative principles which can be used for generating test statistics. The statistics are often asymptotically equivalent, but their small sample distributions are generally different (ENGLE 1984). In the present study, an exact small 
Table 10. Goodness-of-fit measures of the preferred model specifications. ${ }^{a}$

\begin{tabular}{|c|c|c|c|c|}
\hline & $R^{2}$ & $\operatorname{adj} R^{2}$ & $R_{D: S}^{2}$ & $\operatorname{adj} R_{D S S}^{2}$ \\
\hline Private Consumption (Group 1) & 0.978 & 0.969 & 0.298 & 0.198 \\
\hline - Food-at-Home & 0.996 & 0.995 & 0.313 & 0.214 \\
\hline - Food-away-from-Home & 0.996 & 0.994 & 0.244 & 0.136 \\
\hline - Non-Durables & 0.937 & 0.909 & 0.153 & 0.032 \\
\hline - Services & 0.993 & 0.990 & 0.547 & 0.482 \\
\hline Food-at-Home (Group 2) & 0.891 & 0.844 & 0.315 & 0.218 \\
\hline - Animalia & 0.927 & 0.895 & 0.145 & 0.023 \\
\hline - Beverages & 0.887 & 0.839 & 0.517 & 0.448 \\
\hline - Vegetablia & 0.952 & 0.932 & 0.608 & 0.552 \\
\hline - Groceries & 0.860 & 0.800 & 0.087 & -0.043 \\
\hline Animalia (Group 31) & 0.873 & 0.854 & $(0.023)^{\mathrm{b}}$ & $(-0.062)^{b}$ \\
\hline - Meat and Fish & 0.935 & 0.926 & $(0.044)^{\mathrm{b}}$ & $(-0.040)^{b}$ \\
\hline - Dairy Products & 0.908 & 0.894 & $(0.044)^{\mathrm{b}}$ & $(-0.039)^{b}$ \\
\hline - Eggs & 0.918 & 0.905 & $(0.001)$ & $(-0.086)^{b}$ \\
\hline Beverages (Group 32) & 0.926 & 0.899 & 0.203 & 0.094 \\
\hline - Alcoholic Drinks & 0.991 & 0.988 & 0.368 & 0.282 \\
\hline - Fresh Milk & 0.988 & 0.984 & 0.306 & 0.211 \\
\hline - Soft Drinks & 0.976 & 0.967 & 0.453 & 0.379 \\
\hline - Hot Drinks & 0.986 & 0.981 & 0.339 & 0.249 \\
\hline Vegetablia (Group 33) & 0.940 & 0.915 & 0.501 & 0.430 \\
\hline - Bread and Cake & 0.939 & 0.913 & 0.156 & 0.035 \\
\hline - Fruits & 0.944 & 0.920 & 0.766 & 0.732 \\
\hline - Vegetables & 0.940 & 0.914 & 0.528 & 0.461 \\
\hline - Flour & 0.978 & 0.969 & 0.676 & 0.630 \\
\hline Meat and Fish (Group 41) & 0.767 & 0.715 & 0.173 & 0.105 \\
\hline - Meat Products & 0.940 & 0.927 & 0.321 & 0.266 \\
\hline - Carcase Meat & 0.867 & 0.837 & 0.138 & 0.067 \\
\hline- Fish & 0.591 & 0.499 & 0.037 & -0.041 \\
\hline Dairy Products (Group 42) & 0.935 & 0.908 & 0.509 & 0.439 \\
\hline - Cheese & 0.976 & 0.966 & 0.615 & 0.560 \\
\hline - Sour Milk and Cream & 0.956 & 0.937 & 0.516 & 0.446 \\
\hline - Butter & 0.976 & 0.965 & 0.606 & 0.550 \\
\hline - Margarine & 0.848 & 0.782 & 0.362 & 0.270 \\
\hline
\end{tabular}

a Groups 1, 2, 33, and 42: switching dynamic AIDS, unrestricted; Group 41: switching dynamic AIDS, homogeneity and symmetry restricted: Group 32: dynamic AIDS, unrestricted; Group 31: static AIDS, unrestricted.

b The measures are from the switching dynamic AIDS, unrestricted.

sample adjustment to the LR test statistic was employed. The adjusted LR test is a special case of the exact LR statistic (70). The $F$ - (rather than $\chi^{2}$-) distributions were used, as suggested by KIVIET (1986). ${ }^{17}$ This LR principle was followed in

\footnotetext{
${ }^{17}$ KIVIET (1986) compared the effectiveness of various small sample correction factors in the model with lagged dependent variables in the context of serial correlation. He showed that the Lagrange-multiplier type $F$ test has a type I error probability that is relatively invariant to sample size, order of serial correlation, true coefficient values, and redundant regressors (type I error is a
}

the tests for autocorrelation (BG), heteroskedasticity (BP and $\mathrm{ARCH}$ ), and functional misspecification (RESET and HWu). The $P$-values of the test statistics are presented in Table 11. The $P$ values less than 0.05 indicate that a given hy-

probability of rejecting $\mathrm{H}_{0}$ even when it is true). The BG test used in the present study, although employing the adjusted LR test, is asymptotically equivalent to the Lagrange multiplier test (EDGERTON 1992b, p. 21). Consequently, the use of $F$-distributions should yield better small sample approximations than the use of $\chi^{2}$-distributions. 
Table 11. Misspecification tests: small sample $P$-values."

\begin{tabular}{|c|c|c|c|c|c|c|c|c|}
\hline & BG & $\mathrm{BP}$ & ARCH & RESET & $\mathrm{HWu}(\mathrm{x})$ & HWu(di) & JB & Cusumsq \\
\hline Private Consumption (Group 1) & 0.694 & 0.599 & 0.197 & 0.197 & & 0.497 & & \\
\hline - Food-at-Home & 0.360 & 0.555 & 0.332 & 0.359 & & 0.186 & 0.339 & 0.010 \\
\hline - Food-away-from-Home & 0.365 & 0.595 & 0.182 & 0.736 & & 0.373 & 0.911 & 0.011 \\
\hline - Non-Durables & 0.738 & 0.943 & 0.867 & 0.014 & & 0.603 & 0.861 & 0.005 \\
\hline - Services & 0.813 & 0.360 & 0.464 & 0.782 & & 0.386 & 0.982 & 0.010 \\
\hline Food-at-Home (Group 2) & 0.180 & 0.494 & 0.919 & 0.158 & 0.688 & 0.356 & & \\
\hline - Animalia & 0.878 & 0.593 & 0.592 & 0.434 & 0.724 & 0.703 & 0.960 & 0.108 \\
\hline - Beverages & 0.462 & 0.052 & 0.344 & 0.238 & 0.341 & 0.128 & 0.633 & 0.050 \\
\hline - Vegetablia & 0.885 & 0.318 & 0.853 & 0.643 & 0.302 & 0.118 & 0.950 & 0.578 \\
\hline - Groceries & 0.829 & 0.096 & 0.860 & 0.887 & 0.339 & 0.208 & 0.778 & 0.005 \\
\hline Animalia (Group 31) & 0.799 & 0.681 & 0.646 & 0.799 & 0.519 & 0.312 & & \\
\hline - Meat and Fish & 0.288 & 0.266 & 0.916 & 0.927 & 0.319 & 0.125 & 0.378 & 0.904 \\
\hline - Dairy Products & 0.337 & 0.333 & 0.988 & 0.856 & 0.400 & 0.144 & 0.322 & 0.997 \\
\hline - Eggs & 0.602 & 0.789 & 0.806 & 0.233 & 0.521 & 0.804 & 0.945 & 0.324 \\
\hline Beverages (Group 32) & 0.030 & 0.489 & 0.001 & 0.000 & 0.220 & 0.043 & & \\
\hline - Alcoholic Drinks & 0.878 & 0.539 & 0.979 & 0.022 & 0.950 & 0.835 & 0.000 & 0.001 \\
\hline - Fresh Milk & 0.199 & 0.532 & 0.773 & 0.079 & 0.574 & 0.303 & 0.000 & 0.000 \\
\hline - Soft Drinks & 0.518 & 0.679 & 0.240 & 0.350 & 0.218 & 0.166 & 0.575 & 0.011 \\
\hline - Hot Drinks & 0.330 & 0.788 & 0.572 & 0.719 & 0.127 & 0.066 & 0.633 & 0.209 \\
\hline Vegetablia(Group 33) & 0.583 & 0.242 & 0.997 & 0.857 & 0.150 & 0.280 & & \\
\hline - Bread and Cake & 0.618 & 0.131 & 0.945 & 0.632 & 0.065 & 0.047 & 0.787 & 0.000 \\
\hline - Fruits & 0.131 & 0.256 & 0.596 & 0.599 & 0.791 & 0.985 & 0.888 & 0.003 \\
\hline - Vegetables & 0.057 & 0.821 & 0.707 & 0.938 & 0.699 & 0.958 & 0.506 & 0.027 \\
\hline - Flour & 0.720 & 0.740 & 0.453 & 0.231 & 0.027 & 0.083 & 0.621 & 0.001 \\
\hline Meat and Fish (Group 41) & 0.728 & 0.073 & 0.285 & 0.001 & 0.477 & 0.520 & & \\
\hline - Meat Products & 0.248 & 0.560 & 0.512 & 0.877 & 0.934 & 0.967 & 0.838 & 0.075 \\
\hline - Carcase Meat & 0.287 & 0.995 & 0.289 & 0.011 & 0.638 & 0.619 & 0.888 & 0.202 \\
\hline - Fish & 0.811 & 0.002 & 0.079 & 0.000 & 0.168 & 0.192 & 0.770 & 0.000 \\
\hline Dairy Products (Group 42) & 0.218 & 0.257 & 0.354 & 0.046 & 0.078 & 0.107 & & \\
\hline - Cheese & 0.337 & 0.178 & 0.256 & 0.030 & 0.068 & 0.143 & 0.430 & 0.288 \\
\hline - Sour Milk and Cream & 0.636 & 0.013 & 0.109 & 0.084 & 0.208 & 0.192 & 0.817 & 0.102 \\
\hline - Butter & 0.825 & 0.181 & 0.550 & 0.811 & 0.055 & 0.129 & 0.134 & 0.553 \\
\hline - Margarine & 0.222 & 0.138 & 0.466 & 0.033 & 0.111 & 0.103 & 0.582 & 0.007 \\
\hline
\end{tabular}

a The preferred model specification for each group was applied. The abbreviated notations are BG (Breusch-Godfrey statistics), BP (first order Breusch-Pagan test), ARCH (first order autoregressive conditional heteroskedasticity model), RESET (Ramsey's regression equation specification error test), HWu(x) (Hausman-Wu test which uses the total expenditure as the instrument), $\mathrm{HWu}(\mathrm{di})$ (Hausman-Wu test which uses disposable income as the instrument), JB (Jarque-Bera Lagrange multiplier test), and Cusumsq (cumulative sum of squares test).

b The computations of the $P$-values of the Cusumsq statistics were performed by David Edgerton by using the method described in EDGERTON and Wells (1993, 1995).

pothesis of the correctness of the model was rejected at $5 \%$ significance level.

\section{Autocorrelation}

Autocorrelation, or serial correlation, especially combined with lagged endogenous variables, yields inconsistent estimates. The Breusch-God- frey statistics (BG) indicates the amount of autocorrelation (BREUSCH 1978, GodFREY 1978, ENGLE 1984, p. 807). Contrary to the familiar DurbinWatson test, the BG is valid in the presence of lagged endogenous variables. The BG test against autoregressive errors of the first order is defined as a test where $\mathrm{H}_{0}$ is $\alpha_{1}=0 \mathrm{in}$, for $t=1, \ldots, n$, 


$$
y_{t}=x_{t}^{\prime} \beta+\alpha_{1} \hat{\varepsilon}_{t-1}+v_{t}
$$

where the error term $v_{t}$ is assumed to be a white noise process $N I D\left(0, \sigma^{2}\right)$, i.e. the values of $v_{t}$ are assumed to be drawn independently from a normal distribution with a zero mean and $\sigma^{2}$ variance. The $\mathrm{H}_{0}$ in (79) implies that there is no first order autocorrelation and, consequently, the original model is preferred, whereas the competing $\mathrm{H}_{1}$ suggests an alternative specification in which the lagged estimated error term is included as a variable. The $F$-statistic was used for the null hypothesis; it is asymptotically $F_{l, T-k-1}$ distributed, where $k$ is the number of explanatory variables. The system-wise BG tested for autocorrelation in the system.

Autocorrelation was rejected for all equations, and the hypothesis that none of the equations in the group suffered from autocorrelation was rejected only in Beverages (Group 32). The results indicate that, except for Beverages, the dynamic specification was correct.

\section{Heteroskedasticity}

The heteroskedasticity problem arises if the error variance is not constant for all the observations. Consequently, the estimated variance is biased, and the estimators are unbiased but inefficient. Heteroskedasticity was checked by the first order Breusch-Pagan test (BP), for $t=1, \ldots, T$,

$\hat{\varepsilon}_{t}^{2}=\alpha_{0}+\alpha_{1} \hat{y}_{t}+\alpha_{2} \hat{y}_{t}^{2}+v_{t}$

$\mathrm{H}_{0}$ is $\alpha_{1}=\alpha_{2}=0$ or homoskedasticity (BREUSCH and PAGAN 1979). Heteroskedasticity was rejected, or homoskedasticity was accepted, for all equations, except Fish and Sour Milk and Cream.

\section{ARCH effects}

First order autoregressive conditional heteroskedastic model (ARCH) tests for the ARCH effects in errors which arise from the fact that uncertainty in the economic relationships is captured by the variance $\sigma^{2}$ of the error $\varepsilon_{t}$. This error variance affects the behaviour of economic agents in a way that an unusually high error term in one period results in an increase in uncertainty for the next period. Thus, in an ARCH model, the errors $\varepsilon_{\mathrm{t}}$ are not autocorrelated, but the variance of $\varepsilon_{t}$ depends on the past of errors, $\varepsilon_{t-1}^{2}$. Restated, the error variance is modelled by the ARCH model (ENGLE 1982). The ARCH test is calculated, for $t=1, \ldots, T$,

$$
\hat{\varepsilon}_{t}^{2}=\alpha_{0}+\alpha_{1} \hat{\varepsilon}_{t-1}^{2}+v_{t}
$$

$\mathrm{H}_{0}$ is that the regression coefficient $\alpha_{1}$ is zero, or there is no misspecification caused by the ARCH effects. The test may also indicate misspecification caused by the omission of relevant variables. Significant ARCH effects were recorded only in Beverages (Group 32). The result is in accordance with the following test.

\section{Functional misspecification}

Ramsey's regression equation specification error test (RESET) of second order is calculated as

$$
y_{t}=x_{t}^{\prime} \beta+\alpha_{2} \hat{y}_{t}^{2}+v_{t}
$$

where $\mathrm{H}_{0}$ is $\alpha_{2}=0$, or there is no functional misspecification (RAMSEY 1969). If the hypothesis of no-functional-misspecification is rejected, some form of misspecification is detected, for example, omitted variables, incorrect functional form, or endogeneity in the explanatory variables (EDGERTON 1992b, p. 25). The RESET was significant in 6 out of 26 equations, i.e. Non-Durables, Alcoholic Drinks, Carcase Meat, Fish, Cheese, and Margarine indicated misspecification. The RESET was also significant for Beverages, Meat and Fish, and Dairy Products (Groups 32, 41, and 42).

A problem that arises in the estimation of systems of demand equations, such as the AIDS, is that expenditure may be endogenous in the sense that it is correlated with the equation errors. The endogeneity may arise from the simultaneous- 
equation nature of the problem, i.e. since the total expenditure is defined as the sum of expenditures on individual goods, and as these expenditures are assumed to be endogenous, the total expenditure might be expected to be jointly endogenous. One should be aware of the endogeneity because, if expenditure is correlated with the equation errors, the resulting estimators will be both biased and inconsistent (ATTFIELD 1985, LAFRANCE 1991). Even if the RESET tested for many forms of misspecification, in order to test for endogeneity of expenditure, the Hausman-Wu specification test is more specific. The idea with the Hausmann-Wu specification test is that an instrumental variable is included as an extra variable in the model (Hausman 1978, Wu 1973). If the exogeneity assumption is correct, the extra variable should have no effect. The group expenditure $x_{t}$ in (68) was considered a priori exogenous. However, $x_{t}$ and disturbance terms may be correlated, indicating an endogeneity of expenditure. The Hausman-Wu test judges whether a departure from exogeneity is important. A two-step test was performed. First, $x_{t}$ was regressed on the set of explanatory variables (all considered $a$ priori exogenous) and $z_{t}$, which marks the instrument for $x_{i}$ :

$\ln \left(\frac{x_{t}}{\hat{P}_{t}}\right)=\hat{y}_{t}=\alpha_{i}+\sum \gamma_{i j} \ln p_{j t}+\gamma_{0} \ln \left(\frac{z_{t}}{\hat{P}_{t}}\right)$

where $\hat{P}_{t}$ is the AIDS estimate of $P_{t}$. Predicted values $\hat{y}_{t}$ were obtained. At the second step, budget shares were regressed on $x_{t}$, the set of explanatory variables, and $\hat{y}_{i}$ :

$w_{i t}=\alpha_{i}+\sum \gamma_{i j} \ln p_{j t}+\beta_{i} \ln \left(\frac{x_{t}}{\hat{P}_{t}}\right)+\gamma_{i} \hat{y}_{t}+v_{i t}$

The significance of the prediction term was tested. $\mathrm{H}_{0}$ was $\gamma_{i}=0$, or the group expenditure was exogenous. Two instruments $z_{t}$ were used. The $\mathrm{HWu}(\mathrm{x})$ used the total per capita expenditure (which equals $x_{t}$ at Stage 1) as the instrument, and the HWu(di) used disposable per capita income in the complete system as the instrument. If $x_{t}$ is assumed exogenous, its use in the instru- ment set can be justified elsewhere but at the first stage. If $x$ is assumed endogenous, instead of that, disposable income should be used in the instrument set. Disposable income can be applied for all stages.

The Hausman-Wu test was significant in two equations in Group 33, namely Bread and Cake and Flour, and in one group, namely Beverages (Group 32). In Bread and Cake and Flour, the misspecification was probably a problem with group expenditure endogeneity since the RESET was not significant in those bundles (c.f. EDGERTON 1993, p. 17-19). In Beverages, both the RESET and HWu(di) were significant, which could, for example, indicate that the separability structure was incorrectly specified. In all three cases, however, the result is less clear since only one of the two tests was significant. Thus, it can be concluded that the recursive manner in which the group expenditures appeared in the system did not lead to any significant misspecification. If the exogeneity hypotheses were rejected more clearly, some form of instrumental variables method should have been applied.

\section{Separability structure}

No explicit test was carried out to check whether the separable groups that were compounded from individual food items were consistent with consumer preferences. ${ }^{18}$ However, implicitly it can be concluded that omitted variables and endogeneity of explanatory variables may suggest nonseparability (EDGERTON 1992b). The RESET test searched for some form of misspecification, for example, omitted variables and endogeneity in

${ }^{18}$ The problem with most separability tests is that they use either the Wald or LR criteria and, thus, parameter estimates from the unrestricted (non-separable) model are needed. In the present study the estimates were not available. EALES and UNNEVEHR (1988) derived a parametric restriction which they used to test for weak separability in an AIDS model. The test showed that consumers chose among meat products rather than meat aggregates, such as beef or chicken. HAYES et al. (1990) tested for separability hypothesis by using parametric restrictions in the AIDS model of the Japanese meat demand system. Separability between meats and fish was accepted. 
the explanatory variables. Thus, it can be employed to test for separability. The second test suitable for this purpose is the Hausmann-Wu test (Alston and Chalfant 1987, Edgerton 1992b). The total per capita expenditure and disposable per capita income were included as extra variables in the model (the $\mathrm{HWu}(\mathrm{x})$ and $\mathrm{HWu}(\mathrm{di})$ tests, respectively). If the separability assumption is correct, the extra variable should have no effect.

By using the RESET test as the criteria, the separability assumption may have been wrong in Beverages, Meat and Fish, and Dairy Products (Groups 32, 41, and 42). By using the $\mathrm{HWu}(\mathrm{x})$ endogeneity criteria, the specification of the separability structure was correct. According to the HWu(di) endogeneity criteria, separability structure was questioned in Beverages (Group 32).

\section{Normality}

The asymptotic Jarque-Bera Lagrange multiplier test (JB) was performed to approximate the normality of observations (JARQUE and BERA 1987). The test checks the departure from normality due to either skewness or kurtosis. The small sample approximation, which approaches the asymptotic results more rapidly, is written as

$$
\begin{aligned}
\lambda & =\frac{(\tau-1)^{2}}{\tau-2}\left[\frac{\hat{b}_{1}^{2}}{6}\right. \\
& \left.+\frac{(\tau-1)(\tau+1)}{24 \tau(\tau-3)}\left(\hat{b}_{2}-3 \frac{\tau-1}{\tau+1}\right)^{2}\right]
\end{aligned}
$$

where $\tau=(T-k)$ is the degrees of freedom, $\hat{b}_{1}=$ $\hat{\mu}_{3} / \hat{\mu}_{2}^{3 / 2}$ is the measure of the skewness of distribution (the degree of symmetry), and $\hat{b}_{2}=\hat{\mu}_{4} / \hat{\mu}_{2}{ }^{2}$ is the measure of the kurtosis of distribution (the peakness of the distribution and the thickness of its tails) ( $\hat{\mu}_{i}$ are sample moments). The statistic $\lambda$ is asymptotically distributed as $\chi_{2}{ }^{2}$ (EDGERTON 1992b, JUDGE et al. 1988, p. 890892). Normality cannot be tested in Godfrey's local equivalent alternatives form. Thus, only equation-wise rather than multivariate normality was tested. The hypothesis of the normality of observations was rejected for the equations of Alcoholic Drinks and Fresh Milk within Beverages (Group 32).

\section{Parameter instability}

The cumulative sum of squares test (Cusumsq) tests for the stability (over time) of regression relationships, or structural changes in parameters. The application follows the ordinary-leastsquares-residuals form of the test (MCCABE and Harrison 1980, Moschini and Meilke 1984). ${ }^{19}$ The Cusumsq statistic, C, based on the iteratedseemingly-unrelated-regression residuals, is calculated as, for $(k+1) \leq s \leq T$,

$$
C=\max \left|\frac{1}{\hat{\sigma}^{2} T} \sum_{t=1}^{s} \hat{\varepsilon}_{t}^{2}-\frac{s-k}{T-k}\right|
$$

where $\hat{\sigma}^{2}$ is the estimated variance of the distribution of the parameter, $T$ is the number of observations, and $k$ denotes the average number of estimated parameters per equation in the unrestricted system. Godfrey's local equivalent alternatives form is not available to allow for system testing. The $P$-values were given by the program described in EDGERTON and Wells (1993, 1995).

If a change in tastes were seen as a change in the parameters of the utility function, then variation in the estimated parameters of the preferred models could be taken as evidence of changes in tastes. The modelling failed to track a stable preference structure: the parameter constancy was rejected in 14 out of 26 equations. Thus, the results

${ }^{19}$ There are standard and ordinary-least-squares based Cusum and Cusumsq tests. The seminal work on the $\mathrm{Cu}$ sum and Cusumsq was made by Brown et al. (1975). The tests use a set of recursive residuals which are independent $N\left(0, \sigma^{2}\right)$ variables under $\mathrm{H}_{0}$. MCCABE and HARRISON (1980) generalised the Cusumsq test to ordinary-leastsquares residuals which are dependent and heteroskedastic even under $\mathrm{H}_{0}$. The regression model under consideration is: $y_{t}=x^{\prime}, \beta+\varepsilon, t=1, \ldots, T$ (note that the vector of parameters is allowed to vary over time). The $\mathrm{H}_{0}$ is that the coefficients of the model remain constant over time, or $\beta=\beta, t=1, \ldots, T$. PLOBERGER and KRÄMER (1992) showed that also the Cusum test can be applied to ordinary-leastsquares residuals. 
suggested a structural change in the demand for most food products - in addition to the structural change which was already captured by the switching expenditure parameter. However, that conclusion cannot be accepted. Caution is in order because of the fragility of the inference.

As a reasoning for the fragility acts the confusion in studying the hypothesis of a structural change in the demand for meats in North America. The consumption data implied that consumers had shifted away from red meat (especially beef) toward white meat (especially chicken). The shift started both in the United States and Canada during the latter half of the 1970s (DAHLGRAN 1987, ReYnoldS and GodDARD 1991). The research problem was what caused the shift in meat demand. The competing explanations were (a) that consumer preferences changed due to increased nutritional consciousness of consumers concerned with limiting their intake of fat and cholesterol, or (b) that the shift was due entirely to changes in relative prices and income. The researchers who found structural change in consumer preferences affecting meat consumption in the United States are, for example, Chavas (1983), Moschini and MeILKe (1989), and CHOI and Sosin (1990). The shifting demand structure was accepted in Canada by CHEN and VeEMAN (1991) and Reynolds and Goddard (1991). The estimated joint points suggest an abrupt change of demand regimes in the United States during the years 1975 and 1976 (MosCHINI and MEILKE 1989), whereas the estimated joint points in Canada suggest a gradual structural change adjustment. The change was estimated to have begun in 1975 and completed in 1984 (a transition period of nine years) (REYNOLDS and GODDARD 1991).

The researchers who did not identify structural change to have occurred in meat demand in the United States are, for example, MoschinI and Meilke (1984), Wohlgenant (1985), and DahlGRAN (1987). In Canada, a stable demand structure was accepted by Alston and CHALFAnT (1991a).

Alston and Chalfant (1991a, b) concluded that the presented inference was not valid to support the structural change hypothesis. They at- tributed the differences in results primarily to choices about specification of the functional form of the demand equations. Most of the referred studies (as well as the present study) examined preference changes by testing the stability of the estimated parameters. The fundamental problem in parametric tests for structural change is that the tests are conditional on the joint hypothesis of the functional form and other aspects of the model specification. Parameter instability can arise from all sorts of misspecification. Parametric tests for structural change test for the stability of a particular functional form for demand equations, rather than the unconditional hypothesis that consumption patterns have undergone structural change. The use of an incorrect functional form or some other specification error (for example, omitted variables, incorrect separability structure, endogenous prices, or interacting demand and supply) may, therefore, lead to a false finding of structural change (AlstON and CHALFANT 1991b, EALES and UnNeVEhr 1988, 1993, Dahlgran 1987). In the present study, the indications of structural change in demand were obtained using the same data that were used to estimate the structure. To be able to reject the hypothesis of stable preferences, additional non-sample evidence concerning the functional form of demand equations would be needed.

The misspecification test results were employed when selecting the preferred model specifications (Section 5.1). The results presented in this section acted as performance criteria of the preferred specifications. To sum up, the results indicated that: (a) the dynamic specification was correct; (b) some form of misspecification was detected, for example, one or more omitted variables or incorrect functional form; (c) there was structural change in parameters; (d) the separability structure was not correctly specified, it was questioned at least in Beverages; and (e) since there were very few problems with the endogeneity of group expenditure, the recursive manner in which the group expenditures appeared in the system did not lead to any remarkable misspecification. 


\section{Elasticity estimates}

The estimated models are interpreted by elasticities which are calculated at the means of the input variables over the estimation period (1961$1991)$ and for the last year (1991).

\subsection{Within-group elasticities}

Within-group elasticities, showing the effects within a particular group, with estimates of the standard errors are presented in Table 12. The estimated standard errors provide confidence intervals for the elasticities. If an elasticity lies within two standard errors of being one (zero), it is said that the elasticity does not significantly or statistically, at the 5\% level, differ from unity (zero). The $95 \%$ confidence interval is obtained. Width of the confidence interval describes the preciseness of the elasticity estimate.

\section{Short-run expenditure elasticities}

At the mean values, the highest within-group expenditure responses, around two, were estimated for Food-away-from-Home, Vegetables, and Cheese. At the 1991 values, Cheese was not in that group. At the mean values, Bread and Margarine were inferior goods. Dairy Products, Fresh milk, Carcase Meat, and Fish may also have been inferior goods since their elasticities did not deviate from zero statistically. The expenditure elasticity of Fresh Milk deviated neither from zero nor unity. This may imply that the demand for Fresh Milk did not depend on changes in the total expenditure. In 10 of the 26 cases, the mean expenditure elasticity was not significantly different from unity. Consequently, the budget shares of Non-Durables, Vegetablia, Eggs, all beverages, Flour, Sour Milk and Cream, and Butter did not vary significantly as the total expenditure increased (Table 12).

Over time, expenditure response increased in Sour Milk and Cream, Soft Drinks, and Bread and Cake. In Carcase Meat, Fish, and Margarine the result was less clear, whereas in 11 of the total 17 bundles, the elasticities of which were studied as a function of time, the expenditure response remained about the same or (as in most cases) decreased (Figures 9 to 11).

Concerning the confidence intervals, the developments in the food aggregates diverged from each other. In Food-at-Home, the expenditure response became less clear over time, whereas in Food-away-from-Home the expenditure response became clearer. The expenditure elasticity of Food-at-Home was $1.16 \pm 0.10$ in 1961 and 1.22 \pm 0.16 in 1991 , whereas that of Food-away-fromHome was $3.59 \pm 0.97$ in 1961 and $2.02 \pm 0.37$ in 1991 (Table 13). Still in 1991 - after the opposite developments - the expenditure response of Foodaway-from-Home had a high uncertainty compared to the expenditure response of Food-atHome.

The confidence interval remained about the same over the observation period in Carcase Meat, Fish, and Margarine. The confidence interval widened in Butter, Eggs, Fresh Milk, Hot Drinks, and Flour, implying that the response to changes in the total expenditure became less clear. In nine bundles the confidence interval narrowed over time, and thus the elasticity measure became more useful in analysing the responses to expenditure changes (Figures 9 to 11).

\section{Short-run own-price elasticities}

At the mean values, Services was the only bundle showing a positive own-price response. Besides Services, estimated elasticities for Dairy Products, Eggs, Fresh Milk, Carcase Meat, and Margarine were not significantly different from zero, implying that the price response could have been a positive value. The elasticities for Foodaway-from-Home, Meat Products, Cheese, Sour Milk and Cream, and Butter were close to unity, which implies that a change in the own price might not have affected the expenditure on these particular bundles. 
Table 12. Within-group expenditure and own-price elasticities for the AIDS food demand system (standard errors in parentheses).

\begin{tabular}{|c|c|c|c|c|c|c|c|c|}
\hline \multirow[t]{3}{*}{ Category } & \multicolumn{4}{|c|}{ Expenditure elasticity } & \multicolumn{4}{|c|}{ Uncompensated own-price elasticity } \\
\hline & \multicolumn{2}{|c|}{ Mean } & \multicolumn{2}{|c|}{1991} & \multicolumn{2}{|c|}{ Mean } & \multicolumn{2}{|c|}{1991} \\
\hline & Short run & Long run & Short run & Long run & Short run & Long run & Short run & Long run \\
\hline \multicolumn{9}{|c|}{ Private Consumption (Group 1) } \\
\hline - Food-at-Home & $\begin{array}{l}1.187 \\
(0.061)\end{array}$ & -0.367 & $\begin{array}{l}1.218 \\
(0.081)\end{array}$ & -0.080 & $\begin{array}{c}-0.303 \\
(0.068)\end{array}$ & -0.556 & $\begin{array}{l}-0.070 \\
(0.089)\end{array}$ & -0.303 \\
\hline - Food-away-from-Home & $\begin{array}{c}2.188 \\
(0.186)\end{array}$ & 2.722 & $\begin{array}{l}2.018 \\
(0.187)\end{array}$ & 2.467 & $\begin{array}{l}-1.086 \\
(0.121)\end{array}$ & -1.589 & $\begin{array}{l}-1.079 \\
(0.101)\end{array}$ & -1.562 \\
\hline - Non-Durables & $\begin{array}{l}1.121 \\
(0.130)\end{array}$ & 0.225 & $\begin{array}{c}1.069 \\
(0.144)\end{array}$ & 0.325 & $\begin{array}{c}-0.292 \\
(0.110)\end{array}$ & -0.337 & $\begin{array}{l}-0.198 \\
(0.126)\end{array}$ & -0.259 \\
\hline - Services & $\begin{array}{c}0.487 \\
(0.059)\end{array}$ & 2.404 & $\begin{array}{c}0.627 \\
(0.044)\end{array}$ & 2.220 & $\begin{array}{c}0.040 \\
(0.115)\end{array}$ & -0.945 & $\begin{array}{l}-0.164 \\
(0.088)\end{array}$ & -0.840 \\
\hline \multicolumn{9}{|l|}{ Food-at-Home (Group 2) } \\
\hline - Animalia & $\begin{array}{c}0.782 \\
(0.069)\end{array}$ & 0.691 & $\begin{array}{c}0.926 \\
(0.056)\end{array}$ & 0.859 & $\begin{array}{l}-0.650 \\
(0.088)\end{array}$ & -0.496 & $\begin{array}{l}-0.719 \\
(0.080)\end{array}$ & -0.568 \\
\hline - Beverages & $\begin{array}{l}1.199 \\
(0.083)\end{array}$ & 1.505 & $\begin{array}{l}1.105 \\
(0.079)\end{array}$ & 1.323 & $\begin{array}{l}-0.789 \\
(0.078)\end{array}$ & -1.463 & $\begin{array}{l}-0.761 \\
(0.078)\end{array}$ & -1.411 \\
\hline - Vegetablia & $\begin{array}{c}0.780 \\
(0.112)\end{array}$ & 0.662 & $\begin{array}{c}0.825 \\
(0.067)\end{array}$ & 0.740 & $\begin{array}{c}-0.392 \\
(0.123)\end{array}$ & -0.381 & $\begin{array}{l}-0.448 \\
(0.137)\end{array}$ & -0.451 \\
\hline - Groceries & $\begin{array}{c}1.553 \\
(0.116)\end{array}$ & 1.456 & $\begin{array}{c}1.396 \\
(0.128)\end{array}$ & 1.331 & $\begin{array}{l}-0.513 \\
(0.089)\end{array}$ & -0.470 & $\begin{array}{l}-0.420 \\
(0.102)\end{array}$ & -0.384 \\
\hline \multicolumn{9}{|l|}{ Animalia (Group 31) } \\
\hline - Meat and Fish & $\begin{array}{c}1.444 \\
(0.048)\end{array}$ & & $\begin{array}{c}1.431 \\
(0.050)\end{array}$ & & $\begin{array}{l}-0.720 \\
(0.073)\end{array}$ & & $\begin{array}{l}-0.731 \\
(0.068)\end{array}$ & \\
\hline - Dairy Products & $\begin{array}{c}0.190 \\
(0.097)\end{array}$ & & $\begin{array}{c}0.168 \\
(0.090)\end{array}$ & & $\begin{array}{c}-0.042 \\
(0.079)\end{array}$ & & $\begin{array}{c}-0.017 \\
(0.084)\end{array}$ & \\
\hline - Eggs & $\begin{array}{c}1.007 \\
(0.141)\end{array}$ & & $\begin{array}{l}1.008 \\
(0.174)\end{array}$ & & $\begin{array}{l}-0.153 \\
(0.187)\end{array}$ & & $\begin{array}{c}0.046 \\
(0.239)\end{array}$ & \\
\hline \multicolumn{9}{|l|}{ Beverages (Group 32) } \\
\hline - Alcoholic Drinks & $\begin{array}{c}1.311 \\
(0.164)\end{array}$ & 0.825 & $\begin{array}{l}1.242 \\
(0.134)\end{array}$ & 1.655 & $\begin{array}{l}-0.761 \\
(0.088)\end{array}$ & 2.552 & $\begin{array}{l}-0.841 \\
(0.066)\end{array}$ & 2.551 \\
\hline - Fresh Milk & $\begin{array}{c}0.573 \\
(0.313)\end{array}$ & 0.852 & $\begin{array}{l}0.360 \\
(0.435)\end{array}$ & -0.012 & $\begin{array}{l}-0.368 \\
(0.245)\end{array}$ & -1.664 & $\begin{array}{l}-0.090 \\
(0.322)\end{array}$ & -0.791 \\
\hline - Soft Drinks & $\begin{array}{c}0.637 \\
(0.192)\end{array}$ & 0.587 & $\begin{array}{c}0.743 \\
(0.128)\end{array}$ & 0.868 & $\begin{array}{l}-1.295 \\
(0.106)\end{array}$ & -2.155 & $\begin{array}{l}-1.200 \\
(0.073)\end{array}$ & -2.054 \\
\hline - Hot Drinks & $\begin{array}{c}0.808 \\
(0.250)\end{array}$ & 1.066 & $\begin{array}{c}0.575 \\
(0.536)\end{array}$ & 0.409 & $\begin{array}{l}-0.285 \\
(0.080)\end{array}$ & -0.526 & $\begin{array}{c}0.541 \\
(0.136)\end{array}$ & 0.533 \\
\hline \multicolumn{9}{|l|}{ Vegetablia (Group 33) } \\
\hline - Bread and Cake & $\begin{array}{c}-0.102 \\
(0.138)\end{array}$ & -0.137 & $\begin{array}{c}0.385 \\
(0.104)\end{array}$ & 0.745 & $\begin{array}{c}-0.586 \\
(0.121)\end{array}$ & -1.022 & $\begin{array}{l}-0.986 \\
(0.109)\end{array}$ & -1.744 \\
\hline - Fruits & $\begin{array}{c}1.814 \\
(0.237)\end{array}$ & 2.517 & $\begin{array}{c}1.514 \\
(0.243)\end{array}$ & 4.256 & $\begin{array}{l}-0.729 \\
(0.122)\end{array}$ & -1.762 & $\begin{array}{l}-0.736 \\
(0.148)\end{array}$ & -1.650 \\
\hline - Vegetables & $\begin{array}{c}1.995 \\
(0.238)\end{array}$ & 1.692 & $\begin{array}{l}2.136 \\
(0.213)\end{array}$ & 1.638 & $\begin{array}{l}-0.586 \\
(0.074)\end{array}$ & -0.510 & $\begin{array}{l}-0.580 \\
(0.064)\end{array}$ & -0.528 \\
\hline - Flour & $\begin{array}{c}0.825 \\
(0.400)\end{array}$ & 0.460 & $\begin{array}{c}0.211 \\
(0.469)\end{array}$ & -2.392 & $\begin{array}{l}-0.650 \\
(0.172)\end{array}$ & -2.898 & $\begin{array}{c}-0.380 \\
(0.243)\end{array}$ & -1.547 \\
\hline \multicolumn{9}{|l|}{ Meat and Fish (Group 41) } \\
\hline - Meat Products & $\begin{array}{c}1.694 \\
(0.067)\end{array}$ & 2.104 & $\begin{array}{c}1.653 \\
(0.070)\end{array}$ & 2.026 & $\begin{array}{l}-0.792 \\
(0.111)\end{array}$ & -0.941 & $\begin{array}{c}-0.799 \\
(0.112)\end{array}$ & -0.956 \\
\hline - Carcase Meat & $\begin{array}{c}0.179 \\
(0.137)\end{array}$ & -0.078 & $\begin{array}{c}0.264 \\
(0.105)\end{array}$ & 0.031 & $\begin{array}{l}-0.152 \\
(0.175)\end{array}$ & 0.173 & $\begin{array}{l}-0.233 \\
(0.161)\end{array}$ & 0.071 \\
\hline - Fish & $\begin{array}{c}0.192 \\
(0.239)\end{array}$ & 0.039 & $\begin{array}{c}0.284 \\
(0.184)\end{array}$ & 0.145 & $\begin{array}{l}-0.709 \\
(0.070)\end{array}$ & -0.852 & $\begin{array}{l}-0.737 \\
(0.070)\end{array}$ & -0.884 \\
\hline \multicolumn{9}{|l|}{ Dairy Products (Group 42) } \\
\hline - Cheese & $\begin{array}{l}2.119 \\
(0.270)\end{array}$ & 3.663 & $\begin{array}{l}1.613 \\
(0.183)\end{array}$ & 2.202 & $\begin{array}{l}-0.726 \\
(0.141)\end{array}$ & -1.487 & $\begin{array}{l}-0.921 \\
(0.101)\end{array}$ & -1.114 \\
\hline - Sour Milk and Cream & $\begin{array}{c}0.860 \\
(0.304)\end{array}$ & 2.545 & $\begin{array}{c}0.981 \\
(0.250)\end{array}$ & 2.392 & $\begin{array}{l}-0.606 \\
(0.288)\end{array}$ & -0.672 & $\begin{array}{c}-0.712 \\
(0.235)\end{array}$ & -0.771 \\
\hline - Butter & $\begin{array}{c}1.042 \\
(0.257)\end{array}$ & -2.632 & $\begin{array}{l}1.095 \\
(0.585)\end{array}$ & -1.190 & $\begin{array}{l}-1.010 \\
(0.138)\end{array}$ & -3.050 & $\begin{array}{l}-1.004 \\
(0.306)\end{array}$ & -4.000 \\
\hline - Margarine & $\begin{array}{c}-1.105 \\
(0.326)\end{array}$ & -0.661 & $\begin{array}{c}-1.136 \\
(0.344)\end{array}$ & -0.852 & $\begin{array}{c}-0.387 \\
(0.287)\end{array}$ & -0.762 & $\begin{array}{c}-0.375 \\
(0.285)\end{array}$ & -0.878 \\
\hline
\end{tabular}



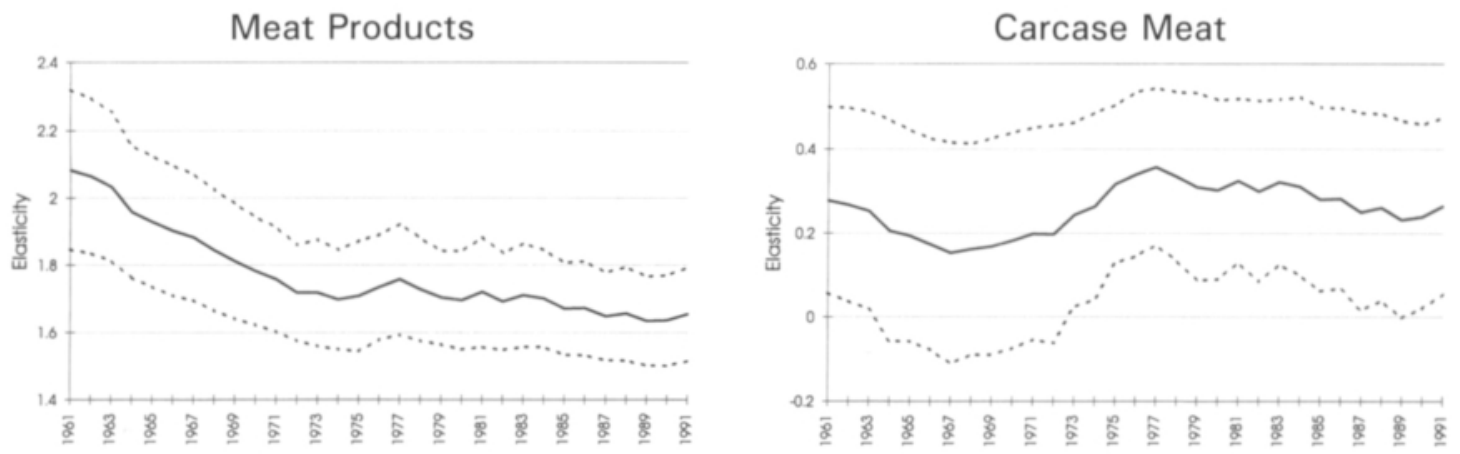

Fish

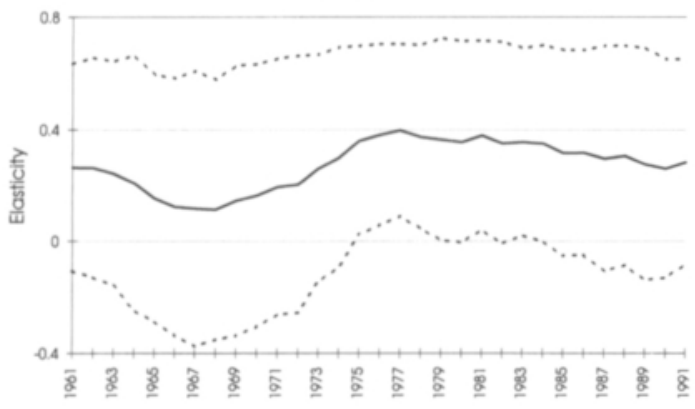

Cheese

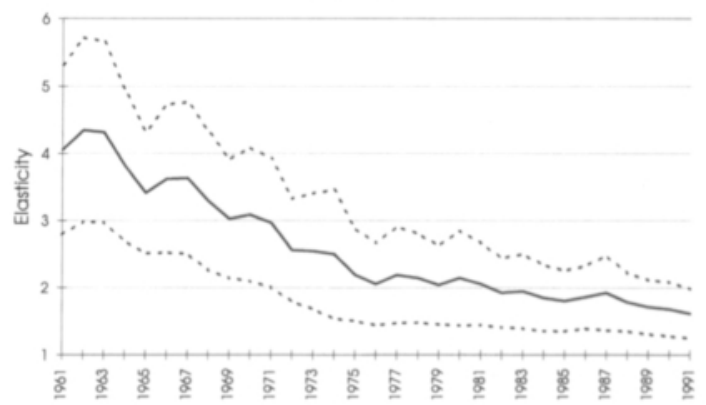

Sour Milk and Cream
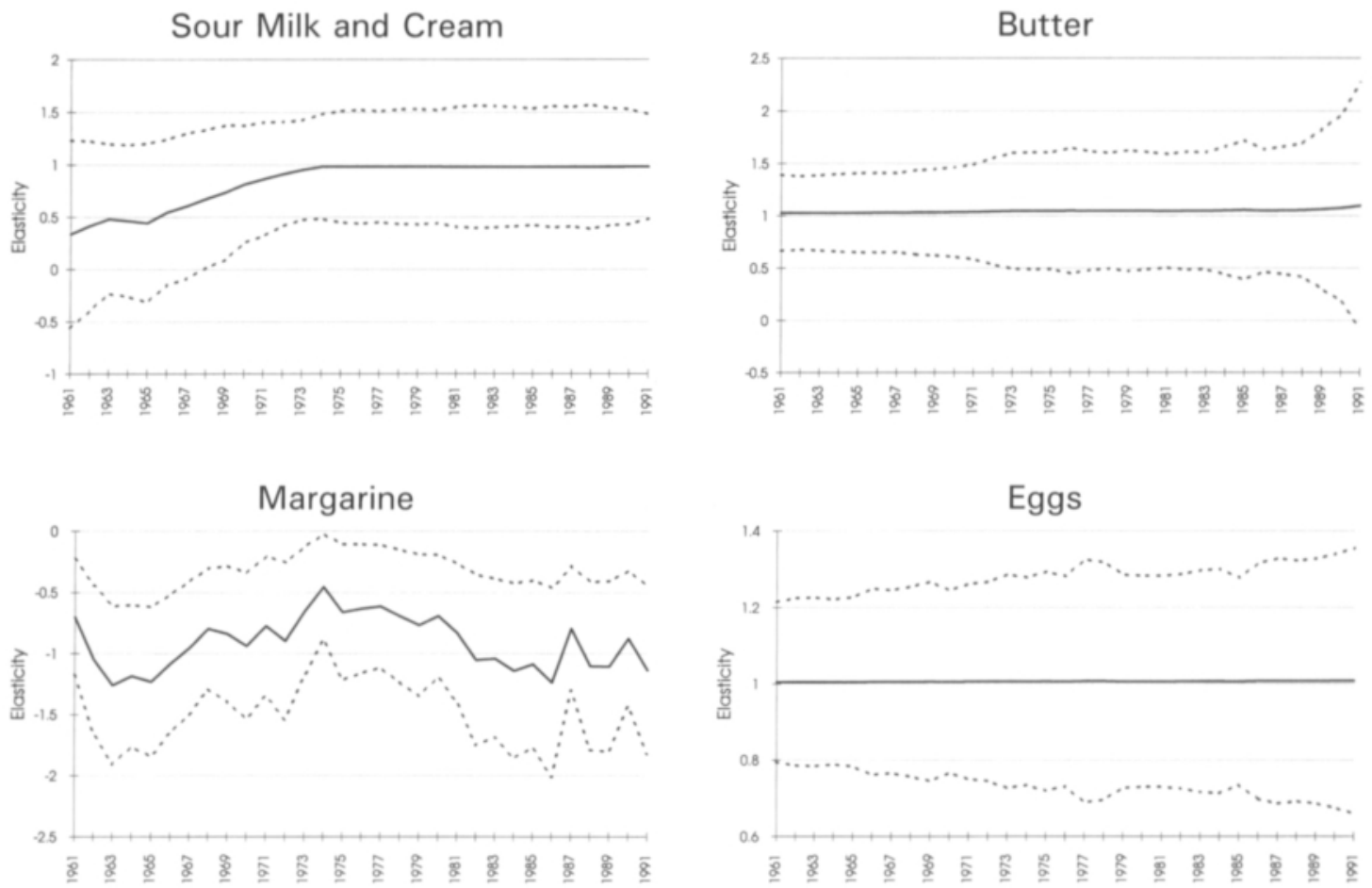

Fig. 9. Within-group expenditure elasticities of Animalia with the 95\% confidence intervals in 1961-1991. 

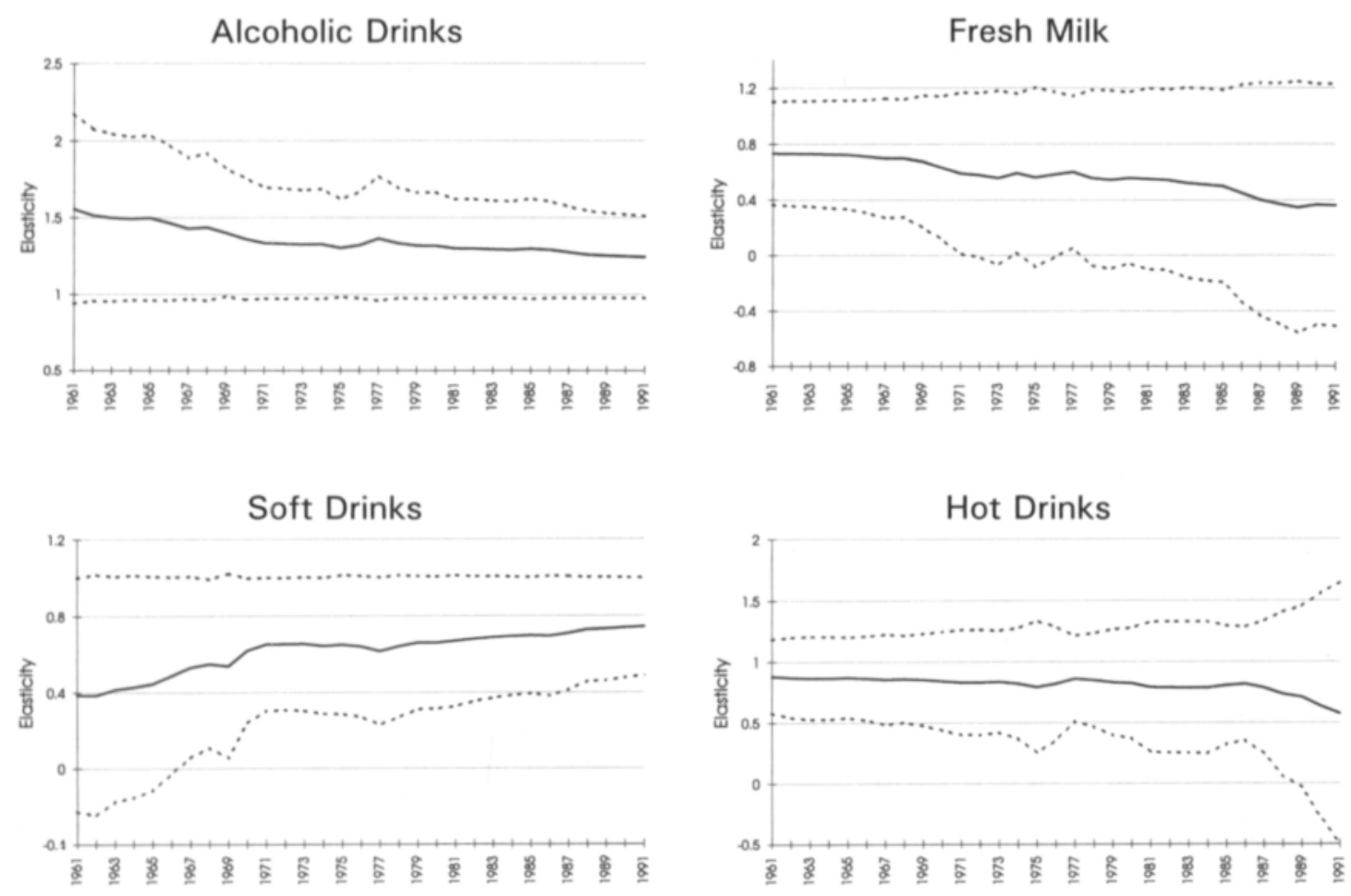

Fig. 10. Within-group expenditure elasticities of Beverages with the 95\% confidence intervals in 1961-1991.

Over time, the negativity of own-price elasticities became less clear. This is actually what one would expect as a consequence of increasing total expenditure. Although in 1991 only Eggs and Hot Drinks showed a positive own-price response, in 10 of the total of 26 bundles the response was not significantly a negative value. Since the confidence intervals did not change on the average, the decrease in the number of significantly negative elasticities was caused by decreased price responses. Especially in Food-at-Home, Eggs, Fresh Milk, Hot Drinks, and Flour, the own price lost part of its relevance as the determinant of demand. In Alcoholic Drinks, Bread and Cake, and Cheese the price became more important over time (Table 12).

The confidence interval of the own-price elasticity widened especially in Fresh Milk, Flour, and Butter, implying a less clear interpretation concerning the own-price response. This was also the case in Food-at-Home. While the price response of Food-at-Home decreased, the confidence interval of the elasticity widened, so that in 1991 the own-price response was no longer statistically different from zero. In Food-awayfrom-Home, Soft Drinks, and Sour Milk and Cream the narrowing confidence regions indicated that the own-price response became a more relevant measure to describe consumer reactions (Tables 12 and 13).

\section{Long-run elasticities}

In Food-at-Home and Non-Durables, the longrun expenditure elasticity was very low compared to the short-run behaviour. Butter turned from expenditure-elastic good into inferior good as the time horizon lengthened. Services, Fruits, Cheese, 

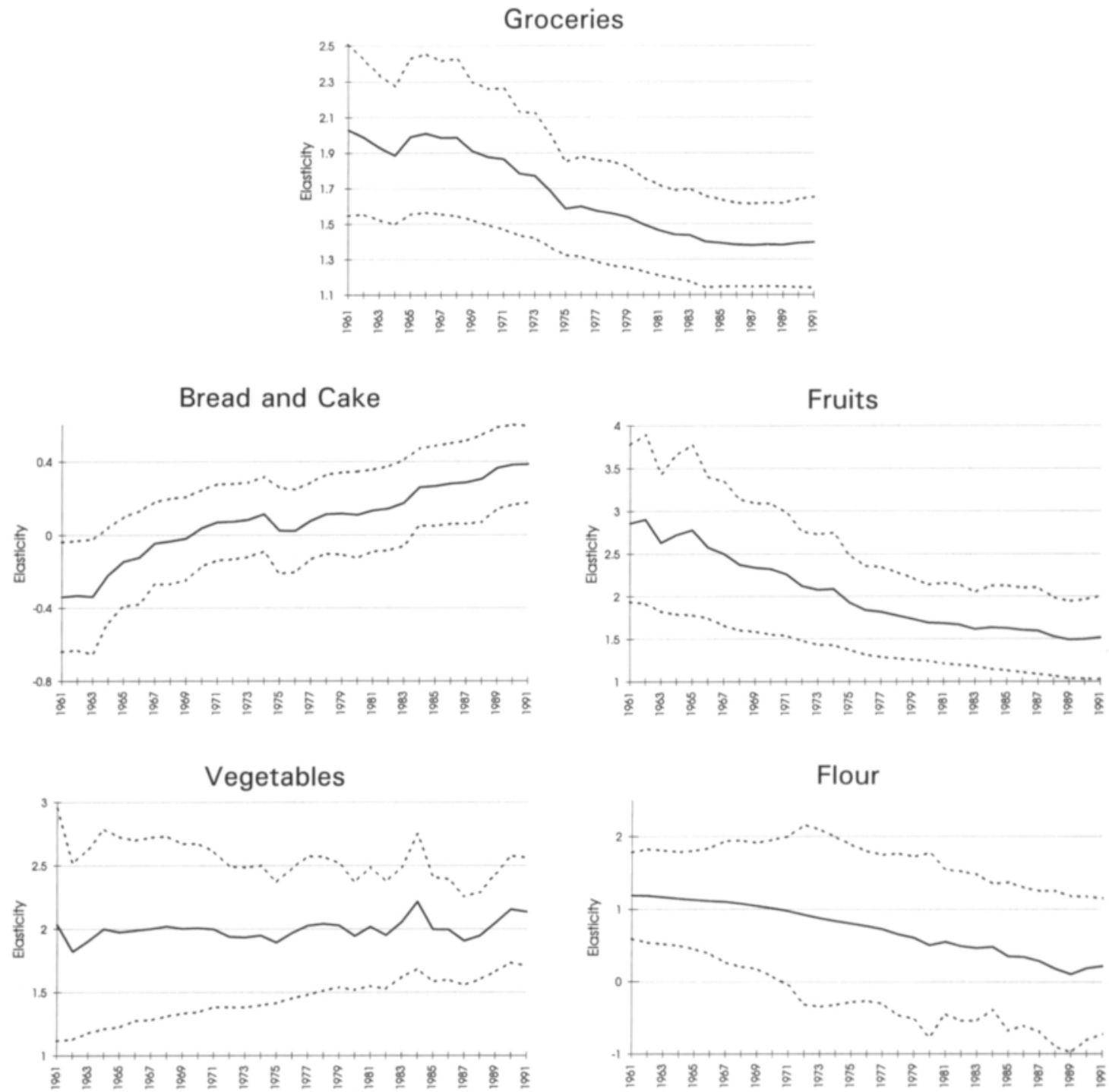

Fig. 11. Within-group expenditure elasticities of Groceries and Vegetablia with the 95\% confidence intervals in 19611991.

and Sour Milk and Cream became highly expenditure-elastic goods in the long run, with elasticities of 2.4 to 3.7 at the mean values (Table 12).

The long-run own-price responses generally increased as the time horizon lengthened. Noteworthy are two exceptions to this rule. The longrun elasticity of Alcoholic Drinks was 2.5, while the short-run elasticity was -0.8 . The elasticity of Carcase Meat changed from -0.2 to 0.2 as the time horizon lengthened. In the long run, Soft Drinks, Flour, and Butter were highly price-elastic goods at the mean values (Table 12).

The AIDS easily leads to unstable long-run elasticities which have high numerical values ( $\mathrm{Sec}-$ tion 4.8). Because this was found to be true in the present analysis, in the subsequent sections the attention is given merely to the short-run elasticities, which are easier to interpret. 
Table 13. Expenditure and uncompensated own-price elasticities for Food-at-Home and Food-away-from-Home in 1961-1991.

\begin{tabular}{|c|c|c|c|c|c|c|c|c|}
\hline \multirow[t]{2}{*}{ Year } & \multicolumn{4}{|c|}{ Food-at-Home } & \multicolumn{4}{|c|}{ Food-away-from-Home } \\
\hline & $\begin{array}{l}\text { Expen- } \\
\text { diture } \\
\text { elasticity }\end{array}$ & $\begin{array}{c}2 * \text { Stan- } \\
\text { dard } \\
\text { error }\end{array}$ & $\begin{array}{c}\text { Lower } \\
\text { confidence } \\
\text { interval }\end{array}$ & $\begin{array}{c}\text { Upper } \\
\text { confidence } \\
\text { interval }\end{array}$ & $\begin{array}{c}\text { Expen- } \\
\text { diture } \\
\text { elasticity }\end{array}$ & $\begin{array}{c}2 * \text { Stan- } \\
\text { dard } \\
\text { error }\end{array}$ & $\begin{array}{c}\text { Lower } \\
\text { confidence } \\
\text { interval }\end{array}$ & $\begin{array}{c}\text { Upper } \\
\text { confidence } \\
\text { interval }\end{array}$ \\
\hline 1961 & 1.16 & 0.10 & 1.06 & 1.26 & 3.59 & 0.97 & 2.61 & 4.56 \\
\hline 1971 & 1.19 & 0.12 & 1.07 & 1.30 & 2.45 & 0.52 & 1.93 & 2.97 \\
\hline 1981 & 1.19 & 0.13 & 1.06 & 1.32 & 2.28 & 0.46 & 1.83 & 2.74 \\
\hline 1991 & 1.22 & 0.16 & 1.06 & 1.38 & 2.02 & 0.37 & 1.64 & 2.39 \\
\hline & $\begin{array}{c}\text { Own- } \\
\text { price } \\
\text { elasticity } \\
\end{array}$ & & & & $\begin{array}{c}\text { Own- } \\
\text { price } \\
\text { elasticity } \\
\end{array}$ & & & \\
\hline 1961 & -0.46 & 0.11 & -0.56 & -0.35 & -1.19 & 0.57 & -1.76 & -0.62 \\
\hline 1971 & -0.36 & 0.13 & -0.49 & -0.23 & -1.12 & 0.31 & -1.43 & -0.81 \\
\hline 1981 & -0.27 & 0.15 & -0.41 & -0.12 & -1.09 & 0.26 & -1.35 & -0.83 \\
\hline 1991 & -0.07 & 0.18 & -0.25 & 0.11 & -1.08 & 0.20 & -1.28 & -0.88 \\
\hline
\end{tabular}

\subsection{Total elasticities}

Besides the effects within the particular group, total elasticities also account for the effects channeled through group expenditures.

\section{Expenditure and own-price elasticities}

At sample means, there were two inferior goods, namely Margarine and Bread and Cake, but in 1991 only Margarine. Most of the bundles were expenditure inelastic. Meat Products, Alcoholic Drinks, Hot Drinks, Groceries, Fruits, Vegetables, and Food-away-from-Home were expenditure elastic. Over time, Hot Drinks became inelastic goods (Table 14).

In general, the estimated own-price elasticities have an acceptable sign. Soft Drinks and Food-away-from-Home were the only elastic categories, whereas the rest of the categories were own-price inelastic. Very small responses were measured in the demand for Fresh Milk, Meat Products, and Carcase Meat. Eggs and Hot Drinks became Giffen goods in 1991 with a positive own-price elasticity. This probably indicates that price became an unimportant deter- minant of the demand for Eggs and Hot Drinks (Table 14).

\section{Cross-price elasticities}

The cross-price elasticities reflect substitute and complement relations. ${ }^{20}$ The elasticities are presented in Tables 15 to 19. The diagonal entries of the tables are estimated own-price elasticities, while the off-diagonal entries are estimated crossprice elasticities. For example, the third row in Table 15 indicates that Non-Durables were complements to Food-at-Home and Services and substitutes for Food-away-from-Home.

Food-at-Home was a complement to Foodaway-from-Home, Non-Durables, and Services. Food-away-from-Home was a complement to Food-at-Home, Non-Durables, and Services. Services were complements to Food-at-Home and Non-

\footnotetext{
${ }^{20}$ Strictly speaking, the relation depends on the sign of the compensated cross-price elasticity. However, uncompensated, rather than compensated, responses are derived from the reality. To avoid confusion between compensated and uncompensated responses, only uncompensated elasticity estimates are presented, and the interpretation is based on them.
} 
Table 14. Total expenditure and own-price elasticities.

\begin{tabular}{|c|c|c|c|c|}
\hline \multirow[t]{2}{*}{ Category } & \multicolumn{2}{|c|}{ Expenditure elasticity } & \multicolumn{2}{|c|}{$\begin{array}{l}\text { Uncompensated own- } \\
\text { price elasticity }\end{array}$} \\
\hline & Mean & 1991 & Mean & 1991 \\
\hline Meat Products & 2.27 & 2.67 & -0.08 & -0.11 \\
\hline Carcase Meat & 0.24 & 0.43 & -0.11 & -0.16 \\
\hline Fish & 0.26 & 0.46 & -0.69 & -0.71 \\
\hline Cheese & 0.37 & 0.31 & -0.20 & -0.27 \\
\hline Sour Milk and Cream & 0.15 & 0.19 & -0.39 & -0.39 \\
\hline Butter & 0.18 & 0.21 & -0.63 & -0.82 \\
\hline Margarine & -0.20 & -0.22 & -0.52 & -0.51 \\
\hline Eggs & 0.93 & 1.14 & -0.13 & 0.07 \\
\hline Alcoholic Drinks & 1.87 & 1.67 & -0.40 & -0.37 \\
\hline Fresh Milk & 0.82 & 0.48 & -0.30 & -0.05 \\
\hline Soft Drinks & 0.91 & 1.00 & -1.28 & -1.16 \\
\hline Hot Drinks & 1.15 & 0.77 & -0.23 & 0.56 \\
\hline Groceries & 1.84 & 1.70 & -0.39 & -0.30 \\
\hline Bread and Cake & -0.09 & 0.39 & -0.61 & -0.87 \\
\hline Fruits & 1.68 & 1.52 & -0.32 & -0.43 \\
\hline Vegetables & 1.85 & 2.15 & -0.32 & -0.28 \\
\hline Flour & 0.76 & 0.21 & -0.54 & -0.36 \\
\hline Food-away-from-Home & 2.19 & 2.02 & -1.09 & -1.08 \\
\hline
\end{tabular}

Durables, and substitutes for Food-away-fromHome. Thus, when the prices of Food-away-fromHome and Services increased (as they generally did over the observation period), the demand for Food-at-Home was pushed downwards. A push upwards for Food-at-Home was given by NonDurables, when their prices decreased (as they generally did). When Food-at-Home and Non-
Durables became cheaper (as they generally did), the demand for Services tended to increase. A further push upwards for Services was given by Food-away-from-Home, which became more expensive. The own-price elasticity of Services was zero, in other categories the elasticities were negative (Table 15).

Table 15. Total expenditure and price elasticities at Stage 1 (Group 1) (standard errors in parentheses). ${ }^{a}$

\begin{tabular}{|c|c|c|c|c|c|c|c|c|c|c|}
\hline \multirow[t]{3}{*}{ Category affected } & \multirow{2}{*}{\multicolumn{2}{|c|}{$\begin{array}{l}\text { Expenditure } \\
\text { elasticity }\end{array}$}} & \multicolumn{8}{|c|}{ Uncompensated price elasticity, category price of which changes } \\
\hline & & & \multicolumn{2}{|c|}{ Food-at-Home } & \multicolumn{2}{|c|}{$\begin{array}{l}\text { Food-away- } \\
\text { from-Home }\end{array}$} & \multicolumn{2}{|c|}{ Non-Durables } & \multicolumn{2}{|c|}{ Services } \\
\hline & Mean & 1991 & Mean & 1991 & Mean & 1991 & Mean & 1991 & Mean & 1991 \\
\hline Food-at-Home & $\begin{array}{c}1.19 \\
(0.06)\end{array}$ & $\begin{array}{c}1.22 \\
(0.08)\end{array}$ & $\begin{array}{c}-0.30 \\
(0.07)\end{array}$ & $\begin{array}{c}-0.07 \\
(0.09)\end{array}$ & $\begin{array}{c}-0.29 \\
(0.04)\end{array}$ & $\begin{array}{c}-0.38 \\
(0.05)\end{array}$ & $\begin{array}{c}-0.19 \\
(0.07)\end{array}$ & $\begin{array}{c}-0.24 \\
(0.09)\end{array}$ & $\begin{array}{c}-0.44 \\
(0.15)\end{array}$ & $\begin{array}{l}-0.57 \\
(0.20)\end{array}$ \\
\hline Food-away-from-Home & $\begin{array}{c}2.19 \\
(0.19)\end{array}$ & $\begin{array}{c}2.02 \\
(0.19)\end{array}$ & $\begin{array}{c}-0.13 \\
(0.17)\end{array}$ & $\begin{array}{c}-0.04 \\
(0.15)\end{array}$ & $\begin{array}{c}-1.09 \\
(0.12)\end{array}$ & $\begin{array}{c}-1.08 \\
(0.10)\end{array}$ & $\begin{array}{c}-0.16 \\
(0.09)\end{array}$ & $\begin{array}{c}-0.13 \\
(0.08)\end{array}$ & $\begin{array}{c}-1.00 \\
(0.28)\end{array}$ & $\begin{array}{l}-0.93 \\
(0.26)\end{array}$ \\
\hline Non-Durables & $\begin{array}{c}1.12 \\
(0.13)\end{array}$ & $\begin{array}{c}1.07 \\
(0.14)\end{array}$ & $\begin{array}{c}-0.20 \\
(0.13)\end{array}$ & $\begin{array}{c}-0.20 \\
(0.15)\end{array}$ & $\begin{array}{c}0.15 \\
(0.08)\end{array}$ & $\begin{array}{c}0.16 \\
(0.08)\end{array}$ & $\begin{array}{c}-0.29 \\
(0.11)\end{array}$ & $\begin{array}{c}-0.20 \\
(0.13)\end{array}$ & $\begin{array}{c}-0.69 \\
(0.27)\end{array}$ & $\begin{array}{l}-0.72 \\
(0.32)\end{array}$ \\
\hline Services & $\begin{array}{c}0.49 \\
(0.06)\end{array}$ & $\begin{array}{c}0.63 \\
(0.04)\end{array}$ & $\begin{array}{c}-0.52 \\
(0.05)\end{array}$ & $\begin{array}{c}-0.45 \\
(0.04)\end{array}$ & $\begin{array}{c}0.21 \\
(0.03)\end{array}$ & $\begin{array}{c}0.18 \\
(0.03)\end{array}$ & $\begin{array}{c}-0.20 \\
(0.05)\end{array}$ & $\begin{array}{c}-0.17 \\
(0.04)\end{array}$ & $\begin{array}{c}0.04 \\
(0.11)\end{array}$ & $\begin{array}{l}-0.16 \\
(0.09)\end{array}$ \\
\hline
\end{tabular}

a column of price elasticities represents the impact of a percentage change in the price of a category, ceteris paribus, on the quantities of categories affected. A row of price elasticities represents the combined effects of percentage changes in the prices of each category on the quantity demanded of the category associated with that row. 
Eggs were complements to Meat and Fish, but Meat and Fish were not complements to Eggs. The interpretation is valid for both the elasticities at the mean values and the 1991 values. Eggs were substitutes for Dairy Products, but Dairy Products were not substitutes for Eggs. The interpretation is the same at the mean values and the 1991 values. Soft Drinks were substitutes for Alcoholic Drinks, but Alcoholic Drinks were not substitutes for Soft Drinks. The behavior was similar both at the mean values and the 1991 values. Consumers substituted between Flour and
Bread and Cake. The consumers were more willing to switch to Flour if Bread and Cake became more expensive, but less eager to switch to Bread and Cake if Flour became more expensive. This asymmetrics was especially clear in 1991. Fresh Milk was a complement to and Vegetables were substitutes for Alcoholic Drinks, but Alcoholic Drinks were not complements to nor substitutes for Fresh Milk and Vegetables. Especially the 1991 elasticities suggest that Fruits were substitutes for Bread and Cake, but not vice versa (Tables 16 and 17).

Table 16. Total [uncompensated] price elasticities at the mean values at Stage 3 (Groups 31, 32, and 33).

\begin{tabular}{|c|c|c|c|c|c|c|c|c|c|c|c|}
\hline \multirow{2}{*}{$\begin{array}{l}\text { Category } \\
\text { affected }^{a}\end{array}$} & \multicolumn{11}{|c|}{ Category price of which changes" } \\
\hline & $\begin{array}{l}\text { Meat } \\
\text { \&Fish }\end{array}$ & Dairy & Eggs & $\begin{array}{c}\text { Alco- } \\
\text { hol }\end{array}$ & $\begin{array}{l}\text { Fresh } \\
\text { Milk }\end{array}$ & $\begin{array}{c}\text { Soft } \\
\text { Drinks }\end{array}$ & $\begin{array}{c}\text { Hot } \\
\text { Drinks }\end{array}$ & $\begin{array}{l}\text { Bread } \\
\& \text { Cake }\end{array}$ & Fruits & $\begin{array}{l}\text { Vege- } \\
\text { tables }\end{array}$ & Flour \\
\hline Meat and Fish & -0.24 & -0.31 & -0.15 & -0.03 & -0.02 & -0.00 & -0.01 & 0.03 & 0.02 & 0.01 & 0.01 \\
\hline Dairy & -0.25 & -0.01 & 0.22 & -0.00 & -0.00 & -0.00 & -0.00 & 0.00 & 0.00 & 0.00 & 0.00 \\
\hline Eggs & -1.08 & 0.59 & -0.13 & -0.02 & -0.01 & -0.00 & -0.01 & 0.02 & 0.01 & 0.01 & 0.01 \\
\hline Alcohol & 0.36 & 0.21 & 0.03 & -0.40 & -0.15 & 0.01 & -0.09 & -0.09 & -0.06 & -0.04 & -0.03 \\
\hline Fresh Milk & 0.16 & 0.09 & 0.01 & -0.40 & -0.30 & 0.28 & -0.04 & -0.04 & -0.02 & -0.02 & -0.01 \\
\hline Soft Drinks & 0.18 & 0.10 & 0.01 & 0.71 & 0.33 & -1.28 & 0.06 & -0.05 & -0.03 & -0.02 & -0.02 \\
\hline Hot Drinks & 0.22 & 0.13 & 0.02 & 0.13 & -0.02 & -0.19 & -0.23 & -0.06 & -0.03 & -0.02 & -0.02 \\
\hline Bread and Cake & 0.02 & 0.01 & 0.00 & -0.02 & -0.01 & -0.00 & -0.01 & -0.61 & -0.10 & -0.04 & 0.42 \\
\hline Fruits & -0.41 & -0.24 & -0.03 & 0.32 & 0.18 & 0.04 & 0.12 & 0.25 & -0.32 & 0.08 & -0.19 \\
\hline Vegetables & -0.45 & -0.27 & -0.04 & 0.35 & 0.20 & 0.05 & 0.13 & -0.48 & 0.33 & -0.32 & -0.22 \\
\hline Flour & -0.19 & -0.11 & -0.02 & 0.15 & 0.08 & 0.02 & 0.05 & 0.67 & 0.00 & -0.00 & -0.54 \\
\hline
\end{tabular}

a The abbreviated notations are Dairy (Dairy Products) and Alcohol (Alcoholic Drinks).

Table 17. Total [uncompensated] price elasticities in 1991 at Stage 3 (Groups 31, 32, and 33).

\begin{tabular}{|c|c|c|c|c|c|c|c|c|c|c|c|}
\hline \multirow{2}{*}{$\begin{array}{l}\text { Category } \\
\text { affected }^{\mathrm{a}}\end{array}$} & \multicolumn{11}{|c|}{ Category price of which changes ${ }^{a}$} \\
\hline & $\begin{array}{l}\text { Meat } \\
\text { \&Fish }\end{array}$ & Dairy & Eggs & $\begin{array}{c}\text { Alco- } \\
\text { hol }\end{array}$ & $\begin{array}{l}\text { Fresh } \\
\text { Milk }\end{array}$ & $\begin{array}{c}\text { Soft } \\
\text { Drinks }\end{array}$ & $\begin{array}{c}\text { Hot } \\
\text { Drinks }\end{array}$ & $\begin{array}{l}\text { Bread } \\
\& \text { Cake }\end{array}$ & Fruits & $\begin{array}{l}\text { Vege- } \\
\text { tables }\end{array}$ & Flour \\
\hline Meat and Fish & -0.21 & -0.27 & -0.14 & 0.03 & 0.01 & 0.00 & 0.00 & 0.06 & 0.04 & 0.03 & 0.02 \\
\hline Dairy & -0.26 & 0.01 & 0.22 & 0.00 & 0.00 & 0.00 & 0.00 & 0.01 & 0.00 & 0.00 & 0.00 \\
\hline Eggs & -1.37 & 0.70 & 0.07 & 0.02 & 0.00 & 0.00 & 0.00 & 0.04 & 0.03 & 0.02 & 0.01 \\
\hline Alcohol & 0.47 & 0.24 & 0.03 & -0.37 & -0.10 & 0.03 & -0.07 & -0.04 & -0.03 & -0.02 & -0.01 \\
\hline Fresh Milk & 0.14 & 0.07 & 0.01 & -0.63 & -0.05 & 0.43 & -0.16 & -0.01 & -0.01 & -0.01 & -0.00 \\
\hline Soft Drinks & 0.28 & 0.15 & 0.02 & 0.69 & 0.24 & -1.16 & 0.02 & -0.03 & -0.02 & -0.01 & -0.01 \\
\hline Hot Drinks & 0.22 & 0.11 & 0.01 & 0.06 & -0.23 & -0.42 & 0.56 & -0.02 & -0.01 & -0.01 & -0.01 \\
\hline Bread and Cake & -0.07 & -0.03 & -0.00 & 0.11 & 0.03 & 0.01 & 0.01 & -0.87 & 0.05 & 0.05 & 0.35 \\
\hline Fruits & -0.26 & -0.14 & -0.01 & 0.42 & 0.10 & 0.05 & 0.05 & 0.64 & -0.43 & 0.02 & -0.25 \\
\hline Vegetables & -0.37 & -0.19 & -0.02 & 0.59 & 0.14 & 0.08 & 0.07 & -0.30 & 0.24 & -0.28 & -0.33 \\
\hline Flour & -0.04 & -0.02 & -0.00 & 0.06 & 0.01 & 0.01 & 0.01 & 1.09 & -0.16 & -0.17 & -0.36 \\
\hline
\end{tabular}

a The abbreviated notations are Dairy (Dairy Products) and Alcohol (Alcoholic Drinks). 
Table 18. Total expenditure and price elasticities for Meat and Fish (Group 41).

\begin{tabular}{|c|c|c|c|c|c|c|c|c|}
\hline \multirow[t]{3}{*}{$\begin{array}{l}\text { Category } \\
\text { affected }\end{array}$} & \multicolumn{2}{|c|}{$\begin{array}{l}\text { Expenditure } \\
\text { elasticity }\end{array}$} & \multicolumn{6}{|c|}{$\begin{array}{l}\text { Uncompensated price elasticity, category price } \\
\text { of which changes }\end{array}$} \\
\hline & \multirow[b]{2}{*}{ Mean } & \multirow[b]{2}{*}{1991} & \multicolumn{2}{|c|}{ Meat Products } & \multicolumn{2}{|c|}{ Carcase Meat } & \multicolumn{2}{|c|}{ Fish } \\
\hline & & & Mean & 1991 & Mean & 1991 & Mean & 1991 \\
\hline Meat Products & 2.27 & 2.67 & -0.08 & -0.11 & -0.26 & -0.19 & -0.07 & -0.05 \\
\hline Carcase Meat & 0.24 & 0.43 & -0.17 & -0.11 & -0.11 & -0.16 & 0.23 & 0.21 \\
\hline Fish & 0.26 & 0.46 & -0.17 & -0.11 & 0.81 & 0.76 & -0.69 & -0.71 \\
\hline
\end{tabular}

Table 19. Total expenditure and price elasticities for Dairy Products (Group 42).

\begin{tabular}{|c|c|c|c|c|c|c|c|c|c|c|}
\hline \multirow{3}{*}{$\begin{array}{l}\text { Category } \\
\text { affected }\end{array}$} & \multirow{2}{*}{\multicolumn{2}{|c|}{$\begin{array}{l}\text { Expenditure } \\
\text { elasticity }\end{array}$}} & \multicolumn{8}{|c|}{ Uncompensated price elasticity, category price of which changes } \\
\hline & & & \multicolumn{2}{|c|}{ Cheese } & \multicolumn{2}{|c|}{$\begin{array}{l}\text { Sour Milk } \\
\text { and Cream }\end{array}$} & \multicolumn{2}{|c|}{ Butter } & \multicolumn{2}{|c|}{ Margarine } \\
\hline & Mean & 1991 & Mean & 1991 & Mean & 1991 & Mean & 1991 & Mean & 1991 \\
\hline Cheese & 0.37 & 0.31 & -0.20 & -0.27 & 0.43 & 0.46 & 0.43 & 0.20 & -0.33 & -0.14 \\
\hline Sour Milk and Cream & 0.15 & 0.19 & 0.08 & 0.30 & -0.39 & -0.39 & 0.07 & -0.07 & 0.01 & 0.00 \\
\hline Butter & 0.18 & 0.21 & 0.04 & -0.07 & 0.16 & 0.11 & -0.63 & -0.82 & 0.39 & 0.73 \\
\hline Margarine & -0.20 & -0.22 & 0.10 & 0.25 & -0.56 & -0.57 & 0.84 & 0.67 & -0.52 & -0.51 \\
\hline
\end{tabular}

Between Meat Products and Carcase Meat, the cross-price effects were small. Fish was a substitute for Carcase Meat. Thus, consumers switched to Fish if Carcase Meat became more expensive. The process went the other way less efficiently: consumers were less willing to switch to Carcase Meat when Fish became more expensive (Table 18).

Cheese was a substitute for Sour Milk and Cream, but Sour Milk and Cream were substitutes for Cheese only in 1991. Consumers shifted from Butter to Cheese, but Butter was not a substitute for Cheese. Butter and Margarine were substitutes for each other, which implies that consumers substituted to the fat the price of which decreased. For Margarine, the price of Butter was more important than its own price, while for Butter its own price was more important. Margarine was a complement to Sour Milk and Cream, but the opposite was not true (Table 19).

\subsection{Elasticities compared with elasticities obtained in other studies}

The elasticity estimates obtained in the present study are compared to those obtained in other studies. To make the results more comparable, cited are only studies that employ expenditure data. One exception is made: Rouniainen (1979) will be cited to provide an example of elasticities obtained by using disappearance data.

From the present study, total elasticities at mean values are reported. Total elasticities are also reported from other studies when they are available. All the reported elasticities obtained in Finland are total elasticities (simply because the studies employed single equation models and used the total income or expenditure as the expenditure variable, or, alternatively, first-stage results from a system analysis are cited). 
Table 20. Demand elasticities of Food-at-Home and Food-away-from-Home: a comparison between the present study and other Finnish studies.

\begin{tabular}{|c|c|c|c|c|c|}
\hline \multirow[t]{2}{*}{ Study } & \multirow[t]{2}{*}{ Model and data } & \multicolumn{2}{|c|}{ Food-at-Home } & \multicolumn{2}{|c|}{$\begin{array}{l}\text { Food-away- } \\
\text { from-Home }\end{array}$} \\
\hline & & $E_{i}$ & $e_{i i}$ & $E_{i}$ & $e_{i i}$ \\
\hline Present study & AIDS, NA:1960-91 & 1.19 & -0.30 & 2.19 & -1.09 \\
\hline KAARLEHTO (1961) & Single eq., budget: $1955 / 56$ & & & 0.83 & \\
\hline MARJOMAA (1969) & $\begin{array}{l}\text { Single eq., NA:1948-64, } \\
\text { budget: } 1955 / 56,59 / 60\end{array}$ & $0.55^{b}$ & & & \\
\hline VIRÉN (1983) & LES, NA:1960-81 & $0.58^{c}$ & $-0.50^{c}$ & & \\
\hline LAURILA (1985) & Single eq., NA:1964-75 & $0.49^{d}$ & $-0.41^{\mathrm{d}}$ & & \\
\hline MELLIN (1985) & Single eq., NA: $1950-78$ & $0.75^{c}$ & $-0.19^{c}$ & & \\
\hline
\end{tabular}

a The abbreviated notations are $E_{i}$ (expenditure elasticity), $e_{u}$ (uncompensated own-price elasticity), NA (National Accounts), budget (household budget data), single eq. (single equation model), LES (linear expenditure system).

${ }^{b}$ Excludes alcoholic drinks; average of two estimates.

"Includes tobacco; average of two estimates.

${ }^{\mathrm{d}}$ Excludes alcoholic drinks and soft drinks; average of two estimates.

\section{Food-at-Home and Food-away-from-Home}

The expenditure elasticity of Food-at-Home obtained in the present study is relatively high, both in a national and international comparison. The estimated elasticities range from 0.6 to 0.7 in France, Italy, and Ireland, whereas the estimates in the Netherlands, Belgium, Denmark, Germany, and the United Kingdom are even lower (Table 20, Michalek and Keyzer 1992). An estimate of 0.9 was obtained in Germany using a different data set (GolLnick 1975). A partial explanation for the relatively high expenditure elasticity of Food-at-Home obtained in the present study is that Alcoholic Drinks were included in Food-at-Home. Instead, for example in the European comparison (MichaleK and Keyzer 1992) Alcoholic Drinks were not included in Food-atHome. In Finland, Alcoholic Drinks have a big share in Food-at-Home ( $22 \%$ in 1991) and a high expenditure elasticity (1.7 in 1991).

The obtained own-price elasticity of Food-atHome is comparable with other Finnish studies, and also with the results obtained in other countries. In France, Italy, the United Kingdom, Belgium, and Canada the estimated response ranged from -0.1 to -0.2 , whereas in the Netherlands, Denmark, Germany, and Ireland the response ranged from -0.4 and -0.6 (MICHALEK and KEYZER 1992, GODDARD 1983).

The expenditure and own-price elasticities of Food-away-from-Home obtained in the present study are high compared to the elasticities obtained in Canada, where the expenditure elasticities ranged from 1.0 to 1.4 and the own-price elasticities ranged from -0.3 to -0.8 (GODDARD 1983).

\section{Beverages}

The expenditure elasticities of Alcoholic Drinks and Soft Drinks obtained in the present study correspond well with former Finnish studies. Relatively elastic demand was obtained in Fresh Milk and Hot Drinks. The discrepancy in Fresh Milk is partly explained by the difference in the composition of the bundle. Unlike the present study, the fresh milk of Marjomaa and Laurila included sour milk and cream.

In Soft Drinks and Hot Drinks, the own-price elasticities obtained in the present study are similar to those obtained by Mellin. On the basis of 
Table 21. Demand elasticities of Beverages: a comparison between the present study and other Finnish studies."

\begin{tabular}{|c|c|c|c|c|c|c|c|c|c|}
\hline \multirow[t]{2}{*}{ Study } & \multirow[t]{2}{*}{ Model and data } & \multicolumn{2}{|c|}{ Alcoholic Drinks } & \multicolumn{2}{|c|}{ Fresh Milk } & \multicolumn{2}{|c|}{ Soft Drinks } & \multicolumn{2}{|c|}{ Hot Drinks } \\
\hline & & $E_{i}$ & $e_{i i}$ & $E_{i}$ & $e_{i i}$ & $E_{i}$ & $e_{i i}$ & $E_{i}$ & $e_{i i}$ \\
\hline Present study & $\begin{array}{l}\text { AIDS, } \\
\text { NA: } 1960-91\end{array}$ & 1.87 & -0.40 & 0.82 & -0.30 & 0.91 & -1.28 & 1.15 & -0.23 \\
\hline KAARLEHTO (1961) & $\begin{array}{l}\text { Single eq., } \\
\text { budget: } 1955 / 56\end{array}$ & 1.03 & & & & 0.37 & & & \\
\hline MARJOMAA (1969) & $\begin{array}{l}\text { Single eq., } \\
\text { NA:1948-64, } \\
\text { budget:1955/56, } \\
59 / 60\end{array}$ & $0.9^{c}$ & & $0.4^{b c}$ & & $0.45^{\mathrm{c}}$ & & $0.85^{\mathrm{c}}$ & \\
\hline VIRÉN (1983) & $\begin{array}{l}\text { Single eq., } \\
\text { NA:1950-81 }\end{array}$ & 1.39 & -1.08 & & & 1.57 & -1.69 & 0.75 & -0.48 \\
\hline LAURILA (1985) & $\begin{array}{l}\text { Single eq., } \\
\text { NA:1964-75 }\end{array}$ & 1.97 & -0.70 & $0.19^{b}$ & $-0.47^{\mathrm{b}}$ & 1.41 & -2.12 & 0.57 & -0.25 \\
\hline MELLIN (1985) & $\begin{array}{l}\text { Single eq., } \\
\text { NA:1950-78 }\end{array}$ & $1.61^{\mathrm{c}}$ & $-0.77^{c}$ & & & $1.33^{c}$ & $-1.33^{c}$ & $0.62^{c}$ & -0.26 \\
\hline
\end{tabular}

a The abbreviated notations are $E_{i}$ (expenditure elasticity), $e_{i i}$ (uncompensated own-price elasticity), NA (National Accounts), Single eq. (single equation model), budget (household budget data).

${ }^{\mathrm{b}}$ Includes sour milk and cream. In the present study, estimated $E_{i}$ and $e_{i i}$ for Sour Milk and Cream are 0.15 and -0.39 , respectively.

${ }^{\mathrm{c}}$ Average of two elasticity estimates.

the present study, demand for Alcoholic Drinks is more inelastic than in the cited studies (Table 21).

Compared with the results obtained in the present study, in Germany the demand for Alcoholic Drinks was estimated to be less sensitive to changes in the total expenditure (elasticity of 1.1), and more sensitive to changes in own price (elasticity of -0.5). In Soft Drinks the expenditure elasticity obtained in the present study is similar to that obtained in Germany (GoLLNICK 1975).

In a European comparison, the expenditure elasticity of Hot Drinks obtained in the present study corresponds with the results obtained in Ireland. In other Western European countries the estimated response is inelastic (Michalek and KeYZer 1992, GollnICK 1975). The obtained own-price elasticity corresponds with the elasticities obtained in Belgium, Italy, and France. In the Netherlands, the United Kingdom, and Ireland the response was about double (i.e. between -0.4 to -0.6 ), whereas the estimate obtained in the United States was even higher $(-1.1)$ (Michalek and KeYZer 1992, HeIEN and Wessells 1988).
A wide range is characteristics to the estimated demand elasticities of milk in the United States. The estimated expenditure elasticities range from -0.6 to 0.8 , and the own-price elasticities from -0.1 to -1.6 (a survey by HAIDACHER 1992, HeIEN and Wessells 1988). The own-price elasticities of Fresh Milk obtained in Finland correspond well with those obtained in Canada $(-0.4)$, Australia (-0.3), and New Zealand (-0.5) (GRIFFITH et al. 1992).

\section{Vegetablia}

The estimated expenditure elasticities of demand for cereals in Finland show a lot of variation. The composition of the categories in Marjomaa's and Laurila's studies equaled the categories used in the present study. The comparison shows that an expenditure response close to zero in Bread and Cake was obtained only in the present study, whereas Marjomaa and Laurila obtained responses of 1.0 and 0.5 , respectively. The estimated price responses are more comparable. The de- 
Table 22. Demand elasticities of Vegetablia: a comparison between the present study and other Finnish studies. ${ }^{a}$

\begin{tabular}{|c|c|c|c|c|c|c|c|}
\hline \multirow[t]{2}{*}{ Study } & \multirow[t]{2}{*}{ Model and data } & \multicolumn{2}{|c|}{ Bread and Cake } & \multicolumn{2}{|c|}{ Fruits } & \multicolumn{2}{|c|}{ Flour } \\
\hline & & $E i$ & $e_{i i}$ & $E i$ & $e_{i i}$ & $E i$ & $e_{i i}$ \\
\hline Present study & AIDS, NA:1960-91 & -0.09 & -0.61 & 1.68 & -0.32 & 0.76 & -0.54 \\
\hline KAARLEHTO (1961) & Single eq., budget:1955/56 & $0.21^{\mathrm{b}}$ & & & & & \\
\hline MARJOMAA (1969) & $\begin{array}{l}\text { Single eq., NA:1948-64, } \\
\text { budget: } 1955 / 56,59 / 60\end{array}$ & $1.00^{\mathrm{c}}$ & & $0.65^{\mathrm{c}}$ & & $-0.60^{c}$ & \\
\hline RoUHIAINEN (1979) & $\begin{array}{l}\text { Single eq., disappearance } \\
\text { data: } 1950-77\end{array}$ & $-0.35^{b}$ & $-0.15^{b}$ & 1.30 & -0.30 & & \\
\hline VIRÉN (1983) & Single eq., NA: $1950-81$ & $0.16^{\mathrm{b}}$ & $-0.16^{b}$ & & & & \\
\hline LAURILA (1985) & Single eq., NA:1964-75 & 0.53 & -0.63 & 0.93 & -0.61 & -1.07 & -0.30 \\
\hline Mellin (1985) & Single eq., NA: $1950-78$ & $0.40^{b}$ & $-0.29^{b c}$ & & & & \\
\hline
\end{tabular}

a The abbreviated notations are $E_{i}$ (expenditure elasticity), $e_{i i}$ (uncompensated own-price elasticity), NA (National Accounts), Single eq. (single equation model), budget (household budget data).

${ }^{\mathrm{b}}$ Covers bread, cake, and flour.

${ }^{c}$ Average of two elasticity estimates.

mand elasticities of Fruits obtained in the present study are similar to those obtained by Rouhiainen (Table 22).

The expenditure elasticity of Bread and Cake obtained in the present study corresponds well with the results obtained in Belgium, Denmark, Germany, the United Kingdom, Italy (between 0.0 and 0.1 ), and the United States (between -0.3 and 0.2 ). The expenditure elasticities of 0.4 , estimated in the Netherlands and Canada, and 1.1, estimated in Ireland, are higher than the elasticity obtained in the present study. The own-price elasticity of Bread and Cake obtained in the present study is comparable with the elasticities obtained in Ireland, France, Canada $(-0.6)$, and the United States (between -0.4 and -0.8 ) (Michalek and KeYZer 1992, Fulponi 1989, SAFYURTLU et al. 1986, BLANCIFORTI and GREEN 1983b, HuANG and HaIDACHER 1983). Noteworthy is, however, that all the referred foreign studies combined bread, cake, and flour.

The expenditure elasticity of Fruits obtained in the present study is higher than the elasticities obtained in the United States (between -0.6 to $1.0)$ and Germany (1.0), whereas the own-price elasticity obtained in the present study is smaller than the elasticities obtained in the United States (between -0.4 to -0.8$)$ and Germany $(-0.5)$
(HeIEN and Wessells 1988, HuANG and HaidACHER 1983, GOLLNICK 1975).

\section{Meat and Fish}

The expenditure elasticity of Meat Products obtained in the present study is high related to the former studies in Finland. The comparison is, however, difficult because meat products and carcase meat are often joined together. The expenditure elasticity of Fish obtained in the present study is comparable with the estimates obtained by Kaarlehto and Marjomaa. The own-price elasticity of Fish obtained in the present study is comparable with the elasticities obtained by Virén and Mellin (Table 23).

International comparison of the demand elasticities for meat is difficult because all cited studies combined meat products and carcase meat. On the basis of the present study, the expenditure elasticity of combined meat is well over one in Finland. That is more than the elasticities obtained in the United States (1.1), Italy (0.9), and France (0.7). In the Netherlands, Belgium, Denmark, Germany, the United Kingdom, and Ireland, the estimated elasticities ranged from 0.0 to 0.4 . The ownprice elasticity of meat obtained in the present study is comparable with the elasticities obtained in 
Table 23. Demand elasticities of Meat and Fish: a comparison between the present study and other Finnish studies.

\begin{tabular}{|c|c|c|c|c|c|c|c|}
\hline \multirow[t]{2}{*}{ Study } & \multirow[t]{2}{*}{ Model and data } & \multicolumn{2}{|c|}{ Meat Products } & \multicolumn{2}{|c|}{ Carcase Meat } & \multicolumn{2}{|c|}{ Fish } \\
\hline & & $E_{i}$ & $e_{i i}$ & $E_{i}$ & $e_{i i}$ & $E_{i}$ & $e_{i i}$ \\
\hline Present study & AIDS, NA:1960-91 & 2.27 & -0.08 & 0.24 & -0.11 & 0.26 & -0.69 \\
\hline KAARLEHTO (1961) & Single eq., budget:1955/56 & $0.31^{\mathrm{b}}$ & & & & 0.27 & \\
\hline MARJOMAA (1969) & $\begin{array}{l}\text { Single eq., NA:1948-64, } \\
\text { budget:1955/56, 59/60 }\end{array}$ & $1.60^{c}$ & & $<0$ & & $0.20^{c}$ & \\
\hline RouHIAINEN (1979) & $\begin{array}{l}\text { Single eq., disappearance } \\
\text { data: } 1950-77\end{array}$ & $1.10^{\mathrm{bc}}$ & $-0.75^{b c}$ & & & 0.70 & 0.00 \\
\hline VIRÉN (1983) & Single eq., NA: $1950-81$ & & & & & 0.66 & -0.56 \\
\hline LAURILA (1985) & Single eq., NA:1964-75 & 0.85 & 0.36 & 1.31 & -1.27 & 0.86 & -1.22 \\
\hline MELLIN (1985) & Single eq., NA: $1950-78$ & $0.93^{b}$ & & & & $0.47^{c}$ & -0.50 \\
\hline
\end{tabular}

a The abbreviated notations are $E_{i}$ (expenditure elasticity), $e_{i j}$ (own-price elasticity), NA (National Accounts), Single eq. (single equation model), budget (household budget data).

${ }^{\mathrm{b}}$ Refers to the total meat, which covers both meat products and carcase meat.

'Average of two elasticity estimates.

France, Ireland, the United Kingdom, and the Netherlands (between -0.1 and -0.3 ) (HEIEN and Wessells 1988, MichaleK and Keyzer 1992).

The expenditure elasticity of Fish obtained in the present study is higher than the elasticities obtained in the Netherlands, the United Kingdom, and Germany (Michalek and Keyzer) (close to zero) but lower than the elasticities obtained in Denmark, Belgium, Italy, and Germany (Gollnick) (between 0.3 and 0.6). The own-price elasticities of Fish obtained in Belgium, Denmark, the United Kingdom, Ireland, and Germany (between -0.6 and -0.8 ) compare well with the elasticity obtained in the present study (MichaleK and KEYZER 1992, GolLNICK 1975).

\section{Dairy Products}

The expenditure elasticity of Cheese obtained in the present study is lower than the elasticities obtained in the former Finnish studies. The expenditure elasticity of Butter obtained in the present study is comparable with that obtained by Kaarlehto (Table 24).

A wide range is characteristics to the elasticity estimates of dairy products obtained in the United States. The expenditure elasticity of Cheese has ranged from -0.8 to 1.0 in different studies, whereas the own-price elasticity of Cheese has ranged from -0.3 to -0.9 (a survey by HAIDACHER 1992, HeIEN and Wessells 1988). The estimated expenditure elasticity of Cheese in the United Kingdom (0.2) is lower than that obtained in the present study. The own-price elasticity of Cheese estimated in Australia $(-0.1)$ is close to that obtained in the present study, whereas the estimate of -1.2 implies a price-elastic Cheese demand in the United Kingdom (GRIFFITH et al. 1992, MAFF 1990).

The variation in the estimated expenditure elasticities of Butter range from -2.3 to 1.1 in the United States, whereas the own-price elasticities range from -0.2 to -1.9 . In Germany, Butter was estimated to be an inferior good, whereas in the United Kingdom, a zero expenditure elasticity was obtained (HAIDACHer 1992, HeIEN and Wessells 1988, GolLniCK 1975, MAFF 1990).

The estimated own-price elasticities of Butter in the United Kingdom, Australia, New Zealand, and Canada (between -0.5 and -0.9 ) are comparable with the elasticity obtained in the present study, whereas the estimation in Germany $(-1.2)$ implies that the demand for Butter was priceelastic there (GRIFFITH et al. 1992, MAFF 1990, GOLLNICK 1975).

The expenditure elasticity of Margarine obtained in the United Kingdom (-0.4) implies a higher inferiority than the inferiority obtained in 
Table 24. Demand elasticities of Dairy Products: a comparison between the present study and other Finnish studies. ${ }^{a}$

\begin{tabular}{|c|c|c|c|c|c|c|c|}
\hline \multirow[t]{2}{*}{ Study } & \multirow[t]{2}{*}{ Model and data } & \multicolumn{2}{|c|}{ Cheese } & \multicolumn{2}{|c|}{ Butter } & \multicolumn{2}{|c|}{ Margarine } \\
\hline & & $E_{i}$ & $e_{i i}$ & $E_{i}$ & $e_{i i}$ & $E_{i}$ & $e_{i i}$ \\
\hline Present study & AIDS, NA:1960-91 & 0.37 & -0.20 & 0.18 & -0.63 & -0.20 & -0.52 \\
\hline KAARLEHTO (1961) & Single eq., budget: $1955 / 56$ & & & 0.12 & & & \\
\hline MARJOMAA (1969) & $\begin{array}{l}\text { Single eq., NA:1948-64, } \\
\text { budget: } 1955 / 56,59 / 60\end{array}$ & $0.70^{b}$ & & & & & \\
\hline ROUHIAINEN (1979) & $\begin{array}{l}\text { Single eq., disappearance } \\
\text { data: } 1950-77\end{array}$ & 1.50 & 0.00 & -0.90 & -0.20 & 0.65 & -0.05 \\
\hline LAURILA (1985) & Single eq., NA:1964-75 & 0.80 & -0.84 & & & & \\
\hline
\end{tabular}

a The abbreviated notations are $E_{i}$ (expenditure elasticity), $e_{i i}$ (own-price elasticity), NA (National Accounts), Single eq. (single equation model), budget (household budget data).

${ }^{\mathrm{b}}$ Average of two elasticity estimates.

the present study. Part of the own-price elasticities of Margarine obtained in the United Kingdom (ranging from -0.2 to -0.7 ) are comparable with the elasticity obtained in the present study, whereas the estimate of -0.3 in the United States is lower than that obtained in the present study (MAFF 1990, Williams 1992, HeiEn and Wessells 1988).

The cross-price elasticities of demand for Butter and Margarine were relatively high in Finland. Butter's response to a price change of Margarine was between 0.2 and 0.3 in the United Kingdom, whereas in the present study the response was 0.4. Margarine's response to a price change of Butter was between 0.3 and 0.8 in the United Kingdom, whereas in the present study the response was 0.8 (WILLIAMS 1992).

\section{Eggs and Groceries}

The expenditure elasticity of Eggs obtained in the present study $(0.9)$ is higher than the elasticities previously obtained in Finland (between 0.4 and 0.8$)$, the United States $(-0.1)$, and Canada (0.3). The own-price elasticities of Eggs obtained in different studies correspond well: in addition to the present study, an estimate of -0.1 has been obtained in Finland, the United States, and Canada (MarjomaA 1969, Rouhiainen 1979, LaurI-
LA 1985, HUANG and HAIDACHER 1983, SAFYURTLU et al. 1986). The estimate in Germany was -0.4 (GollNiCK 1975).

On the basis of the present study, the expenditure elasticity of Groceries (1.8) is higher than the elasticities previously obtained in Finland (between 0.6 and 1.2) (MARJOMAA 1969, VIRÉN 1983, LAURILA 1985, Mellin 1985). The own-price elasticities compare well: -0.4 in the present study and -0.5 in VirÉN (1983), LAURILA (1985), and MELLIN (1985).

The comparison showed that there is a great deal of variability in the elasticity estimates obtained in different studies. Many reasons are available for explaining why results are not equal. The reference group (country, consumer segment), the observation period (consumer reactions may have changed over time), and the composition of consumed goods are probably the most obvious sources of discrepancy. Part of the discrepancy can probably be explained by differences in preferences and overall consumption possibilities. In addition, the type of data set and estimation method affects the results.

A comparison of the results from different studies employing different types of data sets is difficult. The present study employed the National Accounts expenditure data. If the total expendi- 
ture and consumed volumes rise, which has been a commonplace feature during the last decades, higher estimates for expenditure elasticities can be expected than would be the case if disappearance data with physical units were employed. The hypothesis got support when the estimated elasticities obtained in the present study were compared with those obtained by RoUHIAINEN (1979), who employed disappearance data. In Bread and Cake, Fresh Milk, Butter, Eggs, Fruits, and Vegetables the expenditure elasticities obtained in the present study were clearly higher than those obtained by Rouhiainen. Instead, Rouhiainen's elasticities for Fish, Cheese, and Margarine were higher than those obtained in the present study.

The tendency in the estimates for own-price elasticities depends on the trends in prices and consumed volumes. Given the relative price decreases while the consumption increases, which was the case, for example, in Fruits, Fish, Cheese, and Eggs, a bigger response to own price will be recorded than would be the case if the consumption were measured in physical units (which would show a less increased consumption). The tendency was found to be true in Fish and Cheese, whereas in Fruits and Eggs the elasticities obtained in the present study and by Rouhiainen were equal. Given the relative price increases while the consumption decreases, which was the case, for example, in Butter, a smaller response to own price will be recorded than would be the case if the consumption were measured in physical units (which would show a more decreased consump- tion). The tendency was not found in Butter: the own-price elasticity obtained in the present study was higher than that obtained by Rouhiainen. A partial explanation may be that Butter is a commodity the quality of which has undergone only minor changes over the observation period.

In many groups, comparisons between the present study and other studies were difficult because of differences in the composition of bundles. For example, in most of the referred studies, cereals, meats, fluid milk products, and fruits and vegetables were combined bundles.

One probable source for the variability in elasticity estimates is the fact that the estimation methods vary. Although the samples were not the same, for example, the present study, VIRÉN (1983), Mellin (1985), and LaURILA (1985) employed the same data source. However, there was a big difference in estimation methods. The present study was the only system analysis, the other studies employed single equation models. ${ }^{21}$ Since the complete systems approach has many advantages, the elasticities obtained in the present study should be more reliable. Long-term trends in consumption influence especially the expenditure elasticities (HAIDACHER 1992, p. 194-195). Static models are usually unable to isolate the effects of a positive or negative trend from the behavioural response to the total expenditure. The dynamic behaviour was found to be important in explaining changes in consumption patterns in Finland. Unlike the present study, most of the cited studies employed static models.

\section{Projections to year 2000}

\subsection{Introductory remarks}

So far in the present study, the factors affecting the consumption have been identified and quantified. In this chapter, the results are employed to predict future consumption. By means of predictions for future values of exogenous variables, predictions for future values of endogenous vari- ables are made. In the literature these ex ante predictions are called either projections (DEATON 1975) or forecasts (HARVEY 1981). In the present study the terms projection and forecast are used interchangeably.

${ }^{21}$ The only exceptions to this rule were the two elasticities of Food-at-Home estimated by VIRÉN (1983) by using the LES. 
The preferred models are used for projecting per capita food consumption patterns to the year 2000. Future time path for exogenous variables is specified, and the estimated models are run forward to calculate conditional predictions for the endogenous variables. After predicting the growth path of the population size, effects on the demand at the market level can be derived.

Considering policy analysis, two general types of problems are appropriate to be analysed within a complete demand systems context: (a) programs or policies that use prices as instruments for change, and (b) policies that use quantities as instruments (EASTWOOD and Sun 1987). The present study focuses on the first type of problem. The quantities consumed will be simulated under four different sets of price variables (price policies) over the period 1992-2000. The beginning of the simulation period shows how the consumers have probably behaved, whilst the rest of the simulation period builds conditional predictions how the consumers will behave in the future under the specified exogenous variables. The procedure gathers information on how given changes in prices and expenditure affect the food choice.

The objective of this chapter is to answer the questions:

1. What kind of effects can be foreseen on the household demand for food products during a period of transition to alternative price patterns, given that certain changes occur in the total expenditure of households?

2. How will the alternative projections concerning household demand affect the aggregate demand for food products, given that certain changes occur in the size of population?

\subsection{Forecasting accuracy}

Model performance in within-sample (ex post) predictions as well as in out-of-sample (ex ante) predictions is studied. As performance criteria are used the mean absolute percentage error (MAPE) and the coefficient of determination derived from the root-mean-square prediction error $\left(R^{2} \mathrm{RMSE}\right)$. Both criteria measure the prediction error, or the difference between predicted and actual budget shares.

The MAPE describes the average of the absolute values of percentage prediction errors. The root-mean-square prediction error is the square root of the average of the squared values of prediction errors. The measure weights large prediction errors more heavily than small ones. The $R^{2}$ RMSE gives the proportion of the variation in the forecasted variable that is captured by the forecast. Thus, the $R^{2}$ RMSE measures the ability of the forecasting model to explain the data used to develop the forecasting model (KENNEDY 1985, p. 206-207, HuANG and HAIDACHER 1986).

To evaluate the accuracy of ex ante predictions, a competing model specification, a simple random walk model, is introduced. Applied to the present analysis, the random walk model states that the subsequent observation equals the current observation plus a random disturbance term $\left(I N\left(0, \sigma^{2}\right)\right)$, or

$$
\hat{y}_{T+1}=y_{T}+E\left(\varepsilon_{T+1}\right)=y_{T}
$$

where $T$ is 1990 . For comparison, the AIDS models were estimated with data covering 1960-1990, and the year 1991 was predicted. The performance criteria are based on the out-of-sample prediction errors. The procedure is similar to the model selection procedure known as cross-validation (MADDALA 1992, p. 504-506). Since only one period ahead is predicted, the MAPE measures the difference between the predicted and actual budget share in 1991, expressed in percentages. In the case of the random walk model, the MAPE measures the deviation of the 1990 actual budget share from the actual 1991 budget share, whereas in the case of the AIDS, the MAPE measures the deviation of the AIDS projection for 1991 from the actual 1991 budget share. For example, the AIDS model predicted that the budget share of Food-at-Home is 0.2675 in 1991 . However, the actual value was 0.2650 . Thus, the absolute error was 0.0025 , which is $0.9 \%$ (the MAPE in Table 25) of the actual value. The ratio of the 
Table 25. Model performance in ex post predictions over the sample period (1961-1991) and in ex ante predictions for 1991 (estimation period 1961-1990). ${ }^{a}$

\begin{tabular}{|c|c|c|c|c|c|c|}
\hline & \multicolumn{2}{|c|}{$\begin{array}{l}\text { Within sample } \\
\text { predictions }\end{array}$} & \multicolumn{4}{|c|}{$\begin{array}{l}\text { Predictions for } 1991 \text { (estimation period } \\
\qquad 1961-1990)\end{array}$} \\
\hline & \multirow{2}{*}{$\begin{array}{c}\text { MAPE } \\
\text { AIDS }\end{array}$} & \multirow{2}{*}{$\begin{array}{c}\mathrm{R}^{2} \mathrm{RMSE} \\
\text { AIDS }\end{array}$} & \multicolumn{2}{|c|}{ MAPE } & \multicolumn{2}{|c|}{$R^{2} \mathrm{RMSE}$} \\
\hline & & & $\begin{array}{l}\text { Random } \\
\text { walk }\end{array}$ & AIDS & $\begin{array}{l}\text { Random } \\
\text { walk }\end{array}$ & AIDS \\
\hline \multicolumn{7}{|c|}{ Private Consumption (Group 1) } \\
\hline - Food-at-Home & 0.6 & 0.996 & 4.0 & 0.9 & 0.936 & 0.997 \\
\hline - Food-away-from-Home & 1.5 & 0.996 & 5.4 & 6.3 & 0.918 & 0.888 \\
\hline - Non-Durables & 1.1 & 0.932 & 0.1 & 1.8 & 1.000 & 0.900 \\
\hline - Services & 0.5 & 0.993 & 3.4 & 1.1 & 0.556 & 0.955 \\
\hline - average & 0.9 & & 3.2 & 2.5 & & \\
\hline \multicolumn{7}{|l|}{ Food-at-Home (Group 2) } \\
\hline - Animalia & 0.8 & 0.920 & 1.7 & 1.2 & 0.794 & 0.894 \\
\hline - Beverages & 1.2 & 0.873 & 1.7 & 0.3 & 0.839 & 0.994 \\
\hline - Groceries & 2.0 & 0.835 & 1.5 & 2.0 & 0.953 & 0.910 \\
\hline - Vegetablia & 1.3 & 0.950 & 0.6 & 1.3 & 0.992 & 0.968 \\
\hline - average & 1.3 & & 1.4 & 1.2 & & \\
\hline \multicolumn{7}{|l|}{ Animalia (Group 31) } \\
\hline - Meat and Fish & 1.1 & 0.931 & 0.3 & 0.5 & 0.997 & 0.992 \\
\hline - Dairy Products & 1.9 & 0.899 & 1.7 & 0.2 & 0.966 & 1.000 \\
\hline - Eggs & 3.3 & 0.910 & 10.4 & 10.7 & 0.692 & 0.669 \\
\hline - average & 2.1 & & 4.1 & 3.8 & & \\
\hline \multicolumn{7}{|l|}{ Beverages (Group 32) } \\
\hline - Alcoholic Drinks & 1.6 & 0.991 & 1.7 & 1.6 & 0.987 & 0.989 \\
\hline - Fresh Milk & 2.4 & 0.988 & 2.4 & 8.9 & 0.998 & 0.964 \\
\hline - Soft Drinks & 2.9 & 0.975 & 0.9 & 3.5 & 0.997 & 0.957 \\
\hline - Hot Drinks & 2.4 & 0.986 & 11.1 & 8.7 & 0.961 & 0.976 \\
\hline - average & 2.3 & & 4.0 & 5.7 & & \\
\hline \multicolumn{7}{|l|}{ Vegetablia (Group 33) } \\
\hline - Bread and Cake & 1.4 & 0.937 & 0.3 & 3.4 & 0.999 & 0.782 \\
\hline - Fruits & 3.3 & 0.941 & 1.0 & 7.6 & 0.995 & 0.716 \\
\hline - Vegetables & 2.6 & 0.936 & 0.7 & 2.3 & 0.997 & 0.967 \\
\hline - Flour & 3.6 & 0.978 & 0.3 & 2.1 & 1.000 & 0.997 \\
\hline - average & 2.7 & & 0.6 & 3.8 & & \\
\hline \multicolumn{7}{|l|}{ Meat and Fish (Group 41) } \\
\hline - Meat Products & 1.5 & 0.937 & 0.5 & 1.3 & 0.994 & 0.965 \\
\hline - Carcase Meat & 2.2 & 0.852 & 1.8 & 1.4 & 0.949 & 0.969 \\
\hline - Fish & 4.6 & 0.259 & 3.8 & 1.6 & 0.881 & 0.978 \\
\hline - average & 2.8 & & 2.0 & 1.4 & & \\
\hline \multicolumn{7}{|l|}{ Dairy Products (Group 42) } \\
\hline - Cheese & 4.3 & 0.975 & 6.1 & 0.9 & 0.884 & 0.997 \\
\hline - Sour Milk and Cream & 2.8 & 0.954 & 0.4 & 13.4 & 0.999 & 0.151 \\
\hline - Butter & 3.3 & 0.975 & 13.5 & 16.9 & 0.946 & 0.915 \\
\hline - Margarine & 3.9 & 0.820 & 1.9 & 7.5 & 0.979 & 0.684 \\
\hline - average & 3.6 & & 5.5 & 9.7 & & \\
\hline
\end{tabular}

a The AIDS refers to the preferred model specifications which were named in Table 7. The abbreviated notations are MAPE (mean absolute percentage error) and $R^{2}$ RMSE (coefficient of determination derived from the root-meansquare prediction error). 
explained variation to the total variation is 0.997 (the $R^{2} \mathrm{RMSE}$ ).

Within the sample, mean absolute errors of $3 \%$ and above were recorded in Eggs, Fruits, Flour, Fish, Cheese, Butter, and Margarine. In groups Vegetablia, Meat and Fish, and Dairy Products (Groups 33, 41, and 42) the errors were relatively large (Table 25). In ex ante predictions, the random walk model performed better than the AIDS in Beverages, Vegetablia, and Dairy Products (Groups 32, 33, and 42). In Vegetablia and Dairy Products, several low coefficients of determination were recorded.

The results indicate that the preferred AIDS specifications were good forecasting models in a number of groups. Within Vegetablia and Dairy Products (Groups 33 and 42), the prediction errors were large both in ex post and ex ante prediction. This suggests that the models specified should not be used for these two groups for forecasting. Forecasts on the demand for Eggs and Fish must be interpreted with caution since large prediction errors were recorded. Otherwise the models specified for Groups 31 and 41, including Eggs and Fish, respectively, showed such a good performance that the groups were included in simulations. The model specified for Beverages (Group 32) showed large prediction errors in ex ante predictions, but relatively small prediction errors in ex post predictions. The group was included in the simulations.

As a result of checking the forecasting accuracy, future consumption will be projected for all groups, except Vegetablia and Dairy Products (Groups 33 and 42). For projecting, the preferred AIDS specifications will be used (Table 7). Because the forecasting accuracy was evaluated concerning only one year (1991), the evidence would not have been sufficient, for example, to replace the AIDS with the random walk model, even if the random walk model showed better forecasting accuracy in some groups. This is because long-term (9 years) projections will be made, and the budget shares in most commodities have changed considerably in 10-year periods (Table 3 ). Thus, the assumption that budget shares will remain at the 1991 level during the whole 1990 s is quite unjustified. The comparison between the models was made in order to evaluate how good short-term forecasts can be attained by using the AIDS, compared with the forecasts attained by using the random walk model. The prediction error tests stressed a need to interpret the results with caution. The measured errors implied problems to long-term projections since prediction errors are cumulative over time and, thus, the error is likely to be the greater the longer is the projection.

\subsection{Projections of exogenous variables}

Predictions for future patterns of relative prices, total expenditure, and mean population are required. Four alternative predictions are made concerning prices. All the price hypotheses employ the same budget constraint and size of population. The growth path of Private Consumption is mainly based on the predictions made by the Ministry of Finance, whereas the growth path of the size of population is based on the projections made by the Central Statistical Office (Table 26).

Table 26. Predictions for private consumption expenditures and mean population in 1992-2000.

\begin{tabular}{ccc}
\hline Year & $\begin{array}{c}\text { Private Consumption, } \\
\text { change from previous } \\
\text { year, \% }\end{array}$ & $\begin{array}{c}\text { Mean Population, } \\
\text { millions }\end{array}$ \\
\hline 1992 & -2.5 & 5.037 \\
1993 & -4.5 & 5.054 \\
1994 & 1.5 & 5.066 \\
1995 & 3.5 & 5.075 \\
1996 & 3.5 & 5.081 \\
1997 & 3.0 & 5.087 \\
1998 & 2.0 & 5.091 \\
1999 & 2.0 & 5.093 \\
2000 & 2.0 & 5.095 \\
\hline
\end{tabular}

a The 1992 figure excludes Durables and Semi-Durables. Other figures refer to Total Private Consumption (including Durables and Semi-Durables). The figures refer to changes in aggregate demand; the per capita figures would be on an average $0.1 \%$-points lower.

Sources of Private Consumption: The 1992 figure, Statistical Office (1993); 1993-1997 figures, Ministry of Finance (1993, p. 31); 1998-2000 figures, VARTIA and YLÄ-ANTTILA (1992, p. 297). Source of mean population: Statistical Office (1992). 
Table 27. Projections of relative prices in 2000: change from 1991 to 2000 , $\%$.

\begin{tabular}{|c|c|c|c|c|c|c|}
\hline \multirow[t]{3}{*}{ Category } & \multicolumn{3}{|c|}{$\begin{array}{l}\text { Price change related to group } \\
\text { price index }\end{array}$} & \multicolumn{3}{|c|}{$\begin{array}{c}\text { Price change related to general } \\
\text { price index (price of Private } \\
\text { Consumption) }\end{array}$} \\
\hline & \multicolumn{3}{|c|}{ Price option } & \multicolumn{3}{|c|}{ Price option } \\
\hline & $\begin{array}{c}1960-91 \\
\text { trend }\end{array}$ & $\begin{array}{c}1980-91 \\
\text { trend }\end{array}$ & $\begin{array}{l}\text { Structural } \\
\text { change }\end{array}$ & $\begin{array}{c}1960-91 \\
\text { trend }\end{array}$ & $\begin{array}{c}1980-91 \\
\text { trend }\end{array}$ & $\begin{array}{l}\text { Structural } \\
\text { change }\end{array}$ \\
\hline Food-at-Home & -4 & -5 & -11 & -4 & -5 & -11 \\
\hline - Animalia & -1 & -2 & 1 & -5 & -7 & -10 \\
\hline - Meat and Fish & -1 & 2 & 0 & -6 & -5 & -10 \\
\hline - Meat Products & -0 & 2 & -1 & -6 & -3 & -11 \\
\hline - Carcase Meat & 4 & 8 & 2 & -2 & 2 & -8 \\
\hline - Fish & -14 & -37 & 0 & -18 & -41 & -10 \\
\hline - Dairy Products & 2 & -4 & -2 & -3 & -11 & -11 \\
\hline - Eggs & -8 & -8 & 10 & -13 & -14 & -1 \\
\hline - Beverages & -4 & 5 & -8 & -8 & -1 & -18 \\
\hline - Alcoholic Drinks & -1 & 2 & -11 & -8 & 2 & -27 \\
\hline - Fresh Milk & -0 & -12 & 20 & -8 & -12 & -1 \\
\hline - Soft Drinks & 6 & 6 & -1 & -2 & 5 & -19 \\
\hline - Hot Drinks & -2 & -2 & 55 & -9 & -3 & 27 \\
\hline - Groceries & 0 & -6 & 1 & -4 & -11 & -10 \\
\hline - Vegetablia & 5 & -1 & 7 & 1 & -7 & -5 \\
\hline Food-away-from-Home & 11 & 18 & 4 & 11 & 18 & 4 \\
\hline Non-Durables & 1 & -12 & 4 & 1 & -12 & 4 \\
\hline Services & 1 & 5 & 4 & 1 & 5 & 4 \\
\hline
\end{tabular}

An analysis which starts from the total consumption has the advantage that it is not necessary to assume food expenditures to be exogenously determined. Thus, the total expenditure is needed only for Stage 1, since for the following stages it is supplied by the preceding stage.

The variables $h$ in (68) are imposed to be one over the prediction period. This is justified by the fact that shifting parameters are not useful for the projections, because one cannot explain the cause of structural change and forecast the direction and magnitude of the change (c.f. MYERS 1986, p. 180).

One of the four alternative price options assumes that prices remain at the 1991 level, two options assume historical trends to continue, whereas one option assumes a structural change in price patterns:

1. The 1991-price option. The prices are assumed to remain at the 1991 level, which is the last year of observation in the data set. The option implies that there will be no changes in relative prices between the years 1991 and 2000 .

2. The 1960-91-trend option. The relative prices over 1992-2000 are assumed to follow the 1960-1991 trend in Finland, which, for example, for Food-at-Home, implies a decrease of $4 \%$ in relative price extended over 1992 2000 (Table 27).

3. The 1980-91-trend option. The relative prices over 1992-2000 are assumed to follow the 1980-1991 trend in Finland which, for example, for Food-at-Home, implies a decrease of $5 \%$ in relative price extended over 1992-2000 (Table 27).

4. The structural-change option. The relative prices over 1992-2000 are assumed to face a structural change. The set of relative prices in Denmark in 1992 was taken as a characterisation what the relative prices would be in Finland in 2000. The prices are assumed to change gradually and, thus, the prices concerning the years between 1991 and 2000 are derived from 
a linear trend starting from the year 1991 prices and ending to the year 2000 prices. Thus, full adjustment is assumed to be reached by 2000 . The option can be seen as a potential price path if Finland joins the European Union.

As a benchmark for the structural-change option, a comparison of price patterns in Denmark and Finland was used. For the comparison, average retail prices of forty food items were collected in Denmark and Finland. The aim was to choose representative goods for the commodity bundles presented in Table 2. The Danish krona was converted to the Finnish markka by the exchange rate of DKK 1 = FIM $0.7809 .{ }^{22}$ The expenditure patterns studied in the 1990 Finnish Household Expenditure Survey were used to weight both the Danish and Finnish prices. For example, the retail price for Fresh Milk is a combination of 1992 prices of standard milk and skim milk, weighted by the mutual budget shares of the commodities in Finland in 1990. No reference prices concerning Food-away-from-Home, Non-Durables, and Services were available. The structural-change option implies that the price of Food-at-Home would decrease by $11 \%$ related to the price of Private Consumption (Table 27). No prediction concerning the development of general price index was made. Thus, to offset the decrease of the relative price of Food-at-Home, Food-away-from-Home, Non-Durables, and Services were assumed to become $4 \%$ more expensive related to the price of Private Consumption by the year 2000 . No reference price concerning Fish was available, either. The relative price of Fish was assumed to remain at the 1991 level in the structural-change option.

In the simulations the relative prices within groups are used (rather than prices related to the price of Private Consumption). For example, if one price in a group increases, at least one price has to decrease. All the relative prices cannot be projected independently of each other, but an ad-

\footnotetext{
${ }^{22}$ Average of the Bank of Finland middle rates in December 31, 1991, June 30, 1992, December 31, 1992, and June 30, 1993.
}

justment must be carried out. The changes in relative prices - weighted by budget shares - must add up to zero. In the first price option no price changes were predicted, and the size of the inconsistency is zero, i.e. the condition is automatically satisfied. For other options, the condition has to be imposed. The equation is, for goods $i$ within group $r$,

$$
\begin{aligned}
& \sum_{i=1}^{n} \frac{p_{i, 2000} / p_{i, 1991}}{\phi_{(r)}} w_{(r) i, 1991} \\
& =\sum_{i=1}^{n} \frac{p_{i, 2000}^{*}}{p_{i, 1991}} w_{(r) i, 1991}=1
\end{aligned}
$$

where $p_{i, 1991}\left(=c_{i, 1991} / q_{i, 1991}\right)$ is the $i$ th price in $1991, p_{i, 2000}$ and $p_{i, 2000}^{*}$ are uncorrected and corrected predictions for the price in 2000 , respectively, $w_{(r) i, 199)}$ is the $i$ th budget share within the $r$ th group in 1991, and $\phi_{(r)}$ is the normalisation constant for group $r{ }^{23}$ Consequently, the condition states that Stone's price index remains the same for the whole forecast period, or, for $t=$ $1992, \ldots, 2000$,

$$
\sum_{i=1}^{n} p_{i, t} w_{(r) i, 1991}=P
$$

The conditions imply that no prediction is made for a change in the general price level between 1991 and 2000 and, thus, predicted changes in consumption patterns can be interpreted without the risk of money illusion.

If the relative prices within groups are converted to price changes related to the price of Private Consumption, almost all food prices tend to decrease over the forecast period. For example, in the structural-change option, only Hot Drinks and Food-away-from-Home are predicted to become more expensive (Table 27).

\footnotetext{
${ }^{23}$ The size of inconsistency is very small in the 1960 91-trend and 1980-91-trend options. There $\phi_{(\mathrm{r})}$ differs from 1 only slightly, indicating that the initially derived relative prices are almost consistent. This is actually what one would expect because of the method of prediction of the prices.
} 
Table 28. Projected changes in food consumption: changes in real expenditure from 1991 to 2000 , \%, under various price options.

\begin{tabular}{|c|c|c|c|c|c|c|c|c|}
\hline \multirow[t]{3}{*}{ Category } & \multicolumn{4}{|c|}{ Per capita } & \multicolumn{4}{|c|}{ Overall market (aggregate) } \\
\hline & \multicolumn{4}{|c|}{ Price option } & \multicolumn{4}{|c|}{ Price option } \\
\hline & $\begin{array}{l}1991 \\
\text { price }\end{array}$ & $\begin{array}{c}1960-91 \\
\text { trend }\end{array}$ & $\begin{array}{c}1980-91 \\
\text { trend }\end{array}$ & $\begin{array}{c}\text { Structural } \\
\text { change }\end{array}$ & $\begin{array}{l}1991 \\
\text { price }\end{array}$ & $\begin{array}{c}1960-91 \\
\text { trend }\end{array}$ & $\begin{array}{c}1980-91 \\
\text { trend }\end{array}$ & $\begin{array}{c}\text { Structural } \\
\text { change }\end{array}$ \\
\hline Food-at-Home & 9 & 5 & 4 & 5 & 11 & 6 & 6 & 7 \\
\hline - Animalia & 9 & 6 & 7 & 5 & 11 & 7 & 9 & 6 \\
\hline - Meat and Fish & 14 & 9 & 12 & 6 & 16 & 11 & 14 & 7 \\
\hline - Meat Products & 25 & 15 & 20 & 9 & 27 & 17 & 22 & 11 \\
\hline - Carcase Meat & 2 & -2 & -10 & 2 & 4 & 0 & -9 & 3 \\
\hline - Fish & 2 & 16 & 46 & 3 & 3 & 18 & 48 & 5 \\
\hline - Dairy Products & 1 & -1 & -2 & 3 & 3 & 1 & -1 & 4 \\
\hline - Eggs & 10 & 8 & -2 & 4 & 12 & 9 & 0 & 5 \\
\hline - Beverages & 12 & 5 & 1 & 9 & 14 & 7 & 3 & 11 \\
\hline - Alcoholic Drinks & 17 & 7 & 5 & 8 & 19 & 9 & 6 & 10 \\
\hline - Fresh Milk & 0 & 6 & -4 & 8 & 2 & 8 & -3 & 9 \\
\hline - Soft Drinks & 13 & -4 & -2 & 1 & 15 & -2 & 0 & 2 \\
\hline - Hot Drinks & 4 & 1 & -5 & 17 & 6 & 3 & -3 & 19 \\
\hline - Groceries & 12 & 9 & 6 & 10 & 14 & 11 & 8 & 12 \\
\hline - Vegetablia & 4 & 2 & 2 & 0 & 6 & 3 & 4 & 1 \\
\hline Food-away-from-Home & 21 & 8 & 2 & 13 & 23 & 9 & 4 & 15 \\
\hline
\end{tabular}

\subsection{Projected volumes for $\mathbf{2 0 0 0}$}

Consumption volumes were derived by multiplying the estimated budget shares by the total expenditure in current prices. The outcome was divided by the price index. The series were converted to per capita volumes by dividing them by the predicted mean population of the corresponding year. Under four price options, four different projections were attained for each category.

If the prices remained at the 1991 level, the per capita consumption of Meat Products and Food-away-from-Home would increase by more than $20 \%$ until the year 2000. The consumption of Eggs, Alcoholic Drinks, Soft Drinks, and Groceries would increase substantially, too, whereas the consumption of Carcase Meat, Fish, Dairy Products, and Fresh Milk would be nearly stagnated. If the prices followed the 1960-91-trend option, the consumption of Meat Products and Fish would increase by $15-16 \%$ until the year 2000. The consumption of Carcase Meat, Dairy Products, and Soft Drinks would decrease. The 1980-91-trend option would imply that the consumption of Meat Products and Fish would increase strongly, while the consumption of Carcase Meat, Dairy Products, Eggs, Fresh Milk, Soft Drinks, and Hot Drinks would decrease. If the prices changed as the structural-change option suggests, the consumption of Hot Drinks and Groceries would increase the most, while the consumption of Carcase Meat, Soft Drinks, and Vegetablia would be nearly stagnated (Table 28). In Hot Drinks, the outcome is explained by two facts: first, at the end of the 1980s, Hot Drinks became a Giffen good with a positive own-price elasticity; second, the structural-change option implies a strong increase in the price of Hot Drinks. Because of the doubtful outcome, the projection concerning Hot Drinks in the structural-change option will be ignored when deriving the conclusions from the analysis.

The consumption of Food-at-Home would increase the most strongly if the price structure remained at the 1991 level until 2000. The other price options were equal with respect to the de- 
velopment of the consumption of Food-at-Home. Also the consumption of Food-away-from-Home would be at the highest level under the 1991price option. The price path of the structuralchange option would generate a $13 \%$ increase in the per capita consumption of Food-away-fromHome, whereas the 1980-91-trend option would imply nearly stagnated consumption of Foodaway-from-Home (Table 28).

\subsection{Projected budget shares for 2000}

Projections on the budget shares of the aggregates of Food-at-Home - Animalia, Beverages, and Vegetablia - vary remarkably little under various price paths. The budget share of Animalia was projected to range from $33.5 \%$ to $34.0 \%$ in the year 2000, whereas in 1991 the budget share was $33.5 \%$. The budget share of Beverages was projected to range from $30.5 \%$ to $32.9 \%$ in the year 2000, whereas in 1991 the budget share was right in the middle of the range. The budget share of Vegetablia was projected to range from $24.3 \%$ to $26.0 \%$ in the year 2000 , whereas in 1991 the budget share was $25.5 \%$ (Table 29). More changes, however, were projected in disaggregated categories.

The structural-change price option would cause biggest changes in food consumption patterns. On an average, shares would change $0.75 \%$-points (Table 29). In absolute terms, the largest increases in budget shares were projected in Fresh Milk and Hot Drinks. In both cases, the increase in the budget share was generated by increases in consumption and prices. The largest decrease in the budget share, caused by decreasing prices, was projected in Alcoholic Drinks. Related to the other price options, in the structural-change option the budget shares of Carcase Meat, Fish, Dairy Products, Eggs, Fresh Milk, Hot Drinks, and Groceries would be high in the year 2000. On the other hand, allocation on Meat Products, Alcoholic Drinks, and Soft Drinks would be relatively low.

If the paths of relative prices followed the 1980-91-trend option, the budget shares of Meat Products and Alcoholic Drinks would increase the most. Related to the other price options, the 1980-91-trend option would generate high shares for Meat Products, Alcoholic Drinks, and Soft Drinks, and low shares for Carcase Meat, Fish, Dairy Products, Eggs, and Fresh Milk. The average change in budget shares would be $0.66 \%$ points by the year 2000 .

If the price structure that was valid in 1991 remained until 2000 , an average change of $0.53 \%$ points in the budget shares was projected. In absolute terms, the largest increases in budget shares were projected for Meat Products and Alcoholic Drinks. Compared with the other price options, under the 1991-price option Carcase Meat would have a low budget share.

The 1960-91-trend option would generate the smallest changes in consumption patterns by the year 2000 (Table 29).

Under the 1991-price option Food-at-Home would take $22 \%$ of consumers' budget ${ }^{24}$ over the whole forecast period. Under the 1960-91-trend option, the allocation on Food-at-Home would start to decline in 1995 to end up at $20 \%$ in the year 2000. Similar developments under the 1980 91-trend and structural-change options would end up at shares of $19 \%$ and $18 \%$ in 2000 , respectively. Considering the combined Food-at-Home and Food-away-from-Home, 28\% of consumers' budget was allocated on food in 1991. The 1991price option would imply a slow gradual rise in the budget share, while other options would imply a gradual decline in the budget share during the last half of the 1990s. The predicted shares in 2000 are between $27 \%$ (the structural-change option) and 30\% (the 1991-price option) (Figure 12).

${ }^{24}$ The budget shares of Food-at-Home and Food-awayfrom-Home are related to Total Private Consumption (including Durables and Semi-Durables). For this purpose, a projection for the development of Total Private Consumption had to be made over the forecast period. The changes were assumed to be equal to the changes in Private Consumption (excluding Durables and Semi-Durables). There was one exception: for the year 1992, instead of a $2.5 \%$ decrease in the total expenditure, a $5.7 \%$ decrease was presumed, which is the recorded figure (Statistical Office 1993). 
Table 29. Budget shares of food products in 1991 and projections for 2000 under alternative price options.

\begin{tabular}{|c|c|c|c|c|c|}
\hline \multirow{3}{*}{$\begin{array}{l}\text { Category (mutual dependency of } \\
\text { categories in parentheses) }\end{array}$} & \multicolumn{5}{|c|}{ Share from Food-at-Home, \% } \\
\hline & \multirow{2}{*}{$\begin{array}{l}\text { Actual } \\
\text { in } 1991\end{array}$} & \multicolumn{4}{|c|}{ Projections for 2000 , price option } \\
\hline & & $\begin{array}{l}1991 \\
\text { price }\end{array}$ & $\begin{array}{l}1960-91 \\
\text { trend }\end{array}$ & $\begin{array}{l}\text { 1980-91 } \\
\text { trend }\end{array}$ & $\begin{array}{l}\text { Structural } \\
\text { change }\end{array}$ \\
\hline Food-at-Home $(=1+8+13+14)$ & 100.0 & 100.0 & 100.0 & 100.0 & 100.0 \\
\hline- Animalia $(1=2+6+7)$ & 33.5 & 33.6 & 33.6 & 33.5 & 34.0 \\
\hline - Meat and Fish $(2=3+4+5)$ & 21.3 & 22.2 & 21.8 & 22.6 & 21.8 \\
\hline - Meat Products (3) & 11.4 & 12.8 & 12.2 & 13.3 & 11.8 \\
\hline - Carcase Meat (4) & 7.8 & 7.3 & 7.5 & 7.3 & 7.8 \\
\hline - Fish (5) & 2.2 & 2.1 & 2.1 & 1.9 & 2.2 \\
\hline - Dairy Products (6) & 11.0 & 10.2 & 10.6 & 9.8 & 10.8 \\
\hline - Eggs (7) & 1.2 & 1.3 & 1.2 & 1.1 & 1.4 \\
\hline- Beverages $(8=9+10+11+12)$ & 31.9 & 32.9 & 31.0 & 32.9 & 30.5 \\
\hline - Alcoholic Drinks (9) & 21.6 & 22.7 & 20.8 & 23.1 & 18.1 \\
\hline - Fresh Milk (10) & 5.1 & 5.1 & 5.4 & 4.8 & 6.3 \\
\hline - Soft Drinks (11) & 2.7 & 2.8 & 2.6 & 2.9 & 2.4 \\
\hline - Hot Drinks (12) & 2.5 & 2.3 & 2.2 & 2.2 & 3.8 \\
\hline - Groceries (13) & 9.1 & 9.2 & 9.4 & 8.6 & 9.5 \\
\hline - Vegetablia (14) & 25.5 & 24.3 & 26.0 & 24.9 & 26.0 \\
\hline Standard deviation from actual in $1991^{\mathrm{a}}$ & a $\quad 0.00$ & 0.53 & 0.35 & 0.66 & 0.75 \\
\hline
\end{tabular}

a The standard deviation concerns the categories with a single digit (11 altogether). It is computed as follows: sum of absolute departures from the respective actual shares in 1991 divided by 11 .

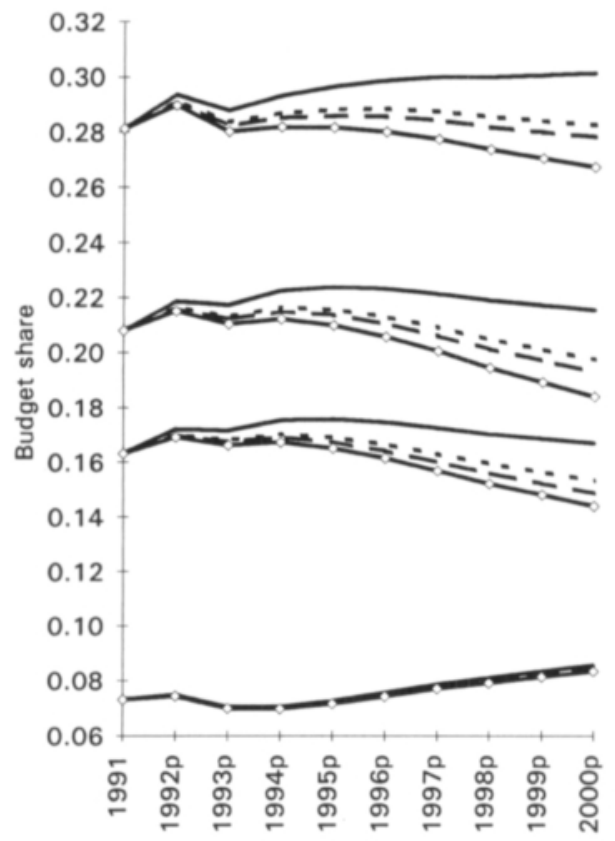

Combined

Food-at-Home and

Food-away-from-Home

\section{Food-at-Home}

Food-at-Home excluding

Alcoholic Drinks

\section{Food-away-from-Home}

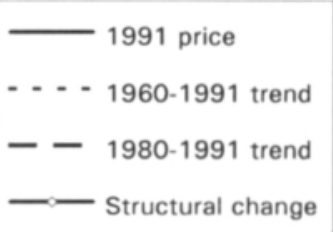

Fig. 12. Actual (1991) and projected (1992-2000) budget shares under alternative price options. Notes: The abbreviated notation is p (projected). The expenditures are related to Total Private Consumption (including Durables and SemiDurables). 
The budget share of Food-at-Home excluding Alcoholic Drinks was predicted to increase or remain the same during the first half of the 1990s. After that the share will decline gradually. The resulting budget shares in 2000 are between 14\% (the structural-change option) and 17\% (the 1991-price option). The expenditure on Foodaway-from-Home was predicted to be invariant with respect to the price options. The predicted budget share in 2000 is $9 \%$ under all options (Figure 12).

\section{Discussion and conclusions}

\subsection{Food consumption in Finland}

Although the real expenditure on food increased over the observation period, 1950-1991, the share of food of the total expenditure decreased. The result reflects Engel's law, which states that increasing wealth aims at diminishing the share of food in the total consumption. In Finland, the increasing wealth coincided with slightly decreasing food quantities (in terms of energy intake), but increasing food quality. The consumers were increasingly buying food products with more value added, i.e. more processing, packaging, etc.

Within the category Food-at-Home, the budget shares of the broad aggregate groups, Animalia, Beverages, and Vegetablia, remained about the same over the four decades, while structural changes took place within the aggregates. Within Animalia, consumption shifted from Dairy Products to Meat and Fish. Within Beverages, consumption shifted from Fresh Milk and Hot Drinks to Alcoholic Drinks and Soft Drinks. Within Vegetablia, consumption shifted from Flour to Fruits, while the shares of Bread and Cake and Vegetables remained about the same. Finnish experience does not support the "universal correlation" between rising per capita expenditure and increasing per capita consumption of food from animal sources stressed by SENAUER et al. (1991, p. 1314). Until the 1970s, Vegetablia consumption decreased compared to Animalia consumption. After that the trend disappeared.

The consumption of Meat Products and Fish increased steadily over the observation period, while the consumption of Carcase Meat increased rapidly in the late 1960s and early 1970s. After that the consumption of Carcase Meat tended downwards. From 1975 to 1991, the drinking of Fresh Milk decreased by $35 \%$, or at the annual rate of $2.7 \%$. The consumption of Cheese and Sour Milk and Cream increased substantially, while the consumption of Butter decreased. The share of Margarine of total fats increased from $29 \%$ in 1960 to $41 \%$ in 1991 , while the share of Butter decreased accordingly. Increasing publichealth concerns, together with price and income effects, were found to have shaped historic changes in fat and oil demand in the United States (YEN and CHERN 1992). Over the observation period, the fat question was a major health issue in Finland, too. Consumers were worried about the harmful effects of animal fats on coronary heart disease. The diet and health professionals were a major contributory factor to the attitudes towards butter (RIMPELÄ et al. 1989).

The econometric analysis employed annual time-series of the National Accounts covering the years 1960-1991. In principle, the data were suitable for food demand analysis. However, future research would benefit from the following improvements. First, the data should be revised with respect to the disaggregation level of a number of categories. By further disaggregation, more complete insight of the consumption could be gained. Roots and vegetables should be separated from each other. Butter and buttervegetable-oil mixture should not be combined, as they are now. Various fruits and vegetables should be separated. For example, fruits could be 
allocated into apples, citrus fruits, bananas, and other fruits, whereas fresh vegetables could be allocated into tomatoes, cucumbers, cabbages and lettuces, and other fresh vegetables. Also, in categories such as bread, coffee cake, sour milk products, and alcoholic drinks the current disaggregation level is insufficient. Some data problems arise because series are too short with respect to the methods employed. For example, disaggregated meat and meat products are available only from 1975, and potatoes and potato products were first separated in 1975. These problems will be alleviated as longer series will become available.

Second, in order to analyse the consumer preferences for domestically produced versus imported food products, separate data on domestic and imported products should be available. This subject becomes increasingly interesting if Finland joins the European Union and, consequently, food trade increases.

Third, the data frequency should be changed from annual to quarter basis. The more observations are available, the more sophisticated econometric methods are available (for example, extended use of time-series elements in econometric analysis). On the other hand, consumer preferences tend to change over time and, thus, the observation period must not cover too long a time period. Increasing the frequency of the data would alleviate the problem when making the trade-off between the length of time-series and constant consumer preferences. For example, in fruits and vegetables the increased frequency would offer more variation in prices, which is an advantage in estimating price effects.

Fourth, regionally collected data would allow studying differences in the consumer behaviour between various areas of the country. Consequently, the analysis could be modified to incorporate demographic effects.

When revising the data, a crucial point is that the new series are derived back to obtain historical values, too. Empirical demand analysis based on time-series data normally requires the minimum of 20 observations.

\subsection{Food demand system for Finland}

A complete demand systems approach was adopted in the present study. The advantage of the methodology is - compared with a single equation approach - that the methodology is consistent with the demand theory, which implies that, for example, the restrictions derived from the theory affect the analysis. The systems describe the allocation of expenditures among commodities in a way that the expenditures on sub-groups sum up to the total expenditure. Also, the systems account for interdependency among commodities, and they try to specify a sound correspondence between the theory on individual consumer and the market data.

As the complete demand system, the AIDS was employed for investigating consumer behaviour and estimating market level parameters for food demand in Finland. The AIDS form is based on a specific functional form for the consumer expenditure function. The AIDS has several advantages over many other forms. First, the AIDS model is derived from a utility function which assumes weak separability. Thus, the AIDS model is indirectly non-additive, allowing the consumption of one good to affect the marginal utility of another good. Second, the AIDS expenditure function has the property of a flexible functional form: it contains sufficient parameters to be regarded as a close approximation to any expenditure function and, hence, any underlying preference ordering. Third, systems the derivation of which starts from preferences represented by a PIGLOG expenditure functions will in general have better aggregation properties than other systems. Fourth, the AIDS suits well for testing the Slutsky conditions of homogeneity and symmetry since the restrictions are not imposed a priori.

Expenditure and price series of 18 food categories were available. A four-stage budgeting system was specified. First, the consumer was presumed to determine the amount to spend on four aggregate groups, one of which was Food-atHome. Second, Food-at-Home was allocated into Animalia, Beverages, Groceries, and Vegetablia. Third, those broad categories were divided into 
11 sub-categories. Finally, two sub-categories were disaggregated further.

The conventional AIDS was extended by developing a dynamic generalisation of the model and allowing for systematic shifts in the expenditure parameters over time. Four modifications of the AIDS were specified: static AIDS, dynamic AIDS, switching static AIDS, and switching dynamic AIDS. Each variant was estimated as an unconstrained form, homogeneity-constrained form, and homogeneity-and-symmetry-constrained form. Altogether 12 variations of the AIDS were estimated for each commodity group using timeseries data on consumption expenditures in Finland over the period 1960 to 1991 . Tests on parameter restrictions (testing the assumptions derived from the demand theory) and misspecification tests (testing the assumptions concerning the error terms) were used to choose the most preferred model specification for each group. The following specifications were chosen: (a) the switching dynamic AIDS, unrestricted, for four groups (Private Consumption, Food-at-Home, Vegetablia, and Dairy Products), (b) the switching dynamic AIDS, homogeneity and symmetry restricted, for one group (Meat and Fish), (c) the dynamic AIDS, unrestricted, for one group (Beverages), and (d) the static AIDS, unrestricted, for one group (Animalia).

The model specifications that permitted structural change in parameters generally yielded better explanations of the data. The two joint points, to present the beginning and end of the gradually switching period, were found by a maximumlikelihood procedure. In Food-at-Home and Vegetablia the first joint point was in 1961, whereas in Meat and Fish and Dairy Products it was in 1967 and 1965, respectively. In Private Consumption and Food-at-Home the second joint point was in 1984, whereas in Meat and Fish and Dairy Products it was in 1975 and 1974, respectively. The economic interpretation - if there is one - of the joint points varies from one group to another. One cannot say that something fundamental happened in consumer preferences in a certain year, but one has to say that preferences shifted in different commodity groups in different years.
None of the 12 variations of the AIDS provided an ideal demand system for food demand in Finland. The misspecification tests indicated the following:

1. The dynamic specification was correct.

2. There was structural change in parameters.

3. Some form of misspecification was found, for instance, there were one or more omitted variables or the functional form was incorrect.

4. The test results did not give a clear answer whether the specification of the separability structure succeeded or failed.

The structural change in parameters was the most common problem. Parameter instability could be accommodated, for example, by an alternative specification of the switching regression where other than expenditure parameters are allowed to vary, and thus the model could account for another type of structural change. Alternatively, one could allow more variables to shift, and allow more than one switching period during the estimation period. Non-parametric analysis, or a combination of parametric and nonparametric analysis, could provide new solutions.

If a change in tastes were seen as a change in the parameters of the utility function, then variation in the estimated parameters of the preferred models could be taken as evidence of changes in tastes. The modelling failed to track a stable preference structure: the parameter constancy was rejected in 14 out of 26 equations. Thus, the results suggested a structural change in demand for most food products - in addition to the structural change which was already captured by the switching expenditure parameter. However, this conclusion cannot be accepted. Caution is in order because of the fragility of the inference. To be able to reject the hypothesis of stable preferences, additional non-sample evidence concerning the functional form of demand equations would be necessary.

In order to name possible omitted variables and measure their effects on demand, a new approach should be adopted. Models that incorporate cross-section micro data and demographic variables, in addition to economic variables, give 
a potential standpoint for future research (PoLLAK and WALES 1981, Gould et al. 1990). The AIDS has been modified to incorporate household demographic characteristics and, thus, to allow for taste differences among households (RAY 1980, 1986, CAPPS et al. 1985, HEIEN and WILLetT 1986, Rossi 1988, Heien and Wessells 1988). Ross (1988) stressed the importance to use prior information from cross-section data in the estimation of aggregate demand systems. Especially for forecasting purposes, methods that use information from several sources could be fruitful, for instance, the joint use of cross-sectional and aggregate time-series data (OSKAM and Osinga 1982, OSKam 1992). Demand systems can be generalised in many alternative ways. For example, Chang et al. (1992) and Cox (1992) presented the AIDS that explicitly incorporates the effects of advertising and product promotion on demand.

In accordance with many other studies, the Slutsky conditions (homogeneity, symmetry, and negativity) were often rejected in the present study (reviews by Johnson et al. 1986, Chalfant et al. 1991, Deaton and Muellbauer 1980b, Ch. 3). ${ }^{25}$ There are several potential causes for the outcome: (a) inappropriate theory (for example, consumer behaviour did not follow the linear budget constraint, consumers were irrational and they did not maximise utility, ${ }^{26}$ or consumers suffered from money illusion); (b) unstable preferences (the parameters of the utility function shifted over time as tastes changed); (c) the data did not properly reflect the reality; (d) the constraints were valid, but the functional form was misspecified

${ }^{25}$ The Slutsky conditions have not always been rejected. For example, HAYES et al. (1990), who specified an AIDS model of the Japanese meat demand, found out that the data set satisfied homogeneity and symmetry restrictions. The restrictions were accepted by BURTON and YounG (1992) in meat and fish consumption in Great Britain. Chen and VeEman (1991) analysed Canadian meat consumption patterns, and found out that the properties of homogeneity and symmetry were rejected by the static AIDS, but accepted by the dynamic AIDS,

${ }^{26}$ For example, if compensated price responses of demand functions are not symmetric, consumers make irrational choices in terms of the axioms of choice. in some way (the tests for the validity of the restrictions also tested implicitly for the functional form), (e) there were missing variables, or (f) there was a failure of exact conditions for aggregation (the restrictions held for an individual consumer and for a complete range of goods, but the chosen groupings of consumers and goods were inappropriate) ${ }^{27}$ Rejecting the symmetry may also imply (g) a lack of homogeneity.

\subsection{Elasticity estimates}

In terms of elasticities, Engel's law states that food is expenditure inelastic. According to the present study, the food aggregates, Food-at-Home and Food-away-from-Home, did not fulfill this requirement. However, most of the food categories behaved "correctly." Whereas Meat Products, Alcoholic Drinks, Hot Drinks, Groceries, Fruits, and Vegetables were luxuries, other categories were necessities, except Margarine and Bread and Cake that were slightly inferior.

The estimated own-price elasticities had an acceptable sign. Soft Drinks and Food-away-fromHome were the only elastic categories, whereas the rest of the categories were own-price inelastic.

The demand for food consumed at home was slightly expenditure elastic. This was unexpected since over the observation period the expenditure on Food-at-Home increased at a slower pace than Private Consumption. Moreover, since Foodat-Home was normal in its own-price response, the somewhat decreased price of Food-at-Home does not explain the slow increase in consumption. The explanation lies in cross-price effects.

${ }^{27}$ Although the utility function behind the AIDS is designed to correspond with the market data, the restrictions on this may be too limiting. If some of the assumptions required by the model (and tests) do not hold, then it is possible that the microeconomic assumptions will be rejected when using macro data, even though the model might still be an adequate approximation of the market demand function (EDGERTON 1992b, p. 33). 
Over the observation period, the price of Services caused the most important price effect on the demand for Food-at-Home. While the relative price of Services increased by $59 \%$, the increase did not affect the consumption of Services, because the own-price elasticity of Services was close to zero. However, the price rise affected the demand for Food-at-Home. While total expenditures rose $1 \%$, consumers tended to spend $1.2 \%$ more on Food-at-Home, ceteris paribus. However, the ceteris paribus condition did not hold. The consumers did not spend $1.2 \%$ more on Food-at-Home because - while the total expenditure rose by $1 \%$ - increasing prices of Services required an increasing share of the consumer budget to be allocated to Services. This was possible only because consumers were more willing to save on Food-at-Home than Services. Restated, increased prices of Services shifted consumer expenditure on Food-at-Home downwards. The price of Food-away-from-Home had a similar, although smaller, effect on the demand for Foodat-Home. While the price of Food-away-fromHome increased, expenditure on Food-at-Home decreased.

The results confirmed the commonly accepted hypothesis (e.g. GoDDARD 1983) that the expenditure elasticity of Food-away-from-Home is greater than that of Food-at-Home. Consequently, an increase in private consumption will enlarge the demand for Food-away-from-Home in relation to the demand for Food-at-Home, whereas a decrease in private consumption will reduce the demand for Food-away-from-Home in relation to the demand for Food-at-Home. The results also indicated that Finnish consumer demand for Foodaway-from-Home is more price-elastic than the demand for Food-at-Home.

The analysis showed that the price of any particular good has a potential to affect the quantities demanded of any good. Fish was a substitute for Carcase Meat. Between Meat Products and Carcase Meat, the cross-price effects were small. Cheese was a substitute for Sour Milk and Cream, and Sour Milk and Cream were substitutes for Cheese. Over the observation period, consumers shifted from Butter to Cheese, but Butter was not a substitute for Cheese. Butter and Margarine were substitutes for each other. For Margarine, the price of Butter was more important than its own price, while for Butter its own price was more important. Margarine was a complement to Sour Milk and Cream, but Sour Milk and Cream were not complements to Margarine. Eggs were complements to Meat and Fish, but Meat and Fish were not complements to Eggs. Eggs were substitutes for Dairy Products, but Dairy Products were not substitutes for Eggs. Consumers substituted between Flour and Bread and Cake. Soft Drinks were substitutes for Alcoholic Drinks, but Alcoholic Drinks were not substitutes for Soft Drinks.

A distinction was made between within-group and total elasticities. Within-group elasticities showed the effects within the particular group, whereas total elasticities also accounted for the effects channeled through group expenditures. Associated with the adopted complete demand system framework, the advantage of using the total-elasticity paradigm was that it was possible to pursue price effects across all demand categories. The total expenditure elasticity is widely employed in the literature, but it is common that only within-group price elasticities are derived. This approach, however, may be misleading. With two exceptions (Margarine and Bread and Cake), estimated total elasticities indicated a weaker response to a price change than within-group elasticities did. The difference between within-group and total elasticities was biggest in Meat Products, Cheese, Butter, Alcoholic Drinks, and Fruits (Table 30). If one presumes a $10 \%$ decrease in the prices of Meat Products, for example, as a consequence of membership in the European Union, the expected change in consumption depends on the employed elasticity estimate. If the ownprice elasticity of -0.79 is used, the $10 \%$ price decrease is expected to increase consumption by $8 \%$, ceteris paribus. However, the resulting effect is probably much smaller, since the total ownprice elasticity of -0.08 implies merely an increase of $1 \%$.

A frequently presented hypothesis is that consumers become less price and expenditure sensitive as the total expenditure increases. This is 
Table 30. Comparison of estimated within-group and total own-price elasticities.

\begin{tabular}{|c|c|c|c|}
\hline \multirow[t]{2}{*}{ Category } & \multicolumn{2}{|c|}{$\begin{array}{l}\text { Uncompensated } \\
\text { own-price elasticity } \\
\text { at mean values }\end{array}$} & \multirow[t]{2}{*}{$\begin{array}{c}\text { Difference } \\
\text { (Total - } \\
\text { Within-group) }\end{array}$} \\
\hline & Within-group & Total & \\
\hline Meat Products & -0.79 & -0.08 & 0.71 \\
\hline Carcase Meat & -0.15 & -0.11 & 0.04 \\
\hline Fish & -0.71 & -0.69 & 0.02 \\
\hline Cheese & -0.73 & -0.20 & 0.53 \\
\hline \multicolumn{4}{|l|}{ Sour Milk and } \\
\hline Cream & -0.61 & -0.39 & 0.22 \\
\hline Butter & -1.01 & -0.63 & 0.38 \\
\hline Margarine & -0.39 & -0.52 & -0.13 \\
\hline Eggs & -0.15 & -0.13 & 0.02 \\
\hline Alcoholic Drinks & -0.76 & -0.40 & 0.36 \\
\hline Fresh Milk & -0.37 & -0.30 & 0.07 \\
\hline Soft Drinks & -1.30 & -1.28 & 0.02 \\
\hline Hot Drinks & -0.29 & -0.23 & 0.06 \\
\hline Groceries & -0.51 & -0.39 & 0.12 \\
\hline Bread and Cake & -0.59 & -0.61 & -0.02 \\
\hline Fruits & -0.73 & -0.32 & 0.41 \\
\hline Vegetables & -0.59 & -0.32 & 0.27 \\
\hline Flour & -0.65 & -0.54 & 0.11 \\
\hline $\begin{array}{l}\text { Food-away-from- } \\
\text { Home }\end{array}$ & & 9 & 0.00 \\
\hline
\end{tabular}

based on the assumption that poor consumers react firmly to price and income changes, while rich consumers can afford to be less sensitive (e.g. Buse 1986, Senauer et al. 1991). Adapted to the Finnish time-series data, the hypothesis suggests that price and expenditure responses should have decreased because average expenditures increased over time. The present study supported this conclusion only partially. The hypothesis that consumers become less price sensitive over time was satisfied in Food-at-Home. The own-price responsiveness of the goods within Food-at-Home decreased more often than increased, so that the own-price elasticity of Foodat-Home, which shows the net effect of all goods within it, changed from -0.5 in 1961 to -0.1 in 1991. Instead, the own-price elasticity of Foodaway-from-Home remained about the same (between -1.1 to -1.2 ) over the observation period. The expenditure elasticity of Food-at-Home remained about the same (1.2) over the observation period, implying that the shifts in the elasticity estimates of different food products compensated each other. The hypothesis that consumers become less expenditure sensitive over time was supported in Food-away-from-Home: the expenditure elasticity decreased from 3.6 in 1961 to 2.0 in 1991.

\subsection{Projections to year 2000}

The preferred specifications of the AIDS models were used to project food consumption patterns in Finland to the year 2000. Future time paths for exogenous variables were specified, and the estimated models were run forward to calculate predictions for future consumption, both on a per capita basis and in terms of the overall market for food products. To examine the sensitivity of projections to varying assumptions concerning price developments, the simulation was repeated under four different sets of price variables. These were (a) assuming the price structure recorded in the year 1991 to remain the same until the year 2000 (the 1991-price option), (b) assuming the price trends recorded over the period 1960-91 to continue until 2000 (the 1960-91-trend option), (c) assuming the price trends of the period 198091 to continue until 2000 (the 1980-91-trend option), and (d) assuming the Finnish price structure to converge to the price structure recorded in Denmark in 1992 (the structural-change option). Three price options (excluding the 1991-price option) presumed that the price of Food-at-Home will decrease (between $4 \%$ and $11 \%$ until 2000), and the prices of Food-away-from-Home, NonDurables, and Services will increase (an exception: the prices of Non-Durables were presumed to decrease in the 1980-91-trend option). The structural-change option measured expected consequences of Finland's possible membership in the European Union. None of the options was treated as a base-case forecast.

Before simulating, forecast accuracy was checked by means of prediction errors tests. In two groups, Vegetablia and Dairy Products, the prediction errors were large and, therefore, the 
Table 31. Projected per capita real expenditure in 2000 under various price options (index, actual real expenditure in 1991: 100).

\begin{tabular}{|c|c|c|c|c|}
\hline Category & $\begin{array}{l}\text { Lowest } \\
\text { forecast }\end{array}$ & $\begin{array}{l}\text { Highest } \\
\text { forecast }\end{array}$ & $\begin{array}{l}\text { Price option that } \\
\text { generated lowest } \\
\text { forecast }\end{array}$ & $\begin{array}{l}\text { Price option that } \\
\text { generated highest } \\
\text { forecast }\end{array}$ \\
\hline Food-at-Home & 104 & 109 & $1980-91$ trend & 1991 price \\
\hline - Animalia & 105 & 109 & Structural change & 1991 price \\
\hline - Meat and Fish & 106 & 114 & Structural change & 1991 price \\
\hline - Meat Products & 109 & 125 & Structural change & 1991 price \\
\hline - Carcase Meat & 90 & 102 & $1980-91$ trend & $\begin{array}{l}1991 \text { price, } \\
\text { Structural change }\end{array}$ \\
\hline - Fish & 102 & 146 & 1991 price & $1980-91$ trend \\
\hline - Dairy Products & 98 & 103 & $1980-91$ trend & Structural change \\
\hline - Eggs & 98 & 110 & $1980-91$ trend & 1991 price \\
\hline - Beverages & 101 & 112 & $1980-91$ trend & 1991 price \\
\hline - Alcoholic Drinks & 105 & 117 & $1980-91$ trend & 1991 price \\
\hline - Fresh Milk & 96 & 108 & $1980-91$ trend & Structural change \\
\hline - Soft Drinks & 96 & 113 & $1960-91$ trend & 1991 price \\
\hline - Hot Drinks & 95 & 104 & $1980-91$ trend & 1991 price \\
\hline - Groceries & 106 & 112 & $1980-91$ trend & 1991 price \\
\hline - Vegetablia & 100 & 104 & Structural change & 1991 price \\
\hline Food-away-from-Home & 102 & 121 & $1980-91$ trend & 1991 price \\
\hline
\end{tabular}

projections were not made for the categories within those two groups. In initial trials, if projections were made far enough into the future, the budget shares of Flour (within Vegetablia) and Butter (within Dairy Products) tended to zero, with the other goods taking up all of the group expenditure. The outcome was similar to WOHLGENANT's (1986) experience in the context of a complete systems approach (the Fourier flexible functional form). One has to exercise caution in using complete systems to forecast outside the sample.

The projections were sensitive to alternative price developments. The greatest variations in the projected volumes for the year 2000 were obtained in Meat Products, Fish, Soft Drinks, and Food-away-from-Home, where the gaps between the lowest and highest forecasts were $16-44 \%$. In Food-at-Home, Animalia, Dairy Products, Groceries, and Vegetablia - all relatively broad categories - the gaps between the lowest and highest forecasts were $6 \%$ or less. The 1980-91-trend option generated the lowest forecast in 10 of the 16 cases, whereas the 1991-price option generat- ed the highest forecast in 13 of the 16 cases (Table 31 ).

The 1991-price option implied that the per capita consumption of Meat Products, Alcoholic Drinks, Soft Drinks, Groceries, and Food-awayfrom-Home would increase substantially by the year 2000, while the consumption of Fresh Milk and Dairy Products would remain unchanged. The 1960-91-trend option implied that the per capita consumption of Meat Products and Fish would increase substantially, while the consumption of Carcase Meat, Dairy Products, and Soft Drinks would decrease. The 1980-91-trend option implied that the per capita consumption of Meat Products and Fish would increase substantially, while the consumption of Carcase Meat, Dairy Products, Eggs, Fresh Milk, Soft Drinks, and Hot Drinks would decrease. The structural-change option implied that the per capita consumption of Groceries and Food-away-from-Home would increase substantially, while the consumption of Soft Drinks and Vegetablia would remain unchanged.

The per capita consumption of Meat Products, Alcoholic Drinks, and Groceries was projected 
Table 32. Schematic presentation of the projected changes in per capita food consumption under various price options.

\begin{tabular}{|c|c|c|c|c|}
\hline & \multicolumn{4}{|c|}{ Price option } \\
\hline & 1991 price & $1960-91$ trend & $1980-91$ trend & Structural change \\
\hline \multirow{6}{*}{$\begin{array}{l}\text { Category whose real } \\
\text { expenditure is projected to } \\
\text { increase by } 5 \% \text { or more } \\
\text { from } 1991 \text { to } 2000\end{array}$} & Meat Products & $\begin{array}{l}\text { Meat Products } \\
\text { Fish }\end{array}$ & $\begin{array}{l}\text { Meat Products } \\
\text { Fish }\end{array}$ & Meat Products \\
\hline & Eggs & Eggs & & \\
\hline & Alcoholic Drinks & $\begin{array}{l}\text { Alcoholic Drinks } \\
\text { Fresh Milk }\end{array}$ & Alcoholic Drinks & $\begin{array}{l}\text { Alcoholic Drinks } \\
\text { Fresh Milk }\end{array}$ \\
\hline & Soft Drinks & & & \\
\hline & Groceries & Groceries & Groceries & Groceries \\
\hline & $\begin{array}{l}\text { Food-away- } \\
\text { from-Home }\end{array}$ & $\begin{array}{l}\text { Food-away- } \\
\text { from-Home }\end{array}$ & & $\begin{array}{l}\text { Food-away- } \\
\text { from-Home }\end{array}$ \\
\hline \multirow{6}{*}{$\begin{array}{l}\text { Category whose real } \\
\text { expenditure is projected to } \\
\text { decrease by } 2 \% \text { or more } \\
\text { from } 1991 \text { to } 2000\end{array}$} & & Carcase Meat & Carcase Meat & \\
\hline & & & Dairy Products & \\
\hline & & & Eggs & \\
\hline & & & Fresh Milk & \\
\hline & & Soft Drinks & Soft Drinks & \\
\hline & & & Hot Drinks & \\
\hline
\end{tabular}

to increase at least $5 \%$ until the year 2000 under all price options, while the consumption of Carcase Meat, Dairy Products, Hot Drinks, and Vegetablia was projected not to increase as much as $5 \%$ in any price option (Table 32 ).

The projections of endogenous variables depend largely on the functional form and its specification (for example, variables incorporated, separability structure), the parameter estimates of the model, and the projections of exogenous variables. To attain up-to-date projections, the procedure introduced in the present study should be repeated regularly. In the short run, new information on price developments, total expenditures, and population growth may generate more exact projections. Because consumer behaviour changes over time, new data will update the parameter estimates. In the long run, also the models have to be respecified.

\subsection{Conclusions and policy implications}

The study analysed the demand for food products in Finland in a system context. As a complete demand system, the AIDS was employed. The conventional AIDS was extended by developing a dynamic generalisation of the model (the dynamic AIDS) and allowing for systematic shifts in the structural relationships over time (the switching static and dynamic AIDS). The switching dynamic AIDS was chosen as the preferred model specification for most commodity groups.

The goodness-of-fit measures of the preferred model specifications were good. The diagnostic tests indicated that the dynamic specification of the models was correct. However, the chosen methodology had weaknesses. The structural change in parameters was the most common problem. Moreover, it is likely that there were one or more omitted variables or the functional form was incorrect in some way.

Interpretation of the models was made by deriving own-price, cross-price, and expenditure elasticities. A distinction was made between within-group and total elasticities. The total expenditure elasticity is widely employed, but it is common that only within-group price elasticities are derived. The study showed that this approach is misleading.

The demand for Food-away-from-Home was expenditure elastic, whereas most of the catego- 
ries of Food-at-Home were expenditure inelastic. Most of the estimated own-price elasticities had an acceptable sign. Food-away-from-Home was very sensitive both to changes in the total expenditure and own price, at the mean values of the input variables over the estimation period (1961-1991) as well as at the values of the last year (1991). At the other extreme, at the mean values Carcase Meat was insensitive both to changes in the total expenditure and own price. In 1991 Carcase Meat became moderately sensitive to changes in the total expenditure. At the mean values, Meat Products and Hot Drinks were very sensitive to expenditure changes, but insensitive to price changes. For Meat Products, this was also true in 1991, but Hot Drinks became moderately sensitive to the total expenditure. At the mean values, Fish, Sour Milk and Cream, Butter, Margarine, and Bread and Cake were insensitive to changes in the total expenditure, but moderately sensitive to changes in prices. Cheese, Eggs, and Fresh Milk were insensitive to price changes, but moderately sensitive to changes in the total expenditure. Alcoholic Drinks, Fruits, Vegetables, and Groceries were very sensitive to changes in the total expenditure, and moderately sensitive to price changes. Demand for Soft Drinks was moderately sensitive to changes in the total expenditure, and very sensitive to price changes. The demand structure remained quite steady over time: the same characterisation suits for 10 [out of 18] categories in both time periods (at the mean values as well as at the 1991 values), whereas the rest of the categories shifted only with respect to either expenditure or price elasticity (Tables 33 and 34).

Since food prices are strongly affected by agricultural and trade policies and taxation, the analysis of price effects can be seen as a policy analysis, where the estimated demand system was used as an instrument to gather information on the effects of policy changes. Manipulation of prices has simultaneous effects on the quantities demanded of a wide range of products. The prices of Services and Food-away-from-Home affected strongly the demand for Food-at-Home. Consequently, policies that increase the prices of Serv- ices and Food-away-from-Home will shift consumer expenditure on Food-at-Home downwards, and policies that decrease the prices of Services and Food-away-from-Home will shift expenditure on Food-at-Home upwards. Since the demand for Food-away-from-Home was more price elastic than the demand for Food-at-Home, policies that alter the prices of Food-away-from-Home and Food-at-Home will affect the demand for Food-away-from-Home more strongly than the demand for Food-at-Home. These phenomena should be taken into account when deciding the value-added-tax rates for Food-at-Home and, for example, the food catered at places of work. An equal tax increase for both Food-at-Home and Food-away-from-Home would have only a small effect on the demand for Food-at-Home, whereas the demand for Food-away-from-Home would decrease much more.

Policies that affect the price ratio between Carcase Meat and Fish easily cause a shift to Fish (if Carcase Meat becomes more expensive), or a shift away from Fish (if Carcase Meat becomes cheaper), but less easily a shift to or away from Carcase Meat (if the price of Fish changes). If the price ratio between Butter and Margarine is altered, consumers will shift to the fat the relative price of which decreases. Policies that affect the price ratio between Flour and Bread and Cake easily cause a shift to or away from Flour (if Bread and Cake become more expensive or cheaper, respectively), but less easily a change in the demand for Bread and Cake (if the price of Flour changes). Policies that increase the price of $\mathrm{Al}$ coholic Drinks will make consumers to a certain degree shift to Soft Drinks, and policies that decrease the price of Alcoholic Drinks will make consumers to a certain degree shift away from Soft Drinks, but policies that change the price of Soft Drinks will not make consumers change the consumption of Alcoholic Drinks.

The choice of a price policy influences the consumption of Meat Products, Fish, Soft Drinks, and Food-away-from-Home considerably. For broad categories, such as Food-at-Home, Animalia, Dairy Products, Groceries, and Vegetablia, the choice of a price policy has only limited con- 
Table 33. Schematic presentation of the demand elasticities at the mean values.

\begin{tabular}{llll}
\hline $\begin{array}{l}\text { Range of total } \\
\text { expenditure } \\
\text { elasticity }\end{array}$ & \multicolumn{2}{c}{ Range of total uncompensated own-price elasticity } \\
\hline$-0.20 . .0 .30$ & Carcase Meat & $\begin{array}{l}\text { Fish } \\
\text { Sour Milk and Cream } \\
\text { Butter } \\
\text { Margarine } \\
\text { Bread and Cake }\end{array}$ & \\
& & Flour & Soft Drinks \\
$0.31 . .1 .00$ & Eggs & Fresh Milk & \\
& Cheese & Alcoholic Drinks & Food-away-from-Home \\
& Meat Products & Fruits \\
Hot Drinks & Vegetables & \\
& & Groceries & \\
& & &
\end{tabular}

Table 34. Schematic presentation of the demand elasticities at the 1991 values.

\begin{tabular}{|c|c|c|c|}
\hline \multirow{2}{*}{$\begin{array}{l}\text { Range of total } \\
\text { expenditure } \\
\text { elasticity }\end{array}$} & \multicolumn{3}{|c|}{ Range of total uncompensated own-price elasticity } \\
\hline & $0 . .-0.30$ & $-0.31 . .-1.00$ & $<-1.01$ \\
\hline$-0.20 . .0 .30$ & & $\begin{array}{l}\text { Sour Milk and } \mathrm{Cr} \\
\text { Butter } \\
\text { Margarine } \\
\text { Flour }\end{array}$ & \\
\hline $0.31 . .1 .00$ & $\begin{array}{l}\text { Carcase Meat } \\
\text { Cheese } \\
\text { Fresh Milk } \\
\text { Hot Drinks }\end{array}$ & $\begin{array}{l}\text { Fish } \\
\text { Bread and Cake }\end{array}$ & Soft Drinks \\
\hline$>1.01$ & $\begin{array}{l}\text { Meat Products } \\
\text { Eggs } \\
\text { Vegetables } \\
\text { Groceries }\end{array}$ & $\begin{array}{l}\text { Alcoholic Drinks } \\
\text { Fruits }\end{array}$ & Food-away-from-Home \\
\hline
\end{tabular}

awn-price elasticity of 0.56 was estimated.

sequences. The consumption of categories like Meat Products, Alcoholic Drinks, and Groceries tends to increase no matter what price policy is chosen - the question is how much. Instead, the consumption of Carcase Meat, Dairy Products, and Vegetablia tends to be stagnated no matter what price policy is chosen.

If the policy is to maintain the relative prices as they were in 1991, the consumption of Meat Products, Alcoholic Drinks, Soft Drinks, Groceries, and Food-away-from-Home would increase substantially by the year 2000 , while the consumption of Fresh Milk and Dairy Products would remain unchanged. As a consequence of a policy that allows the historical price trends in Finland to continue, the consumption of Meat Products and Fish would increase substantially, while the consumption of Carcase Meat, Dairy Products, and Soft Drinks - possibly also Eggs, Fresh Milk, and Hot Drinks - would decrease. The price development that was presumed to follow from entering the European Union would imply that the 
consumption of Groceries and Food-away-fromHome would increase substantially, while the consumption of Soft Drinks and Vegetablia would remain unchanged.

A predicted consequence of the membership in the European Union is that the share of food in consumers' budget would decrease. The expected decrease is faster than the decrease that would take place if future price developments were based on the historical trends. If Finland joins the Union, the budget share of Food-at-Home would decrease from $21 \%$ in 1991 to $18 \%$ in 2000 , whereas the budget share of Food-at-Home excluding Alcoholic Drinks would decrease from $16 \%$ in 1991 to $14 \%$ in 2000 . Under other price options, the budget shares of Food-at-Home and Food-at-Home excluding Alcoholic Drinks would be up to $22 \%$ and $17 \%$ in 2000 , respectively.

In Finland many agricultural commodities are produced in excess of domestic consumption. Diverse measures of control policy have targeted to achieve more balanced supply and demand (KOLA 1991). According to the present analysis, aggregate demand is expected to contribute to more balanced markets of milk, meat, and eggs. The aggregate demand for Fresh Milk is expected to increase $1 \%$ annually until 2000 under the price option that describes Finland entering the European Union, while the demand for Dairy Products (other than Fresh Milk) is expected to increase $0.5 \%$ annually. Under the other price op- tions, the increases would be the same or smaller. However, the slightly increasing aggregate demand would not solve the problem of overproduction, since the domestic production of milk was about one-fourth above the domestic consumption in 1992 (National Board of Agriculture 1993). Moreover, the increase in the demand for raw milk can even be adverse if consumers shift to consuming higher-valued dairy products, instead of increased physical quantities.

The price option describing Finland entering the European Union is expected to increase the aggregate demand for Meat Products and Carcase Meat $0.8 \%$ annually until 2000 , while the demand for Eggs is expected to increase $0.5 \%$ annually. Under the other price options, the increases would be about twice that much (with an exception of Eggs under the 1980-91-trend option: the demand would remain unchanged). However, especially in meats the impact in the aggregate demand for raw materials will be smaller, since part of the increase will probably affect the quality of consumption (in terms of value), rather than physical quantities.

Foreign trade can change rapidly the balance between domestic demand and supply. For example, increased amount of imported food easily offsets the slow increase in aggregate demand and, consequently, the need for production control would not be lessened.

\section{Summary}

The objectives of the study were: (a) to present the food consumption patterns in Finland over the period 1950-1991, (b) to estimate a demand system for a 18-category breakdown of food expenditures, (c) to verify how well the Finnish consumer behaviour corresponds to the consumer theory, (d) to estimate price and expenditure elasticities of food products, (e) to obtain projections on future food demand in Finland, (f) to examine the sensitivity of the projections to al- ternative price developments, and (g) to derive policy implications.

The National Accounts provided annual volume and price series on household consumption. While the real expenditure on food has increased, the share of food of the total expenditure has decreased. In the early 1950 s, combined Food-atHome and Food-away-from-Home corresponded to about $40 \%$ of consumers' expenditure. In 1991 the share was $28 \%$. There was a shift to meals 
eaten outside the home. While the budget share of Food-away-from-Home increased from 3\% to $7 \%$ over the observation period, Food-at-Home fell from $37 \%$ to $21 \%$, and Food-at-Home excluding Alcoholic Drinks fell from 34\% to $16 \%$.

Within Food-at-Home, the budget shares of the broad aggregate groups, Animalia (food from animal sources), Beverages, and Vegetablia (food from vegetable sources), remained about the same over the four decades, while structural change took place within the aggregates. Within Animalia, consumption shifted from Dairy Products (other than Fresh Milk) to Meat and Fish. Within Beverages, consumption shifted from Fresh Milk and Hot Drinks to Alcoholic Drinks and Soft Drinks. Within Vegetablia, consumption shifted from Flour to Fruits, while the shares of Bread and Cake and Vegetables remained about the same.

The empirical application examined the existing market demand structure and estimated market level parameters for food demand in Finland. With a strong consideration on methodological aspects, the analysis was carried out within the framework of a standard demand analysis, which lays emphasis on estimating the responses of prices and total expenditure. A complete demand systems approach was adopted. The advantage of the methodology is - compared with a single equation approach - that the systems account for interdependency among commodities, and they try to specify a sound correspondence between the microeconomic theory of an individual consumer and the market data. Moreover, the systems describe the allocation of expenditures among commodities in a way that the expenditures on subgroups sum up to the total expenditure.

As a complete demand system, the Almost Ideal Demand System (AIDS) was employed. The AIDS is a system of demand equations in a budget share form. The AIDS form is based on a specific functional form for the consumer expenditure function. The expenditure function was specified, and the AIDS Marshallian demand functions were derived by minimising the expenditure necessary to reach a certain utility level. The necessary conditions for the procedure were called the Slutsky conditions. Ideally, the resulting demand func- tion to be applied to aggregate data will be consistent with the conditions and, consequently, with the microeconomic theory of consumer behaviour.

A four-stage budgeting system was specified, consisting of seven sub-systems. First, consumers were presumed to decide the amount to spend on four aggregate groups, one of which was Foodat-Home, one was Food-away-from-Home. Second, Food-at-Home was allocated into Animalia, Beverages, Groceries, and Vegetablia. Third, the broad categories were divided into 11 sub-categories. Finally, two sub-categories were disaggregated further.

The conventional AIDS was extended by developing a dynamic generalisation of the model and allowing for systematic shifts in structural relationships over time. Four modifications of the AIDS were specified: static AIDS, dynamic AIDS, switching static AIDS, and switching dynamic AIDS. Each variant was estimated either as an unconstrained form, a homogeneity-constrained form, and a homogeneity-and-symmetry-constrained form. The equations were estimated using the iterated feasible generalised least squares method. Tests on parameter restrictions (static, non-switching, homogeneity, and symmetry) and misspecification tests (testing the assumptions concerning the error terms) were used to choose the most preferred model specification for each group. The following specifications were chosen: (a) the switching dynamic AIDS, unrestricted, for four groups (Private Consumption, Food-at-Home, Vegetablia, and Dairy Products), (b) the switching dynamic AIDS, homogeneity and symmetry restricted, for one group (Meat and Fish), (c) the dynamic AIDS, unrestricted, for one group (Beverages), and (d) the static AIDS, unrestricted, for one group (Animalia).

The preferred models were evaluated by testing the Slutsky conditions, measuring the goodness of fit, and testing the assumptions that lay behind the estimation.

The estimated models did not usually satisfy the Slutsky conditions, which implies that the correspondence between the consumer behaviour and the theory was not good. There are several potential causes for the outcome, besides the con- 
clusion that the theory is inappropriate. For example, preferences may have been unstable, the data may have been improper, the Slutsky conditions may have been valid, but maybe the functional form was misspecified, some variables may have been missing, or maybe the conditions held for an individual consumer and for a complete range of goods, but the chosen groupings of consumers and goods were inappropriate.

The goodness-of-fit measures were good, and, compared to static specifications, dynamics usually provided a better fit.

The misspecification tests indicated that (a) the dynamic specification was correct, (b) some form of misspecification was found, for instance, there were one or more omitted variables or the functional form was incorrect, and (c) there was structural change in parameters.

Interpretation of the models was made by deriving own-price, cross-price, and expenditure elasticities. A distinction was made between within-group and total elasticities. Within-group elasticities showed the effects within a particular group, whereas total elasticities also accounted for the effects channeled through group expenditures. The total expenditure elasticity is widely employed in the literature, but it is common that only within-group price elasticities are derived. The study showed that this approach is misleading. A price change has simultaneous effects on the quantities demanded of a wide range of products. Associated with the adopted complete demand system framework, the advantage of using total elasticities was that the effects of price changes could be pursued across all demand categories.

The implications of the estimated elasticities are as follows:

1. In all categories, an increase in the own price decreases the consumption. Given the own prices of Soft Drinks and Food-away-fromHome increase, the expenditure on the categories decreases. In other categories, a price increase increases the expenditure on the respective category.

2. An increase in the prices of Services and Food-
away-from-Home shifts consumer expenditure on Food-at-Home downwards, and a decrease in the prices of Services and Food-away-fromHome shifts expenditure on Food-at-Home upwards.

3. Given a change in the prices of Food-awayfrom-Home and Food-at-Home, the demand for Food-away-from-Home is affected more strongly than the demand for Food-at-Home.

4. If the price ratios within Food-at-Home alter, the effect on the demand for Carcase Meat, Dairy Products, Eggs, Alcoholic Drinks, Fresh Milk, Hot Drinks, Groceries, and Vegetablia would be small, whereas the effect on the demand for Meat Products, Fish, and Soft Drinks would be great.

5. A change in the price ratio between Carcase Meat and Fish easily causes a shift to Fish (if Carcase Meat becomes more expensive) or a shift away from Fish (if Carcase Meat becomes cheaper). The change in the price ratio causes a shift to or away from Carcase Meat less easily (if the price of Fish changes).

6. As a result of a change in the price ratio between Butter and Margarine, consumers shift to the fat the relative price of which decreases.

7. A change in the price ratio between Flour and Bread and Cake easily causes a shift to or away from Flour (if Bread and Cake become more expensive or cheaper, respectively). The change in the price ratio causes a change in the demand for Bread and Cake less easily (if the price of Flour changes).

8. An increase in the price of Alcoholic Drinks makes consumers shift to Soft Drinks, and a decrease in the price of Alcoholic Drinks makes consumers shift away from Soft Drinks. Change in the prices of Soft Drinks do not make consumers change the consumption of Alcoholic Drinks.

9. If private consumption increases by $1 \%$, the consumption of Meat Products, Alcoholic Drinks, Hot Drinks, Fruits, Vegetables, Groceries, and Food-away-from-Home increases more than $1 \%$, the consumption of Margarine and Bread and Cake decreases, whereas 
the consumption of other categories increases by $0-1 \%$.

10. An increase in private consumption enlarges the demand for Food-away-from-Home compared to the demand for Food-at-Home, whereas a decrease in private consumption reduces the demand for Food-away-fromHome compared to the demand for Food-atHome.

The estimated demand system was applied for projecting the future consumption of food products in Finland to the year 2000. The approach was to choose a certain change in the real total consumption expenditure and alternative sets of relative prices for the forecast period. Four different options of price variables were defined. These were (a) assuming the price structure recorded in the year 1991 to remain until the year 2000 (the 1991-price option), (b) assuming the price trends recorded over the period 1960-91 to continue until 2000 (the 1960-91-trend option), (c) assuming the price trends of the period 1980 91 to continue until 2000 (the 1980-91-trend option), and (d) assuming the Finnish price structure to converge to the price structure recorded in Denmark in 1992 (the structural-change option). Unlike the other price options, the structuralchange option implied that, over the forecast period, relative prices would no longer rely on the historical trends recorded in Finland.

Before simulating, forecast accuracy was checked by means of prediction errors tests. Within two groups, Vegetablia and Dairy Products, the prediction errors were large and, therefore, the projections were made only for the groups, rather than for the within-group categories.

The projections were sensitive to alternative price developments. The greatest variation in the projected volumes for the year 2000 were obtained in Meat Products, Fish, Soft Drinks, and Food-away-from Home, where the gaps between the lowest and highest forecasts were $16-44 \%$. In Food-at-Home, Animalia, Dairy Products, Groceries, and Vegetablia the gaps between the lowest and highest forecasts were $6 \%$ or less. The 1980-91-trend option generated the lowest fore- cast in 10 of the 16 cases, whereas the 1991price option generated the highest forecast in 13 of the 16 cases.

The following implications were derived:

1. The 1991-price option implied that the per capita consumption of Meat Products, Alcoholic Drinks, Soft Drinks, Groceries, and Foodaway-from-Home would increase substantially by the year 2000, while the consumption of Fresh Milk and Dairy Products would remain unchanged.

2. The 1960-91-trend option implied that the per capita consumption of Meat Products and Fish would increase substantially, while the consumption of Carcase Meat, Dairy Products, and Soft Drinks would decrease.

3. The 1980-91-trend option implied that the per capita consumption of Meat Products and Fish would increase substantially, while the consumption of Carcase Meat, Dairy Products, Eggs, Fresh Milk, Soft Drinks, and Hot Drinks would decrease.

4. The structural-change option implied that the per capita consumption of Groceries and Foodaway-from-Home would increase substantially, while the consumption of Soft Drinks and Vegetablia would remain unchanged.

The structural-change option measured the expected consequences of Finland's possible membership in the European Union. A consequence of the membership is that the share of food in consumers' budget would decrease. The expected decrease is faster than the decrease that would take place if future price developments were based on historical trends. Given Finland joins the Union, the budget share of Food-at-Home would decrease from $21 \%$ in 1991 to $18 \%$ in 2000 , whereas the budget share of Food-at-Home excluding Alcoholic Drinks would decrease from $16 \%$ in 1991 to $14 \%$ in 2000 (the other price options predicted shares between $19 \%$ and $22 \%$ and between $15 \%$ and $17 \%$ in 2000 , respectively). The budget share of Food-away-from-Home was predicted to be invariant with respect to the price options: the predicted share in 2000 was $9 \%$ under all options. 


\section{References}

Alessie, R. \& KAPTEYN, A. 1991. Habit Formation, Interdependent Preferences and Demographic Effects in the Almost Ideal Demand System. Economic Journal 101: 404-419.

Alston, J.M. \& Chalfant, J.A. 1987. Weak Separability and a Test for the Specification of Income in Demand Models with an Application to the Demand for Meat in Australia. Australian Journal of Agricultural Economics 31, 1: 1-15.

- \& Chalfant, J.A. 1991a. Can We Take the Con Out of Meat Demand Studies? Western Journal of Agricultural Economics 16: 1, 36-48.

- \& Chalfant, J.A. 1991b. Unstable Models from Incorrect Forms. American Journal of Agricultural Economics 73: 1171-1181.

- \& Chalfant, J.A. 1993. The Silence of the Lambdas: A Test of the Almost Ideal and Rotterdam Models. American Journal of Agricultural Economics 75: 304 313.

AmemiYa, T. 1983. Non-Linear Regression Models. In: Griliches, Z. \& Intriligator, M.D. (eds.). Handbook of Econometrics, Vol. 1, p. 333-389. North-Holland.

ANDERSON, G. \& BLUNDELL, R. 1982. Estimation and Hypothesis Testing in Dynamic Singular Equation Systems. Econometrica 50: 1559-1571.

- \& Blundell, R. 1983. Testing Restrictions in a Flexible Dynamic Demand System: An Application to Consumers' Expenditure in Canada. Review of Economic Studies 50: 397-410.

- \& Blundell, R. 1984. Consumer Non-Durables in the U.K.: A Dynamic Demand System. Economic Journal 94: Supplement, 35-44.

Assarsson, B. 1991. Alcohol Pricing Policy and the Demand for Alcohol in Sweden, 1978-1988. Models and Projections of Demand for Food in the Nordic Countries, Working paper SW/9. Uppsala: Uppsala University. 20 p.

ATTFIELD, C.L.F. 1985. Homogeneity and Endogeneity in Systems of Demand Equations. Journal of Econometrics 27: 197-209.

Baccouche, R. \& Laisney, F. 1991. Describing the Separability Properties of Empirical Demand Systems. Journal of Applied Econometrics 6: 181-206.

BARTEN, A.P. 1967. Evidence on the Slutsky Conditions for Demand Equations. Review of Economics and Statistics 49: 77-84.

- 1969. Maximum Likelihood Estimation of a Complete System of Demand Equations. European Economic Review 1: 7-73.

BERNDT, E.R. \& SAVIN, N.E. 1975. Estimation and Hypothesis Testing in Singular Equation Systems with Autoregressive Disturbances. Econometrica 43: 937957.

- \& Savin, N.E. 1977. Conflict among Criteria for Testing Hypotheses in the Multivariate Linear Regression Model. Econometrica 45: 5, 1263-1277.
BEWLEY, R. 1986. Allocation Models: Specification, Estimation, and Applications. Cambridge, Massachusetts: Ballinger. 339 p.

BlancIForTi, L.A. \& GreEn, R.D. 1983a. An Almost Ideal Demand System Incorporating Habits: An Analysis of Expenditures on Food and Aggregate Commodity Groups. Review of Economics and Statistics 65, 3: 511-515.

- \& Green, R.D. 1983b. The Almost Ideal Demand System: A Comparison and Application to Food Groups. Agricultural Economics Research 35, 3: 1-10.

-, Green, R.D. \& KInG, G.A. 1986. U.S. Consumer Behavior Over the Postwar Period: An Almost Ideal Demand System Analysis. University of California: Giannini Foundation Monograph Number 40. 66 p.

BREUSCH, T.S. 1978. Testing for Autocorrelation in Dynamic Linear Models. Australian Economic Papers 17: 334-355.

- \& Pagan, A.R. 1979. A Simple Test for Heteroscedasticity and Random Coefficient Variation. Econometrica 47: 1287-1294.

Brown, R.L., Durbin, J. \& Evans, J.M. 1975. Techniques for Testing the Constancy of Regression Relationships Over Time. Journal of the Royal Statistical Society B 37: 149-163.

Bulletin of Statistics. Helsinki: Central Statistical Office of Finland. Various volumes.

Burton, M.P. \& Young, T. 1992. The Structure of Changing Tastes for Meat and Fish in Great Britain. European Review of Agricultural Economics 19, 2: 165-180.

BUSE, R.C. 1986. Is the Structure of the Demand for Food Changing? Implications for Projections. In: Capps, O., Jr. \& Senauer, B. (eds.). Food Demand Analysis: Implications for Future Consumption. p. 105-129. Blacksburg, Virginia: Department of Agricultural Economics, Virginia Polytechnic Institute and State University.

Call, S.T. \& Holahan, W.L. 1983. Microeconomics. Second edition. Belmont, California: Wadsworth Publishing Company.

Capps, O., Jr. \& Havlicek, J., Jr. 1987. Concepts of Consumer Demand Theory. In: Raunikar, R. \& Huang, C.-L. (eds.). Food Demand Analysis: Problems, Issues, and Empirical Evidence. p. 3-32. Ames: Iowa State University Press.

-, Tedford, J.R. \& HavliceK, J., Jr. 1985. Household Demand for Convenience and Nonconvenience Foods. American Journal of Agricultural Economics 67: 862869.

Chalfant, J.A. 1987. A Globally Flexible, Almost Ideal Demand System. Journal of Business \& Economic Statistics 5, 2: 233-242.

-, GraY, R.S. \& White, K.J. 1991. Evaluating Prior Beliefs in a Demand System: The Case of Meat Demand in Canada. American Journal of Agricultural Economics 73, 2: 476-490. 
Chang, H.-S., Green, R.D. \& Blaylock, J. 1992. Advertising, Product Promotion, and Market Demand. In: Johnson, S.R. et al. (eds.). Market Demand for Dairy Products. p. 83-102. Ames: Iowa State University Press.

Chavas, J.-P. 1983. Structural Change in Demand for Meat. American Journal of Agricultural Economics 65: 148153.

Chen, P.Y. \& Veeman, M.M. 1991. An Almost Ideal Demand System Analysis for Meats with Habit Formation and Structural Change. Canadian Journal of Agricultural Economics 39: 223-235.

Chiang, A.C. 1984. Fundamental Methods of Mathematical Economics. Third edition. Singapore: McGraw-Hill. $788 \mathrm{p}$.

Chол, S. \& Sosın, K. 1990. Testing for Structural Change: The Demand for Meat. American Journal of Agricultural Economics 72: 227-235.

Christensen, L.R., Jorgenson, D.W. \& LaU, L.J. 1975. Transcendental Logarithmic Utility Functions. American Economic Review 65, 3: 367-383.

Cox, T.L. 1992. A General Conceptual Framework for the Analysis of Advertising Impacts on Commodity Demand. In: Johnson, S.R. et al. (eds.). Market Demand for Dairy Products, p. 103-120. Ames: Iowa State University Press.

Craven, J.A. \& Haidacher, R.C. 1987. Comparison of Estimates from Three Linear Expenditure Systems. In: Raunikar, R. \& Huang, C.-L. (eds.). Food Demand Analysis: Problems, Issues, and Empirical Evidence. p. 91-113. Ames: Iowa State University Press.

Dahlgran, R.A. 1987. Complete Flexibility Systems and the Stationarity of U.S. Meat Demands. Western Journal of Agricultural Economics 12, 2: 152-163.

Deaton, A. 1975. Models and Projections of Demand in Post-War Britain. London: Chapman and Hall. 261 p.

- \& Muellbauer, J. 1980a. An Almost Ideal Demand System. American Economic Review 70: 312-326.

- \& Muellbauer, J. 1980b. Economics and Consumer Behavior. Cambridge, England: Cambridge University Press. $450 \mathrm{p}$.

Eales, J.S. \& Unnevehr, L.J. 1988. Demand for Beef and Chicken Products: Separability and Structural Change. American Journal of Agricultural Economics 70, 3: 521-532.

- \& UnNeVerr, L.J. 1993. Simultaneity and Structural Change in U.S. Meat Demand. American Journal of Agricultural Economics 75: 259-268.

EASTwOOD, D.B. \& Sun, T.Y. 1987. Complete Demand Systems and Policy Analysis. In: Raunikar, R. \& Huang, C.-L. (eds.). Food Demand Analysis: Problems, Issues, and Empirical Evidence, p. 154-167. Ames: Iowa State University Press.

EdGerton, D.L. 1990. Demand Functions - A Review. Models and Projections of Demand for Food in the Nordic Countries, Working paper SW/5. Lund: Department of Economics, University of Lund. 56 p.

1991. Some Practical Problems in the Estimation of Demand Systems. Models and Projections of Demand for Food in the Nordic Countries, Working paper. Un- published. $19 \mathrm{p}$.

- 1992a. Estimating Elasticities in Multi-Stage Demand Systems. A paper presented at AAEA Annual Meeting, Baltimore, Maryland, August 1992. 23 p.

- 1992b. The Structure and Estimation of Demand Systems. Models and Projections of Demand for Food in the Nordic Countries, Working paper. Unpublished. $39 \mathrm{p}$.

- 1993. Extensions to the Common Model for Sweden, Finland and Norway. Models and Projections of Demand for Food in the Nordic Countries, Working paper. Unpublished. $32 \mathrm{p}$.

- \& Wells, C. 1993. On the Use of the Cusumsq Statistic in Medium Sized Samples. Working Paper Series, 22/1993, Lund: Department of Economics, University of Lund. 14 p.

- \& Wells, C. 1995. Critical Values for the Cusumsq Statistic in Medium and Large Sized Samples. Oxford Bulletin of Economics and Statistics, forthcoming.

Engle, R.F. 1982. Autoregressive Conditional Heteroscedasticity with Estimates of the Variance of United Kingdom Inflation. Econometrica 50, 4: 987-1007.

- 1984. Wald, Likelihood Ratio, and Lagrange Multiplier Tests in Econometrics. In: Griliches, Z. \& Intriligator, M.D. (eds.). Handbook of Econometrics. Vol. 2, p. 775-826. North-Holland/Elsevier Science Publishers.

Evans, G.B.A. \& SAvin, N.E. 1982. Conflict among the Criteria Revisited: The W, LR and LM Tests. Econometrica 50, 3: 737-748.

FulPONI, L. 1989. The Almost Ideal Demand System: An Application to Food and Meat Groups for France. Journal of Agricultural Economics 40: 82-92.

GodDARD, D. 1983. An Analysis of Canadian Aggregate Demand for Food at Home and away from Home. Canadian Journal of Agricultural Economics 31: 289318.

GodFreY, L.G. 1978. Testing for Higher Order Serial Correlation in Regression Equations When the Regressors Include Lagged Dependent Variables. Econometrica 46: 1303-1310.

- 1988. Misspecification Tests in Econometrics: The Lagrange Multiplier Principle and Other Approaches. Cambridge: Cambridge University Press. 252 p.

Gofton, L. 1986. The Rules of the Table - Sociological Factors Influencing Food Choice. In: Ritson, C. et al. (eds.). The Food Consumer. p. 127-153. John Wiley \& Sons.

GollniCK, H.G.L. 1975. Dynamic Structure of Household Expenditures in the Federal Republic of Germany: Analysis and Projections 1955-1969/1971 and 1975/1977. Amsterdam, Oxford: North-Holland. 251 p.

Gould, B.W, Cox, T.L. \& Perali, F. 1990. The Demand for Fluid Milk Products in the U.S.: A Demand Systems Approach. Western Journal of Agricultural Economics 15, 1: 1-12.

GreEN, R. \& Alston, J.M. 1990. Elasticities in AIDS Models. American Journal of Agricultural Economics 72, 2: 442-445.

GrifFIth, G.R., LATtimore, R.G. \& Robertson, J.C. 1992. 
Demand Parameters and Policy Analysis for the Dairy Sector. In: Johnson, S.R. et al. (eds.). Market Demand for Dairy Products. p. 11-27. Ames: Iowa State University Press.

Haggrén, E. \& Kettunen, L. 1976. Maataloustuotteiden kulutusennusteet vuoteen 1985 (Consumption of Agricultural Products in Finland in 1985, in Finnish). The Agricultural Economics Research Institute, Finland, Research reports, No. 37. Helsinki. 48 p.

HaidACHER, R.C. 1992. Market Demand Structure for Dairy Products in the United States. In: Johnson, S.R. et al. (eds.). Market Demand for Dairy Products. p. 178210. Ames: Iowa State University Press.

HÄMÄLÄINEN, H. 1973. Yksityisten kulutusmenojen rakenne ja kehitys Suomessa vuosina 1965-1975. Summary: Private Consumption Patterns and Trends in Finland 1965-1975. The Research Institute of the Finnish Economy, Series B 5. 159 p.

Hansen, G. \& Sienknecht, H.-P. 1989. A Comparison of Demand Systems - A Case Study for West-Germany. Empirical Economics 14: 43-61.

Harvey, A.C. 1981. The Econometric Analysis of Time Series. Oxford: Philip Allan. 384 p.

Hausman, J. 1978. Specification Tests in Econometrics. Econometrica 46: 1251-71.

Hayes, D.J., Wahl, T.I. \& Williams, G.W. 1990. Testing Restrictions on a Model of Japanese Meat Demand. American Journal of Agricultural Economics 72: 556566.

Heien, D.M. \& Wessells, C.R. 1988. The Demand for Dairy Products: Structure, Prediction, and Decomposition. American Journal of Agricultural Economics 70, 2: 219-228.

— \& Willett, L.S. 1986. The Demand for Sweet Spreads: Demographic and Economic Effects for Detailed Commodities. Northeastern Journal of Agricultural and Resource Economics 15: 160-167.

Hicks, J.R. 1936. Value and Capital. Oxford University Press.

HJerpPE, R. 1989. The Finnish Economy 1860-1985. Growth and Structural Change. Bank of Finland Publications: Studies on Finland's economic growth, XIII. Helsinki: Bank of Finland, and Government Printing Centre. 295 p.

HuANG, K.S. \& Haidacher, R.C. 1983. Estimation of a Composite Food Demand System for the United States. Journal of Business \& Economic Statistics 1, 4: 285291.

- \& Haidacher, R.C. 1986. Projecting Aggregate Food Expenditures to the Year 2000. In: Capps, O., Jr. \& Senauer, B. (eds.). Food Demand Analysis: Implications for Future Consumption. p. 67-85. Blacksburg, Virginia: Department of Agricultural Economics, Virginia Polytechnic Institute and State University.

InTRILIGATOR, M.D. 1978. Econometric Models, Techniques, and Applications. Englewood Cliffs, New Jersey: Prentice-Hall. 638 p.

JARQUE, C.M. \& BERA, A.K. 1987. A Test for Normality of Observations and Regression Residuals. International
Statistical Review 55, 2: 163-172.

Johnson, S.R., Green, R.D., HASSAn, Z.A. \& SAFyURTLU, A.N. 1986. Market Demand Functions. In: Capps, O., Jr. \& Senauer, B. (eds.). Food Demand Analysis: Implications for Future Consumption. p. 1-33. Blacksburg, Virginia: Department of Agricultural Economics, Virginia Polytechnic Institute and State University.

JudGE, G.G., GRIFFITHS, W.E., HIL., R.C., LÜTKEPOHL, H. \& LEE, T.-C. 1985. The Theory and Practice of Econometrics. Second edition. New York: John Wiley \& Sons. 1019 p.

-, Hill, R.C., Griffiths, W.E., LÖTKEPOHL, H. \& LeE, T.-C. 1988. Introduction to the Theory and Practice of Econometrics. Second edition. New York: John Wiley \& Sons. 1024 p.

KAARLEHTO, P. 1959. Kananmunien kysynnän joustavuudesta kokonaismarkkinatilastojen valossa. Summary: On the Elasticity of Demand for Eggs. In: The Marketing Research Institute of Pellervo Society 1933-58. p. 39-50. Publications of the Marketing Research Institute of Pellervo Society, Finland, No. 1. Helsinki.

- 1961. Tulotason vaikutuksesta elintarvikemenoihin ja kulutusmääriin. Abstract: Income Elasticity of Food Expenditure and Consumption. Journal of the Scientific Agricultural Society of Finland 33, 1: 17-31.

KENNEDY, P. 1985. A Guide to Econometrics. Second edition. Oxford: Basil Blackwell. 238 p.

Kettunen, L. 1968. Demand and Supply of Pork and Beef in Finland. Publications of the Agricultural Economics Research Institute, Finland, No. 11. Helsinki. $93 \mathrm{p}$.

- 1976. Consumption of Agricultural Products in Finland in 1985. Journal of the Scientific Agricultural Society of Finland 48: 386-394.

KIVIET, J.F. 1986. On the Rigour of Some Misspecification Tests for Modelling Dynamic Relationships. Review of Economic Studies 53: 241-261.

Klevmarken, N.A. 1979. A Comparative Study of Complete Systems of Demand Functions. Journal of Econometrics 10: 165-191.

KoIvisto, E. \& KOPONEN, V. 1961a. Juuston kysynnästä. Summary: On Demand for Cheese. Publications of the Marketing Research Institute of Pellervo Society, Finland, No. 2. Helsinki. 8 p.

- \& KOPONEN, V. 1961b. Voin ja margariinin kysynnästä. Summary: On Demand for Butter and Margarine. Publications of the Marketing Research Institute of Pellervo Society, Finland, No. 3. Helsinki. 35 p.

- \& NAAPURI, M. 1961. Voin kulutus tuottajatalouksissa. Summary: Butter Consumption in Farm Households. Publications of the Marketing Research Institute of Pellervo Society, Finland, No. 4. Helsinki. 10 p.

KolA, J. 1991. Production Control in Finnish Agriculture. Agricultural Economics Research Institute, Finland, Research publications No. 64. Helsinki. 133 p. (Ph.D. diss., University of Helsinki).

KOPONEN, V. 1961. Lihajalosteiden kysynnän analysointia. Summary: An Analysis of the Demand for Processed Meat Products. Publications of the Marketing 
Research Institute of Pellervo Society, Finland, No. 5. Helsinki. 13 p.

- 1964. Kananmunien kysynnästä ja tarjonnasta. Summary: On Demand and Supply for Eggs. Publications of the Marketing Research Institute of Pellervo Society, Finland, No. 8. Helsinki. 29 p.

LAFranCE, J.T. 1991. When Is Expenditure "Exogenous" in Separable Demand Models? Western Journal of Agricultural Economics 16, 1: 49-62.

LAURILA, E.H. 1985. Kulutus Suomen kansantaloudessa 1900-1975. Summary: Consumption in Finnish Economy in the Years 1900-1975. The Research Institute of the Finnish Economy, Series B 42 . Helsinki. 717 p.

- 1987. Yksityinen kulutus Suomessa ajanjaksona 1880 1980. Summary: Private Consumption in Finland in the Period 1880-1980. The Research Institute of the Finnish Economy, Series B 52. Helsinki. 68 p.

LAURILA, I.P. 1990. Food Consumption in Finland, 19501989. Models and Projections of Demand for Food in the Nordic Countries, Working paper FI/9. Helsinki: University of Helsinki. $34 \mathrm{p}$.

LESER, C.E.V. 1963. Forms of Engel Functions. Econometrica 31: 694-703.

LEONTIEF, W. 1947. Introduction to a Theory of the Internal Structure of Functional Relationships. Econometrica $15: 361-373$.

LewBel, A. 1989. Nesting the AIDS and Translog Demand Systems. International Economic Review 30, 2: 349-356.

MCCABE, B.P.M. \& Harrison, M.J. 1980. Testing the Constancy of Regression Relationships Over Time using Least Squares Residuals. Applied Statistics 29, 2: 142 148.

MCLAREN, K.R. 1990. A Variant on the Arguments for the Invariance of Estimators in a Singular System of Equations. Econometric Reviews 9, 1: 91-102.

MadDalA, G.S. 1992. Introduction to Econometrics. Second edition. New York: Macmillan. 631 p.

MAFF 1990. Household Food Consumption and Expenditure 1989. Annual Report of the National Food Survey Committee. London: Ministry of Agriculture, Fisheries and Food, HMSO.

MAGNUS, J.R. 1978. Maximum Likelihood Estimation of the GLS Model with Unknown Parameters in the Disturbance Covariance Matrix. Journal of Econometrics 7: 281-312 (with corrigenda, Journal of Econometrics 10: 261.)

MANKINEN, R. 1988. Yksityisten kulutusmenojen rakenne ja kehitys Suomessa 1970-1991. Summary: Private Consumption Expenditure in Finland 1970-1991. The Research Institute of the Finnish Economy, Series B 56. Helsinki. 153 p.

MAnSER, M. 1976. Elasticities of Demand for Food: An Analysis Using Non-additive Utility Functions Allowing for Habit Formation. Southern Economic Journal 43: 879-891.

MARJOMAA, P. 1969. Yksityisten kulutusmenojen rakenne ja kehitys Suomessa vuosina 1948-1965. Summary: Private Consumption Expenditure Patterns and Trends in Finland 1948-1965. The Economic Research Institute of Finnish Industry, Series A 7. Helsinki. 263 p.

Mellin, I. 1983. Simple Static and Dynamic Regression Models: An Application to Consumption Expenditure in Finland. Department of Statistics, University of Helsinki, Research report, No. 42 . Helsinki. 69 p.

- 1985. Consumption Expenditure in Finland: Static and Dynamic Properties. Department of Statistics, University of Helsinki, Research report, No. 55. Helsinki. $128 \mathrm{p}$.

Mergos, G.J. \& Donatos, G.S. 1989. Demand for Food in Greece: An Almost Ideal Demand System Analysis. Journal of Agricultural Economics 40, 2: 178-184.

MichaleK, J. \& Keyzer, M.A. 1992. Estimation of a TwoStage LES-AIDS Consumer Demand System for Eight EC Countries. European Review of Agricultural Economics 19: 137-163.

Ministry of Finance 1993. Talouspolitiikan linja. Kansantalouden kehitys ja talouspolitiikka vuosina 1993-1997. (The Development of the Finnish Economy in 19931997, in Finnish). Helsinki: Valtiovarainministeriö (Ministry of Finance). 144 p.

Moschini, G. \& MeILKE, K.D. 1984. Parameter Stability and the U.S. Demand for Beef. Western Journal of Agricultural Economics 9, 2: 271-282.

- \& MeIlKe, K.D. 1989. Modeling the Pattern of Structural Change in U.S. Meat Demand. American Journal of Agricultural Economics 71, 2: 253-261.

MTTL 1992. Ravintotaseet vuosina 1990 ja 1991 (ennakko). (The Food Balance Sheets for 1990 and 1991, in Finnish). The Agricultural Economics Research Institute, Finland. Mimeogr.

National Accounts. Unpublished tables of the Central Statistical Office of Finland.

MYERS, L.H. 1986. Comments: Food Demand Analysis: Implications for Future Consumption. In: Capps, O., Jr. \& Senauer, B. (eds.). Food Demand Analysis: Implications for Future Consumption. p. 177-184. Blacksburg, Virginia: Department of Agricultural Economics, Virginia Polytechnic Institute and State University.

National Board of Agriculture 1993. Maatilahallitus 1992. Summary: National Board of Agriculture Yearbook. Helsinki: National Board of Agriculture. 33 p.

NYBERG, A. 1967. Alkoholijuomien kulutus ja hinnat. (The Consumption and Prices of Alcoholic Drinks, in Finnish). Väkijuomakysymyksen tutkimussäătiön julkaisu n:o 15 (Institute for Alcohol Research). Helsinki.

OsKam, A.J. 1992. Bayesian Estimation and Demand Forecasting: An Application for the Netherlands. In: Johnson, S.R. et al. (eds.). Market Demand for Dairy Products. p. 211-232. Ames: Iowa State University Press.

- \& Osinga, E. 1982. Analysis of Demand and Supply in the Dairy Sector of the Netherlands. European Review of Agricultural Economics 9: 365-413.

Pagan, A.R. \& Wickens, M.R. 1989. A Survey of Some Recent Econometric Methods. Economic Journal 99: 962-1025.

Phlips, L. 1983. Applied Consumption Analysis. Revised and Enlarged Edition. Amsterdam: North-Hol- 
land. $331 \mathrm{p}$.

Ploberger, W. \& Krämer, W. 1992. The CUSUM Test with OLS Residuals. Econometrica 60, 2: 271-285.

Pollak, R.A. 1970. Habit Formation and Dynamic Demand Functions. Journal of Political Economy 78: 745763.

- \& WALES, T.J. 1981. Demographic Variables in Demand Analysis. Econometrica 49, 6: 1533-1551.

- \& Wales, T.J. 1992. Demand System Specification and Estimation. New York, Oxford: Oxford University Press. 217 p.

PrÄttÄLÄ, R. 1989. Young People and Food. Socio-Cultural Studies of Food Consumption Patterns. Ph.D. diss., Department of Nutrition, University of Helsinki. 70 p.

Price, D.W. 1986. The Effects of Household Size and Composition on the Demand for Food. In: Capps, O., Jr. \& Senauer, B. (eds.). Food Demand Analysis: Implications for Future Consumption. p. 131-148. Blacksburg, Virginia: Department of Agricultural Economics, Virginia Polytechnic Institute and State University.

PUDNEY, S.E. 1981. An Empirical Method of Approximating the Separable Structure of Consumer Preferences. Review of Economic Studies 48: 561-577.

Rahiala, M. 1984. Yksityiset kulutusmenot Suomessa 1984-1988. (Private Consumption Expenditure in Finland 1984-1988, in Finnish). The Research Institute of the Finnish Economy, Series C 30. Helsinki. 131 p.

RAmSEY, J.B. 1969. Tests for Specification Errors in Classical Linear Least Squares Regression Analysis. Journal of the Royal Statistical Society, Series B, 31: 350371.

RAY, R. 1980. Analysis of a Time Series of Household Expenditure Surveys for India. Review of Economics and Statistics 62, 4: 595-602.

- 1985. Specification and Time Series Estimation of Dynamic Gorman Polar Form Demand Systems. European Economic Review 27: 357-374.

- 1986. Demographic Variables and Equivalence Scales in a Flexible Demand System: The Case of AIDS. Applied Economics 18: 265-278.

REYNOLDS, A. \& GodDARD, E. 1991. Structural Change in Canadian Meat Demand. Canadian Journal of Agricultural Economics 39: 211-222.

RICKERTSEN, K. 1992. Static and Dynamic AIDS Models of Demand for Food in Norway. Models and Projections of Demand for Food in the Nordic Countries, Working paper NO/6. Ås: The Agricultural University of Norway. 52 p.

Rimpel.̈̈, M., Rimpel.̈, A. \& Karvonen, S. 1989. Nuorten terveystapatutkimus. (Health-Related Habits of Young People, in Finnish). Julkaisuja 4/1989. Helsingin yliopiston kansanterveystieteen laitos (Department of Public Health, University of Helsinki). 20 p.

Roos, G. \& Aнola, M. 1989. Suomalaiset ja ruoka. (The Finns and Food, in Finnish). Maa- ja metsätalousministeriön elintarviketutkimusprojekti, 4.5.1.10/7 (Ministry of Agriculture and Forestry). Helsinki. 123 p.

Rossı, N. 1988. Budget Share Demographic Translation and the Aggregate Almost Ideal Demand System. Eu- ropean Economic Review 31: 1301-1318.

RouhiaInen, J. 1979. Changes in Demand for Food Items in Finland 1950-77 with Consumption Forecasts for 1980, 1985 and 1990. Publications of the Agricultural Economics Research Institute, Finland, No. 40. Helsinki. 84 p. (Ph.D. diss., University of Helsinki).

SAFYURTLY, A.N., JohnSON, S.R. \& HASSAN, Z.A. 1986. Recent Evidence on Market Demand Systems for Food in Canada. Canadian Journal of Agricultural Economics 34: 475-493.

SANDELIN, G. 1959. Naudanlihan kysynnästä. Summary: About Demand for Beef. In: The Marketing Research Institute of Pellervo Society 1933-58. p. 34-38. Publications of the Marketing Research Institute of Pellervo Society, Finland, No. 1. Helsinki.

Senauer, B., Asp, E. \& Kinsey, J. 1991. Food Trends and the Changing Consumer. St. Paul, Minnesota: Eagan Press. 385 p.

SimpurA, J. \& Österberg, E. 1989. Alkoholin kulutus kasvaa - muuttuvatko juomatavat? Abstract: Is Increasing Alcohol Consumption Changing Drinking Patterns in Finland? Alcohol Policy 54, 5: 219-227.

SLuTSKy, E.E. 1915. Sulla Teoria del Bilancio del Consomatore. Giornale degli Economisti 51: 1-26. English translation in: Stigler, G.J. \& Boulding, K. (eds.). 1953. Readings in Price Theory. p. 26-56. London-Chicago: Allen and Unwin.

Statistical Office 1992. Väestö 1992:6 (Population, in Finnish). Helsinki: Central Statistical Office of Finland.

- 1993. Kansantalouden tilinpito. (The National Accounts, in Finnish). Kansantalous 1993:4. Helsinki: Central Statistical Office of Finland.

SöDER, L. 1984. Kotitaloudet kansantalouden tilinpidossa. Summary: Households in National Accounts. Studies, No. 109. Helsinki: Central Statistical Office of Finland. 102 p.

Stewart, J. 1991. Econometrics. London: Philip Allan. $331 \mathrm{p}$.

StONE, J.R.N. 1954a. The Measurement of Consumers' Expenditure and Behaviour in the United Kingdom, 1920-1938. Vol. 1. Cambridge, U.K.: Cambridge University Press.

- 1954b. Linear Expenditure System and Demand Analysis: An Application to the Pattern of British Demand. Economic Journal 64: 511-527.

TANGermann, S. 1986. Economic Factors Influencing Food Choice. In: Ritson, C. et al. (eds.). The Food Consumer. p. 85-106. John Wiley \& Sons.

Teklu, T., Hassan, Z.A., Johnson, S.R. \& Stonehouse, D.P. 1992. Empirical Demand Systems. In: Johnson, S.R. et al. (eds.). Market Demand for Dairy Products. p. 46-65. Ames: Iowa State University Press.

THEIL, H. 1965. The Information Approach to Demand Analysis. Econometrica 33: 67-87.

- 1975, 1976. Theory and Measurement of Consumer Demand, Vol. 1, Vol. 2. Amsterdam: North-Holland. 335 p., 490 p.

ThомAS, R.L. 1985. Introductory Econometrics. Theory and Applications. London: Longman. 374 p. 
United Nations 1968. A System of National Accounts. Series F, No. 2, Rev. 3. New York: United Nations.

VÄISÄNEN, A. 1980. Yksityisten kulutusmenojen rakenne ja kehitys Suomessa vuosina 1970-1982. (Private Consumption Expenditure in Finland 1970-1982, in Finnish). The Research Institute of the Finnish Economy, Series B 23. Helsinki. 93 p.

VARIAN, H.R. 1992. Microeconomic Analysis. Third edition. New York: W.W. Norton \& Company. 548 p.

VARTIA. P. \& YLÄ-AnTTILA, P. 1992. Kansantalous 2017. Abstract: The Finnish Economy in 2017. Helsinki: The Research Institute of the Finnish Economy. 350 p.

VIRÉN, M. 1983. Yksityisten kulutusmenojen rakenne ja kehitys Suomessa vuosina 1950-1986. Summary: Private Consumption Expenditure in Finland 1950-1986. The Research Institute of the Finnish Economy, Series B 37. Helsinki. 235 p.

White, H. 1980. A Heteroskedasticity-Consistent Covariance Matrix Estimator and a Direct Test for Heteroskedasticity. Econometrica 48, 4: 817-838.

Williams, R.E. 1992. A Review of the Use of Demand Analysis for Milk and Dairy Products in the United Kingdom. In: Johnson, S.R. et al. (eds.). Market Demand for Dairy Products, p. 233-255. Ames: Iowa
State University Press.

Wohlgenant, M.K. 1985. Estimating Cross Elasticities of Demand for Beef. Western Journal of Agricultural Economics 10, 2: 322-329.

- 1986. Global Behavior of Demand Elasticities for Food: Implications for Demand Projections. In: Capps, O., Jr. \& Senauer, B. (eds.). Food Demand Analysis: Implications for Future Consumption. p. 35-48. Blacksburg, Virginia: Department of Agricultural Economics, Virginia Polytechnic Institute and State University.

WORKING, H. 1943. Statistical Laws of Family Expenditure. Journal of the American Statistical Association 38: 43-56.

Wu, D.-M. 1973. Alternative Tests of Independence Between Stochastic Regressors and Disturbances. Econometrica 41: 733-50.

Yen, S.T. \& Chern, W.S. 1992. Flexible Demand Systems with Serially Correlated Errors: Fat and Oil Consumption in the United States. American Journal of Agricultural Economics 74, 3: 689-697.

Zellner, A. 1962. An Efficient Method of Estimating Seemingly Unrelated Regressions and Tests for Aggregation Bias. Journal of American Statistical Association 57: 348-368. 


\title{
SELOSTUS
}

\section{Elintarvikkeiden kysyntä Suomessa: ekonometrinen tutkimus}

\author{
ILKKA P. LAURILA
}

Suomen Akatemia ja Helsingin yliopisto

Tutkimuksen tarkoituksena oli (a) tarkastella elintarvikkeiden kysynnän rakennetta Suomessa, (b) estimoida elintarvikkeiden kysyntäjärjestelmä, jossa elintarvikkeet on jaettu 18 ryhmään, (c) testata, miten hyvin suomalainen kulutuskäyttäytyminen vastaa kuluttajan teorian kuvaamaa käyttäytymistä, (d) estimoida elintarvikkeiden hinta- ja menojoustot, (e) laatia ennusteet elintarvikkeiden kulutuksen kehitykselle vuoteen 2000 , (f) tarkastella ennusteiden riippuvuutta vaihtoehtoisista hintaskenaarioista ja (g) tarkastella, miten tutkimuksen tuloksia voidaan ottaa huomioon, kun valmistellaan elintarvikkeiden hintoihin vaikuttavia toimenpiteitä.

Havaintoaineistona käytettiin kansantalouden tilinpidon yksityisiä kulutusmenoja kuvaavia aikasarjoja vuosilta 1950-1991. Aineisto osoitti, että vaikka elintarvikkeisiin käytetty rahamäärä kasvoi reaalisesti, elintarvikkeiden osuus kaikista kulutusmenoista supistui. 1950-luvun alussa kuluttajat käyttivät kotona ja kodin ulkopuolella nautittuihin elintarvikkeisiin $40 \%$ kaikista menoistaan; vuonna 1991 osuus oli $28 \%$. Ruokailu kodin ulkopuolella lisääntyi kotona tapahtuvan ruokailun kustannuksella. Kodin ulkopuolella nautittujen elintarvikkeiden osuus kokonaismenoista kasvoi havaintojakson aikana 3\%:sta $7 \%$ :iin samalla kun kotiin hankittujen elintarvikkeiden osuus kokonaismenoista laski $37 \%$ :sta $21 \%$ :iin. Jos alkoholijuomat jätetään ottamatta huomioon, kotiin hankittujen elintarvikkeiden osuus kokonaismenoista laski 34\%:sta 16\%:iin.

Kotiin hankittujen elintarvikkeiden keskinäiset budjettiosuudet såilyivăt 40 vuoden ajan varsin muuttumattomina, kun asiaa tarkastellaan suurryhmien tasolla. Näitä suurryhmiä ovat eläinkunnan tuotteet, kasvikunnan tuotteet ja juomat. Sen sijaan suurryhmien sisällä tapahtui siirtymiä. Eläinkunnan tuotteissa kulutusmenot siirtyivät meijerituotteista lihaan ja kalaan. Kasvikunnan tuotteissa kulutusmenot siirtyivät jauhoista hedelmiin samalla kun leipomotuotteiden ja vihannesten osuudet säilyivät entisellään. Juomissa kulutusmenot siirtyivät maidosta ja kahvista alkoholijuomiin ja virvoitusjuomiin.

Kotitalouksien kuluttamat elintarvikkeet jaettiin 18 tuoteryhmään, ja näiden tuoteryhmien kulutuksen riippuvuus hinnoista, kokonaismenoista ja aiemmasta kulutusrakenteesta haluttiin selvittäă. Tutkimusongelmaa lähestyttiin nk. täydellisen kysyntäjärjestelmän avulla. Menetelmän etu yhden yhtälön menetelmiin verrattuna on ensinnäkin se, että hyödykkeiden väliset riippuvuudet on mahdollista ottaa analyysissä huomioon ja toiseksi se, että tảydellinen kysyntäjärjestelmä on suora linkki kuluttajan teorian ku- vaaman yksittäisen kuluttajan ja kansantalouden tason havaintoaineiston välillä. Täydellisenä kysyntäjärjestelmänä käytettiin AIDS-mallia (Almost Ideal Demand System, "lähes täydellinen kysyntäjärjestelmä”). Tavanomaisen staattisen AIDS-mallin ohella estimoinnissa käytettiin dynaamista AIDS-mallia sekä mallia, jossa joidenkin parametrien arvojen annettiin muuttua ajan funktiona (nk. rakenteellisen muutoksen AIDS). Nelitasoinen hierarkkinen kysyntäjärjestelmä muodostui seitsemästä osaongelmasta. Kullekin osaongelmalle valittiin sopivimman tyyppinen AIDS-malli. Valintakriteereinä käytettiin tuloksia testeistä, joissa testattiin kysyntäteoriasta johdettuja parametrien rajoituksia sekä mallin hyvyyttä tilastollisessa mielessà.

Valtaosa estimoiduista malleista ei täyttänyt kysyntäteoriasta johdettuja Slutskyn ehtoja, mikä on tavallinen tulos vastaavissa tutkimuksissa. Mallien selitysasteet olivat korkeita, ja useimmiten dynamiikan lisääminen korotti selitysastetta huomattavasti. Testien mukaan mallien dynamiikka oli määritelty oikein, mutta jäljelle jäi ongelmia, muun muassa parametrien arvojen epävakautta.

Estimoidut mallit tulkittiin hinta- ja menojoustojen avulla. Havaintojakson aikana kysynnässä tapahtui rakenteellisia muutoksia niin että 1960-luvun joustot poikkesivat 1990-luvun joustoista. Seuraavassa esitettävät joustot kuvaavat kysyntää keskimäärin vuosina 1961-1991. Lihajalosteet, alkoholijuomat, kahvi, kuivatuotteet (makeiset, mausteet, keittoainekset, jäătelö, sokeri ja hillot), hedelmät sekä vihannekset olivat luksustuotteita (menojousto yli yhden). Sama koski kodin ulkopuolella tapahtuvaa ruokailua. Muut tuoteryhmät olivat välttämättömyyshyödykkeitä (menojousto alle yhden). Voin, margariinin, hapanmaitotuotteiden ja kerman sekä leipomotuotteiden menojoustot olivat lăhellä nollaa, mikä tarkoittaa sitä, että kokonaismenojen kehityksellä oli vain vähäinen vaikutus kyseisten elintarvikkeiden kulutukseen. Virvoitusjuomat ja kodin ulkopuolella tapahtuva ruokailu olivat hintajoustavia, eli niiden kulutus muuttui herkästi oman hinnan muutosten seurauksena. Kaikkien muiden tuoteryhmien kulutus oli oman hinnan suhteen jäykkää (taulukko).

Estimoitua kysyntäjärjestelmää käytettiin tulevan kulutuksen ennustamiseen. Vuoteen 2000 ulottuvien ennusteiden laadintaa varten arvioitiin kokonaiskulutusmenojen tuleva kehitys sekä laadittiin neljä vaihtoehtoista skenaariota hyödykkeiden hintasuhteiden kehityksestä. Kaksi skenaariota perustui Suomessa havaittuun aikaisempaan kehitykseen (1960-91 ja 1980-91 trendit), yksi skenaario 
Taulukko. Kysynnän hinta- ja tulojoustot Suomessa keskimäärin vuosina 1961-1991.

\begin{tabular}{|c|c|c|c|}
\hline \multirow{2}{*}{$\begin{array}{l}\text { Menojouston } \\
\text { vaihteluväli }\end{array}$} & \multicolumn{3}{|c|}{ Hintajousto oman hinnan suhteen (kompensoimaton) } \\
\hline & $0 . .-0.30$ & $-0.31 . .-1.00$ & $<-1.01$ \\
\hline$-0.20 . .0 .30$ & Jalostamaton liha & $\begin{array}{l}\text { Kala } \\
\text { Hapanmaitotuotteet } \\
\text { ja kerma } \\
\text { Voi } \\
\text { Margariini } \\
\text { Leipomotuotteet }\end{array}$ & \\
\hline $0.31 . .1 .00$ & $\begin{array}{l}\text { Kananmunat } \\
\text { Maito } \\
\text { Juusto }\end{array}$ & Jauhot & Virvoitusjuomat \\
\hline$>1.01$ & $\begin{array}{l}\text { Lihajalosteet } \\
\text { Kahvi }\end{array}$ & $\begin{array}{l}\text { Alkoholijuomat } \\
\text { Hedelmät } \\
\text { Vihannekset } \\
\text { Kuivatuotteet }\end{array}$ & $\begin{array}{l}\text { Kodin } \\
\text { ulkopuolinen } \\
\text { ruokailu }\end{array}$ \\
\hline
\end{tabular}

jähmetti hintasuhteet sellaisiksi kuin ne olivat vuonna 1991, ja yksi skenaario kuvasi hintasuhteiden kehitystä siinä tilanteessa, että Suomesta tulisi Euroopan unionin jäsen. Lukuunottamatta skenaariota, jossa hintasuhteet säilyisivät sellaisina kuin ne olivat vuonna 1991, kotiin hankittujen elintarvikkeiden oletettiin halpenevan keskimäärin 4$11 \%$ vuodesta 1991 vuoteen 2000.

Ennusteet olivat herkkiä hintasuhteiden muutoksille. Suurin merkitys sillä, mikä skenaario toteutuu, on lihajalosteiden, kalan ja virvoitusjuomien kulutukseen sekä kodin ulkopuolella tapahtuvaan ruokailuun. Sen sijaan laajojen tuoteryhmien, kuten kasvikunnan tuotteiden sekä meijerituotteiden - ja yleisemminkin eläinkunnan tuotteiden - kulutus kehittyy ennusteen mukaan 1990-luvulla suuremmin riippumatta hintasuhteiden muutoksista.

Jos kulutushyödykkeiden hintasuhteet säilyisivät 1990luvun sellaisina kuin ne olivat vuonna 1991, lihajalosteiden, alkoholijuomien, virvoitusjuomien ja kuivatuotteiden kulutus sekä kodin ulkopuolinen ruokailu kasvaisivat huomattavasti, kun taas maidon ja muiden meijerituotteiden kulutus säilyisi ennallaan. Jos kulutushyödykkeiden hintasuhteet noudattaisivat historiallisia trendejä, lihajalos- teiden ja kalan kulutus kasvaisi huomattavasti, kun taas jalostamattoman lihan, meijerituotteiden (muiden kuin maidon) ja virvoitusjuomien - mahdollisesti myös kananmunien, maidon ja kahvin - kulutus alenisi. Euroopan unionin jäsenyyden mahdollisesti mukanaan tuoma hintarakenne kasvattaisi kuivatuotteiden kulutusta sekä kodin ulkopuolista ruokailua, kun taas virvoitusjuomien ja kasvikunnan tuotteiden kulutus säilyisi ennallaan.

Suomen jäsenyyden Euroopan unionissa arvioitiin vaikuttavan siten, että elintarvikkeiden osuus kuluttajien budjetissa laskee. Lasku olisi nopeampi kuin lasku, joka syntyisi siitä, että hyödykkeiden hintasuhteet jähmettyisivät vuoden 1991 tilanteen mukaisiksi tai muuttuisivat historiallisten trendien viitoittamana. Euroopan unioni -vaihtoehdossa kotiin hankittujen elintarvikkeiden ja kodin ulkopuolella tapahtuvan ruokailun yhteinen budjettiosuus laskisi vuoden 1991 28\%:sta 27\%:iin vuonna 2000. Kotiin hankittujen elintarvikkeiden budjettiosuus laskisi $21 \%$ :sta $18 \%$ :iin, kun taas kotiin hankitut elintarvikkeet vähennettynä alkoholijuomilla vastaisivat keskivertokuluttajan budjetista $14 \%$ vuonna 2000, kun budjettiosuus vuonna 1991 oli $16 \%$. 


\section{Definition of commodity bundles}

The following categories were used in the present study. Budget shares describe the composition of the categories.

Total Private Consumption (including Durables and Semi-Durables) refers to the final consumption expenditure of households in the domestic market. The category is composed of Private Consumption (78\% of the expenditure in 1991), Semi-Durables (13\%), and Durables (9\%).

Private Consumption refers to the final consumption expenditure of households in the domestic market excluding Durables and Semi-Durables. The category consists of Food-at-Home (27\% of the expenditure in 1991), Food-awayfrom-Home $(9 \%)$, Non-Durables $(19 \%)$, and Services $(45 \%)$.

Food-at-Home is that part of consumers' expenditure which is allocated to food and drink consumed at home. The bundle is composed of Animalia (34\% of the expenditure in 1991), Beverages (32\%), Vegetablia (26\%), and Groceries $(9 \%)$.

Food-away-from-Home consists of expenditure on food and drink in restaurants and cafes. Consumers' expenditure on food catered at places of work is included. Noteworthy is that the share of services of the expenditure is remarkable.

Non-Durables consist of non-durable goods excluding Food-at-Home. Fuels, medicines, home cleaning chemicals, and literature are the largest groups.

Services consist of services excluding expenditure on Food-away-from-Home. The biggest expenditure groups are rents and insurance, house service, medical and sanitational treatment, travel tickets, telecommunications, education, culture, hotel fees, TV licenses, and lottery.

Animalia (food from animal sources) is composed of Meat and Fish (64\% of the expenditure in 1991), Dairy Products $(33 \%)$, and Eggs $(4 \%)$.

Beverages refer to Alcoholic Drinks (68\% of the expenditure in 1991), Fresh Milk (16\%), Soft Drinks (9\%), and Hot Drinks $(8 \%)$.

Vegetablia (food from vegetable sources) are Bread and Cake (41\% of the expenditure in 1991), Fruits (28\%), Vegetables $(19 \%)$, and Flour $(13 \%)$.

Groceries cover candies and chocolate (36\% of the expenditure in 1991), spices and soups (24\%), ice-cream $(17 \%)$, sugar $(15 \%)$ jam $(7 \%)$, and honey $(1 \%)$.

Meat and Fish is composed of Meat Products (53\% of the expenditure in 1991), Carcase Meat (36\%), and Fish $(10 \%)$.

Dairy Products include Cheese (40\% of the expenditure in 1991), Sour Milk and Cream (31\%), Butter (17\%), and Margarine (12\%).

Meat Products are combined of sausages (56\% of the expenditure in 1991), canned and prepared meat (34\%), and other meat products $(10 \%)$.

Carcase Meat consists of beef and veal (59\% of the expenditure in 1991$)$, pork (22\%), poultry (12\%), game (5\%), mutton, lamb, and reindeer $(2 \%)$. Unlike in some other definitions, the bundle includes poultry.

Fish covers unprocessed fish (69 \% of the expenditure in 1991) and canned and processed fish (31\%).

Alcoholic Drinks refer to beverages which contain alcohol.

Fresh Milk is composed of standard milk, i.e. pasteurised and homogenised milk with fat content close to the rawmaterial, low fat milk (since 1970), skimmed milk (altogether 94\% in 1991), and whole milk, i.e. the milk delivered directly from the farm and the milk consumed by the producer's household $(6 \%)$.

Soft Drinks consist of soft drinks and mineral waters.

Hot Drinks are coffee $(89 \%$ of the expenditure in 1991$)$, tea $(5 \%)$, cocoa $(4 \%)$, and coffee and tea extracts $(2 \%)$.

Bread and Cake is composed of coffee cake (52\% of the expenditure in 1991) and bread (48\%).

Fruits consist of cultivated fruits and berries ( $58 \%$ of the expenditure in 1991$)$, juices (19\%), canned fruits (11\%), wild berries $(10 \%)$, and dried fruits and nuts $(2 \%)$.

Vegetables are a combination of potatoes from farms (36\% of the expenditure in 1991), vegetables and roots from industry $(31 \%)$, vegetables and roots from farms $(28 \%)$, mushrooms $(3 \%)$, and potatoes from industry $(2 \%)$.

Flour covers flour and hulled grain (68\% of the expenditure in 1991$)$, potato flour $(5 \%)$, rice $(4 \%)$, malt $(1 \%)$, and other cereal products $(21 \%)$.

Cheese consists of emmentaler (swiss) and edam (51\% of the expenditure in 1991) and others (49\%).

Sour Milk and Cream cover sour milk products (64\% of the expenditure in 1991) and cream (36\%).

Butter covers dairy butter, butter-vegetable-oil mixtures, and cottage butter, which, however, was only $0.2 \%$ of the total in 1991 .

Margarine covers margarine (90\% of the expenditure in 1991$)$ and oils (10\%). 


\section{Food demand system for Finland: parameter estimates}

In the following tables, parameter coefficients of the preferred specifications of the AIDS models are presented. Group by group, the presentation follows the same mode. First come the sample period, the two joint points in the switching regressions (for the beginning and the end of switch period), and the [natural] logarithm of the subsistence expenditure $\left(\alpha_{0}\right)$. There are three tables for each group: (a) parameter values, (b) their robust standard errors (White's heteroskedasticity consistent standard errors), and (c) the $t$-values, which were obtained by dividing the coefficient by the respective standard error. $\alpha_{i}$ is the constant in equation $i, \gamma_{i j}$ is the price parameter for commodity $j$ in equation $i, \beta$ is the expenditure parameter in equation $i, \beta_{i}$ is the shifting expenditure parameter in equation $i, \theta_{i j}$ is the dynamic parameter for share $j$ in equation $i$.

\section{GROUP 1: PRIVATE CONSUMPTION}

MODEL: SWITCHING DYNAMIC AIDS (UNRESTRICTED)

Sample period: 1961-1991

\section{PARAMETER ESTIMATES}

\begin{tabular}{|c|c|c|c|c|c|c|c|c|c|c|c|}
\hline 1 & $\alpha_{l}$ & $\gamma 1$ & $\gamma 12$ & $\gamma 13$ & $\gamma 14$ & $\beta \mathrm{t}$ & $\beta * 1$ & $\theta \mathrm{u} 1$ & $\theta 12$ & $\theta, 3$ & $\theta, 4$ \\
\hline 1 & 0.0319 & 0.2565 & -0.1061 & -0.0535 & -0.1082 & 0.0693 & -0.0114 & 0.2777 & -0.8025 & 0.2433 & 0.2816 \\
\hline 2 & -0.0493 & 0.0118 & -0.0151 & 0.0037 & -0.0156 & 0.0951 & 0.0021 & -0.0786 & 0.2075 & -0.1146 & -0.0143 \\
\hline 3 & 0.0719 & -0.0364 & 0.0290 & 0.1530 & -0.1265 & 0.0334 & -0.0205 & 0.2092 & -0.4283 & 0.0828 & 0.1363 \\
\hline 4 & 0.9455 & -0.2320 & 0.0923 & -0.1032 & 0.2503 & -0.1978 & 0.0298 & -0.4083 & 1.0233 & -0.2115 & -0.4035 \\
\hline
\end{tabular}

\section{STANDARD ERRORS OF PARAMETERS (ROBUST)}

\begin{tabular}{|c|c|c|c|c|c|c|c|c|c|c|c|}
\hline 1 & $\alpha_{t}$ & $\gamma \mathrm{nl}$ & $\gamma 2$ & $\gamma 13$ & $\gamma 14$ & $\beta_{\mathbf{t}}$ & $\beta * 1$ & $\theta \mathrm{n}$ & $\theta, 2$ & $\theta, 3$ & $\theta, 4$ \\
\hline 1 & 0.0731 & 0.0242 & 0.0140 & 0.0255 & 0.0464 & 0.0217 & 0.0029 & 0.0807 & 0.1615 & 0.0913 & 0.1239 \\
\hline 2 & 0.0582 & 0.0147 & 0.0130 & 0.0102 & 0.0180 & 0.0171 & 0.0012 & 0.0487 & 0.1296 & 0.0416 & 0.0711 \\
\hline 3 & 0.1061 & 0.0284 & 0.0166 & 0.0247 & 0.0510 & 0.0283 & 0.0029 & 0.0858 & 0.2576 & 0.0937 & 0.1559 \\
\hline 4 & 0.0649 & 0.0201 & 0.0143 & 0.0201 & 0.0277 & 0.0205 & 0.0028 & 0.0752 & 0.1464 & 0.0768 & 0.0979 \\
\hline
\end{tabular}

\section{T-STATISTIC}

\begin{tabular}{|c|c|c|c|c|c|c|c|c|c|c|c|}
\hline 1 & $\alpha l$ & $\gamma \mathrm{nl}$ & $\gamma 22$ & $\gamma 13$ & $\gamma 14$ & $\beta \mathrm{t}$ & $\beta * 1$ & $\theta \mathrm{ul}$ & $\theta, 2$ & $\theta 13$ & $\theta, 4$ \\
\hline 1 & 0.44 & 10.60 & -7.59 & -2.10 & -2.33 & 3.20 & -3.93 & 3.44 & -4.97 & 2.66 & 2.27 \\
\hline 2 & -0.85 & 0.80 & -1.17 & 0.36 & -0.87 & 5.55 & 1.68 & -1.61 & 1.60 & -2.76 & -0.20 \\
\hline 3 & 0.68 & -1.28 & 1.74 & 6.19 & -2.48 & 1.18 & -7.05 & 2.44 & -1.66 & 0.88 & 0.87 \\
\hline 4 & 14.58 & -11.52 & 6.43 & -5.13 & 9.03 & -9.64 & 10.48 & -5.43 & 6.99 & -2.76 & -4.12 \\
\hline
\end{tabular}


GROUP 2: FOOD-AT-HOME

MODEL: SWITCHING DYNAMIC AIDS (UNRESTRICTED)

Sample period: 1961-1991 Joint points: 1961 and 1984

$\alpha 0: 7.5380$

PARAMETER ESTIMATES

\begin{tabular}{|l|lllllllllll|}
\hline $\mathrm{l}$ & $\alpha \mathrm{l}$ & $\gamma \mathrm{l} 1$ & $\gamma \mathrm{l} 2$ & $\gamma \mathrm{l} 3$ & $\gamma \mathrm{l} 4$ & $\beta_{\mathrm{l}}$ & $\beta * 1$ & $\theta \mathrm{l} 1$ & $\theta \mathrm{l} 2$ & $\theta \mathrm{\imath} 3$ & $\theta \mathrm{l} 4$ \\
\hline 1 & 0.3332 & 0.0850 & -0.0904 & -0.0461 & -0.0194 & -0.1465 & 0.1217 & 0.0750 & 0.1511 & 0.0519 & -0.2780 \\
2 & 0.2598 & 0.0920 & 0.0850 & -0.1000 & -0.0258 & 0.1155 & -0.0819 & -0.0029 & 0.2115 & -0.3688 & 0.1603 \\
3 & 0.3897 & -0.1523 & 0.0307 & 0.1258 & -0.0081 & -0.0642 & 0.0199 & -0.1263 & -0.3333 & 0.2495 & 0.2101 \\
4 & 0.0173 & -0.0248 & -0.0253 & 0.0204 & 0.0532 & 0.0952 & -0.0597 & 0.0542 & -0.0293 & 0.0675 & -0.0924 \\
\hline
\end{tabular}

STANDARD ERRORS OF PARAMETERS (ROBUST)

\begin{tabular}{|l|lllllllllll|}
\hline $\mathrm{t}$ & $\alpha \mathrm{l}$ & $\gamma \mathrm{t} 1$ & $\gamma \mathrm{t} 2$ & $\gamma \mathrm{l} 3$ & $\gamma \mathrm{l} 4$ & $\beta \mathrm{t}$ & $\beta \bullet 1$ & $\theta \mathrm{l} 1$ & $\theta \mathrm{t} 2$ & $\theta \mathrm{t3}$ & $\theta \mathrm{t} 4$ \\
\hline 1 & 0.0465 & 0.0263 & 0.0234 & 0.0220 & 0.0115 & 0.0323 & 0.0244 & 0.1059 & 0.0874 & 0.0834 & 0.1721 \\
2 & 0.0520 & 0.0377 & 0.0245 & 0.0291 & 0.0119 & 0.0399 & 0.0309 & 0.0990 & 0.1004 & 0.0916 & 0.1374 \\
3 & 0.0563 & 0.0319 & 0.0278 & 0.0361 & 0.0133 & 0.0442 & 0.0366 & 0.1160 & 0.1403 & 0.1264 & 0.2482 \\
4 & 0.0233 & 0.0193 & 0.0133 & 0.0198 & 0.0093 & 0.0209 & 0.0158 & 0.0559 & 0.0633 & 0.0469 & 0.0773 \\
\hline
\end{tabular}

T-STATISTIC

\begin{tabular}{|c|rrrrrrrrrrrr|}
\hline $\mathrm{t}$ & $\alpha \mathrm{l}$ & $\gamma \mathrm{t} 1$ & $\gamma \mathrm{t} 2$ & $\gamma \mathrm{l} 3$ & $\gamma \mathrm{l} 4$ & $\beta \mathrm{t}$ & $\beta * 1$ & $\theta \mathrm{l} 1$ & $\theta \mathrm{r} 2$ & $\theta \mathrm{l} 3$ & $\theta \mathrm{l} 4$ \\
\hline 1 & 7.16 & 3.23 & -3.86 & -2.09 & -1.69 & -4.54 & 4.98 & 0.71 & 1.73 & 0.62 & -1.62 \\
2 & 5.00 & 2.44 & 3.47 & -3.44 & -2.17 & 2.89 & -2.65 & -0.03 & 2.11 & -4.03 & 1.17 \\
3 & 6.92 & -4.78 & 1.11 & 3.48 & -0.61 & -1.45 & 0.54 & -1.09 & -2.37 & 1.97 & 0.85 \\
4 & 0.74 & -1.28 & -1.91 & 1.03 & 5.74 & 4.55 & -3.78 & 0.97 & -0.46 & 1.44 & -1.20 \\
\hline
\end{tabular}

GROUP 31: ANIMALIA

MODEL: STATIC AIDS (UNRESTRICTED)

Sample period: 1961-1991 Joint points: none

$\alpha 0: 6.5058$

PARAMETER ESTIMATES

\begin{tabular}{|c|c|c|c|c|c|c|c|c|c|}
\hline 1 & $\alpha_{\mathrm{t}}$ & $\gamma \mathrm{tl}$ & $\gamma 12$ & $\gamma 13$ & $\beta_{i}$ & $\beta * 1$ & $\theta, 1$ & $\theta 12$ & $\theta+3$ \\
\hline 1 & 0.1830 & 0.2278 & -0.1369 & -0.1018 & 0.2730 & & & & \\
\hline 2 & 0.7688 & -0.1618 & 0.1171 & 0.0619 & -0.2733 & & & & \\
\hline 3 & 0.0481 & -0.0661 & 0.0197 & 0.0398 & 0.0003 & & & & \\
\hline
\end{tabular}

STANDARD ERRORS OF PARAMETERS (ROBUST)

\begin{tabular}{|c|c|c|c|c|c|c|c|c|c|}
\hline 1 & $\alpha_{1}$ & $\gamma, 1$ & $\gamma \mathrm{L} 2$ & $\gamma 13$ & $\beta_{t}$ & $\beta * 1$ & $\theta, 1$ & $\theta 12$ & $\theta 13$ \\
\hline 1 & 0.0462 & 0.0494 & 0.0408 & 0.0179 & 0.0304 & & & & \\
\hline 2 & 0.0476 & 0.0490 & 0.0414 & 0.0151 & 0.0312 & & & & \\
\hline 3 & 0.0095 & 0.0131 & 0.0113 & 0.0089 & 0.0066 & & & & \\
\hline
\end{tabular}

T-STATISTIC

\begin{tabular}{|c|c|c|c|c|c|c|c|c|c|}
\hline 1 & $\alpha_{1}$ & $\gamma \mathrm{tl}$ & $\gamma 12$ & $\gamma+3$ & $\beta_{1}$ & $\beta * 1$ & $\theta, 1$ & $\theta\llcorner 2$ & $\theta 13$ \\
\hline 1 & 3.96 & 4.61 & -3.35 & -5.70 & 8.98 & & & & \\
\hline 2 & 16.16 & -3.30 & 2.83 & 4.10 & -8.76 & & & & \\
\hline 3 & 5.04 & -5.03 & 1.75 & 4.47 & 0.05 & & & & \\
\hline
\end{tabular}


GROUP 32: BEVERAGES

MODEL: DYNAMIC AIDS (UNRESTRICTED)

Sample period: 1961-1991 Joint points: none

$\alpha 0: 6.2005$

PARAMETER ESTIMATES

\begin{tabular}{|c|c|c|c|c|c|c|c|c|c|c|c|}
\hline 1 & $\alpha_{\mathrm{l}}$ & $\gamma, 1$ & $\gamma 12$ & $\gamma 13$ & $\gamma 14$ & $\beta_{1}$ & $\beta * 1$ & $\theta \mathrm{t1}$ & $\theta\llcorner 2$ & $\theta, 3$ & $\theta, 4$ \\
\hline 1 & 0.6616 & 0.1667 & -0.0890 & 0.0019 & -0.0613 & 0.1623 & & -0.4968 & -0.7176 & 1.5869 & -0.3725 \\
\hline 2 & 0.1813 & -0.1704 & 0.1148 & 0.0558 & -0.0437 & -0.1088 & & 0.2394 & 0.5546 & -0.9503 & 0.1563 \\
\hline 3 & 0.1422 & 0.0270 & 0.0065 & -0.0205 & -0.0039 & -0.0224 & & -0.0176 & -0.1514 & 0.1815 & -0.0125 \\
\hline 4 & 0.0149 & -0.0234 & -0.0323 & -0.0373 & 0.1089 & -0.0311 & & 0.2750 & 0.3144 & -0.8181 & 0.2287 \\
\hline
\end{tabular}

STANDARD ERRORS OF PARAMETERS (ROBUST)

\begin{tabular}{|c|c|c|c|c|c|c|c|c|c|c|c|}
\hline 1 & $\alpha_{1}$ & $\gamma \mathrm{tl}$ & $\gamma 12$ & $\gamma 13$ & $\gamma 14$ & $\beta_{1}$ & $\beta * 1$ & $\theta, 1$ & $\theta\llcorner 2$ & $\theta 13$ & $\theta 14$ \\
\hline 1 & 0.1575 & 0.0455 & 0.0474 & 0.0216 & 0.0206 & 0.0888 & & 0.3861 & 0.1747 & 0.6731 & 0.2387 \\
\hline 2 & 0.1327 & 0.0348 & 0.0317 & 0.0203 & 0.0151 & 0.0759 & & 0.3528 & 0.1326 & 0.6157 & 0.2183 \\
\hline 3 & 0.0530 & 0.0150 & 0.0120 & 0.0070 & 0.0039 & 0.0113 & & 0.0886 & 0.0550 & 0.1981 & 0.0683 \\
\hline 4 & 0.1191 & 0.0305 & 0.0380 & 0.0140 & 0.0104 & 0.0397 & & 0.1420 & 0.1298 & 0.3293 & 0.1084 \\
\hline
\end{tabular}

T-STATISTIC

\begin{tabular}{|c|c|c|c|c|c|c|c|c|c|c|c|}
\hline$t$ & $\alpha_{l}$ & $\gamma \mathrm{nl}$ & $\gamma 2$ & $\gamma 13$ & $\gamma 14$ & $\beta_{t}$ & $\beta * 1$ & $\theta \mathrm{\imath} 1$ & $\theta, 2$ & $\theta .3$ & $\theta, 4$ \\
\hline 1 & 4.20 & 3.67 & -1.88 & 0.09 & -2.98 & 1.83 & & -1.29 & -4.11 & 2.36 & -1.56 \\
\hline 2 & 1.37 & -4.89 & 3.62 & 2.75 & -2.89 & -1.43 & & 0.68 & 4.18 & -1.54 & 0.72 \\
\hline 3 & 2.68 & 1.80 & 0.55 & -2.91 & -1.01 & -1.98 & & -0.20 & -2.75 & 0.92 & -0.18 \\
\hline 4 & 0.13 & -0.77 & -0.85 & -2.67 & 10.50 & -0.78 & & 1.94 & 2.42 & -2.48 & 2.11 \\
\hline
\end{tabular}

GROUP 33: VEGETABLIA

MODEL: SWITCHING DYNAMIC AIDS (UNRESTRICTED)

Sample period: 1961-1991 Joint points: 1961 and 1989

$\alpha 0: 6.3008$

PARAMETER ESTIMATES

\begin{tabular}{|c|c|c|c|c|c|c|c|c|c|c|c|}
\hline 1 & $\alpha_{t}$ & $\gamma \mathrm{nl}$ & $\gamma 22$ & $\gamma 13$ & $\gamma 4$ & $\beta_{\mathrm{t}}$ & $\beta * 1$ & $\theta \mathrm{t1}$ & $\theta+2$ & $\theta 13$ & $\theta, 4$ \\
\hline 1 & 0.7764 & -0.1835 & -0.0246 & 0.0182 & 0.0630 & -0.5450 & 0.2907 & 0.0942 & 0.0776 & -0.1120 & -0.0597 \\
\hline 2 & -0.0350 & 0.1490 & 0.0792 & -0.0637 & -0.0712 & 0.3555 & -0.2169 & 0.0914 & 0.2724 & 0.1598 & -0.5236 \\
\hline 3 & -0.0959 & -0.0213 & -0.0229 & 0.0620 & -0.0445 & 0.1394 & 0.0764 & 0.0972 & 0.0092 & -0.2142 & 0.1079 \\
\hline 4 & 0.3546 & 0.0559 & -0.0317 & -0.0165 & 0.0527 & 0.0501 & -0.1502 & -0.2828 & -0.3591 & 0.1665 & 0.4754 \\
\hline
\end{tabular}

STANDARD ERRORS OF PARAMETERS (ROBUST)

\begin{tabular}{|l|lllllllllll|}
\hline $\mathrm{l}$ & $\alpha \mathrm{l}$ & $\gamma \mathrm{l} 1$ & $\gamma \mathrm{l} 2$ & $\gamma \mathrm{l} 3$ & $\gamma \mathrm{l} 4$ & $\beta \mathrm{t}$ & $\beta * 1$ & $\theta \mathrm{t} 1$ & $\theta \mathrm{t} 2$ & $\theta \mathrm{t3}$ & $\theta \mathrm{r} 4$ \\
\hline 1 & 0.0671 & 0.0370 & 0.0493 & 0.0291 & 0.0435 & 0.0574 & 0.0439 & 0.0752 & 0.0717 & 0.0741 & 0.0779 \\
2 & 0.1080 & 0.0433 & 0.0420 & 0.0176 & 0.0313 & 0.0947 & 0.0603 & 0.0883 & 0.0844 & 0.1089 & 0.0807 \\
3 & 0.0663 & 0.0326 & 0.0263 & 0.0234 & 0.0213 & 0.0612 & 0.0336 & 0.0508 & 0.0458 & 0.0448 & 0.0326 \\
4 & 0.0984 & 0.0301 & 0.0285 & 0.0187 & 0.0228 & 0.0794 & 0.0365 & 0.0801 & 0.0653 & 0.0724 & 0.0376 \\
\hline
\end{tabular}

T-STATISTIC

\begin{tabular}{|c|c|c|c|c|c|c|c|c|c|c|c|}
\hline$t$ & $\alpha_{l}$ & $\gamma 1$ & $\gamma 2$ & $\gamma 13$ & $\gamma 4$ & $\beta_{t}$ & $\beta * 1$ & $\theta \mathrm{ul}$ & $\theta, 2$ & $\theta 13$ & $\theta, 4$ \\
\hline 1 & 11.56 & -4.97 & -0.50 & 0.62 & 1.45 & -9.49 & 6.63 & 1.25 & 1.08 & -1.51 & -0.77 \\
\hline 2 & -0.32 & 3.44 & 1.89 & -3.62 & -2.27 & 3.75 & -3.60 & 1.04 & 3.23 & 1.47 & -6.49 \\
\hline 3 & -1.45 & -0.65 & -0.87 & 2.65 & -2.09 & 2.28 & 2.27 & 1.91 & 0.20 & -4.78 & 3.30 \\
\hline 4 & 3.60 & 1.85 & -1.11 & -0.88 & 2.31 & 0.63 & -4.11 & -3.53 & -5.50 & 2.30 & 12.66 \\
\hline
\end{tabular}


GROUP 41: MEAT AND FISH

MODEL: SWITCHING DYNAMIC AIDS (HOMOGENEITY AND SYMMETRY RESTRICTED)

Sample period: 1961-1991 Joint points: 1967 and $1975 \quad \alpha 0: 5.8289$

PARAMETER ESTIMATES

\begin{tabular}{|c|c|c|c|c|c|c|c|c|c|}
\hline$t$ & $\alpha_{1}$ & $\gamma \mathrm{tl}$ & $\gamma+2$ & $\gamma 13$ & $\beta_{1}$ & $\beta * 1$ & $\theta 11$ & $\theta, 2$ & $\theta \imath 3$ \\
\hline 1 & -0.1839 & 0.0852 & -0.0662 & -0.0191 & 0.4343 & -0.0891 & 0.2054 & 0.1192 & -0.3246 \\
\hline 2 & 0.8977 & -0.0662 & 0.0573 & 0.0088 & -0.3369 & 0.0659 & -0.1268 & -0.0445 & 0.1713 \\
\hline 3 & 0.2862 & -0.0191 & 0.0088 & 0.0102 & -0.0974 & 0.0232 & -0.0786 & -0.0747 & 0.1532 \\
\hline
\end{tabular}

STANDARD ERRORS OF PARAMETERS (ROBUST)

\begin{tabular}{|c|c|c|c|c|c|c|c|c|c|}
\hline 1 & $\alpha_{1}$ & $\gamma \mathrm{tl}$ & $\gamma 12$ & $\gamma 13$ & $\beta_{1}$ & $\beta * 1$ & $\theta, 1$ & $\theta 12$ & $\theta 13$ \\
\hline 1 & 0.0685 & 0.0665 & 0.0621 & 0.0187 & 0.0465 & 0.0113 & 0.0690 & 0.1178 & 0.1353 \\
\hline 2 & 0.0688 & 0.0621 & 0.0631 & 0.0184 & 0.0519 & 0.0121 & 0.0980 & 0.1388 & 0.1843 \\
\hline 3 & 0.0431 & 0.0187 & 0.0184 & 0.0108 & 0.0264 & 0.0067 & 0.0573 & 0.0862 & 0.1333 \\
\hline
\end{tabular}

T-STATISTIC

\begin{tabular}{|c|c|c|c|c|c|c|c|c|c|}
\hline$t$ & $\alpha_{1}$ & $\gamma, 1$ & $\gamma_{12}$ & $\gamma 13$ & $\beta_{t}$ & $\beta * 1$ & $\theta, 1$ & $\theta \mathfrak{\imath 2}$ & $\theta, 3$ \\
\hline 1 & -2.68 & 1.28 & -1.07 & -1.02 & 9.34 & -7.88 & 2.98 & 1.01 & -2.40 \\
\hline 2 & 13.05 & -1.07 & 0.91 & 0.48 & -6.49 & 5.45 & -1.29 & -0.32 & 0.93 \\
\hline 3 & 6.64 & -1.02 & 0.48 & 0.94 & -3.69 & 3.46 & -1.37 & -0.87 & 1.15 \\
\hline
\end{tabular}

GROUP 42: DAIRY PRODUCTS

MODEL: SWITCHING DYNAMIC AIDS (UNRESTRICTED)

Sample period: 1961-1991 Joint points: 1965 and 1974

$\alpha 0: 5.6733$

\section{PARAMETER ESTIMATES}

\begin{tabular}{|l|lllllllllll|}
\hline $\mathrm{l}$ & $\alpha \mathrm{l}$ & $\gamma \mathrm{l}$ & $\gamma \mathrm{l} 2$ & $\gamma \mathrm{l} 3$ & $\gamma \mathrm{l} 4$ & $\beta \mathrm{l}$ & $\beta * 1$ & $\theta \mathrm{l} 1$ & $\theta \mathrm{L} 2$ & $\theta \mathrm{l} 3$ & $\theta \mathrm{l} 4$ \\
\hline 1 & 0.0407 & 0.0462 & 0.0538 & 0.0117 & -0.0233 & 0.3730 & -0.1307 & 0.1634 & -0.0198 & -0.4573 & 0.3137 \\
2 & 0.2158 & -0.0306 & 0.0911 & -0.0764 & -0.0413 & -0.1094 & 0.1032 & 0.2570 & 0.1959 & 0.0274 & -0.4803 \\
3 & 0.2790 & -0.0826 & -0.0357 & 0.0017 & 0.1047 & 0.0150 & 0.0004 & -0.3773 & -0.2902 & 0.5641 & 0.1034 \\
4 & 0.4645 & 0.0670 & -0.1092 & 0.0629 & -0.0401 & -0.2786 & 0.0270 & -0.0431 & 0.1141 & -0.1343 & 0.0632 \\
\hline
\end{tabular}

STANDARD ERRORS OF PARAMETERS (ROBUST)

\begin{tabular}{|l|lllllllllll|}
\hline $\mathrm{l}$ & $\alpha \mathrm{l}$ & $\gamma \mathrm{l}$ & $\gamma \mathrm{l} 2$ & $\gamma \mathrm{l} 3$ & $\gamma \mathrm{l} 4$ & $\beta \mathrm{l}$ & $\beta * 1$ & $\theta \mathrm{l} 1$ & $\theta \mathrm{\imath} 2$ & $\theta \mathrm{\imath} 3$ & $\theta \mathrm{l} 4$ \\
\hline 1 & 0.0842 & 0.0567 & 0.0713 & 0.0602 & 0.0473 & 0.0729 & 0.0308 & 0.1148 & 0.1194 & 0.0838 & 0.1112 \\
2 & 0.1052 & 0.0344 & 0.0684 & 0.0327 & 0.0378 & 0.0744 & 0.0224 & 0.0749 & 0.0782 & 0.0554 & 0.0875 \\
3 & 0.1164 & 0.0609 & 0.0958 & 0.0517 & 0.0625 & 0.0994 & 0.0399 & 0.1383 & 0.1383 & 0.1050 & 0.1470 \\
4 & 0.0526 & 0.0304 & 0.0549 & 0.0329 & 0.0425 & 0.0382 & 0.0140 & 0.0517 & 0.0665 & 0.0403 & 0.0684 \\
\hline
\end{tabular}

T-STATISTIC

\begin{tabular}{|c|c|c|c|c|c|c|c|c|c|c|c|}
\hline 1 & $\alpha_{l}$ & $\gamma \mathrm{nl}$ & $\gamma 2$ & $\gamma 13$ & $\gamma 14$ & $\beta_{\mathbf{t}}$ & $\beta * 1$ & $\theta \mathrm{u} 1$ & $\theta+2$ & $\theta, 3$ & $\theta, 4$ \\
\hline 1 & 0.48 & 0.81 & 0.75 & 0.20 & -0.49 & 5.12 & -4.25 & 1.42 & -0.17 & -5.46 & 2.82 \\
\hline 2 & 2.05 & -0.89 & 1.33 & -2.33 & -1.09 & -1.47 & 4.61 & 3.43 & 2.51 & 0.50 & -5.49 \\
\hline 3 & 2.40 & -1.36 & -0.37 & 0.03 & 1.68 & 0.15 & 0.01 & -2.73 & -2.10 & 5.37 & 0.70 \\
\hline 4 & 8.82 & 2.21 & -1.99 & 1.91 & -0.94 & -7.30 & 1.93 & -0.83 & 1.72 & -3.33 & 0.92 \\
\hline
\end{tabular}




\section{Glossary}

Symbols

$\alpha_{0}$

$\alpha_{i}$
$\beta_{i}$
$\beta_{i}$

$\beta_{i}$

$c_{i}=q p$

$\varepsilon, v$

$\gamma_{i j}$

$h=1, \ldots, H$

H

$h_{t}$

$i, j, k=1, \ldots, n$ or $1, \ldots, m$

$k$

$k_{4}$

$m$

$m_{1}$

$m_{2}=n-1$

$n$

$N$

$p_{i}=c / q$

$\boldsymbol{p}=\left(p_{1}, \ldots, p_{n}\right)$

$q$

$\boldsymbol{q}=\left(q_{1}, \ldots, q_{n}\right)$

$r, s=1, \ldots, n$

$t=1, \ldots, T$

$T$

$\tau_{1}, \tau_{2}$

$\theta_{i j}$

$w_{i}=c / x$

$x=\Sigma \mathrm{c}_{i}$

$x_{0}$

$x, y$

Functions

$a(p)$

$b(\boldsymbol{p})$

$e_{i i}=\partial \ln g_{i} / \partial \ln p_{i}$

$e_{i j}=\partial \ln g_{i} / \partial \ln p_{j}$

$\tilde{e}_{i j}=\partial \ln h / \partial \ln p$

$\tilde{e}_{i j}=\partial \ln h / \partial \ln p$

$E_{i}=\partial \ln g / \partial \ln x$

$k_{i j}=w_{i} \tilde{e}_{i j}$

$s_{i j}=\partial h_{i} / \partial p_{j}$

$u=v(\boldsymbol{q})$

$u=\psi(x, p)$

$u_{0}=\psi\left(x_{0} \boldsymbol{p}\right)$

$x=c(u, p)$

$q_{i}=g_{i}(x, \boldsymbol{p})$

$q_{i}=h_{i}(u, p)$
Expenditure required for subsistence, or minimum standard of living, when prices equal one (then $\alpha_{0}=a(p)$ )

The $i$ th budget share when expenditure is at the subsistence level or $a(\boldsymbol{p})$

Estimable expenditure parameter

Estimable expenditure parameter for $h_{t}$

Expenditure on the $i$ th good (in current values)

Stochastic error terms

Estimable price parameter

Counter for households

Number of households in the population

Demand shifter

Counters for goods and equations

Average number of estimated parameters per equation in an unrestricted system

Household preferences (in Section 4.5)

Number of goods (within certain $r$ )

Number of tested restrictions per equation

Number of estimated equations in a group

Number of goods, number of equations in a group, number of groups

Number of individuals in the population

Price or implicit price index of the $i$ th good

Price vector

Group price index

Quantity consumed of the $i$ th good (expenditure in constant values)

Quantity vector

Counters for groups

Counter for number of observations or sample size in years

Number of observations or sample size in years

Joint points in time associated with the beginning and ending of the transition period between regimes in a switching regression model

Estimable habit persistence parameter

Budget share of the $i$ th good

Total expenditure

Representative expenditure (in Section 4.5)

Independent and dependent variable, respectively (in Section 5.2.4)

Function of prices, cost (expenditure) of subsistence consumption $(u=0)$

Function of prices, cost (expenditure) of joy consumption $(u=1)$

Uncompensated (Marshallian) own-price elasticity for the $i$ th good

Uncompensated (Marshallian) cross-price elasticity for the $i$ th good with respect to the price of the jth good

Compensated (Hicksian) own-price elasticity

Compensated (Hicksian) cross-price elasticity

Expenditure elasticity of the $i$ th good

Element in the substitution matrix $\boldsymbol{K}$ of compensated price responses

Compensated cross-price effect, element in the substitution or Slutsky matrix $S$ of compensated price responses

[Direct] utility function

Indirect utility function

Representative utility level

Expenditure function

Marshallian [income-uncompensated] demand function

Hicksian [income-compensated] demand function 


\section{Abbreviations}

$\operatorname{adj} R^{2}$

$\operatorname{adj} R_{D: s}^{2}$

AIDS

ARCH

BG

BP

Cusumsq

FIM

HWu(di)

$\mathrm{HWu}(\mathrm{x})$

JB

LAIDS

LES

LR

In

MAPE

PIGLOG

RESET

$R^{2}$

$R^{2}$

$R^{2}$ RMSE
$R^{2}$ adjusted for the loss in degrees of freedom due to addition of more explanatory variables

$R^{2}$ for the dynamic model adjusted for static model and degrees of freedom

Almost Ideal Demand System

Autoregressive conditional heteroskedastic model

Breusch-Godfrey test

Breusch-Pagan test

Cumulative sum of squares test

Finnish Markka (equaled ECU 0.159 and US\$ 0.191 in July 29, 1994)

Hausman-Wu test that uses disposable income as the instrument

Hausman-Wu test that uses total expenditure as the instrument

Jarque-Bera Lagrange multiplier test

Linear approximation, Almost Ideal Demand System

Linear Expenditure System

Likelihood ratio criteria

Natụral (Naperian) logarithm

Mean absolute percentage error

Price-independent, generalised logarithmic (type of expenditure function)

Regression equation specification error test

Coefficient of determination

$R^{2}$ to measure the improvement of a dynamic model over a nested static model

$R^{2}$ derived from the root-mean-square prediction error 